\title{
ROA-classificatiegids 2002
}

Citation for published version (APA):

Researchcentrum voor Onderwijs en Arbeidsmarkt, ROA. (2002). ROA-classificatiegids 2002.

Researchcentrum voor Onderwijs en Arbeidsmarkt, Faculteit der Economische Wetenschappen. ROA Reports No. 3 https://doi.org/10.26481/umarep.2002003

Document status and date:

Published: 01/01/2002

DOI:

10.26481/umarep.2002003

Document Version:

Publisher's PDF, also known as Version of record

\section{Please check the document version of this publication:}

- A submitted manuscript is the version of the article upon submission and before peer-review. There can be important differences between the submitted version and the official published version of record.

People interested in the research are advised to contact the author for the final version of the publication, or visit the DOI to the publisher's website.

- The final author version and the galley proof are versions of the publication after peer review.

- The final published version features the final layout of the paper including the volume, issue and page numbers.

Link to publication

\footnotetext{
General rights rights.

- You may freely distribute the URL identifying the publication in the public portal. please follow below link for the End User Agreement:

www.umlib.nl/taverne-license

Take down policy

If you believe that this document breaches copyright please contact us at:

repository@maastrichtuniversity.nl

providing details and we will investigate your claim.
}

Copyright and moral rights for the publications made accessible in the public portal are retained by the authors and/or other copyright owners and it is a condition of accessing publications that users recognise and abide by the legal requirements associated with these

- Users may download and print one copy of any publication from the public portal for the purpose of private study or research.

- You may not further distribute the material or use it for any profit-making activity or commercial gain

If the publication is distributed under the terms of Article $25 \mathrm{fa}$ of the Dutch Copyright Act, indicated by the "Taverne" license above, 


\section{ROA-classificatiegids 2002}

ROA-R-2002/3

\section{Researchcentrum voor Onderwijs en Arbeidsmarkt}

Faculteit der Economische Wetenschappen en Bedrijfskunde Universiteit Maastricht

Maastricht, februari 2002 
In geval van overname van ROA-classificaties moet telkens duidelijk als bron worden vermeld: "Researchcentrum voor Onderwijs en Arbeidsmarkt" of "ROA". Van publicaties waarin gebruik wordt gemaakt van gegevens uit deze ROA classificatiegids 2002 ontvangen wij gaarne een exemplaar.

Hoewel de grootst mogelijke zorg is besteed aan de inhoud van dit rapport, kan het ROA in generlei opzicht verantwoordelijkheid op zich nemen voor eventuele onvolledigheden of onjuistheden.

ISBN 90-5321-329-5

Sec01.270 


\section{Inhoud}

Bladzijde

Voorwoord

Opleidingen

1 Opleidingstypen, volgorde ROA

2 Opleidingstypen, volgorde SOI '78

3 Opleidingen per opleidingstype

$4 \quad$ Opleidingstype per opleiding

Beroepen

5 Beroepsgroepen, volgorde ROA

129

6 Beroepsgroepen, volgorde SBC ‘92

$7 \quad$ Beroepen per beroepsgroep

Bedrijfssectoren

8 Beknopte bedrijfsclassificatie SBI '93

$9 \quad$ Uitgebreide bedrijfsclassificatie SBI '93

10 Bedrijfstakken per bedrijfssector 



\section{Voorwoord}

Het onderzoeksterrein van het ROA wordt gevormd door de problematiek van de aansluiting van het onderwijs op de arbeidsmarkt. Het ROA streeft er in het bijzonder naar om op een wetenschappelijk verantwoorde manier informatie te verschaffen over de mate waarin het onderwijs aansluit op de arbeidsmarkt. Deze informatie moet bruikbaar zijn voor het beleid van overheden, onderwijsinstellingen, arbeidsvoorzieningsorganisaties, bedrijfsleven e.d. De resultaten van het onderzoek worden naar buiten gebracht in een drietal kernpublicaties die (twee)jaarlijks geactualiseerd worden, te weten De arbeidsmarkt naar opleiding en beroep tot 2006, Schoolverlaters tussen onderwijs en arbeidsmarkt 2000 en Werkgelegenheid en scholing 1999, maar ook in een groot aantal studies van specifieke deelmarkten of facetten van de arbeidsmarkt.

Vanwege de grote diversiteit in het onderwijs en op de arbeidsmarkt hanteren al deze rapporten classificaties waarin de in Nederland voorkomende opleidingen, beroepen en bedrijfstakken worden samengevoegd in groepen. In de classificaties die hierbij worden gehanteerd, wordt ernaar gestreefd om clusters van opleidingen, beroepen en bedrijfstakken te vormen die vanuit de problematiek van de aansluiting tussen onderwijs en arbeidsmarkt een duidelijk verwantschap met elkaar vertonen. Het ROA heeft vanwege het belang van een goede classificatie onderzoek verricht naar de clustering van opleidingen die in een hoge mate hetzelfde beroependomein kennen ${ }^{1}$. Daarnaast wordt bij voorkeur gebruik gemaakt van standaardclassificaties van het Centraal Bureau voor de Statistiek (CBS), maar zijn in ieder geval de gehanteerde classificaties te herleiden tot deze standaardindelingen, om daarmee de vergelijkbaarheid met ander onderzoek optimaal te bevorderen.

Hoewel in de genoemde publicaties gebruik wordt gemaakt van gegevens op een zeer groot detailniveau - zo zijn de prognoses in De arbeidsmarkt naar opleiding en beroep tot 2006 gebaseerd op een indeling in 113 opleidingstypen - blijken in de praktijk mensen die belangstelling hebben voor een specifieke opleiding of een specifiek beroep niet altijd met zekerheid te kunnen achterhalen om welk opleidingstype of beroepsgroep het gaat. Vanwege de veelheid aan opleidingen en beroepen kan in de rapporten alleen de koppeling van de gebruikte classificaties met de standaardclassificaties van het CBS worden verstrekt. Om de praktische bruikbaarheid van de informatie over onderwijs en arbeidsmarkt verder te vergroten is deze ROA-classificatiegids samengesteld.

In deze ROA-classificatiegids worden voor opleidingen, beroepen en bedrijfstakken de verbanden aangegeven tussen de classificaties die gehanteerd worden in ROA-publicaties, standaardclassificaties van het CBS en namen van opleidingen, beroepen en bedrijfstakken die in de dagelijkse praktijk worden gehanteerd. De voorliggende ROA-classificatiegids 2002 is de herziene versie van de ROA-classificatiegids 1998. De indeling van de classificatiegids is grotendeels hetzelfde gebleven. Wel hebben er bij de overzichten van de opleidingen enige aanpassingen plaatsgevonden. Zo is de indeling van de tabellen veranderd en is er een extra tabel toegevoegd (zie hierna). Voorts zijn de gebruikte codes en benamingen in de tabellen voor de opleidingen geactualiseerd.

Met betrekking tot de opleidingen hanteert het ROA een indeling in 113 opleidingstypen. Deze opleidingstypen zijn gekoppeld aan de Standaard-Onderwijs-Indeling 1978 (SOI '78) van het

1. H. Heijke, A. Matheeuwsen en E. Willems, Clustering Educational Categories in a Heterogeneous Labour Market, ROA-RM-1998/2E, Maastricht. 
$\mathrm{CBS}^{2}$. In aanvulling op de vorige versie van de classificatiegids is tabel 2 tussengevoegd, waarin een overzicht wordt gegeven van de opleidingstypen van het ROA gerangschikt naar SOI-code. Onder zowel de ROA-indeling van opleidingstypen als de SOI vallen een groot aantal opleidingen zoals die in de praktijk voorkomen. De lijst met opleidingsnamen, die grotendeels gebaseerd is op registers zoals het $\mathrm{CROHO}$ en het CREBO, is door het ROA van een nummering voorzien. Dit wordt aangeduid als SIS-nummer (Schoolverlaters-InformatieSysteem).

De classificatie die het ROA hanteert voor beroepen is vrijwel identiek aan de StandaardBeroepen-Classificatie 1992 (SBC '92) van het CBS. Het CBS heeft de beroepsgroepen voorzien van een driecijferige SBC-code. Hiervan geeft het eerste cijfer het niveau van het beroep aan: 1 betreft de elementaire beroepen, 2 en 3 de lagere beroepen, 4 en 5 de middelbare beroepen, 6 en 7 de hogere beroepen en 8 en 9 de wetenschappelijke beroepen. Geordend naar SBC-code staan de beroepsgroepen dus weergegeven van elementair naar wetenschappelijk niveau. Het ROA hanteert een afwijkende volgorde waarin de beroepen per beroepsklasse staan geordend. Verder hanteert het CBS een vrij abstracte naamgeving voor de beroepsgroepen. Deze heeft als voordeel dat de naam de lading volledig dekt, maar als nadeel dat hierdoor de herkenbaarheid van de naam vermindert. ROA gebruikt daarom afwijkende namen voor de beroepsgroepen. Deze namen zijn zo bondig mogelijk gehouden, maar geven daardoor mogelijk alleen de kwantitatief gezien belangrijkste beroepen binnen de beroepsgroep weer.

Voor bedrijfssectoren hanteert het ROA de indeling van het Centraal Planbureau (CPB). Hierbij wordt een beknopte en een uitgebreide variant onderscheiden. Het ROA heeft een koppeling gelegd tussen deze indeling van het CPB en de Standaard-Bedrijfs-Indeling 1993 (SBI '93) van het CBS. Om deze koppeling niet nodeloos complex te maken, worden in tabel 10 per bedrijfssector de onderliggende bedrijfstakken met een uiteenlopende mate van detail gepresenteerd. Indien een aanduiding op een hoger aggregatieniveau voldoende duidelijk is, zijn de onderliggende bedrijfsklassen niet afzonderlijk genoemd.

Deze classificatiegids is onder verantwoordelijkheid van Frank Cörvers, samengesteld door Sander Dijksman en Jorn Baars.

2. Het CBS heeft inmiddels een vernieuwde Standaard-Onderwijs-Indeling, de SOI '98, met zes in plaats van vijf digits. Het grote voordeel van deze vernieuwde SOI is dat de WEB-niveaus in het Middelbaar Beroepsonderwijs kunnen worden onderscheiden. De SOI '98 is tot op heden echter nog niet goed bruikbaar in combinatie met de Enquête Beroepsbevolking. 
OPLEIDINGEN 

1. Opleidingstypen, volgorde ROA

OPLEIDINGSNIVEAU

Opleidingscategorie

ROA-nr. Opleidingstype

SOI

\section{BASISONDERWIJS}

Basisonderwijs

1 Basisonderwijs

10111

10121

10123

10128

20112

20121

20123

20128

20180

VMBO

VMBO Theorie

2 VMBO theorie

30112

30114

30115

30116

30117

30121

30123

30128

30131

30132

30133

30134

30135

30138

30141

30142

30143

30144

30145

30146

30148

30154

30155

30164

30174

30180

VMBO Landbouw en natuurlijke omgeving

3 VMBO landbouw en natuurlijke omgeving

30637

32110

32121

32123

32125

32128

32130

32151

32153

32158

32175

32181

32183

32188 
1. Opleidingstypen, volgorde ROA (vervolg)

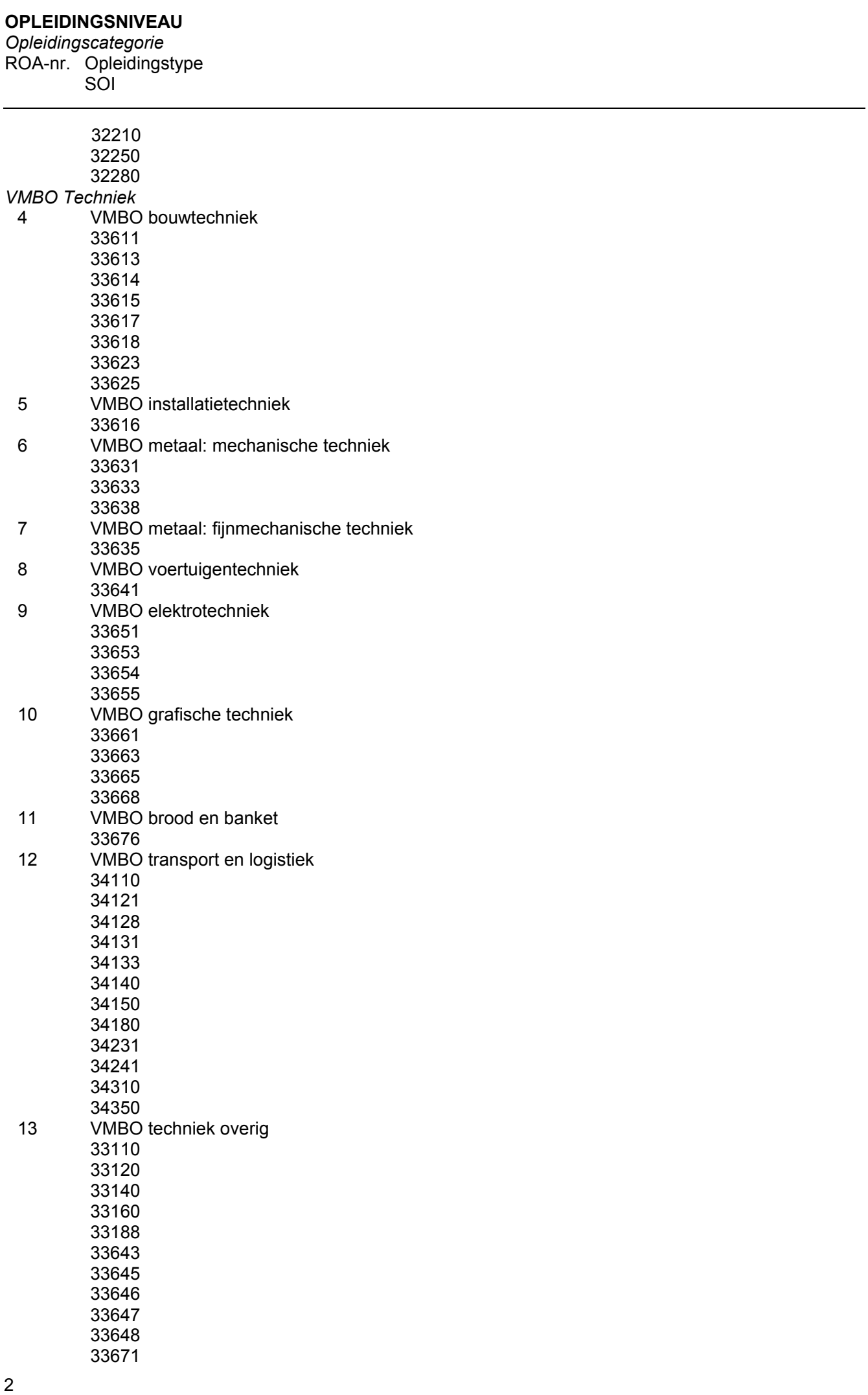


1. Opleidingstypen, volgorde ROA (vervolg)

OPLEIDINGSNIVEAU

Opleidingscategorie

ROA-nr. Opleidingstype

SOI

33672

33674

33675

33678

33682

33688

VMBO Economie

$14 \quad$ VMBO administratie, handel en mode

33673

33685

36110

36120

36131

36133

36135

36138

36142

36143

36145

36146

36148

36150

36180

36280

36611

36618

36628

36630

36680

15 VMBO consumptief en levensmiddelentechniek

33677

34430

38140

38340

VMBO Zorg en welzijn

$16 \quad$ VMBO (uiterlijke) verzorging

30667

30671

35118

35120

35148

35160

35180

35210

35231

35235

35380

35430

37118

37120

37143

37145

37150

37161

37163

37165

37188

38110

38121

38123 
1. Opleidingstypen, volgorde ROA (vervolg)

OPLEIDINGSNIVEAU

Opleidingscategorie

ROA-nr. Opleidingstype

SOI

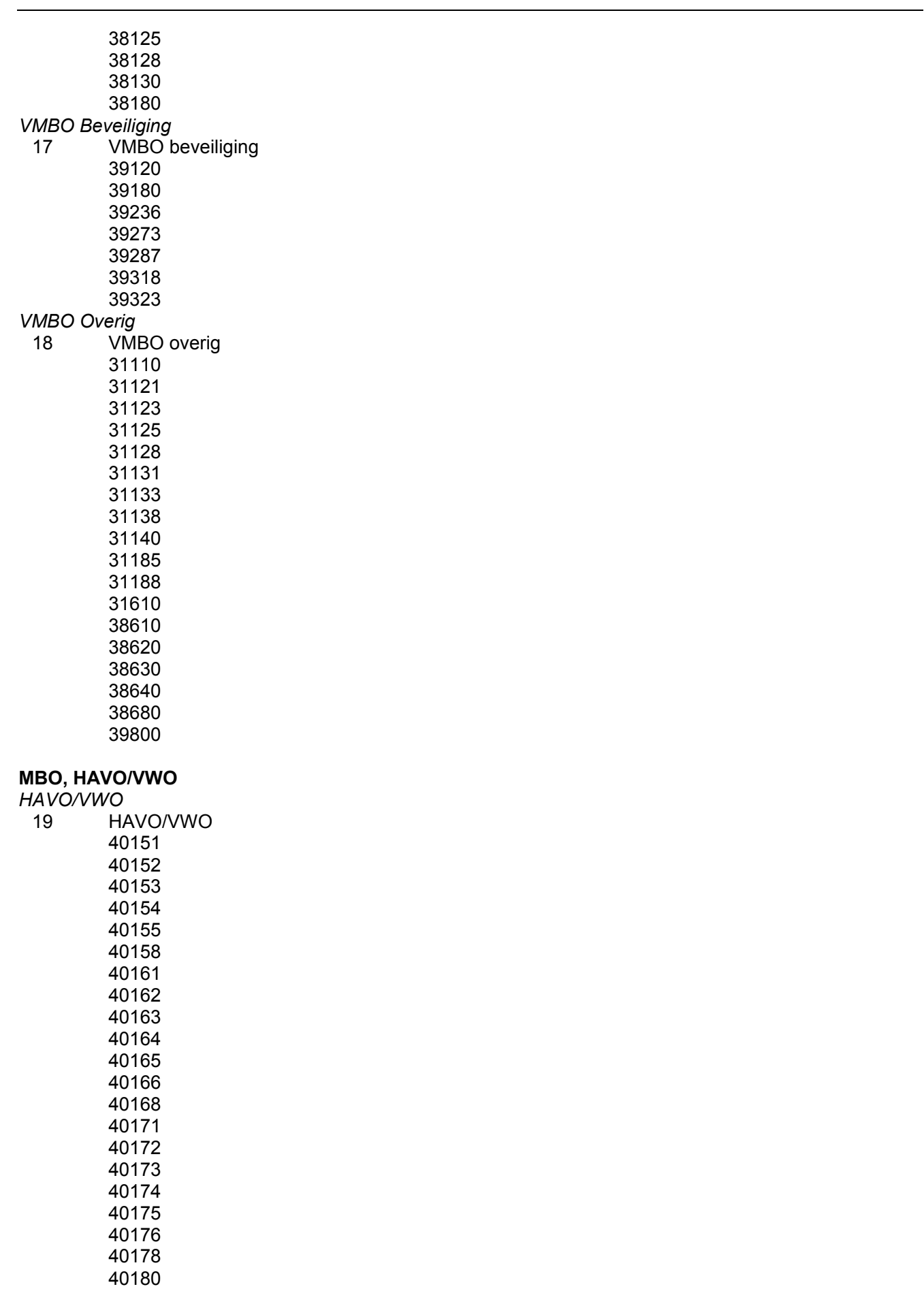


1. Opleidingstypen, volgorde ROA (vervolg)

OPLEIDINGSNIVEAU

Opleidingscategorie

ROA-nr. Opleidingstype

SOI

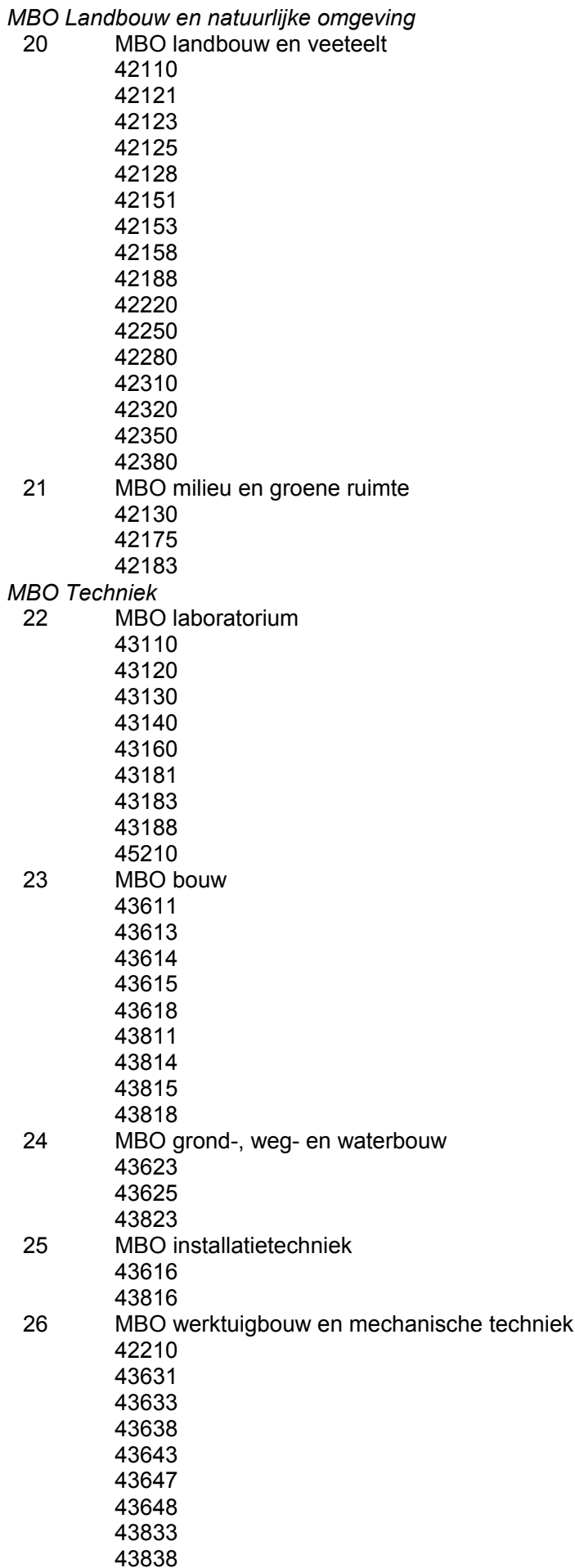


1. Opleidingstypen, volgorde ROA (vervolg)

OPLEIDINGSNIVEAU

Opleidingscategorie

ROA-nr. Opleidingstype

SOI

43843

43847

43848

44231

44250

27 MBO fijnmechanische techniek

43635

43835

$28 \quad \begin{aligned} & 45280 \\ & \text { MBO motorvoertuigentechniek }\end{aligned}$

43641

43841

$29 \quad$ MBO vliegtuigtechniek

43645

30 MBO operationele techniek

43646

$31 \quad$ MBO elektrotechniek

43651

43652

43653

43654

43655

43851

$32 \quad 43853$

rafische techniek

43661

43663

43665

43667

43668

43867

43868

$33 \quad$ MBO procestechniek

43674

43675

43678

43874

$34 \quad$ MBO brood en banket

43676

43876

$35 \quad$ MBO levensmiddelentechniek/vleesverwerking

43677

43877

$36 \quad$ MBO vervoer en logistiek

40657

44110

44131

44133

44140

44150

44180

44210

44238

44241

44248

44310

44320

44333

44340

44350

6 
1. Opleidingstypen, volgorde ROA (vervolg)

OPLEIDINGSNIVEAU

Opleidingscategorie

ROA-nr. Opleidingstype

SOI

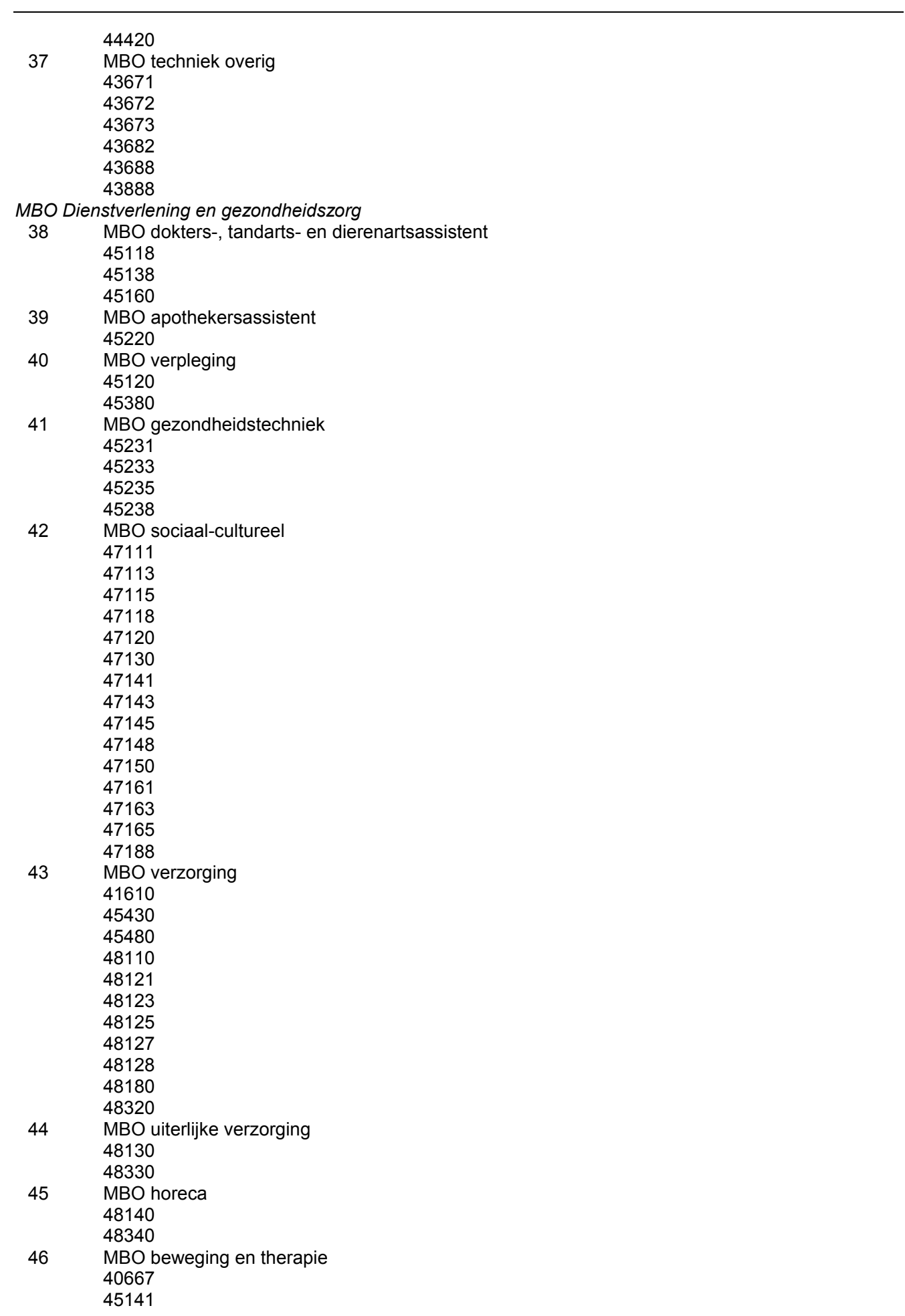


1. Opleidingstypen, volgorde ROA (vervolg)

OPLEIDINGSNIVEAU

Opleidingscategorie

ROA-nr. Opleidingstype

SOI

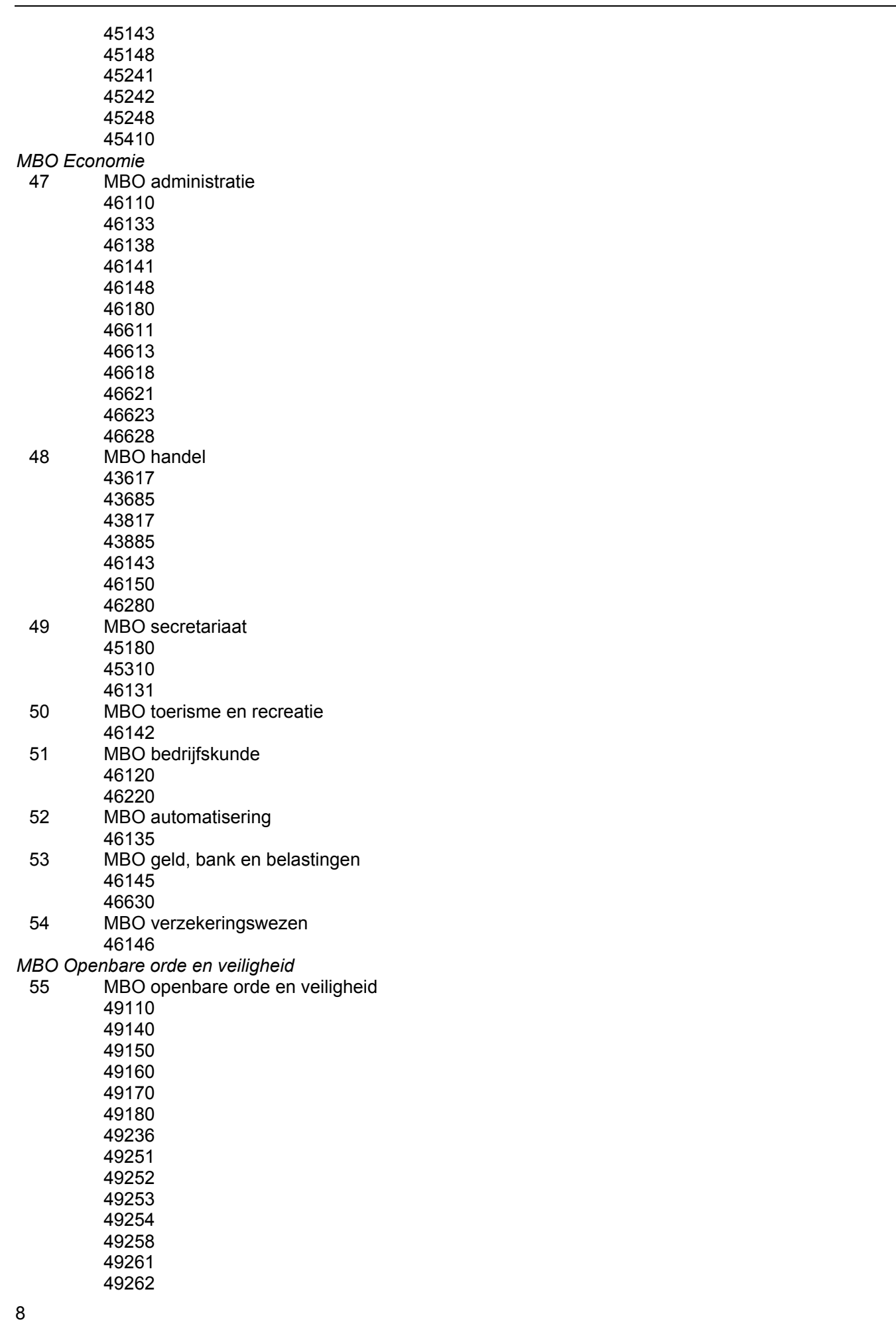


1. Opleidingstypen, volgorde ROA (vervolg)

OPLEIDINGSNIVEAU

Opleidingscategorie

ROA-nr. Opleidingstype

SOI

49263

49264

49266

49267

49272

49273

49274

49276

49287

49312

49318

49323

49351

49352

49353

49358

49361

49362

49363

49368

49371

49372

49373

49378

MBO Overig

$56 \quad$ MBO overig

40617

40627

40637

40647

40651

40653

40658

40671

40674

40688

41110

41121

41123

41131

41133

41150

41181

41185

41188

46240

48610

48620

48630

48640

48680

49800

HBO

HBO Onderwijs tolk en vertaler

$57 \quad$ HBO lerarenopleiding basisonderwijs

40611

50611

50613

50617 
1. Opleidingstypen, volgorde ROA (vervolg)

OPLEIDINGSNIVEAU

Opleidingscategorie

ROA-nr. Opleidingstype

SOI

60613

60617

58 HBO lerarenopleiding talen

50621

50623

50624

50625

50628

60621

60623

60624

60625

60628

70621

70623

70624

70625

70628

59 HBO lerarenopleiding natuur en techniek

50631

50633

50635

50637

50638

50641

50643

50645

50647

50651

50653

50655

50657

50658

60631

60633

60635

60637

60643

60657

60658

70631

70633

70635

60 HBO lerarenopleiding economie en maatschappij

50626

50627

50661

50663

50664

50666

57181

60626

60627

60661

60663

60664

60666

70626

70627

70661

10 
1. Opleidingstypen, volgorde ROA (vervolg)

OPLEIDINGSNIVEAU

Opleidingscategorie

ROA-nr. Opleidingstype

SOI

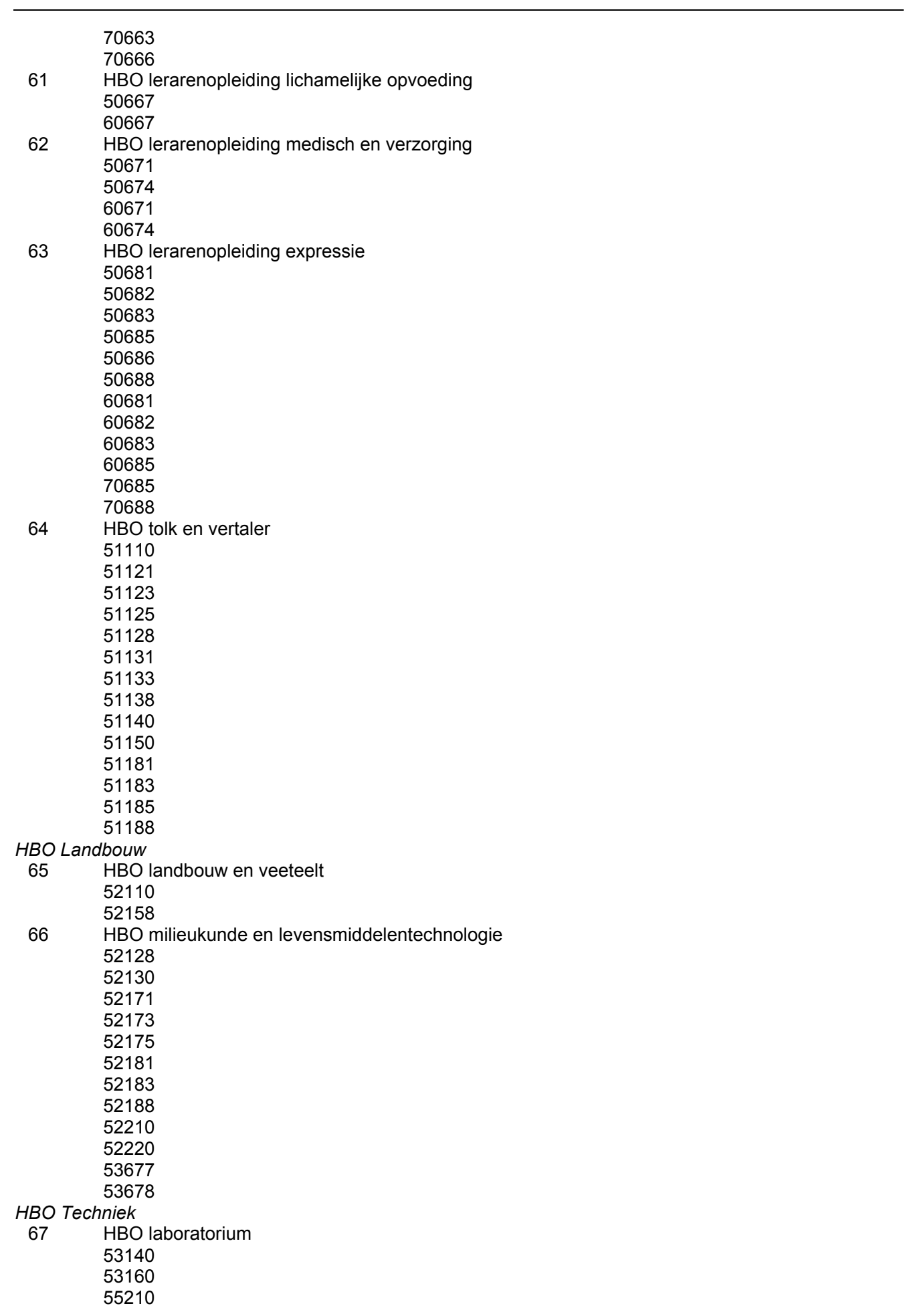


1. Opleidingstypen, volgorde ROA (vervolg)

OPLEIDINGSNIVEAU

Opleidingscategorie

ROA-nr. Opleidingstype

SOI

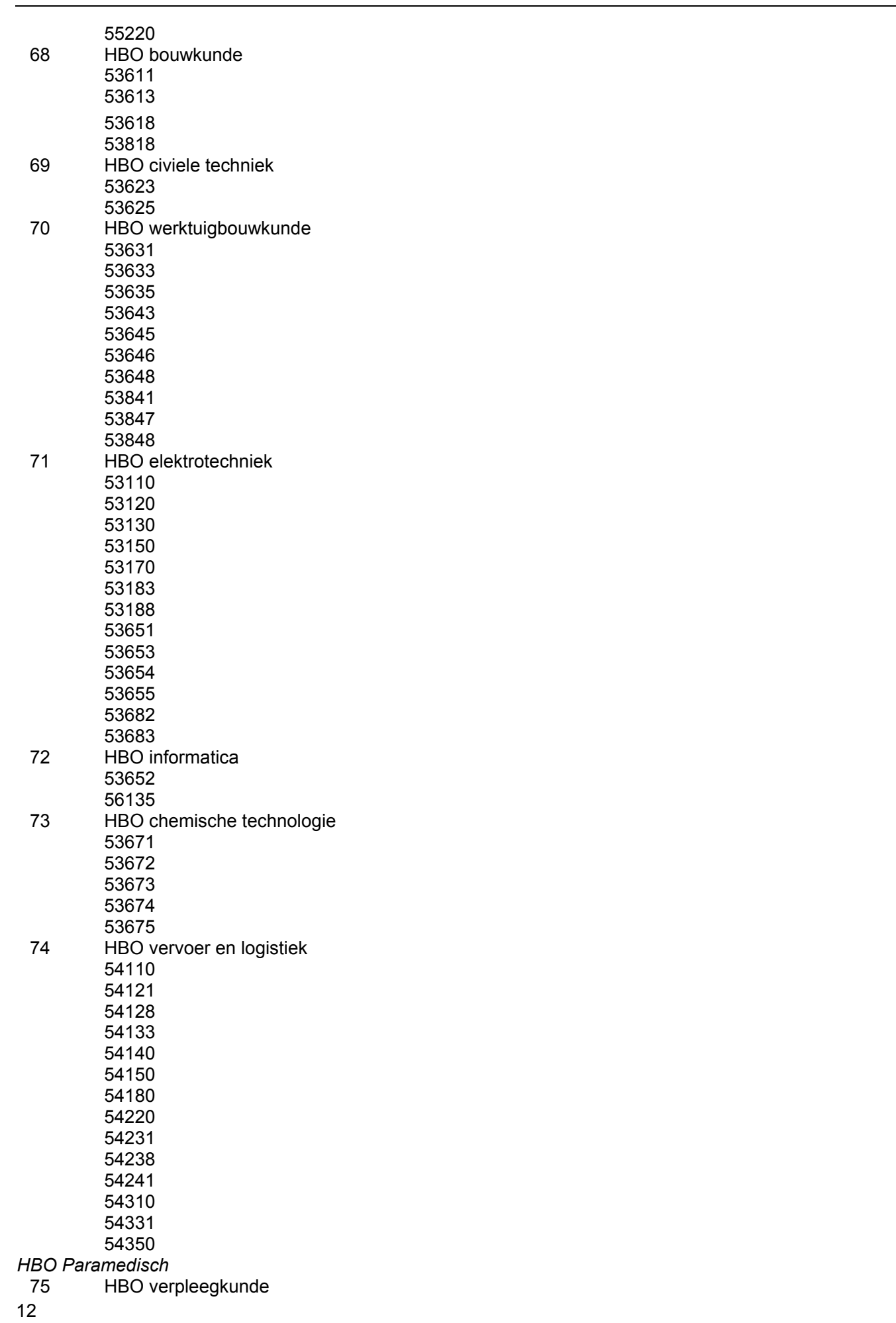


1. Opleidingstypen, volgorde ROA (vervolg)

OPLEIDINGSNIVEAU

Opleidingscategorie

ROA-nr. Opleidingstype

SOI

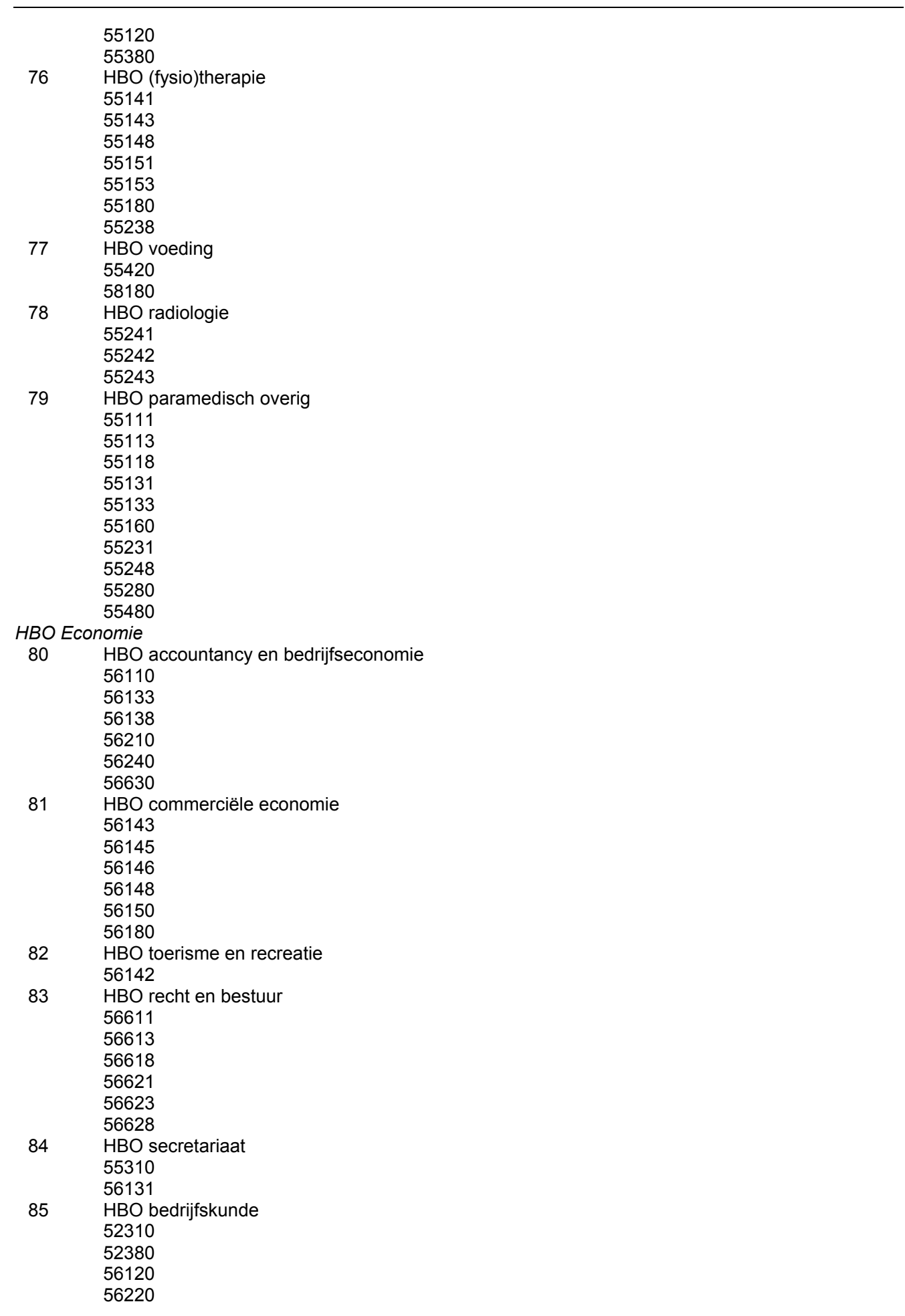


1. Opleidingstypen, volgorde ROA (vervolg)

OPLEIDINGSNIVEAU

Opleidingscategorie

ROA-nr. Opleidingstype

SOI

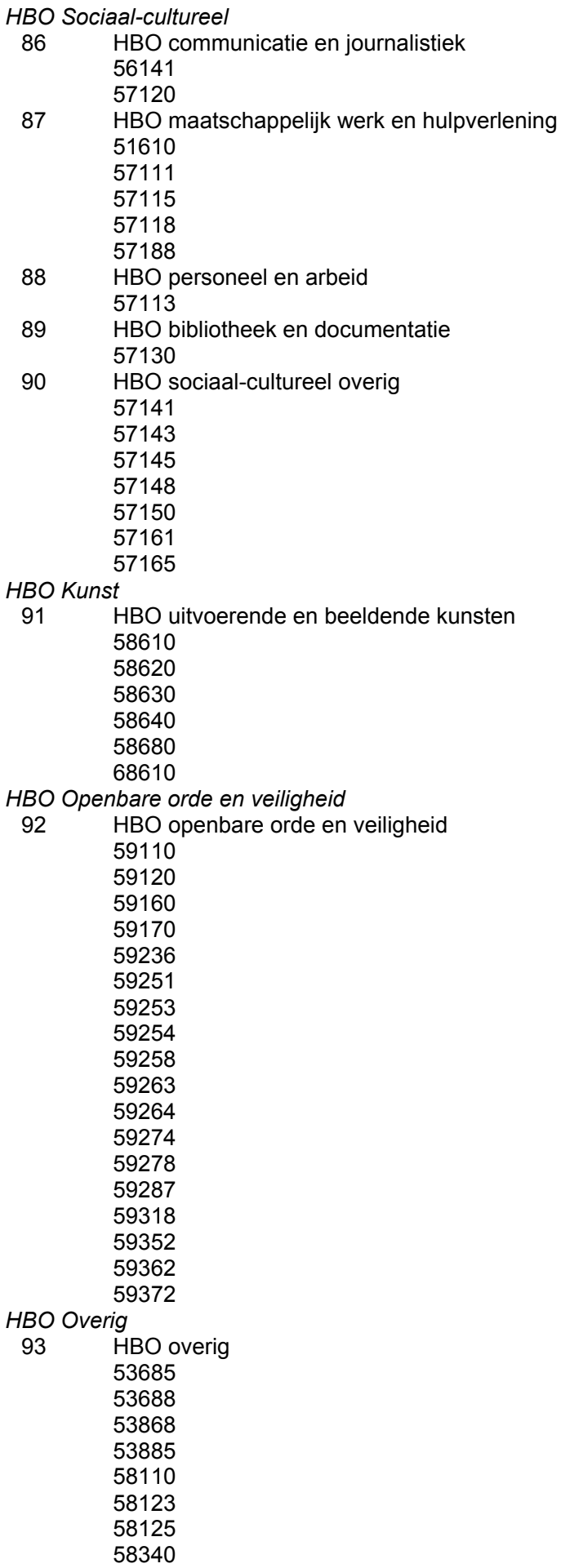


1. Opleidingstypen, volgorde ROA (vervolg)

OPLEIDINGSNIVEAU

Opleidingscategorie

ROA-nr. Opleidingstype

SOI

Wo

WO Letteren en theologie

94 WO letteren

61110

61121

61123

61125

61128

61131

61133

61138

61140

61150

61181

61183

61185

61188

71181

71188

$95 \quad$ WO theologie

61610

71610

WO Landbouw en milieukunde

$96 \quad$ WO landbouw en milieukunde

62110

62128

62130

62158

62171

62173

62175

62183

62188

62210

62220

62310

62380

72175

WO Techniek

$97 \quad$ WO wiskunde en natuurwetenschappen

63110

63120

63130

63140

63150

63160

63170

63181

63188

63631

63674

63675

63677

63682

63683

63688

73120

73140 
1. Opleidingstypen, volgorde ROA (vervolg)

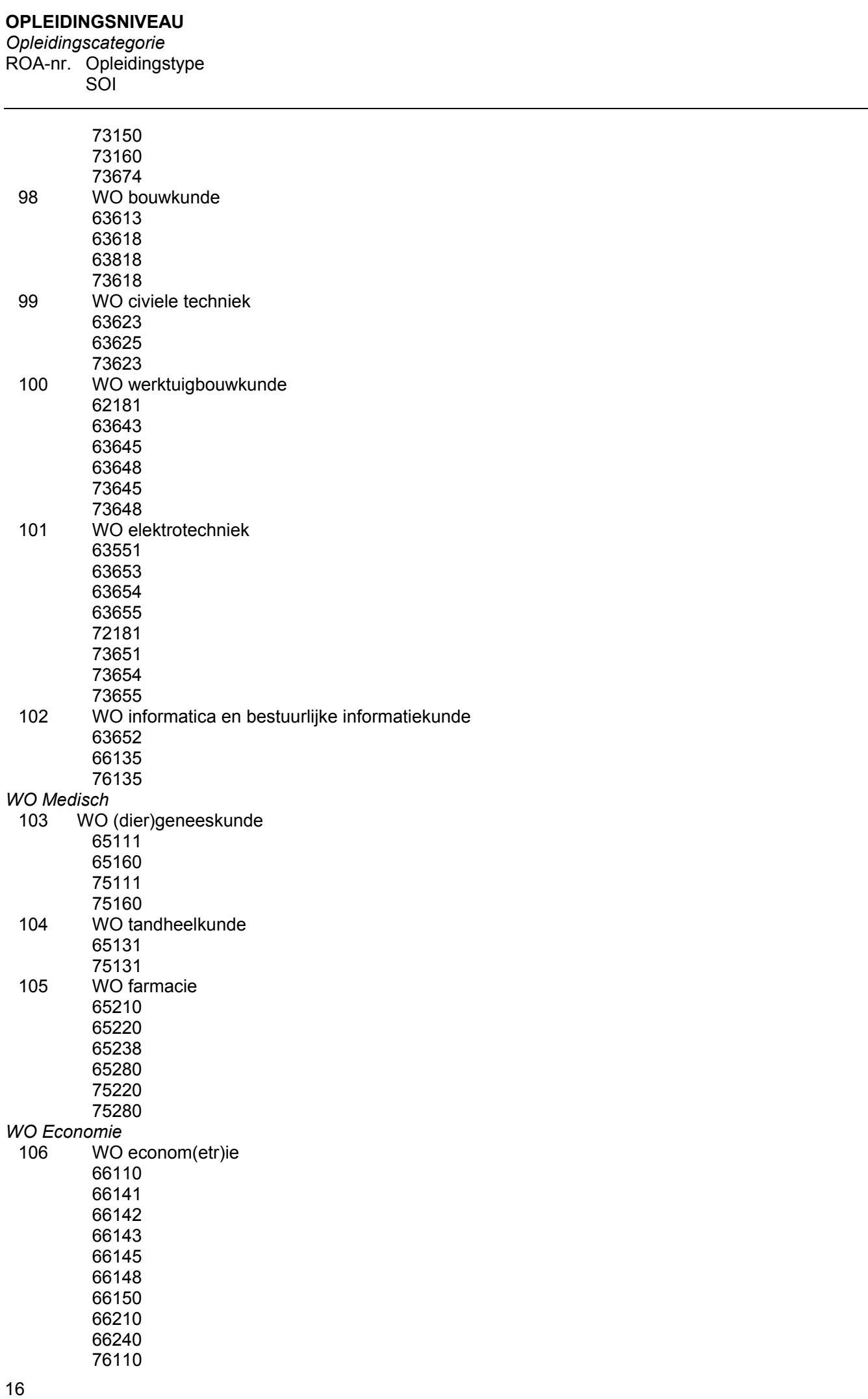


1. Opleidingstypen, volgorde ROA (vervolg)

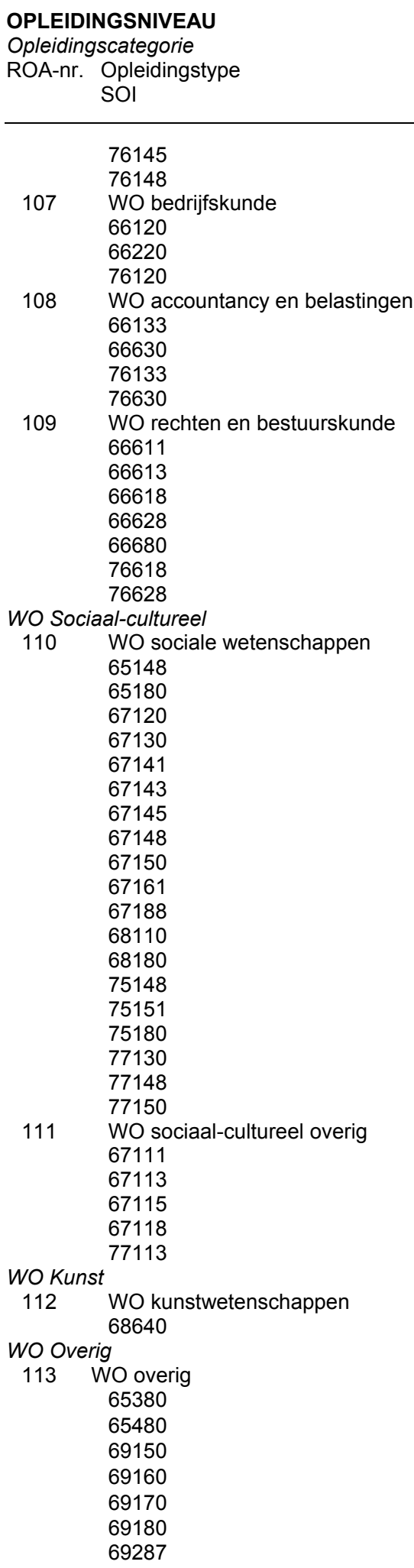





\section{Opleidingstypen, volgorde SOI '78}

SOI opleidingsniveau

SOI ROA-nr. Opleidingstype

\section{Onderwijs aan kleuters}

$\begin{array}{lll}10111 & 1 & \text { Basisonderwijs } \\ 10121 & 1 & \text { Basisonderwijs } \\ 10123 & 1 & \text { Basisonderwijs } \\ 10128 & 1 & \text { Basisonderwijs }\end{array}$

\section{Lager onderwijs}

$\begin{array}{lll}20112 & 1 & \text { Basisonderwijs } \\ 20121 & 1 & \text { Basisonderwijs } \\ 20123 & 1 & \text { Basisonderwijs } \\ 20128 & 1 & \text { Basisonderwijs } \\ 20180 & 1 & \text { Basisonderwijs }\end{array}$

\section{Voortgezet onderwijs, lagere trap}

$\begin{array}{lrl}30112 & 2 & \text { VMBO theorie } \\ 30114 & 2 & \text { VMBO theorie } \\ 30115 & 2 & \text { VMBO theorie } \\ 30116 & 2 & \text { VMBO theorie } \\ 30117 & 2 & \text { VMBO theorie } \\ 30121 & 2 & \text { VMBO theorie } \\ 30123 & 2 & \text { VMBO theorie } \\ 30128 & 2 & \text { VMBO theorie } \\ 30131 & 2 & \text { VMBO theorie } \\ 30132 & 2 & \text { VMBO theorie } \\ 30133 & 2 & \text { VMBO theorie } \\ 30134 & 2 & \text { VMBO theorie } \\ 30135 & 2 & \text { VMBO theorie } \\ 30138 & 2 & \text { VMBO theorie } \\ 30141 & 2 & \text { VMBO theorie } \\ 30142 & 2 & \text { VMBO theorie } \\ 30143 & 2 & \text { VMBO theorie } \\ 30144 & 2 & \text { VMBO theorie } \\ 30145 & 2 & \text { VMBO theorie } \\ 30146 & 2 & \text { VMBO theorie } \\ 30148 & 2 & \text { VMBO theorie } \\ 30154 & 2 & \text { VMBO theorie } \\ 30155 & 2 & \text { VMBO theorie } \\ 30164 & 2 & \text { VMBO theorie } \\ 30174 & 2 & \text { VMBO theorie } \\ 30180 & 2 & \text { VMBO theorie } \\ 30637 & 3 & \text { VMBO landbouw en natuurlijke omgeving } \\ 30667 & 16 & \text { VMBO (uiterlijk) verzorging } \\ 30671 & 16 & \text { VMBO (uiterlijke) verzorging } \\ 31110 & 18 & \text { VMBO overig } \\ 31121 & 18 & \text { VMBO overig } \\ 31123 & 18 & \text { VMBO overig } \\ 31125 & 18 & \text { VMBO overig } \\ 31128 & 18 & \text { VMBO overig } \\ 31131 & 18 & \text { VMBO overig } \\ 31133 & 18 & \text { VMBO overig } \\ 31138 & 18 & \text { VMBO overig } \\ 31140 & 18 & \text { VMBO overig } \\ 31185 & 18 & \text { VMBO overig } \\ 31188 & 18 & \text { VMBO overig } \\ 31610 & 18 & \text { VMBO overig } \\ 32110 & 3 & \text { VMBO landbouw en natuurlijke omgeving } \\ 32121 & 3 & \text { VMBO landbouw en natuurlijke omgeving } \\ & & \end{array}$


2. Opleidingstypen, volgorde SOI '78 (vervolg)

SOI opleidingsniveau

SOl

ROA-nr. Opleidingstype

$32123 \quad 3 \quad$ VMBO landbouw en natuurlijke omgeving

$32125 \quad 3 \quad$ VMBO landbouw en natuurlijke omgeving

$32128 \quad 3 \quad$ VMBO landbouw en natuurlijke omgeving

$32130 \quad 3 \quad$ VMBO landbouw en natuurlijke omgeving

$32151 \quad 3 \quad$ VMBO landbouw en natuurlijke omgeving

$32153 \quad 3 \quad$ VMBO landbouw en natuurlijke omgeving

$32158 \quad 3 \quad$ VMBO landbouw en natuurlijke omgeving

$32175 \quad 3 \quad$ VMBO landbouw en natuurlijke omgeving

$32181 \quad 3 \quad$ VMBO landbouw en natuurlijke omgeving

$\begin{array}{lll}32183 & 3 & \text { VMBO landbouw en natuurlijke omgeving }\end{array}$

$32188 \quad 3 \quad$ VMBO landbouw en natuurlijke omgeving

$32210 \quad 3 \quad$ VMBO landbouw en natuurlijke omgeving

$32250 \quad 3 \quad$ VMBO landbouw en natuurlijke omgeving

$32280 \quad 3 \quad$ VMBO landbouw en natuurlijke omgeving

$33110 \quad 13 \quad$ VMBO techniek overig

$33120 \quad 13 \quad$ VMBO techniek overig

$33140 \quad 13 \quad$ VMBO techniek overig

$33160 \quad 13 \quad$ VMBO techniek overig

$33188 \quad 13 \quad$ VMBO techniek overig

$33611 \quad 4 \quad$ VMBO bouwtechniek

$33613 \quad 4 \quad$ VMBO bouwtechniek

$33614 \quad 4 \quad$ VMBO bouwtechniek

$33615 \quad 4 \quad$ VMBO bouwtechniek

$33616 \quad 5 \quad$ VMBO installatietechniek

$33617 \quad 4 \quad$ VMBO bouwtechniek

$33618 \quad 4 \quad$ VMBO bouwtechniek

$33623 \quad 4 \quad$ VMBO bouwtechniek

$33625 \quad 4 \quad$ VMBO bouwtechniek

$33631 \quad 6 \quad$ VMBO metaal: mechanische techniek

$33633 \quad 6 \quad$ VMBO metaal: mechanische techniek

$33635 \quad 7 \quad$ VMBO metaal: fijnmechanische techniek

$33638 \quad 6 \quad$ VMBO metaal: mechanische techniek

$33641 \quad 8 \quad$ VMBO voertuigentechniek

$33643 \quad 13 \quad$ VMBO techniek overig

$33645 \quad 13 \quad$ VMBO techniek overig

$33646 \quad 13 \quad$ VMBO techniek overig

$33647 \quad 13 \quad$ VMBO techniek overig

$33648 \quad 13 \quad$ VMBO techniek overig

$336519 \quad 9$ VMBO elektrotechniek

$33653 \quad 9 \quad$ VMBO elektrotechniek

336549 VMBO elektrotechniek

336559 VMBO elektrotechniek

$33661 \quad 10 \quad$ VMBO grafische techniek

$33663 \quad 10 \quad$ VMBO grafische techniek

$33665 \quad 10 \quad$ VMBO grafische techniek

$33668 \quad 10 \quad$ VMBO grafische techniek

$33671 \quad 13 \quad$ VMBO techniek overig

$33672 \quad 13 \quad$ VMBO techniek overig

$33673 \quad 14 \quad$ VMBO administratie, handel en mode

$33674 \quad 13 \quad$ VMBO techniek overig

$33675 \quad 13 \quad$ VMBO techniek overig

$33676 \quad 11 \quad$ VMBO brood en banket

$33677 \quad 15 \quad$ VMBO consumptief en levensmiddelentechniek

$33678 \quad 13 \quad$ VMBO techniek overig

$33682 \quad 13 \quad$ VMBO techniek overig

$3368514 \quad$ VMBO administratie, handel en mode

$33688 \quad 13 \quad$ VMBO techniek overig

$34110 \quad 12 \quad$ VMBO transport en logistiek

$34121 \quad 12 \quad$ VMBO transport en logistiek

$34128 \quad 12 \quad$ VMBO transport en logistiek

$34131 \quad 12 \quad$ VMBO transport en logistiek

$34133 \quad 12 \quad$ VMBO transport en logistiek 
2. Opleidingstypen, volgorde SOI '78 (vervolg)

SOl opleidingsniveau

SOl

ROA-nr. Opleidingstype

\begin{tabular}{|c|c|c|}
\hline 34140 & 12 & VMBO transport en logistiek \\
\hline 34150 & 12 & VMBO transport en logistiek \\
\hline 34180 & 12 & VMBO transport en logistiek \\
\hline 34231 & 12 & VMBO transport en logistiek \\
\hline 34241 & 12 & VMBO transport en logistiek \\
\hline 34310 & 12 & VMBO transport en logistiek \\
\hline 34350 & 12 & VMBO transport en logistiek \\
\hline 34430 & 15 & VMBO consumptief en levensmiddelentechniek \\
\hline 35118 & 16 & VMBO (uiterlijke) verzorging \\
\hline 35120 & 16 & VMBO (uiterlijke) verzorging \\
\hline 35148 & 16 & VMBO (uiterlijke) verzorging \\
\hline 35160 & 16 & VMBO (uiterlijke) verzorging \\
\hline 35180 & 16 & VMBO (uiterlijke) verzorging \\
\hline 35210 & 16 & VMBO (uiterlijke) verzorging \\
\hline 35231 & 16 & VMBO (uiterlijke) verzorging \\
\hline 35235 & 16 & VMBO (uiterlijke) verzorging \\
\hline 35380 & 16 & VMBO (uiterlijke) verzorging \\
\hline 35430 & 16 & VMBO (uiterlijke) verzorging \\
\hline 36110 & 14 & VMBO administratie, handel en mode \\
\hline 36120 & 14 & VMBO administratie, handel en mode \\
\hline 36131 & 14 & VMBO administratie, handel en mode \\
\hline 36133 & 14 & VMBO administratie, handel en mode \\
\hline 36135 & 14 & VMBO administratie, handel en mode \\
\hline 36138 & 14 & VMBO administratie, handel en mode \\
\hline 36142 & 14 & VMBO administratie, handel en mode \\
\hline 36143 & 14 & VMBO administratie, handel en mode \\
\hline 36145 & 14 & VMBO administratie, handel en mode \\
\hline 36146 & 14 & VMBO administratie, handel en mode \\
\hline 36148 & 14 & VMBO administratie, handel en mode \\
\hline 36150 & 14 & VMBO administratie, handel en mode \\
\hline 36180 & 14 & VMBO administratie, handel en mode \\
\hline 36280 & 14 & VMBO administratie, handel en mode \\
\hline 36611 & 14 & VMBO administratie, handel en mode \\
\hline 36618 & 14 & VMBO administratie, handel en mode \\
\hline 36628 & 14 & VMBO administratie, handel en mode \\
\hline 36630 & 14 & VMBO administratie, handel en mode \\
\hline 36680 & 14 & VMBO administratie, handel en mode \\
\hline 37118 & 16 & VMBO (uiterlijke) verzorging \\
\hline 37120 & 16 & VMBO (uiterlijke) verzorging \\
\hline 37143 & 16 & VMBO (uiterlijke) verzorging \\
\hline 37145 & 16 & VMBO (uiterlijke) verzorging \\
\hline 37150 & 16 & VMBO (uiterlijke) verzorging \\
\hline 37161 & 16 & VMBO (uiterlijke) verzorging \\
\hline 37163 & 16 & VMBO (uiterlijke) verzorging \\
\hline 37165 & 16 & VMBO (uiterlijke) verzorging \\
\hline 37188 & 16 & VMBO (uiterlijke) verzorging \\
\hline 38110 & 16 & VMBO (uiterlijke) verzorging \\
\hline 38121 & 16 & VMBO (uiterlijke) verzorging \\
\hline 38123 & 16 & VMBO (uiterlijke) verzorging \\
\hline 38125 & 16 & VMBO (uiterlijke) verzorging \\
\hline 38128 & 16 & VMBO (uiterlijke) verzorging \\
\hline 38130 & 16 & VMBO (uiterlijke) verzorging \\
\hline 38140 & 15 & VMBO consumptief en levensmiddelentechniek \\
\hline 38180 & 16 & VMBO (uiterlijke) verzorging \\
\hline 38340 & 15 & VMBO consumptief en levensmiddelentechniek \\
\hline 38610 & 18 & VMBO overig \\
\hline 38620 & 18 & VMBO overig \\
\hline 38630 & 18 & VMBO overig \\
\hline 38640 & 18 & VMBO overig \\
\hline 38680 & 18 & VMBO overig \\
\hline 39120 & 17 & VMBO beveiliging \\
\hline 39180 & 17 & VMBO beveiliging \\
\hline
\end{tabular}


2. Opleidingstypen, volgorde SOI '78 (vervolg)

SOI opleidingsniveau

SOI ROA-nr. Opleidingstype

\begin{tabular}{lll}
\hline 39236 & 17 & VMBO beveiliging \\
39273 & 17 & VMBO beveiliging \\
39287 & 17 & VMBO beveiliging \\
39318 & 17 & VMBO beveiliging \\
39323 & 17 & VMBO beveiliging \\
39800 & 18 & VMBO overig
\end{tabular}

4. Voortgezet onderwijs, hogere trap

\begin{tabular}{|c|c|c|}
\hline 40151 & 19 & HAVO/VWO \\
\hline 40152 & 19 & HAVO/VWO \\
\hline 40153 & 19 & HAVO/VWO \\
\hline 40154 & 19 & HAVO/VWO \\
\hline 40155 & 19 & HAVO/VWO \\
\hline 40158 & 19 & HAVO/VWO \\
\hline 40161 & 19 & HAVO/VWO \\
\hline 40162 & 19 & HAVO/VWO \\
\hline 40163 & 19 & HAVO/VWO \\
\hline 40164 & 19 & HAVO/VWO \\
\hline 40165 & 19 & HAVO/VWO \\
\hline 40166 & 19 & HAVO/VWO \\
\hline 40168 & 19 & HAVO/VWO \\
\hline 40171 & 19 & HAVO/VWO \\
\hline 40172 & 19 & HAVO/VWO \\
\hline 40173 & 19 & HAVO/VWO \\
\hline 40174 & 19 & HAVO/VWO \\
\hline 40175 & 19 & HAVO/VWO \\
\hline 40176 & 19 & HAVO/VWO \\
\hline 40178 & 19 & HAVO/VWO \\
\hline 40180 & 19 & HAVO/VWO \\
\hline 40611 & 57 & HBO lerarenopleiding basisonderwijs \\
\hline 40617 & 56 & MBO overig \\
\hline 40627 & 56 & MBO overig \\
\hline 40637 & 56 & MBO overig \\
\hline 40647 & 56 & MBO overig \\
\hline 40651 & 56 & MBO overig \\
\hline 40653 & 56 & MBO overig \\
\hline 40657 & 36 & MBO vervoer en logistiek \\
\hline 40658 & 56 & MBO overig \\
\hline 40667 & 46 & MBO beweging en therapie \\
\hline 40671 & 56 & MBO overig \\
\hline 40674 & 56 & MBO overig \\
\hline 40688 & 56 & MBO overig \\
\hline 41110 & 56 & MBO overig \\
\hline 41121 & 56 & MBO overig \\
\hline 41123 & 56 & MBO overig \\
\hline 41131 & 56 & MBO overig \\
\hline 41133 & 56 & MBO overig \\
\hline 41150 & 56 & MBO overig \\
\hline 41181 & 56 & MBO overig \\
\hline 41185 & 56 & MBO overig \\
\hline 41188 & 56 & MBO overig \\
\hline 41610 & 43 & MBO verzorging \\
\hline 42110 & 20 & MBO landbouw en veeteelt \\
\hline 42121 & 20 & MBO landbouw en veeteelt \\
\hline 42123 & 20 & MBO landbouw en veeteelt \\
\hline 42125 & 20 & MBO landbouw en veeteelt \\
\hline 42128 & 20 & MBO landbouw en veeteelt \\
\hline 42130 & 21 & MBO milieu en groene ruimte \\
\hline 42151 & 20 & MBO landbouw en veeteelt \\
\hline 42153 & 20 & MBO landbouw en veeteelt \\
\hline 42158 & 20 & MBO landbouw en veeteelt \\
\hline
\end{tabular}


2. Opleidingstypen, volgorde SOI '78 (vervolg)

SOI opleidingsniveau

SOl

ROA-nr. Opleidingstype

\begin{tabular}{|c|c|c|}
\hline 42175 & 21 & MBO milieu en groene ruimte \\
\hline 42183 & 21 & MBO milieu en groene ruimte \\
\hline 42188 & 20 & MBO landbouw en veeteelt \\
\hline 42210 & 26 & MBO werktuigbouw en mechanische techniek \\
\hline 42220 & 20 & MBO landbouw en veeteelt \\
\hline 42250 & 20 & MBO landbouw en veeteelt \\
\hline 42280 & 20 & MBO landbouw en veeteelt \\
\hline 42310 & 20 & MBO landbouw en veeteelt \\
\hline 42320 & 20 & MBO landbouw en veeteelt \\
\hline 42350 & 20 & MBO landbouw en veeteelt \\
\hline 42380 & 20 & MBO landbouw en veeteelt \\
\hline 43110 & 22 & MBO laboratorium \\
\hline 43120 & 22 & MBO laboratorium \\
\hline 43130 & 22 & MBO laboratorium \\
\hline 43140 & 22 & MBO laboratorium \\
\hline 43160 & 22 & MBO laboratorium \\
\hline 43181 & 22 & MBO laboratorium \\
\hline 43183 & 22 & MBO laboratorium \\
\hline 43188 & 22 & MBO laboratorium \\
\hline 43611 & 23 & MBO bouw \\
\hline 43613 & 23 & MBO bouw \\
\hline 43614 & 23 & MBO bouw \\
\hline 43615 & 23 & MBO bouw \\
\hline 43616 & 25 & MBO installatietechniek \\
\hline 43617 & 48 & MBO handel \\
\hline 43618 & 23 & MBO bouw \\
\hline 43623 & 24 & MBO grond-, weg- en waterbouw \\
\hline 43625 & 24 & MBO grond-, weg- en waterbouw \\
\hline 43631 & 26 & MBO werktuigbouw en mechanische techniek \\
\hline 43633 & 26 & MBO werktuigbouw en mechanische techniek \\
\hline 43635 & 27 & MBO fijnmechanische techniek \\
\hline 43638 & 26 & MBO werktuigbouw en mechanische techniek \\
\hline 43641 & 28 & MBO motorvoertuigentechniek \\
\hline 43643 & 26 & MBO werktuigbouw en mechanische techniek \\
\hline 43645 & 29 & MBO vliegtuigtechniek \\
\hline 43646 & 30 & MBO operationele techniek \\
\hline 43647 & 26 & MBO werktuigbouw en mechanische techniek \\
\hline 43648 & 26 & MBO werktuigbouw en mechanische techniek \\
\hline 43651 & 31 & MBO elektrotechniek \\
\hline 43652 & 31 & MBO elektrotechniek \\
\hline 43653 & 31 & MBO elektrotechniek \\
\hline 43654 & 31 & MBO elektrotechniek \\
\hline 43655 & 31 & MBO elektrotechniek \\
\hline 43661 & 32 & MBO grafische techniek \\
\hline 43663 & 32 & MBO grafische techniek \\
\hline 43665 & 32 & MBO grafische techniek \\
\hline 43667 & 32 & MBO grafische techniek \\
\hline 43668 & 32 & MBO grafische techniek \\
\hline 43671 & 37 & MBO techniek overig \\
\hline 43672 & 37 & MBO techniek overig \\
\hline 43673 & 37 & MBO techniek overig \\
\hline 43674 & 33 & MBO procestechniek \\
\hline 43675 & 33 & MBO procestechniek \\
\hline 43676 & 34 & MBO brood en banket \\
\hline 43677 & 35 & MBO levensmiddelentechniek/vleesverwerking \\
\hline 43678 & 33 & MBO procestechniek \\
\hline 43682 & 37 & MBO techniek overig \\
\hline 43685 & 48 & MBO handel \\
\hline 43688 & 37 & MBO techniek overig \\
\hline 43811 & 23 & MBO bouw \\
\hline 43814 & 23 & MBO bouw \\
\hline 43815 & 23 & MBO bouw \\
\hline
\end{tabular}


2. Opleidingstypen, volgorde SOI '78 (vervolg)

SOI opleidingsniveau

SOl

ROA-nr. Opleidingstype

\begin{tabular}{|c|c|c|}
\hline 43816 & 25 & MBO installatietechniek \\
\hline 43817 & 48 & MBO handel \\
\hline 43818 & 23 & MBO bouw \\
\hline 43823 & 24 & MBO grond-, weg- en waterbouw \\
\hline 43833 & 26 & MBO werktuigbouw en mechanische techniek \\
\hline 43835 & 27 & MBO fijnmechanische techniek \\
\hline 43838 & 26 & MBO werktuigbouw en mechanische techniek \\
\hline 43841 & 28 & MBO motorvoertuigentechniek \\
\hline 43843 & 26 & MBO werktuigbouw en mechanische techniek \\
\hline 43847 & 26 & MBO werktuigbouw en mechanische techniek \\
\hline 43848 & 26 & MBO werktuigbouw en mechanische techniek \\
\hline 43851 & 31 & MBO elektrotechniek \\
\hline 43853 & 31 & MBO elektrotechniek \\
\hline 43867 & 32 & MBO grafische techniek \\
\hline 43868 & 32 & MBO grafische techniek \\
\hline 43874 & 33 & MBO procestechniek \\
\hline 43876 & 34 & MBO brood en banket \\
\hline 43877 & 35 & MBO levensmiddelentechniek/vleesverwerking \\
\hline 43885 & 48 & MBO handel \\
\hline 43888 & 37 & MBO techniek overig \\
\hline 44110 & 36 & MBO vervoer en logistiek \\
\hline 44131 & 36 & MBO vervoer en logistiek \\
\hline 44133 & 36 & MBO vervoer en logistiek \\
\hline 44140 & 36 & MBO vervoer en logistiek \\
\hline 44150 & 36 & MBO vervoer en logistiek \\
\hline 44180 & 36 & MBO vervoer en logistiek \\
\hline 44210 & 36 & MBO vervoer en logistiek \\
\hline 44231 & 26 & MBO werktuigbouw en mechanische techniek \\
\hline 44238 & 36 & MBO vervoer en logistiek \\
\hline 44241 & 36 & MBO vervoer en logistiek \\
\hline 44248 & 36 & MBO vervoer en logistiek \\
\hline 44250 & 26 & MBO werktuigbouw en mechanische techniek \\
\hline 44310 & 36 & MBO vervoer en logistiek \\
\hline 44320 & 36 & MBO vervoer en logistiek \\
\hline 44333 & 36 & MBO vervoer en logistiek \\
\hline 44340 & 36 & MBO vervoer en logistiek \\
\hline 44350 & 36 & MBO vervoer en logistiek \\
\hline 44420 & 36 & MBO vervoer en logistiek \\
\hline 45118 & 38 & MBO dokters-, tandarts- en dierenartsassistent \\
\hline 45120 & 40 & MBO verpleging \\
\hline 45138 & 38 & MBO dokters-, tandarts- en dierenartsassistent \\
\hline 45141 & 46 & MBO beweging en therapie \\
\hline 45143 & 46 & MBO beweging en therapie \\
\hline 45148 & 46 & MBO beweging en therapie \\
\hline 45160 & 38 & MBO dokters-, tandarts- en dierenartsassistent \\
\hline 45180 & 49 & MBO secretariaat \\
\hline 45210 & 22 & MBO laboratorium \\
\hline 45220 & 39 & MBO apothekersassistent \\
\hline 45231 & 41 & MBO gezondheidstechniek \\
\hline 45233 & 41 & MBO gezondheidstechniek \\
\hline 45235 & 41 & MBO gezondheidstechniek \\
\hline 45238 & 41 & MBO gezondheidstechniek \\
\hline 45241 & 46 & MBO beweging en therapie \\
\hline 45242 & 46 & MBO beweging en therapie \\
\hline 45248 & 46 & MBO beweging en therapie \\
\hline 45280 & 27 & MBO fijnmechanische techniek \\
\hline 45310 & 49 & MBO secretariaat \\
\hline 45380 & 40 & MBO verpleging \\
\hline 45410 & 46 & MBO beweging en therapie \\
\hline 45430 & 43 & MBO verzorging \\
\hline 45480 & 43 & MBO verzorging \\
\hline 46110 & 47 & MBO administratie \\
\hline
\end{tabular}


2. Opleidingstypen, volgorde SOI '78 (vervolg)

SOI opleidingsniveau

SOI

ROA-nr. Opleidingstype

\begin{tabular}{|c|c|c|}
\hline 46120 & 51 & MBO bedrijfskunde \\
\hline 46131 & 49 & MBO secretariaat \\
\hline 46133 & 47 & MBO administratie \\
\hline 46135 & 52 & MBO automatisering \\
\hline 46138 & 47 & MBO administratie \\
\hline 46141 & 47 & MBO administratie \\
\hline 46142 & 50 & MBO toerisme en recreatie \\
\hline 46143 & 48 & MBO handel \\
\hline 46145 & 53 & MBO geld, bank en belastingen \\
\hline 46146 & 54 & MBO verzekeringswezen \\
\hline 46148 & 47 & MBO administratie \\
\hline 46150 & 48 & MBO handel \\
\hline 46180 & 47 & MBO administratie \\
\hline 46220 & 51 & MBO bedrijfskunde \\
\hline 46240 & 56 & MBO overig \\
\hline 46280 & 48 & MBO handel \\
\hline 46611 & 47 & MBO administratie \\
\hline 46613 & 47 & MBO administratie \\
\hline 46618 & 47 & MBO administratie \\
\hline 46621 & 47 & MBO administratie \\
\hline 46623 & 47 & MBO administratie \\
\hline 46628 & 47 & MBO administratie \\
\hline 46630 & 53 & MBO geld, bank en belastingen \\
\hline 47111 & 42 & MBO sociaal-cultureel \\
\hline 47113 & 42 & MBO sociaal-cultureel \\
\hline 47115 & 42 & MBO sociaal-cultureel \\
\hline 47118 & 42 & MBO sociaal-cultureel \\
\hline 47120 & 42 & MBO sociaal-cultureel \\
\hline 47130 & 42 & MBO sociaal-cultureel \\
\hline 47141 & 42 & MBO sociaal-cultureel \\
\hline 47143 & 42 & MBO sociaal-cultureel \\
\hline 47145 & 42 & MBO sociaal-cultureel \\
\hline 47148 & 42 & MBO sociaal-cultureel \\
\hline 47150 & 42 & MBO sociaal-cultureel \\
\hline 47161 & 42 & MBO sociaal-cultureel \\
\hline 47163 & 42 & MBO sociaal-cultureel \\
\hline 47165 & 42 & MBO sociaal-cultureel \\
\hline 47188 & 42 & MBO sociaal-cultureel \\
\hline 48110 & 43 & MBO verzorging \\
\hline 48121 & 43 & MBO verzorging \\
\hline 48123 & 43 & MBO verzorging \\
\hline 48125 & 43 & MBO verzorging \\
\hline 48127 & 43 & MBO verzorging \\
\hline 48128 & 43 & MBO verzorging \\
\hline 48130 & 44 & MBO uiterlijke verzorging \\
\hline 48140 & 45 & MBO horeca \\
\hline 48180 & 43 & MBO verzorging \\
\hline 48320 & 43 & MBO verzorging \\
\hline 48330 & 44 & MBO uiterlijke verzorging \\
\hline 48340 & 45 & MBO horeca \\
\hline 48610 & 56 & MBO overig \\
\hline 48620 & 56 & MBO overig \\
\hline 48630 & 56 & MBO overig \\
\hline 48640 & 56 & MBO overig \\
\hline 48680 & 56 & MBO overig \\
\hline 49110 & 55 & MBO openbare orde en veiligheid \\
\hline 49140 & 55 & MBO openbare orde en veiligheid \\
\hline 49150 & 55 & MBO openbare orde en veiligheid \\
\hline 49160 & 55 & MBO openbare orde en veiligheid \\
\hline 49170 & 55 & MBO openbare orde en veiligheid \\
\hline 49180 & 55 & MBO openbare orde en veiligheid \\
\hline 49236 & 55 & MBO openbare orde en veiligheid \\
\hline
\end{tabular}


2. Opleidingstypen, volgorde SOI '78 (vervolg)

\begin{tabular}{lll}
\hline \multicolumn{3}{c}{ SOI opleidingsniveau } \\
SOI & ROA-nr. & Opleidingstype \\
\hline 49251 & 55 & MBO openbare orde en veiligheid \\
49252 & 55 & MBO openbare orde en veiligheid \\
49253 & 55 & MBO openbare orde en veiligheid \\
49254 & 55 & MBO openbare orde en veiligheid \\
49258 & 55 & MBO openbare orde en veiligheid \\
49261 & 55 & MBO openbare orde en veiligheid \\
49262 & 55 & MBO openbare orde en veiligheid \\
49263 & 55 & MBO openbare orde en veiligheid \\
49264 & 55 & MBO openbare orde en veiligheid \\
49266 & 55 & MBO openbare orde en veiligheid \\
49267 & 55 & MBO openbare orde en veiligheid \\
49272 & 55 & MBO openbare orde en veiligheid \\
49273 & 55 & MBO openbare orde en veiligheid \\
49274 & 55 & MBO openbare orde en veiligheid \\
49276 & 55 & MBO openbare orde en veiligheid \\
49287 & 55 & MBO openbare orde en veiligheid \\
49312 & 55 & MBO openbare orde en veiligheid \\
49318 & 55 & MBO openbare orde en veiligheid \\
49323 & 55 & MBO openbare orde en veiligheid \\
49351 & 55 & MBO openbare orde en veiligheid \\
49352 & 55 & MBO openbare orde en veiligheid \\
49353 & 55 & MBO openbare orde en veiligheid \\
49358 & 55 & MBO openbare orde en veiligheid \\
49361 & 55 & MBO openbare orde en veiligheid \\
49362 & 55 & MBO openbare orde en veiligheid \\
49363 & 55 & MBO openbare orde en veiligheid \\
49368 & 55 & MBO openbare orde en veiligheid \\
49371 & 55 & MBO openbare orde en veiligheid \\
49372 & 55 & MBO openbare orde en veiligheid \\
49373 & 55 & MBO openbare orde en veiligheid \\
49378 & 55 & MBO openbare orde en veiligheid \\
49800 & 56 & MBO overig
\end{tabular}

\section{Hoger onderwijs, eerste trap}

$\begin{array}{lll}50611 & 57 & \text { HBO lerarenopleiding basisonderwijs } \\ 50613 & 57 & \text { HBO lerarenopleiding basisonderwijs } \\ 50617 & 57 & \text { HBO lerarenopleiding basisonderwijs } \\ 50621 & 58 & \text { HBO lerarenopleiding talen } \\ 50623 & 58 & \text { HBO lerarenopleiding talen } \\ 50624 & 58 & \text { HBO lerarenopleiding talen } \\ 50625 & 58 & \text { HBO lerarenopleiding talen } \\ 50626 & 60 & \text { HBO lerarenopleiding economie en maatschappij } \\ 50627 & 60 & \text { HBO lerarenopleiding economie en maatschappij } \\ 50628 & 58 & \text { HBO lerarenopleiding talen } \\ 50631 & 59 & \text { HBO lerarenopleiding natuur en techniek } \\ 50633 & 59 & \text { HBO lerarenopleiding natuur en techniek } \\ 50635 & 59 & \text { HBO lerarenopleiding natuur en techniek } \\ 50637 & 59 & \text { HBO lerarenopleiding natuur en techniek } \\ 50638 & 59 & \text { HBO lerarenopleiding natuur en techniek } \\ 50641 & 59 & \text { HBO lerarenopleiding natuur en techniek } \\ 50643 & 59 & \text { HBO lerarenopleiding natuur en techniek } \\ 50645 & 59 & \text { HBO lerarenopleiding natuur en techniek } \\ 50647 & 59 & \text { HBO lerarenopleiding natuur en techniek } \\ 50651 & 59 & \text { HBO lerarenopleiding natuur en techniek } \\ 50653 & 59 & \text { HBO lerarenopleiding natuur en techniek } \\ 50655 & 59 & \text { HBO lerarenopleiding natuur en techniek } \\ 50657 & 59 & \text { HBO lerarenopleiding natuur en techniek } \\ 50658 & 59 & \text { HBO lerarenopleiding natuur en techniek } \\ 50661 & 60 & \text { HBO lerarenopleiding economie en maatschappij } \\ 50663 & 60 & \text { HBO lerarenopleiding economie en maatschappij } \\ 50664 & 60 & \text { HBO lerarenopleiding economie en maatschappij }\end{array}$


2. Opleidingstypen, volgorde SOI '78 (vervolg)

\begin{tabular}{|c|c|c|}
\hline \multicolumn{2}{|c|}{ SOI opleidingsniveau } & $\begin{array}{l}\text { eau } \\
\text { Opleidingstype }\end{array}$ \\
\hline 50666 & 60 & HBO lerarenopleiding economie en maatschappij \\
\hline 50667 & 61 & HBO lerarenopleiding lichamelijke opvoeding \\
\hline 50671 & 62 & HBO lerarenopleiding medisch en verzorging \\
\hline 50674 & 62 & HBO lerarenopleiding medisch en verzorging \\
\hline 50681 & 63 & HBO lerarenopleiding expressie \\
\hline 50682 & 63 & HBO lerarenopleiding expressie \\
\hline 50683 & 63 & HBO lerarenopleiding expressie \\
\hline 50685 & 63 & HBO lerarenopleiding expressie \\
\hline 50686 & 63 & HBO lerarenopleiding expressie \\
\hline 50688 & 63 & HBO lerarenopleiding expressie \\
\hline 51110 & 64 & HBO tolk en vertaler \\
\hline 51121 & 64 & HBO tolk en vertaler \\
\hline 51123 & 64 & HBO tolk en vertaler \\
\hline 51125 & 64 & HBO tolk en vertaler \\
\hline 51128 & 64 & HBO tolk en vertaler \\
\hline 51131 & 64 & HBO tolk en vertaler \\
\hline 51133 & 64 & HBO tolk en vertaler \\
\hline 51138 & 64 & HBO tolk en vertaler \\
\hline 51140 & 64 & HBO tolk en vertaler \\
\hline 51150 & 64 & HBO tolk en vertaler \\
\hline 51181 & 64 & HBO tolk en vertaler \\
\hline 51183 & 64 & HBO tolk en vertaler \\
\hline 51185 & 64 & HBO tolk en vertaler \\
\hline 51188 & 64 & HBO tolk en vertaler \\
\hline 51610 & 87 & HBO maatschappelijk werk en hulpverlening \\
\hline 52110 & 65 & HBO landbouw en veeteelt \\
\hline 52128 & 66 & HBO milieukunde en levensmiddelentechnologie \\
\hline 52130 & 66 & HBO milieukunde en levensmiddelentechnologie \\
\hline 52158 & 65 & HBO landbouw en veeteelt \\
\hline 52171 & 66 & HBO milieukunde en levensmiddelentechnologie \\
\hline 52173 & 66 & HBO milieukunde en levensmiddelentechnologie \\
\hline 52175 & 66 & HBO milieukunde en levensmiddelentechnologie \\
\hline 52181 & 66 & HBO milieukunde en levensmiddelentechnologie \\
\hline 52183 & 66 & HBO milieukunde en levensmiddelentechnologie \\
\hline 52188 & 66 & HBO milieukunde en levensmiddelentechnologie \\
\hline 52210 & 66 & HBO milieukunde en levensmiddelentechnologie \\
\hline 52220 & 66 & HBO milieukunde en levensmiddelentechnologie \\
\hline 52310 & 85 & HBO bedrijfskunde \\
\hline 52380 & 85 & HBO bedrijfskunde \\
\hline 53110 & 71 & HBO elektrotechniek \\
\hline 53120 & 71 & HBO elektrotechniek \\
\hline 53130 & 71 & HBO elektrotechniek \\
\hline 53140 & 67 & HBO laboratorium \\
\hline 53150 & 71 & HBO elektrotechniek \\
\hline 53160 & 67 & HBO laboratorium \\
\hline 53170 & 71 & HBO elektrotechniek \\
\hline 53183 & 71 & HBO elektrotechniek \\
\hline 53188 & 71 & HBO elektrotechniek \\
\hline 53611 & 68 & HBO bouwkunde \\
\hline 53613 & 68 & HBO bouwkunde \\
\hline 53618 & 68 & HBO bouwkunde \\
\hline 53623 & 69 & HBO civiele techniek \\
\hline 53625 & 69 & HBO civiele techniek \\
\hline 53631 & 70 & HBO werktuigbouwkunde \\
\hline 53633 & 70 & HBO werktuigbouwkunde \\
\hline 53635 & 70 & HBO werktuigbouwkunde \\
\hline 53643 & 70 & HBO werktuigbouwkunde \\
\hline 53645 & 70 & HBO werktuigbouwkunde \\
\hline 53646 & 70 & HBO werktuigbouwkunde \\
\hline 53648 & 70 & HBO werktuigbouwkunde \\
\hline 53651 & 71 & HBO elektrotechniek \\
\hline 53652 & 72 & HBO informatica \\
\hline
\end{tabular}


2. Opleidingstypen, volgorde SOI '78 (vervolg)

SOI opleidingsniveau

SOI ROA-nr. Opleidingstype

\begin{tabular}{|c|c|c|}
\hline 53653 & 71 & HBO elektrotechniek \\
\hline 53654 & 71 & HBO elektrotechniek \\
\hline 53655 & 71 & HBO elektrotechniek \\
\hline 53671 & 73 & HBO chemische technologie \\
\hline 53672 & 73 & HBO chemische technologie \\
\hline 53673 & 73 & HBO chemische technologie \\
\hline 53674 & 73 & HBO chemische technologie \\
\hline 53675 & 73 & HBO chemische technologie \\
\hline 53677 & 66 & HBO milieukunde en levensmiddelentechnologie \\
\hline 53678 & 66 & HBO milieukunde en levensmiddelentechnologie \\
\hline 53682 & 71 & HBO elektrotechniek \\
\hline 53683 & 71 & HBO elektrotechniek \\
\hline 53685 & 93 & HBO overig \\
\hline 53688 & 93 & HBO overig \\
\hline 53818 & 68 & HBO bouwkunde \\
\hline 53841 & 70 & HBO werktuigbouwkunde \\
\hline 53847 & 70 & HBO werktuigbouwkunde \\
\hline 53848 & 70 & HBO werktuigbouwkunde \\
\hline 53868 & 93 & $\mathrm{HBO}$ overig \\
\hline 53885 & 93 & HBO overig \\
\hline 54110 & 74 & HBO vervoer en logistiek \\
\hline 54121 & 74 & HBO vervoer en logistiek \\
\hline 54128 & 74 & HBO vervoer en logistiek \\
\hline 54133 & 74 & HBO vervoer en logistiek \\
\hline 54140 & 74 & HBO vervoer en logistiek \\
\hline 54150 & 74 & HBO vervoer en logistiek \\
\hline 54180 & 74 & HBO vervoer en logistiek \\
\hline 54220 & 74 & HBO vervoer en logistiek \\
\hline 54231 & 74 & HBO vervoer en logistiek \\
\hline 54238 & 74 & HBO vervoer en logistiek \\
\hline 54241 & 74 & HBO vervoer en logistiek \\
\hline 54310 & 74 & HBO vervoer en logistiek \\
\hline 54331 & 74 & HBO vervoer en logistiek \\
\hline 54350 & 74 & HBO vervoer en logistiek \\
\hline 55111 & 79 & HBO paramedisch overig \\
\hline 55113 & 79 & HBO paramedisch overig \\
\hline 55118 & 79 & HBO paramedisch overig \\
\hline 55120 & 75 & HBO verpleegkunde \\
\hline 55131 & 79 & HBO paramedisch overig \\
\hline 55133 & 79 & HBO paramedisch overig \\
\hline 55141 & 76 & HBO (fysio)therapie \\
\hline 55143 & 76 & HBO (fysio)therapie \\
\hline 55148 & 76 & HBO (fysio)therapie \\
\hline 55151 & 76 & HBO (fysio)therapie \\
\hline 55153 & 76 & HBO (fysio)therapie \\
\hline 55160 & 79 & HBO paramedisch overig \\
\hline 55180 & 76 & HBO (fysio)therapie \\
\hline 55210 & 67 & HBO laboratorium \\
\hline 55220 & 67 & HBO laboratorium \\
\hline 55231 & 79 & HBO paramedisch overig \\
\hline 55238 & 76 & HBO (fysio)therapie \\
\hline 55241 & 78 & $\mathrm{HBO}$ radiologie \\
\hline 55242 & 78 & HBO radiologie \\
\hline 55243 & 78 & HBO radiologie \\
\hline 55248 & 79 & HBO paramedisch overig \\
\hline 55280 & 79 & HBO paramedisch overig \\
\hline 55310 & 84 & $\mathrm{HBO}$ secretariaat \\
\hline 55380 & 75 & HBO verpleegkunde \\
\hline 55420 & 77 & HBO voeding \\
\hline 55480 & 79 & HBO paramedisch overig \\
\hline 56110 & 80 & HBO accountancy en bedrijfseconomie \\
\hline 56120 & 85 & HBO bedrijfskunde \\
\hline
\end{tabular}


2. Opleidingstypen, volgorde SOI '78 (vervolg)

\begin{tabular}{|c|c|c|}
\hline $\begin{array}{l}\text { sol op } \\
\text { SOl }\end{array}$ & $\begin{array}{l}\text { idingsniv } \\
\text { ROA-nr. }\end{array}$ & $\begin{array}{l}\text { eau } \\
\text { Opleidingstype }\end{array}$ \\
\hline 56131 & 84 & HBO secretariaat \\
\hline 56133 & 80 & HBO accountancy en bedrijfseconomie \\
\hline 56135 & 72 & HBO informatica \\
\hline 56138 & 80 & HBO accountancy en bedrijfseconomie \\
\hline 56141 & 86 & HBO communicatie en journalistiek \\
\hline 56142 & 82 & HBO toerisme en recreatie \\
\hline 56143 & 81 & HBO commerciële economie \\
\hline 56145 & 81 & HBO commerciële economie \\
\hline 56146 & 81 & HBO commerciële economie \\
\hline 56148 & 81 & HBO commerciële economie \\
\hline 56150 & 81 & HBO commerciële economie \\
\hline 56180 & 81 & HBO commerciële economie \\
\hline 56210 & 80 & HBO accountancy en bedrijfseconomie \\
\hline 56220 & 85 & HBO bedrijfskunde \\
\hline 56240 & 80 & HBO accountancy en bedrijfseconomie \\
\hline 56611 & 83 & HBO recht en bestuur \\
\hline 56613 & 83 & HBO recht en bestuur \\
\hline 56618 & 83 & HBO recht en bestuur \\
\hline 56621 & 83 & HBO recht en bestuur \\
\hline 56623 & 83 & HBO recht en bestuur \\
\hline 56628 & 83 & $\mathrm{HBO}$ recht en bestuur \\
\hline 56630 & 80 & HBO accountancy en bedrijfseconomie \\
\hline 57111 & 87 & HBO maatschappelijk werk en hulpverlening \\
\hline 57113 & 88 & HBO personeel en arbeid \\
\hline 57115 & 87 & HBO maatschappelijk werk en hulpverlening \\
\hline 57118 & 87 & HBO maatschappelijk werk en hulpverlening \\
\hline 57120 & 86 & HBO communicatie en journalistiek \\
\hline 57130 & 89 & HBO bibliotheek en documentatie \\
\hline 57141 & 90 & HBO sociaal-cultureel overig \\
\hline 57143 & 90 & HBO sociaal-cultureel overig \\
\hline 57145 & 90 & HBO sociaal-cultureel overig \\
\hline 57148 & 90 & HBO sociaal-cultureel overig \\
\hline 57150 & 90 & HBO sociaal-cultureel overig \\
\hline 57161 & 90 & HBO sociaal-cultureel overig \\
\hline 57165 & 90 & HBO sociaal-cultureel overig \\
\hline 57181 & 60 & HBO lerarenopleiding economie en maatschappij \\
\hline 57188 & 87 & HBO maatschappelijk werk en hulpverlening \\
\hline 58110 & 93 & HBO overig \\
\hline 58123 & 93 & $\mathrm{HBO}$ overig \\
\hline 58125 & 93 & HBO overig \\
\hline 58180 & 77 & HBO voeding \\
\hline 58340 & 93 & HBO overig \\
\hline 58610 & 91 & HBO uitvoerende en beeldende kunsten \\
\hline 58620 & 91 & HBO uitvoerende en beeldende kunsten \\
\hline 58630 & 91 & HBO uitvoerende en beeldende kunsten \\
\hline 58640 & 91 & HBO uitvoerende en beeldende kunsten \\
\hline 58680 & 91 & HBO uitvoerende en beeldende kunsten \\
\hline 59110 & 92 & HBO openbare orde en veiligheid \\
\hline 59120 & 92 & HBO openbare orde en veiligheid \\
\hline 59160 & 92 & HBO openbare orde en veiligheid \\
\hline 59170 & 92 & HBO openbare orde en veiligheid \\
\hline 59236 & 92 & HBO openbare orde en veiligheid \\
\hline 59251 & 92 & HBO openbare orde en veiligheid \\
\hline 59253 & 92 & HBO openbare orde en veiligheid \\
\hline 59254 & 92 & HBO openbare orde en veiligheid \\
\hline 59258 & 92 & HBO openbare orde en veiligheid \\
\hline 59263 & 92 & HBO openbare orde en veiligheid \\
\hline 59264 & 92 & HBO openbare orde en veiligheid \\
\hline 59274 & 92 & HBO openbare orde en veiligheid \\
\hline 59278 & 92 & HBO openbare orde en veiligheid \\
\hline 59287 & 92 & HBO openbare orde en veiligheid \\
\hline 59318 & 92 & HBO openbare orde en veiligheid \\
\hline
\end{tabular}


2. Opleidingstypen, volgorde SOI '78 (vervolg)

\begin{tabular}{|c|c|c|}
\hline \multicolumn{3}{|c|}{ SOI opleidingsniveau } \\
\hline 59352 & 92 & HBO openbare orde en veiligheid \\
\hline 59362 & 92 & HBO openbare orde en veiligheid \\
\hline 59372 & 92 & HBO openbare orde en veiligheid \\
\hline
\end{tabular}

\section{Hoger onderwijs, tweede trap}

\begin{tabular}{|c|c|c|}
\hline 60613 & 57 & HBO lerarenopleiding basisonderwijs \\
\hline 60617 & 57 & HBO lerarenopleiding basisonderwijs \\
\hline 60621 & 58 & HBO lerarenopleiding talen \\
\hline 60623 & 58 & HBO lerarenopleiding talen \\
\hline 60624 & 58 & HBO lerarenopleiding talen \\
\hline 60625 & 58 & HBO lerarenopleiding talen \\
\hline 60626 & 60 & HBO lerarenopleiding economie en maatschappij \\
\hline 60627 & 60 & HBO lerarenopleiding economie en maatschappij \\
\hline 60628 & 58 & HBO lerarenopleiding talen \\
\hline 60631 & 59 & HBO lerarenopleiding natuur en techniek \\
\hline 60633 & 59 & HBO lerarenopleiding natuur en techniek \\
\hline 60635 & 59 & HBO lerarenopleiding natuur en techniek \\
\hline 60637 & 59 & HBO lerarenopleiding natuur en techniek \\
\hline 60643 & 59 & HBO lerarenopleiding natuur en techniek \\
\hline 60657 & 59 & HBO lerarenopleiding natuur en techniek \\
\hline 60658 & 59 & HBO lerarenopleiding natuur en techniek \\
\hline 60661 & 60 & HBO lerarenopleiding economie en maatschappij \\
\hline 60663 & 60 & HBO lerarenopleiding economie en maatschappij \\
\hline 60664 & 60 & HBO lerarenopleiding economie en maatschappij \\
\hline 60666 & 60 & HBO lerarenopleiding economie en maatschappij \\
\hline 60667 & 61 & HBO lerarenopleiding lichamelijke opvoeding \\
\hline 60671 & 62 & HBO lerarenopleiding medisch en verzorging \\
\hline 60674 & 62 & HBO lerarenopleiding medisch en verzorging \\
\hline 60681 & 63 & HBO lerarenopleiding expressie \\
\hline 60682 & 63 & HBO lerarenopleiding expressie \\
\hline 60683 & 63 & HBO lerarenopleiding expressie \\
\hline 60685 & 63 & HBO lerarenopleiding expressie \\
\hline 61110 & 94 & WO letteren \\
\hline 61121 & 94 & WO letteren \\
\hline 61123 & 94 & WO letteren \\
\hline 61125 & 94 & WO letteren \\
\hline 61128 & 94 & WO letteren \\
\hline 61131 & 94 & WO letteren \\
\hline 61133 & 94 & WO letteren \\
\hline 61138 & 94 & WO letteren \\
\hline 61140 & 94 & WO letteren \\
\hline 61150 & 94 & WO letteren \\
\hline 61181 & 94 & WO letteren \\
\hline 61183 & 94 & WO letteren \\
\hline 61185 & 94 & WO letteren \\
\hline 61188 & 94 & WO letteren \\
\hline 61610 & 95 & WO theologie \\
\hline 62110 & 96 & WO landbouw en milieukunde \\
\hline 62128 & 96 & WO landbouw en milieukunde \\
\hline 62130 & 96 & WO landbouw en milieukunde \\
\hline 62158 & 96 & WO landbouw en milieukunde \\
\hline 62171 & 96 & WO landbouw en milieukunde \\
\hline 62173 & 96 & WO landbouw en milieukunde \\
\hline 62175 & 96 & WO landbouw en milieukunde \\
\hline 62181 & 100 & WO werktuigbouwkunde \\
\hline 62183 & 96 & WO landbouw en milieukunde \\
\hline 62188 & 96 & WO landbouw en milieukunde \\
\hline 62210 & 96 & WO landbouw en milieukunde \\
\hline 62220 & 96 & WO landbouw en milieukunde \\
\hline 62310 & 96 & WO landbouw en milieukunde \\
\hline 62380 & 96 & WO landbouw en milieukunde \\
\hline
\end{tabular}


2. Opleidingstypen, volgorde SOI '78 (vervolg)

\begin{tabular}{|c|c|c|}
\hline \multicolumn{3}{|c|}{ SOI opleidingsniveau } \\
\hline 63110 & 97 & WO wiskunde en natuurwetenschappen \\
\hline 63120 & 97 & WO wiskunde en natuurwetenschappen \\
\hline 63130 & 97 & WO wiskunde en natuurwetenschappen \\
\hline 63140 & 97 & WO wiskunde en natuurwetenschappen \\
\hline 63150 & 97 & WO wiskunde en natuurwetenschappen \\
\hline 63160 & 97 & WO wiskunde en natuurwetenschappen \\
\hline 63170 & 97 & WO wiskunde en natuurwetenschappen \\
\hline 63181 & 97 & WO wiskunde en natuurwetenschappen \\
\hline 63188 & 97 & WO wiskunde en natuurwetenschappen \\
\hline 63613 & 98 & WO bouwkunde \\
\hline 63618 & 98 & WO bouwkunde \\
\hline 63623 & 99 & WO civiele techniek \\
\hline 63625 & 99 & WO civiele techniek \\
\hline 63631 & 97 & WO wiskunde en natuurwetenschappen \\
\hline 63643 & 100 & WO werktuigbouwkunde \\
\hline 63645 & 100 & WO werktuigbouwkunde \\
\hline 63648 & 100 & WO werktuigbouwkunde \\
\hline 63651 & 101 & WO elektrotechniek \\
\hline 63652 & 102 & WO informatica en bestuurlijke informatiekunde \\
\hline 63653 & 101 & WO elektrotechniek \\
\hline 63654 & 101 & WO elektrotechniek \\
\hline 63655 & 101 & WO elektrotechniek \\
\hline 63674 & 97 & WO wiskunde en natuurwetenschappen \\
\hline 63675 & 97 & WO wiskunde en natuurwetenschappen \\
\hline 63677 & 97 & WO wiskunde en natuurwetenschappen \\
\hline 63682 & 97 & WO wiskunde en natuurwetenschappen \\
\hline 63683 & 97 & WO wiskunde en natuurwetenschappen \\
\hline 63688 & 97 & WO wiskunde en natuurwetenschappen \\
\hline 63818 & 98 & WO bouwkunde \\
\hline 65111 & 103 & WO (dier)geneeskunde \\
\hline 65131 & 104 & WO tandheelkunde \\
\hline 65148 & 110 & WO sociale wetenschappen \\
\hline 65160 & 103 & WO (dier)geneeskunde \\
\hline 65180 & 110 & WO sociale wetenschappen \\
\hline 65210 & 105 & WO farmacie \\
\hline 65220 & 105 & WO farmacie \\
\hline 65238 & 105 & WO farmacie \\
\hline 65280 & 105 & WO farmacie \\
\hline 65380 & 113 & WO overig \\
\hline 65480 & 113 & WO overig \\
\hline 66110 & 106 & WO econom(etr)ie \\
\hline 66120 & 107 & WO bedrijfskunde \\
\hline 66133 & 108 & WO accountancy en belastingen \\
\hline 66135 & 102 & WO informatica en bestuurlijke informatiekunde \\
\hline 66141 & 106 & WO econom(etr)ie \\
\hline 66142 & 106 & WO econom(etr)ie \\
\hline 66143 & 106 & WO econom(etr)ie \\
\hline 66145 & 106 & WO econom(etr)ie \\
\hline 66148 & 106 & WO econom(etr)ie \\
\hline 66150 & 106 & WO econom(etr)ie \\
\hline 66210 & 106 & WO econom(etr)ie \\
\hline 66220 & 107 & WO bedrijfskunde \\
\hline 66240 & 106 & WO econom(etr)ie \\
\hline 66611 & 109 & WO rechten en bestuurskunde \\
\hline 66613 & 109 & WO rechten en bestuurskunde \\
\hline 66618 & 109 & WO rechten en bestuurskunde \\
\hline 66628 & 109 & WO rechten en bestuurskunde \\
\hline 66630 & 108 & WO accountancy en belastingen \\
\hline 66680 & 109 & WO rechten en bestuurskunde \\
\hline 67111 & 111 & WO sociaal-cultureel overig \\
\hline 67113 & 111 & WO sociaal-cultureel overig \\
\hline 67115 & 111 & WO sociaal-cultureel overig \\
\hline
\end{tabular}


2. Opleidingstypen, volgorde SOI '78 (vervolg)

\begin{tabular}{lrl}
\hline \multicolumn{3}{l}{ SOI opleidingsniveau } \\
SOI & ROA-nr. Opleidingstype \\
\hline 67118 & 111 & WO sociaal-cultureel overig \\
67120 & 110 & WO sociale wetenschappen \\
67130 & 110 & WO sociale wetenschappen \\
67141 & 110 & WO sociale wetenschappen \\
67143 & 110 & WO sociale wetenschappen \\
67145 & 110 & WO sociale wetenschappen \\
67148 & 110 & WO sociale wetenschappen \\
67150 & 110 & WO sociale wetenschappen \\
67161 & 110 & WO sociale wetenschappen \\
67188 & 110 & WO sociale wetenschappen \\
68110 & 110 & WO sociale wetenschappen \\
68180 & 110 & WO sociale wetenschappen \\
68610 & 91 & HBO uitvoerende en beeldende kunsten \\
68640 & 112 & WO kunstwetenschappen \\
69150 & 113 & WO overig \\
69160 & 113 & WO overig \\
69170 & 113 & WO overig \\
69180 & 113 & WO overig \\
69287 & 113 & WO overig
\end{tabular}

\section{Hoger onderwijs, derde trap}

$\begin{array}{rrl}70621 & 58 & \text { HBO lerarenopleiding talen } \\ 70623 & 58 & \text { HBO lerarenopleiding talen } \\ 70624 & 58 & \text { HBO lerarenopleiding talen } \\ 70625 & 58 & \text { HBO lerarenopleiding talen } \\ 70626 & 60 & \text { HBO lerarenopleiding economie en maatschappij } \\ 70627 & 60 & \text { HBO lerarenopleiding economie en maatschappij } \\ 70628 & 58 & \text { HBO lerarenopleiding talen } \\ 70631 & 59 & \text { HBO lerarenopleiding natuur en techniek } \\ 70633 & 59 & \text { HBO lerarenopleiding natuur en techniek } \\ 70635 & 59 & \text { HBO lerarenopleiding natuur en techniek } \\ 70661 & 60 & \text { HBO lerarenopleiding economie en maatschappij } \\ 70663 & 60 & \text { HBO lerarenopleiding economie en maatschappij } \\ 70666 & 60 & \text { HBO lerarenopleiding economie en maatschappij } \\ 70685 & 63 & \text { HBO lerarenopleiding expressie } \\ 70688 & 63 & \text { HBO lerarenopleiding expressie } \\ 71181 & 94 & \text { WO letteren } \\ 71188 & 94 & \text { WO letteren } \\ 71610 & 95 & \text { WO theologie } \\ 72175 & 96 & \text { WO landbouw en milieukunde } \\ 72181 & 101 & \text { WO elektrotechniek } \\ 73110 & 97 & \text { WO wiskunde en natuurwetenschappen } \\ 73120 & 97 & \text { WO wiskunde en natuurwetenschappen } \\ 73140 & 97 & \text { WO wiskunde en natuurwetenschappen } \\ 73150 & 97 & \text { WO wiskunde en natuurwetenschappen } \\ 73160 & 97 & \text { WO wiskunde en natuurwetenschappen } \\ 73618 & 98 & \text { WO bouwkunde } \\ 73623 & 99 & \text { WO civiele techniek } \\ 73645 & 100 & \text { WO werktuigbouwkunde } \\ 73648 & 100 & \text { WO werktuigbouwkunde } \\ 73651 & 101 & \text { WO elektrotechniek } \\ 73654 & 101 & \text { WO elektrotechniek } \\ 73655 & 101 & \text { WO elektrotechniek } \\ 73674 & 97 & \text { WO wiskunde en natuurwetenschappen } \\ 75111 & 103 & \text { WO (dier)geneeskunde } \\ 75131 & 104 & \text { WO tandheelkunde } \\ 75148 & 110 & \text { WO sociale wetenschappen } \\ 75151 & 110 & \text { WO sociale wetenschappen } \\ 75160 & 103 & \text { WO (dier)geneeskunde } \\ 75180 & 110 & \text { WO sociale wetenschappen } \\ 75220 & 105 & \text { WO farmacie } \\ 3 & & \\ 7 & & \end{array}$


2. Opleidingstypen, volgorde SOI '78 (vervolg)

SOI opleidingsniveau

SOI ROA-nr. Opleidingstype

$\begin{array}{lll}75280 & 105 & \text { WO farmacie } \\ 76110 & 106 & \text { WO econom(etr)ie } \\ 76120 & 107 & \text { WO bedrijfskunde } \\ 76133 & 108 & \text { WO accountancy en belastingen } \\ 76135 & 102 & \text { WO informatica en bestuurlijke informatiekunde } \\ 76145 & 106 & \text { WO econom(etr)ie } \\ 76148 & 106 & \text { WO econom(etr)ie } \\ 76618 & 109 & \text { WO rechten en bestuurskunde } \\ 76628 & 109 & \text { WO rechten en bestuurskunde } \\ 76630 & 108 & \text { WO accountancy en belastingen } \\ 77113 & 111 & \text { WO sociaal-cultureel overig } \\ 77130 & 110 & \text { WO sociale wetenschappen } \\ 77148 & 110 & \text { WO sociale wetenschappen } \\ 77150 & 110 & \text { WO sociale wetenschappen }\end{array}$





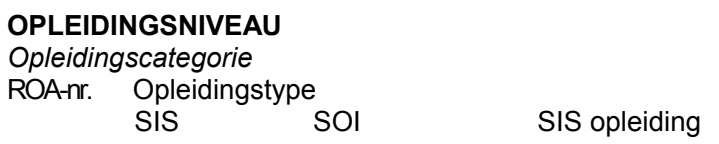

\section{BASISONDERWIJS}

Basisonderwijs

$1 \quad$ Basisonderwijs

$1130010020112 \quad$ Basisonderwijs

$11300201 \quad 20121 \quad$ Speciaal onderwijs (Z)MLK

$11300202 \quad 20123 \quad$ Speciaal onderwijs LOM

VMBO

VMBO theorie

$2 \quad$ VMBO theorie

$\begin{array}{lll}21300000 & 30121 & \text { IVBO } \\ 21300101 & 30121 & \text { VSO (Z)MLK } \\ 21300102 & 30123 & \text { VSO LOM }\end{array}$

VMBO landbouw en natuurlijke omgeving

$3 \quad \mathrm{VMBO}$ landbouw en natuurlijke omgeving

$21310000 \quad 32110 \quad$ IVBO Landbouw

$21310200 \quad 32188 \quad$ IVBO Landbouw en natuurlijke omgeving

$31310000 \quad 32110 \quad$ VBO Landbouw

$31310200 \quad 32188 \quad$ VBO Landbouw en natuurlijke omgeving

$6111000032110 \quad$ BOL AB Landbouw

$\begin{array}{lll}61110100 & 32110 & \text { BOL AB Plantenteelt }\end{array}$

$62137200 \quad 32175 \quad$ BBL AB Milieutechniek

$6213720132175 \quad$ BBL AB Uitvoerend milieumedewerker

VMBO techniek

$4 \quad$ VMBO bouwtechniek

$21330100 \quad 33618$

$21330101 \quad 33611$

$21330102 \quad 33614$

$21330103 \quad 33623$

$21330104 \quad 33615$

$21330105 \quad 33614$

$21330106 \quad 33611$

$21330108 \quad 33614$

$31330100 \quad 33618$

$31330101 \quad 33611$

$31330102 \quad 33614$

$31330103 \quad 33623$

$31330104 \quad 33615$

$31330105 \quad 33614$

$31330106 \quad 33611$

$31330108 \quad 33614$

$31330805 \quad 33623$

$61130200 \quad 33611$

$61130201 \quad 33611$

$61130203 \quad 33611$

$61130204 \quad 33611$

$61130205 \quad 33611$

$62130200 \quad 33611$

$62130201 \quad 33611$

$62130203 \quad 33611$

$62131202 \quad 33615$

$5 \quad$ VMBO installatietechniek

$31330400 \quad 33616$

$61135000 \quad 33616$

$61135001 \quad 33616$

$61135002 \quad 33616$

IVBO Bouwtechniek

IVBO Timmeren

IVBO Metselen

IVBO Wegenbouw

IVBO Schilderen

IVBO Stukadoren

IVBO Meubelmaken

IVBO Tegelzetten

VBO Bouwtechniek

VBO Timmeren

VBO Metselen

VBO Wegenbouw

VBO Schilderen

VBO Stukadoren

VBO Meubelmaken

VBO Tegelzetten

VBO Baggerbedrijf

BOL AB Houtbewerking en woninginrichting

$B O L A B$ Assistent machinaal houtbewerker

BOL AB Assistent bestekzoeker

BOL AB Montagemedewerker timmerindustrie

$B O L A B$ Vloerenstoffeerder

$B B L A B$ Houtbewerking en woninginrichting

BBL AB Assistent machinaal houtbewerker

BBL AB Assistent bestekzoeker

BBL AB Assistent-metaalconserveerder

VBO Installatietechniek

BOL AB Installatie-, service- en onderhoudstechniek

$B O L A B$ Montage-assistent installatietechniek

BOL AB Montage-assistent verwarmingstechniek 


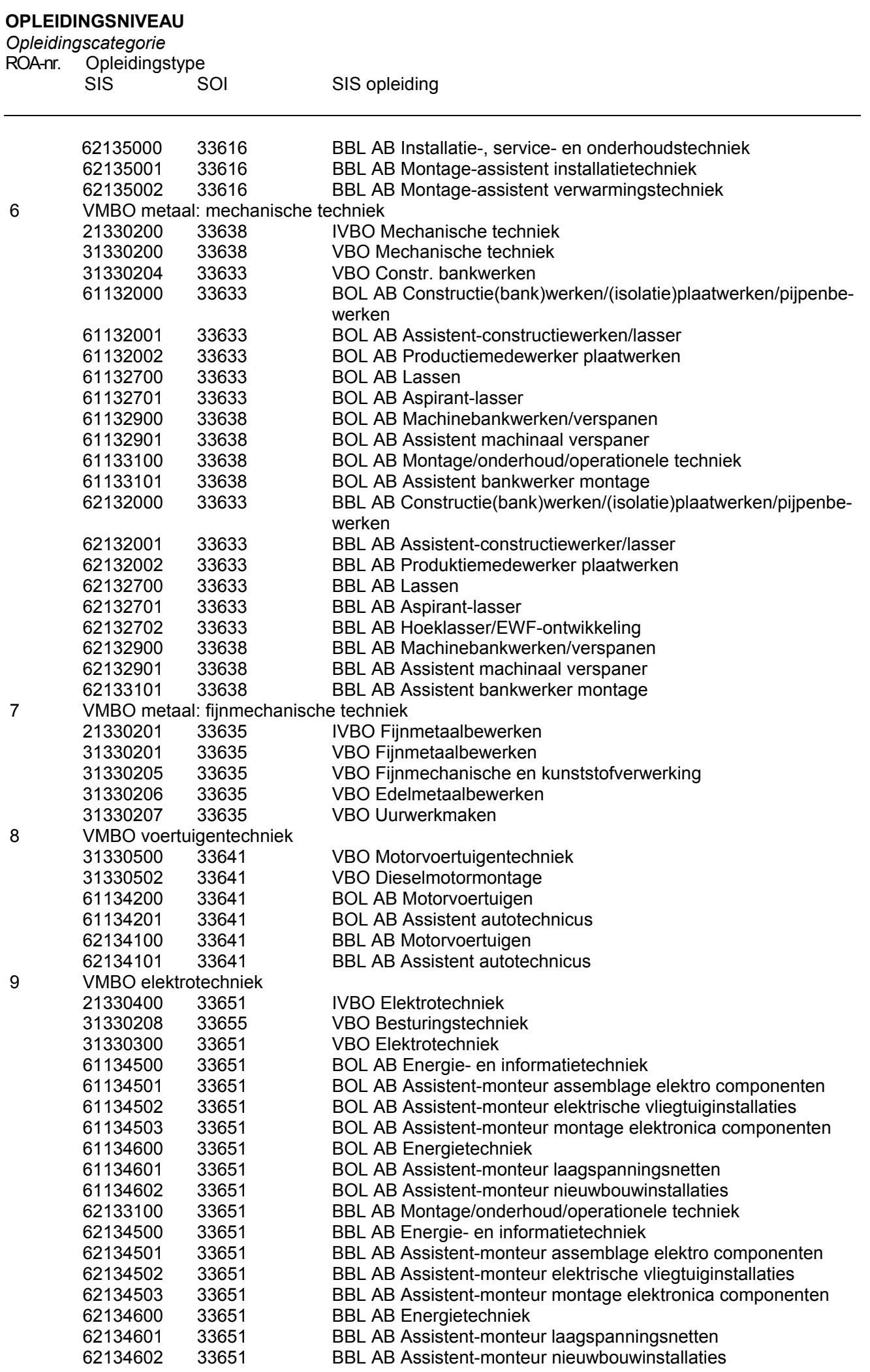




\begin{tabular}{|c|c|c|c|}
\hline \multicolumn{4}{|c|}{$\begin{array}{l}\text { OPLEIDINGSNIVEAU } \\
\text { Opleidingscategorie } \\
\text { ROA-nr. Opleidingstype }\end{array}$} \\
\hline & Sis & SOI & SIS opleiding \\
\hline \multirow[t]{8}{*}{10} & \multicolumn{3}{|c|}{ VMBO grafische techniek } \\
\hline & 31330701 & 33665 & VBO Vormverv. techniek \\
\hline & 31330702 & 33665 & VBO Vormverwerkende techniek \\
\hline & 31330703 & 33663 & VBO Reproduktietekenen \\
\hline & 61136000 & 33668 & $\begin{array}{l}\text { BOL AB Grafische techniek, communicatie, audiovisueel en } \\
\text { multimedia }\end{array}$ \\
\hline & 61136001 & 33668 & BOL AB Grafisch assistent \\
\hline & 62136000 & 33668 & $\begin{array}{l}\text { BBL AB Grafische techniek, communicatie, audiovisueel en } \\
\text { multimedia }\end{array}$ \\
\hline & 62136001 & 33668 & BBL AB Grafisch assistent \\
\hline \multirow[t]{7}{*}{11} & \multicolumn{3}{|c|}{ VMBO brood en banket } \\
\hline & 21330301 & 33676 & IVBO Banketbakken \\
\hline & 21330302 & 33676 & IVBO Brood- en banketbakken \\
\hline & 31330601 & 33676 & VBO Banketbakken \\
\hline & 31330602 & 33676 & VBO Brood- en banketbakken \\
\hline & 61139000 & 33676 & BOL AB Brood- en banketbakken \\
\hline & 61139001 & 33676 & BOL AB Assistent bakker \\
\hline \multirow[t]{15}{*}{12} & \multicolumn{3}{|c|}{ VMBO transport en logistiek } \\
\hline & 31330801 & 34133 & VBO Opleiding SW-VI \\
\hline & 31330802 & 34133 & VBO Kust-, Rijn- en binnenvaart \\
\hline & 31330803 & 34133 & VBO Schipper binnenvaart \\
\hline & 31330804 & 34231 & VBO Machinist binnenvaart \\
\hline & 31330806 & 34131 & VBO Scheepsgezel \\
\hline & 31330807 & 34150 & VBO Haven- en vervoersschool; operationeel havenond. \\
\hline & 31330808 & 34350 & VBO Haven- en vervoersschool; technisch-administratief ond. \\
\hline & 31330809 & 34231 & VBO Scheepstechniek \\
\hline & 61138000 & 34150 & BOL AB Haven en vervoer \\
\hline & 61138001 & 34150 & BOL AB Assistent-operationeel medewerker op- en overslag \\
\hline & 62138000 & 34150 & BBL AB Haven en vervoer \\
\hline & 62138001 & 34150 & BBL AB Assistent-operationeel medewerker op- en overslag \\
\hline & 62138400 & 34110 & BBL AB Wegvervoer \\
\hline & 62138401 & 34180 & $\begin{array}{l}\text { BBL AB Assistent-operationeel medewerker transport en } \\
\text { logistiek }\end{array}$ \\
\hline \multirow[t]{14}{*}{13} & \multicolumn{3}{|c|}{ VMBO techniek overig } \\
\hline & 21330109 & 33671 & IVBO Keramiek \\
\hline & 21350500 & 33688 & IVBO Theoretisch technische opleiding (TTO) \\
\hline & 31330202 & 33678 & VBO Procestechniek \\
\hline & 31330203 & 33643 & VBO Scheepsbouwkunde \\
\hline & 31330501 & 33647 & VBO Landbouwwerktuigentechniek \\
\hline & 31330700 & 33688 & VBO Grafische techniek \\
\hline & 61135100 & 33647 & BOL AB Koudetechniek \\
\hline & 61135101 & 33647 & BOL AB Montage-assistent koudetechniek \\
\hline & 62133102 & 33646 & BBL AB Assistent productietechnisch vakkracht \\
\hline & 62135100 & 33647 & BBL AB Koudetechniek \\
\hline & 62135101 & 33647 & BBL AB Montage-assistent koudetechniek \\
\hline & 62137300 & 33678 & BBL AB Procestechniek \\
\hline & 62137301 & 33678 & BBL AB Basisoperator \\
\hline \multicolumn{4}{|c|}{ VMBO economie } \\
\hline \multirow[t]{11}{*}{14} & \multicolumn{3}{|c|}{ VMBO administratie, handel en mode } \\
\hline & 21330107 & 33685 & IVBO Stofferen \\
\hline & 21340000 & 36110 & IVBO Economie \\
\hline & 21340100 & 36138 & IVBO Administratie \\
\hline & 21340200 & 36150 & IVBO Verkoop \\
\hline & 21350300 & 33685 & IVBO Mode en kleding \\
\hline & 31330107 & 33685 & VBO Stofferen \\
\hline & 31340000 & 36110 & VBO Economie \\
\hline & 31340100 & 36138 & VBO Administratie \\
\hline & 31340200 & 36150 & VBO Verkoop \\
\hline & 31340300 & 36150 & VBO Handel \\
\hline
\end{tabular}




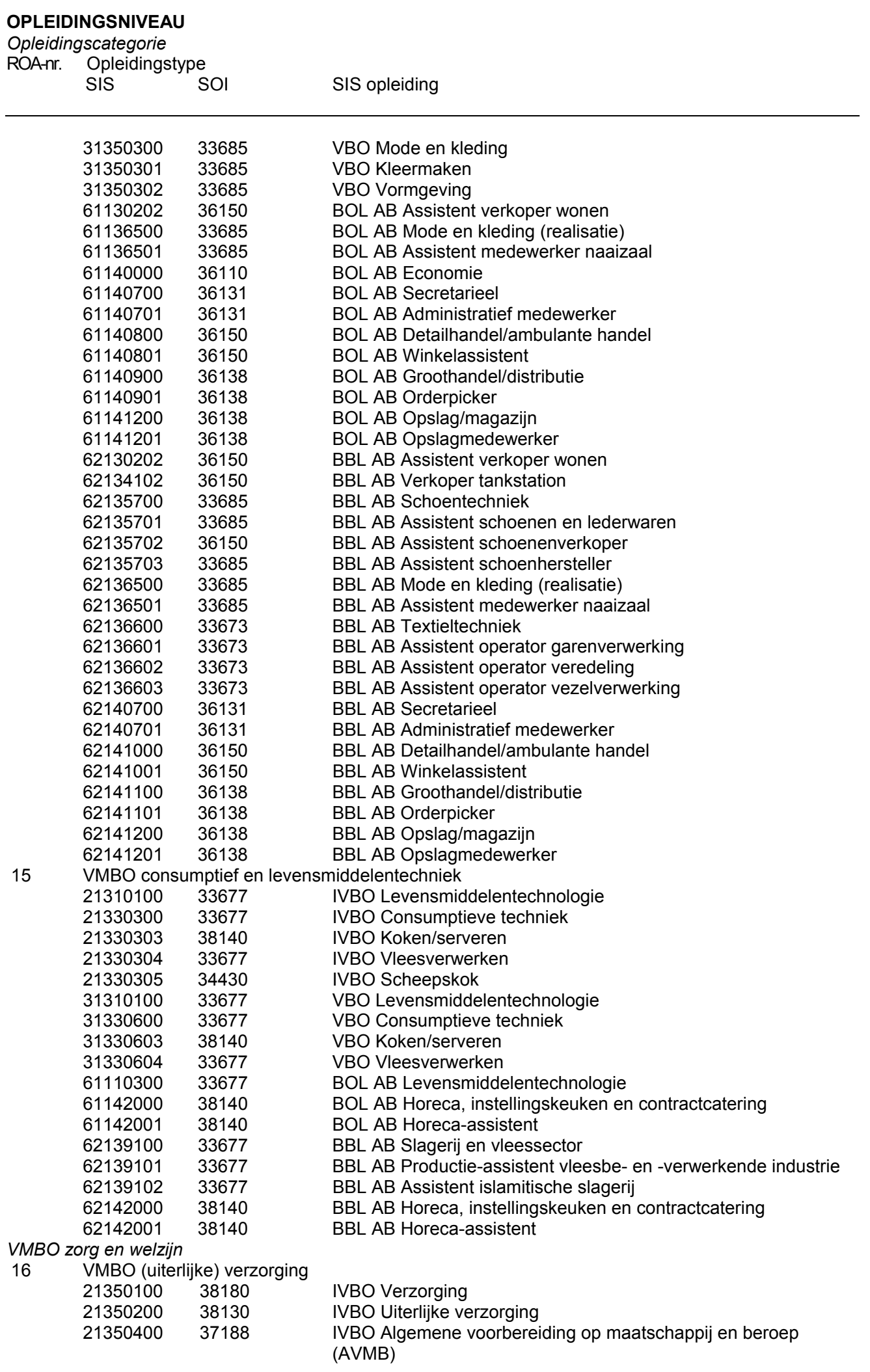




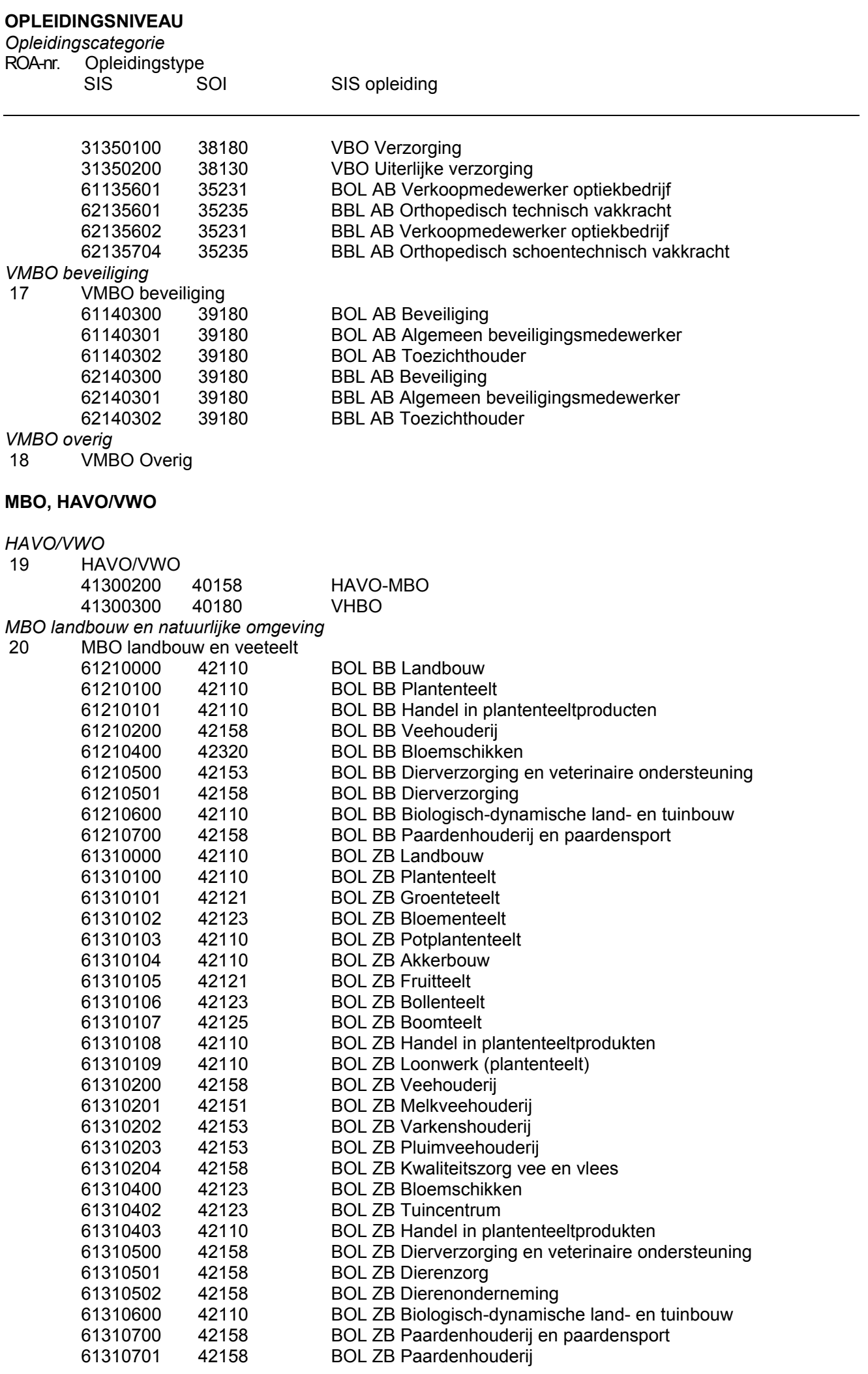




\begin{tabular}{|c|c|c|c|}
\hline \multicolumn{4}{|c|}{$\begin{array}{l}\text { OPLEIDINGSNIVEAU } \\
\text { Opleidingscategorie }\end{array}$} \\
\hline & SIS & SOI & SIS opleidıng \\
\hline & 61410000 & 42110 & BOL KF Landbouw \\
\hline & 61410100 & 42110 & BOL KF Plantenteelt \\
\hline & 61410101 & 42110 & BOL KF Plantenteelt en management \\
\hline & 61410102 & 42110 & BOL KF Plantenteelt en handel \\
\hline & 61410103 & 42110 & BOL KF Plantenteelt en milieu \\
\hline & 61410200 & 42158 & BOL KF Veehouderij \\
\hline & 61410201 & 42158 & BOL KF Veehouderij en management \\
\hline & 61410202 & 42158 & BOL KF Veehouderij en handel \\
\hline & 61410203 & 42158 & BOL KF Veehouderij en milieu \\
\hline & 61410204 & 42158 & BOL KF Kwaliteitszorg vleesketen (veehouderij) \\
\hline & 61410308 & 42158 & BOL KF Mengvoederindustrie \\
\hline & 61410400 & 42123 & BOL KF Bloemschikken \\
\hline & 61410500 & 42153 & BOL KF Dierverzorging en veterinaire ondersteuning \\
\hline & 61410501 & 42158 & BOL KF Dierenzorg \\
\hline & 61410502 & 42158 & BOL KF Dierenonderneming \\
\hline & 61410600 & 42110 & BOL KF Biologisch-dynamische land- en tuinbouw \\
\hline & 61410700 & 42158 & BOL KF Paardenhouderij en paardensport \\
\hline & 61410701 & 42158 & BOL KF Paardensport \\
\hline & 61410702 & 42158 & BOL KF Paardenhouderij en management \\
\hline & 61432600 & 42110 & BOL MKF Landbouwtechniek \\
\hline & 62110100 & 42110 & BBL AB Plantenteelt \\
\hline & 62210000 & 42110 & BBL BB Landbouw \\
\hline & 62210100 & 42110 & BBL BB Plantenteelt \\
\hline & 62210101 & 42110 & BBL BB Handel in plantenteeltproducten \\
\hline & 62210200 & 42158 & BBL BB Veehouderij \\
\hline & 62210400 & 42320 & BBL BB Bloemschikken \\
\hline & 62210500 & 42153 & BBL BB Dierverzorging en veterinaire ondersteuning \\
\hline & 62210501 & 42153 & BBL BB Dierverzorging \\
\hline & 62210600 & 42110 & BBL BB Biologisch-dynamische land- en tuinbouw \\
\hline & 62210700 & 42158 & BBL BB Paardenhouderij en paardensport \\
\hline & 62310000 & 42110 & BBL ZB Landbouw \\
\hline & 62310100 & 42110 & BBL ZB Plantenteelt \\
\hline & 62310101 & 42121 & BBL ZB Groenteteelt \\
\hline & 62310102 & 42123 & BBL ZB Bloementeelt \\
\hline & 62310103 & 42110 & BBL ZB Potplantenteelt \\
\hline & 62310104 & 42110 & BBL ZB Akkerbouw \\
\hline & 62310105 & 42121 & BBL ZB Fruitteelt \\
\hline & 62310106 & 42123 & BBL ZB Bollenteelt \\
\hline & 62310107 & 42125 & BBL ZB Boomteelt \\
\hline & 62310108 & 42110 & BBL ZB Handel in plantenteeltproducten (plantenteelt) \\
\hline & 62310109 & 42110 & BBL ZB Loonwerk (plantenteelt) \\
\hline & 62310200 & 42158 & BBL ZB Veehouderij \\
\hline & 62310201 & 42151 & BBL ZB Melkveehouderij \\
\hline & 62310202 & 42153 & BBL ZB Varkenshouderij \\
\hline & 62310203 & 42153 & BBL ZB Pluimveehouderij \\
\hline & 62310400 & 42123 & BBL ZB Bloemschikken \\
\hline & 62310402 & 42123 & BBL ZB Tuincentrum \\
\hline & 62310403 & 42110 & BBL ZB Handel in plantenteeltproducten (bloemschikken) \\
\hline & 62310500 & 42158 & BBL ZB Dierverzorging en veterinaire ondersteuning \\
\hline & 62310501 & 42158 & BBL ZB Dierenzorg \\
\hline & 62310502 & 42158 & BBL ZB Dierenonderneming \\
\hline & 62310600 & 42110 & BBL ZB Biologisch dynamische land- en tuinbouw \\
\hline & 62310700 & 42158 & BBL ZB Paardenhouderij en paardensport \\
\hline & 62310701 & 42158 & BBL ZB Paardenhouderij \\
\hline & 62310702 & 42250 & BBL ZB Hoefsmid \\
\hline & 62410000 & 42110 & BBL KF Landbouw \\
\hline & 62510000 & 42110 & BBL Specialist Landbouw \\
\hline & 62510100 & 42110 & BBL Specialist Plantenteelt \\
\hline & 62510101 & 42110 & BBL Specialist Plantenteelt en management \\
\hline
\end{tabular}




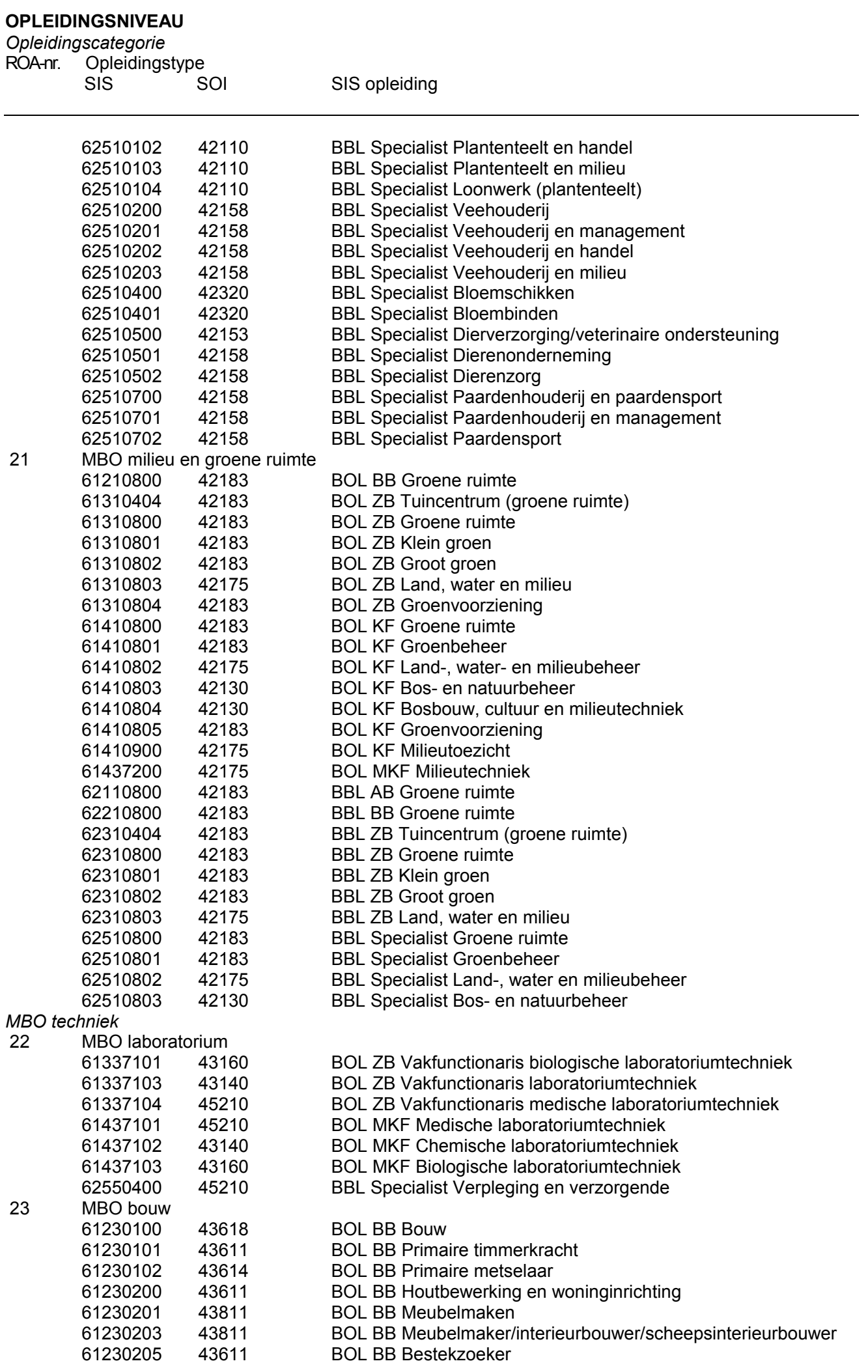




\begin{tabular}{|c|c|c|c|}
\hline \multicolumn{4}{|c|}{$\begin{array}{l}\text { OPLEIDINGSNIVEAU } \\
\text { Opleidingscategorie } \\
\text { ROA-nr. Opleidingstype }\end{array}$} \\
\hline & SIS & SOl & SIS opleiding \\
\hline & 61230207 & 43611 & BOL BB Machinaal houtbewerker houthandel \\
\hline & 61230208 & 43611 & $\begin{array}{l}\text { BOL BB Machinaal houtbewerker houtbewerker } \\
\text { timmerindustrie/meubelindustrie }\end{array}$ \\
\hline & 61230209 & 43611 & BOL BB Parketlegger \\
\hline & 61230211 & 43611 & BOL BB Werkplaatstimmerman \\
\hline & 61231100 & 43815 & BOL BB Beschermings- en afwerkingstechnieken \\
\hline & 61231101 & 43615 & BOL BB Schilder \\
\hline & 61330200 & 43611 & BOL ZB Houtbewerking en woninginrichting \\
\hline & 61330201 & 43611 & BOL ZB Allround bestekzoeker \\
\hline & 61330203 & 43611 & BOL ZB Allround machinaal houtbewerker houthandel \\
\hline & 61330204 & 43611 & $\begin{array}{l}\text { BOL ZB Allround machinaal houtbewerker timmer- } \\
\text { /meubelindustrie }\end{array}$ \\
\hline & 61330205 & 43811 & $\begin{array}{l}\text { BOL ZB Allround } \\
\text { meubelmaker/interieurbouwer/scheepsinterieurbouwer }\end{array}$ \\
\hline & 61330206 & 43611 & BOL ZB Allround werkplaatstimmerman \\
\hline & 61334801 & 43618 & BOL ZB Aankomend ontwerptechnicus gebouwinstallaties \\
\hline & 61430100 & 43618 & BOL MKF Bouw \\
\hline & 61430101 & 43618 & BOL MKF Afbouw \\
\hline & 61430102 & 43618 & BOL MKF Bouwkunde \\
\hline & 61430103 & 43618 & BOL MKF Verkeer- en stedebouwkunde \\
\hline & 61430200 & 43611 & BOL MKF Houtbewerking en woninginrichting \\
\hline & 61430201 & 43611 & BOL MKF Meubelmaken / amb. Procesvoering / jachtbouw \\
\hline & 61430202 & 43611 & BOL MKF Meubelmaken / amb. Procesvoering \\
\hline & 61430203 & 43611 & BOL MKF Meubelmaken \\
\hline & 61430206 & 43811 & BOL MKF Machinale timmerfabricage \\
\hline & 61430207 & 43811 & BOL MKF Kaderfunctionaris houthandel \\
\hline & 61430209 & 43811 & BOL MKF Kaderfunctionaris meubel/interieurbouwbedrijf \\
\hline & 61430210 & 43811 & BOL MKF Kaderfunctionaris timmerindustrie \\
\hline & 61430212 & 43811 & BOL MKF Meubelfabricage \\
\hline & 61430213 & 43611 & BOL MKF Jachtbouw \\
\hline & 61430214 & 43611 & BOL MKF Meubelmaken restaureren \\
\hline & 61431100 & 43815 & BOL MKF Beschermings- en afwerkingstechnieken \\
\hline & 61431101 & 43815 & BOL MKF Ondernemer bescherming en afwerking \\
\hline & 61442004 & 43618 & BOL MKF Restaurateur \\
\hline & 62130204 & 43611 & BBL AB Montagemedewerker timmerindustrie \\
\hline & 62130205 & 43611 & BBL AB Vloerenstoffeerder \\
\hline & 62230100 & 43618 & BBL BB Bouw \\
\hline & 62230101 & 43611 & BBL BB Primaire timmerkracht \\
\hline & 62230102 & 43614 & BBL BB Primaire metselaar \\
\hline & 62230103 & 43613 & BBL BB Betonmodelmaker \\
\hline & 62230104 & 43614 & BBL BB Natuursteenbewerker \\
\hline & 62230105 & 43614 & BBL BB Ovenbouwmetselaar \\
\hline & 62230106 & 43614 & BBL BB Voeger \\
\hline & 62230107 & 43618 & BBL BB Hulpvakkracht (bouw) \\
\hline & 62230109 & 43614 & BBL BB Tegelzetter \\
\hline & 62230110 & 43611 & BBL BB Vakkracht houtskeletbouw \\
\hline & 62230111 & 43611 & BBL BB Betontimmerkracht \\
\hline & 62230112 & 43613 & BBL BB Betonstaalverwerker \\
\hline & 62230113 & 43613 & BBL BB Betonreparateur (SVB) \\
\hline & 62230200 & 43611 & BBL BB Houtbewerking en woninginrichting \\
\hline & 62230202 & 43611 & BBL BB Bestekzoeker \\
\hline & 62230204 & 43611 & BBL BB Machinaal houtbewerker houthandel \\
\hline & 62230205 & 43611 & $\begin{array}{l}\text { BBL BB Machinaal houtbewerker } \\
\text { timmerindustrie/meubelindustrie }\end{array}$ \\
\hline & 62230206 & 43811 & BBL BB Meubelmaker/interieurbouwer/scheepsinterieurbouwer \\
\hline & 62230207 & 43611 & BBL BB Parketlegger \\
\hline & 62230209 & 43611 & BBL BB Werkplaatstimmerman \\
\hline & 62231000 & 43618 & BBL BB Afbouw \\
\hline & 62231001 & 43613 & BBL BB Betonreparateur (SVS) \\
\hline
\end{tabular}




\begin{tabular}{|c|c|c|c|}
\hline \multicolumn{4}{|c|}{$\begin{array}{l}\text { OPLEIDINGSNIVEAU } \\
\text { Opleidingscategorie } \\
\text { ROA-nr Opleidingstype }\end{array}$} \\
\hline & 62231002 & 43613 & BBL BB Dekvloerenlegger \\
\hline & 62231003 & 43611 & BBL BB Monteur systeemwanden en -plafonds \\
\hline & 62231004 & 43614 & BBL BB Stukadoor \\
\hline & 62231100 & 43815 & BBL BB Beschermings- en afwerkingstechnieken \\
\hline & 62231101 & 43615 & BBL BB Schilder \\
\hline & 62231105 & 43615 & BBL BB Glaszetter \\
\hline & 62231203 & 43615 & BBL BB Metaalconserveerder \\
\hline & 62330100 & 43618 & BBL ZB Bouw \\
\hline & 62330101 & 43618 & BBL ZB Restauratietimmerkracht \\
\hline & 62330102 & 43618 & BBL ZB Vakkracht bouwtechniek \\
\hline & 62330104 & 43614 & BBL ZB Voortgezette metselaar \\
\hline & 62330105 & 43611 & BBL ZB Voortgezette timmerkracht \\
\hline & 62330200 & 43611 & BBL ZB Houtbewerking en woninginrichting \\
\hline & 62330201 & 43611 & BBL ZB Machinaal houtbewerken \\
\hline & 62330202 & 43611 & $\begin{array}{l}\text { BBL ZB Allround } \\
\text { meubelmaker/interieurbouwer/scheepsinterieurbouwer }\end{array}$ \\
\hline & 62330204 & 43611 & BBL ZB Allround werkplaatstimmerman \\
\hline & 62330206 & 43611 & BBL ZB Allround bestekzoeker \\
\hline & 62330208 & 43611 & BBL ZB Allround machinaal houtbewerker houthandel \\
\hline & 62330209 & 43611 & $\begin{array}{l}\text { BBL ZB Allround machinaal houtbewerker timmer- } \\
\text { /meubelindustrie }\end{array}$ \\
\hline & 62331000 & 43618 & BBL ZB Afbouw \\
\hline & 62331001 & 43614 & BBL ZB Gezel stukadoor \\
\hline & 62331100 & 43815 & BBL ZB Beschermings- en afwerkingstechnieken \\
\hline & 62331101 & 43615 & BBL ZB Gezel schilder \\
\hline & 62331102 & 43615 & BBL ZB Vakkracht glaszetter \\
\hline & 62334801 & 43618 & BBL ZB Aankomend ontwerptechnicus gebouwinstallaties \\
\hline & 62334802 & 43618 & BBL ZB Aankomend projecttechnicus gebouwinstallaties \\
\hline & 62430100 & 43618 & BBL MKF Bouw \\
\hline & 62430105 & 43618 & BBL MKF Assistent-uitvoerder B\&U \\
\hline & 62430106 & 43613 & BBL MKF Kaderfunctionaris betonstaalverwerkingsbedrijven \\
\hline & 62430107 & 43618 & BBL MKF Restauratiemedewerker \\
\hline & 62430200 & 43611 & BBL MKF Houtbewerking en woninginrichting \\
\hline & 62430203 & 43611 & BBL MKF Kaderfunctionaris meubel/interieurbouwbedrijf \\
\hline & 62430204 & 43611 & BBL MKF Kaderfunctionaris timmerindustrie \\
\hline & 62430210 & 43611 & BBL MKF Kaderfunctionaris houthandel \\
\hline & 62431000 & 43618 & BBL MKF Afbouw \\
\hline & 62442003 & 43618 & BBL MKF Restaurateur \\
\hline & 62530100 & 43618 & BBL Specialist Bouw \\
\hline & 62530101 & 43611 & BBL Specialist Kaderfunctionaris betontimmerbedrijven \\
\hline & 62530102 & 43614 & BBL Specialist Kaderfunctionaris natuursteenbedrijf \\
\hline & 62530103 & 43814 & BBL Specialist Kaderfunctionaris tegelzetbedrijven \\
\hline & 62530104 & 43618 & BBL Specialist Restauratiemedewerker \\
\hline & 62530105 & 43613 & BBL Specialist Kaderfunctionaris betonstaalverwerkingsbedrijven \\
\hline & 62531000 & 43618 & BBL Specialist Afbouw \\
\hline & 62531001 & 43614 & BBL Specialist Restauratiestukadoor \\
\hline & 62531100 & 43815 & BBL Specialist Beschermings- en afwerkingstechnieken \\
\hline & 62531101 & 43615 & BBL Specialist Restauratieschilder \\
\hline & 62531102 & 43615 & BBL Specialist Wandafwerking \\
\hline & 62532701 & 43613 & BBL Specialist European Welding Technologist (EWT) \\
\hline 24 & MBO gronc & weg-en & uw \\
\hline & 61238201 & 43623 & BOL BB Bakschipper/dekknecht baggerbedrijf \\
\hline & 61330500 & 43823 & BOL ZB Grond-, water- en wegenbouw \\
\hline & 61330501 & 43623 & BOL ZB Machinist gww \\
\hline & 61330502 & 43623 & BOL ZB Monteur gww-machines SOMA \\
\hline & 61430500 & 43623 & BOL MKF Grond-, water- en wegenbouw \\
\hline & 61430501 & 43623 & BOL MKF Materieelkundige gww \\
\hline & 61430502 & 43625 & BOL MKF Geodesie \\
\hline & 61430503 & 43823 & BOL MKF Gww \\
\hline
\end{tabular}




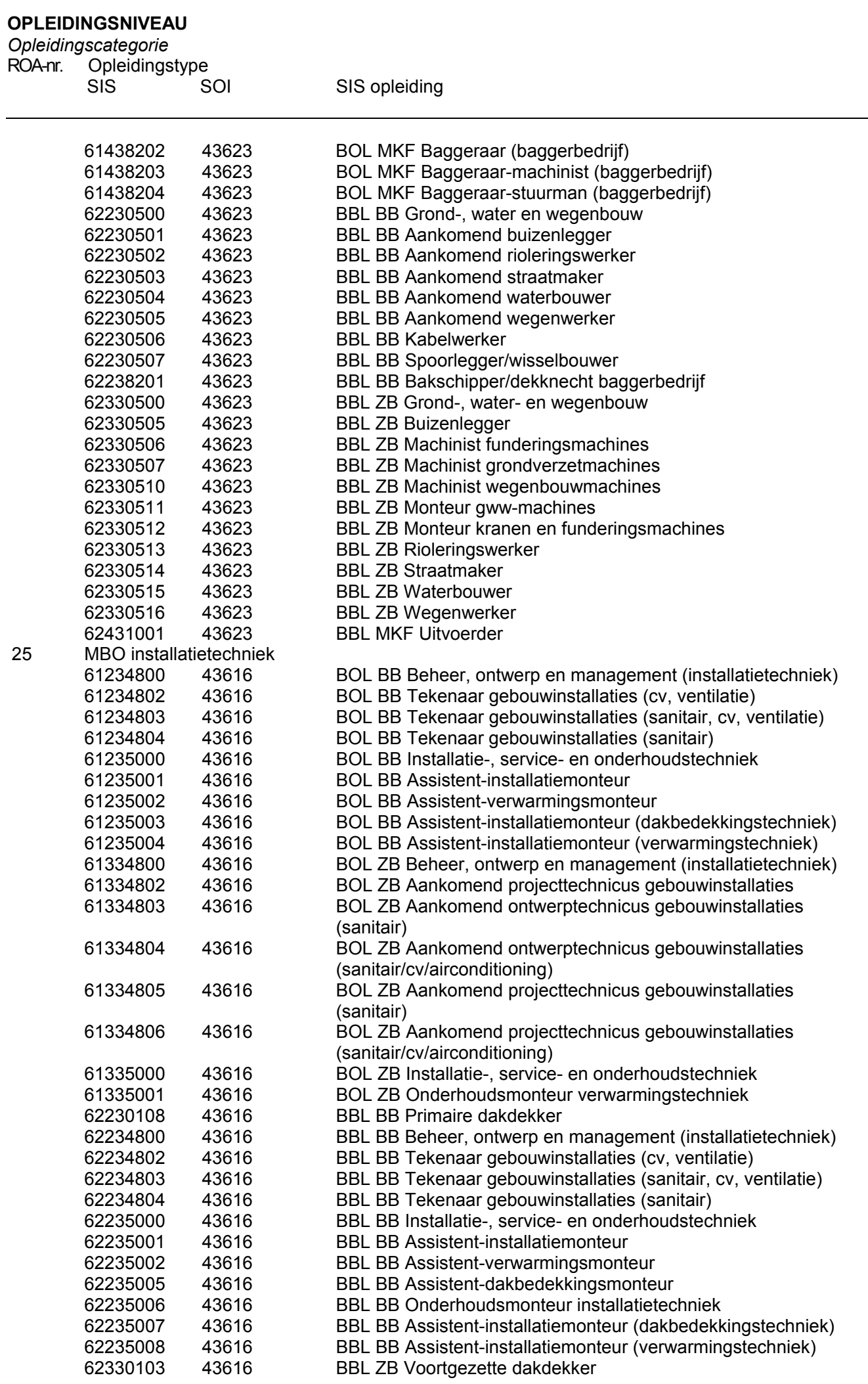




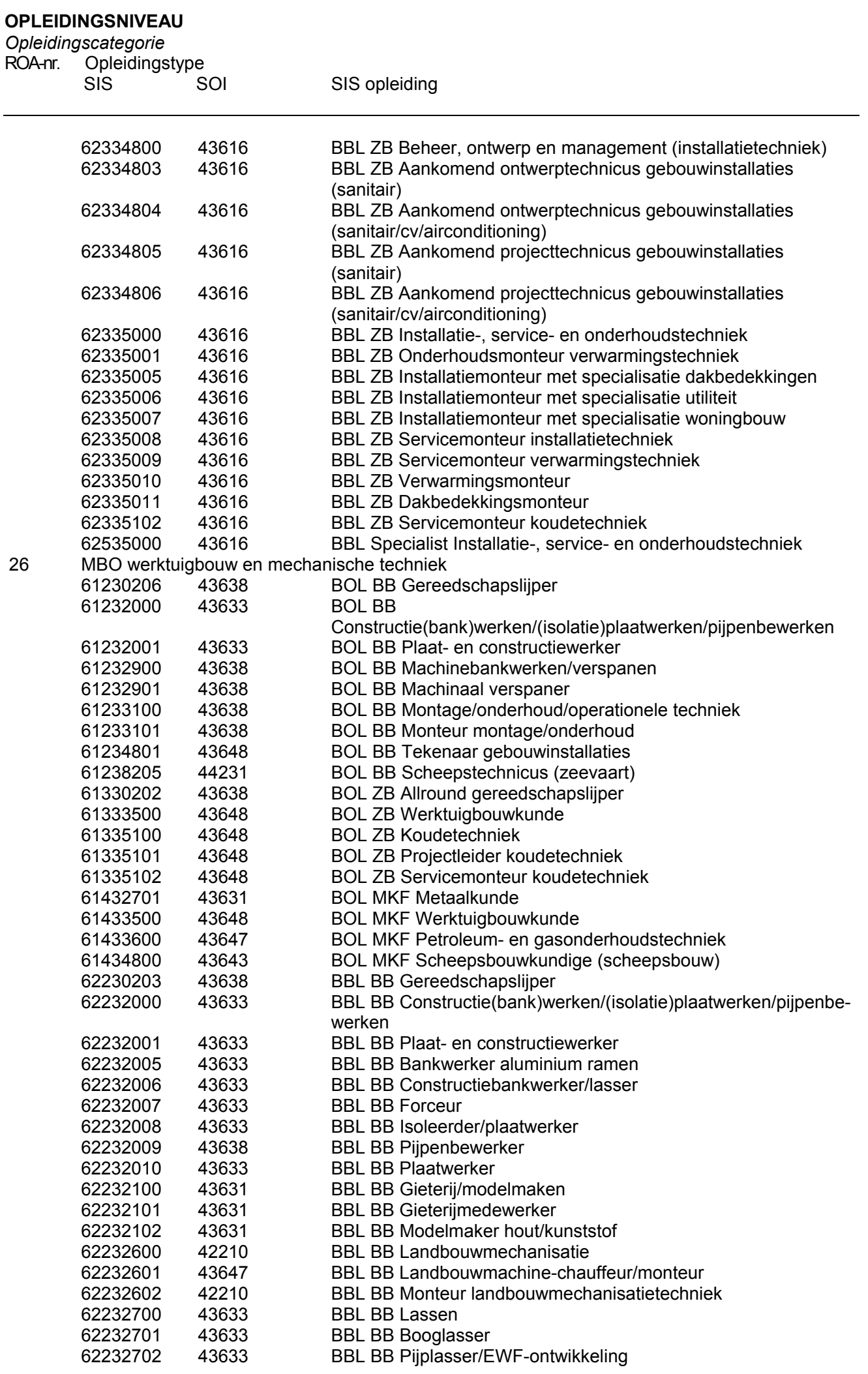




\begin{tabular}{|c|c|c|c|}
\hline \multicolumn{4}{|c|}{$\begin{array}{l}\text { OPLEIDINGSNIVEAU } \\
\text { Opleidingscategorie }\end{array}$} \\
\hline & SIS & SOI & SIS opleidıng \\
\hline & 62232703 & 43633 & BBL BB Plaatlasser/EWF-ontwikkeling \\
\hline & 62232704 & 43633 & BBL BB Draad- en zinkvonker \\
\hline & 62232900 & 43638 & BBL BB Machinebankwerken/verspanen \\
\hline & 62232901 & 43638 & BBL BB Machinaal verspaner \\
\hline & 62232905 & 43638 & BBL BB Draaier \\
\hline & 62232906 & 43638 & BBL BB Frezer \\
\hline & 62232907 & 43638 & BBL BB Machinaal verspaner CNC \\
\hline & 62232909 & 43638 & BBL BB Machinebankwerker werktuigbouw \\
\hline & 62232910 & 43638 & BBL BB Slijper \\
\hline & 62233100 & 43638 & BBL BB Montage/onderhoud/operationele techniek \\
\hline & 62233101 & 43638 & BBL BB Monteur montage/onderhoud \\
\hline & 62233105 & 43647 & BBL BB Assemblagevakkracht \\
\hline & 62233300 & 43643 & BBL BB Scheepsbouw (metaal) \\
\hline & 62233301 & 43643 & BBL BB Scheepsmetaalbewerker \\
\hline & 62233302 & 43643 & BBL BB Meubelmaker scheepsbouw \\
\hline & 62233500 & 43648 & BBL BB Werktuigbouwkunde \\
\hline & 62233501 & 43648 & BBL BB Aankomend werktuigbouwkundig tekenaar \\
\hline & 62234101 & 43647 & BBL BB Assemblagetechnicus \\
\hline & 62234106 & 43647 & BBL BB Dieselmotortechnicus \\
\hline & 62234801 & 43648 & BBL BB Tekenaar gebouwinstallaties \\
\hline & 62234900 & 43647 & BBL BB Distributietechniek \\
\hline & 62234901 & 43647 & BBL BB Assistent-distributiemonteur gas \\
\hline & 62234902 & 43647 & BBL BB Assistent-distributiemonteur water \\
\hline & 62235100 & 43648 & BBL BB Koudetechniek \\
\hline & 62235101 & 43648 & BBL BB Monteur koudetechniek \\
\hline & 62238003 & 44250 & BBL BB Werktuigkundig monteur \\
\hline & 62330207 & 43638 & BBL ZB Allround gereedschapslijper \\
\hline & 62332000 & 43633 & $\begin{array}{l}\text { BBL ZB Contructie(bank)werken/(isolatie) plaatwerken/pijpen be- } \\
\text { werken }\end{array}$ \\
\hline & 62332001 & 43633 & BBL ZB Constructie- en apparatenbouwer \\
\hline & 62332002 & 43647 & BBL ZB Opmeter/werkvoorbereider industriele isolatie \\
\hline & 62332003 & 43633 & BBL ZB Plaatwerker \\
\hline & 62332600 & 42210 & BBL ZB Landbouwmechanisatie \\
\hline & 62332601 & 42210 & BBL ZB Eerste monteur landbouwmechanisatietechniek \\
\hline & 62332700 & 43633 & BBL ZB Lassen \\
\hline & 62332701 & 43633 & BBL ZB European Welding Practioner (EWP)/Meesterlasser \\
\hline & 62332900 & 43638 & BBL ZB Machinebankwerken/verspanen \\
\hline & 62332901 & 43638 & BBL ZB Machinaal verspaner \\
\hline & 62332902 & 43638 & BBL ZB Programmeur/verspaner CNC \\
\hline & 62332903 & 43638 & BBL ZB Slijper \\
\hline & 62333100 & 43638 & BBL ZB Montage/onderhoud/operationale techniek \\
\hline & 62333300 & 43643 & BBL ZB Scheepsbouwer \\
\hline & 62333500 & 43648 & BBL ZB Werktuigbouwkunde \\
\hline & 62333505 & 43648 & BBL ZB Werktuigbouwkundig tekenaar \\
\hline & 62334101 & 43647 & BBL ZB Eerste autotechnicus/eerste bedrijfsautotechnicus \\
\hline & 62334900 & 43647 & BBL ZB Distributietechniek \\
\hline & 62334901 & 43647 & BBL ZB Distributiemonteur gas \\
\hline & 62334902 & 43647 & BBL ZB Distributiemonteur water \\
\hline & 62335100 & 43648 & BBL ZB Koudetechniek \\
\hline & 62335101 & 43648 & BBL ZB Projectleider koudetechniek \\
\hline & 62432700 & 43633 & BBL MKF Lassen \\
\hline & 62432701 & 43633 & BBL MKF European Welding Specialist (EWS) \\
\hline & 62432702 & 43633 & BBL MKF European Welding Specialist plus (EWS-plus) \\
\hline & 62532700 & 43633 & BBL Specialist Lassen \\
\hline & 62533001 & 43647 & BBL Specialist Onderhoudstechnicus instrumentatie \\
\hline & 62533500 & 43648 & BBL Specialist Werktuigbouwkunde \\
\hline & 62533501 & 43647 & BBL Specialist Onderhoudstechnicus werktuigbouw \\
\hline & 62533502 & 43648 & BBL Specialist Werktuigbouwkundig tekenaar/constructeur \\
\hline & 62533700 & 43647 & BBL Specialist Werkvoorbereiden \\
\hline
\end{tabular}




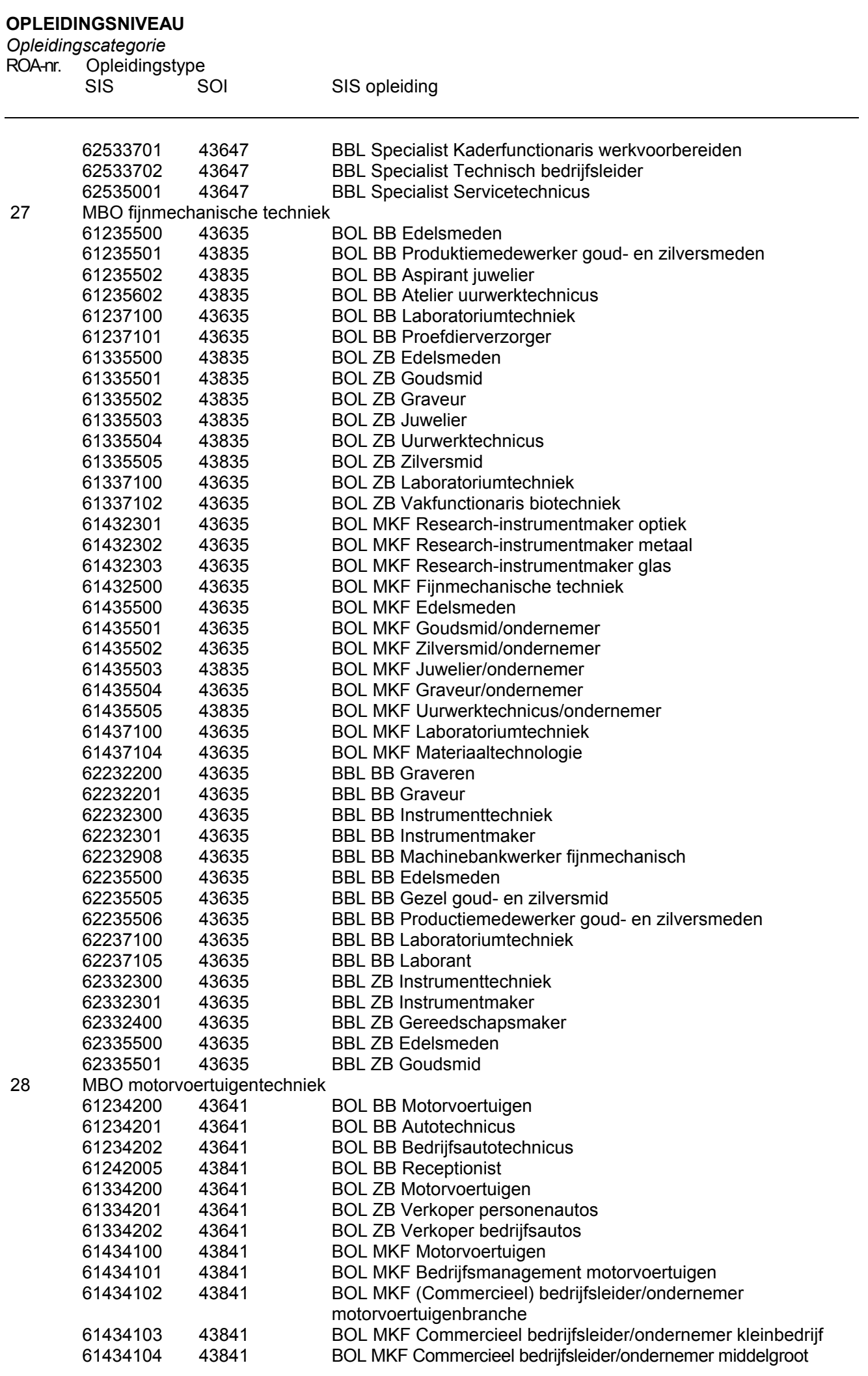




\begin{tabular}{|c|c|c|c|}
\hline \multicolumn{4}{|c|}{$\begin{array}{l}\text { OPLEIDINGSNIVEAU } \\
\text { Opleidingscategorie } \\
\text { ROA-nr. Opleidingstype }\end{array}$} \\
\hline & & & bedrijf \\
\hline & 61434105 & 43841 & $\begin{array}{l}\text { BOL MKF Commercieel bedrijfsleider/ondernemer mobiele } \\
\text { werktuigen }\end{array}$ \\
\hline & 61434106 & 43841 & BOL MKF Servicemanager bedrijfsautos \\
\hline & 61434107 & 43841 & BOL MKF Servicemanager personenautos \\
\hline & 61434108 & 43841 & BOL MKF Verkoopleider bedrijfsautos \\
\hline & 61434109 & 43841 & BOL MKF Verkoopleider personenautos \\
\hline & 61434200 & 43841 & BOL MKF Motorvoertuigen en carrosserietechniek \\
\hline & 62134000 & 43641 & BBL AB Carrosserie en wagenbouw \\
\hline & 62134001 & 43641 & BBL AB Aankomend voorbewerker \\
\hline & 62234000 & 43641 & BBL BB Carrosserie en wagenbouw \\
\hline & 62234001 & 43641 & BBL BB Autoschadehersteller \\
\hline & 62234002 & 43641 & BBL BB Autospuiter \\
\hline & 62234003 & 43641 & BBL BB Caravanhersteller \\
\hline & 62234004 & 43641 & BBL BB Carrosseriebouwer \\
\hline & 62234005 & 43641 & BBL BB Voertuiginterieurbouwer \\
\hline & 62234100 & 43641 & BBL BB Motorvoertuigen \\
\hline & 62234102 & 43641 & BBL BB Autodemontagetechnicus \\
\hline & 62234103 & 43641 & BBL BB Auto elektricien \\
\hline & 62234104 & 43641 & BBL BB Autotechnicus/bedrijfsautotechnicus \\
\hline & 62234105 & 43641 & BBL BB Bromfietstechnicus \\
\hline & 62234108 & 43641 & BBL BB Fietstechnicus \\
\hline & 62234109 & 43641 & BBL BB Motorfietstechnicus \\
\hline & 62234110 & 43641 & BBL BB Onderdelenadviseur \\
\hline & 62234111 & 43641 & BBL BB Revisietechnicus \\
\hline & 62234112 & 43641 & BBL BB Autotechnicus \\
\hline & 62234113 & 43641 & BBL BB Bedrijfsautotechnicus \\
\hline & 62242005 & 43841 & BBL BB Receptionist \\
\hline & 62334000 & 43641 & BBL ZB Carrosserie en wagenbouw \\
\hline & 62334001 & 43641 & BBL ZB Eerste autoschadehersteller \\
\hline & 62334002 & 43641 & BBL ZB Eerste autospuiter \\
\hline & 62334003 & 43641 & BBL ZB Eerste caravanhersteller \\
\hline & 62334004 & 43641 & BBL ZB Eerste carrosseriebouwer \\
\hline & 62334100 & 43641 & BBL ZB Motorvoertuigen \\
\hline & 62334102 & 43641 & BBL ZB Eerste dieselmotortechnicus \\
\hline & 62334103 & 43641 & BBL ZB Motorfietstechnicus \\
\hline & 62334104 & 43841 & BBL ZB Eerste autotechnicus \\
\hline & 62334105 & 43841 & BBL ZB Eerste bedrijfsautotechnicus \\
\hline & 62334106 & 43841 & BBL ZB Verkoper personenautos \\
\hline & 62334107 & 43841 & BBL ZB Verkoper bedrijfsautos \\
\hline & 62434100 & 43841 & BBL MKF Motorvoertuigen \\
\hline & 62434101 & 43841 & BBL MKF Bedrijfsleider/ondernemer in de MVT-branche \\
\hline & 62534000 & 43841 & BBL Specialist Carrosserie en wagenbouw \\
\hline & 62534001 & 43841 & $\begin{array}{l}\text { BBL Specialist Middenkaderfunctionaris } \\
\text { autoschadeherstelbedrijf/autospuitbedrijf }\end{array}$ \\
\hline & 62534002 & 43841 & BBL Specialist Middenkaderfunctionaris carrosseriebedrijf \\
\hline & 62534100 & 43841 & BBL Specialist Motorvoertuigen \\
\hline & 62534101 & 43841 & BBL Specialist Eerste auto-elektrotechnicus \\
\hline & 62534102 & 43841 & BBL Specialist Praktijkinstructeur (motorvoertuigen) \\
\hline & 62534103 & 43641 & BBL Specialist Werkplaatsmanger personenauto's/bedrijfsauto's \\
\hline & 62534104 & 43841 & BBL Specialist Eerste bedrijfsauto-elektrotechnicus \\
\hline & 62534105 & 43841 & BBL Specialist Diagnosetechnicus personenautos \\
\hline & 62534106 & 43841 & BBL Specialist Diagnosetechnicus bedrijfsautos \\
\hline & 62534107 & 43841 & BBL Specialist Onderdelenmanager \\
\hline & 62534108 & 43841 & BBL Specialist Werkplaatsmanager personenautos \\
\hline & 62534109 & 43841 & BBL Specialist Werkplaatsmanager bedrijfsautos \\
\hline 29 & MBO vliegt & techniek & \\
\hline & 61233400 & 43645 & BOL BB Vliegtuigtechnieken \\
\hline & 61233401 & 43645 & BOL BB Bank- en plaatwerker vliegtuigbouwkunde \\
\hline
\end{tabular}




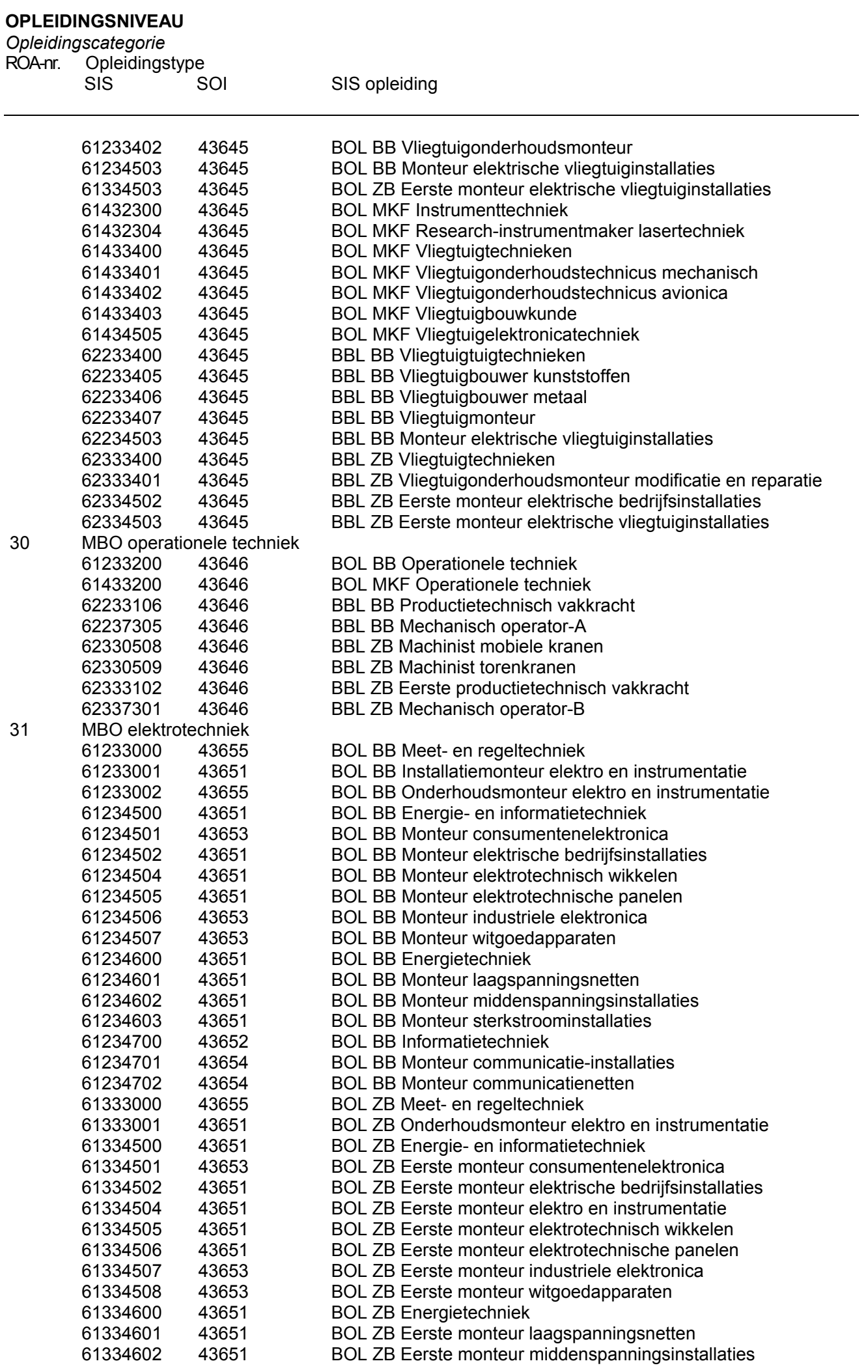




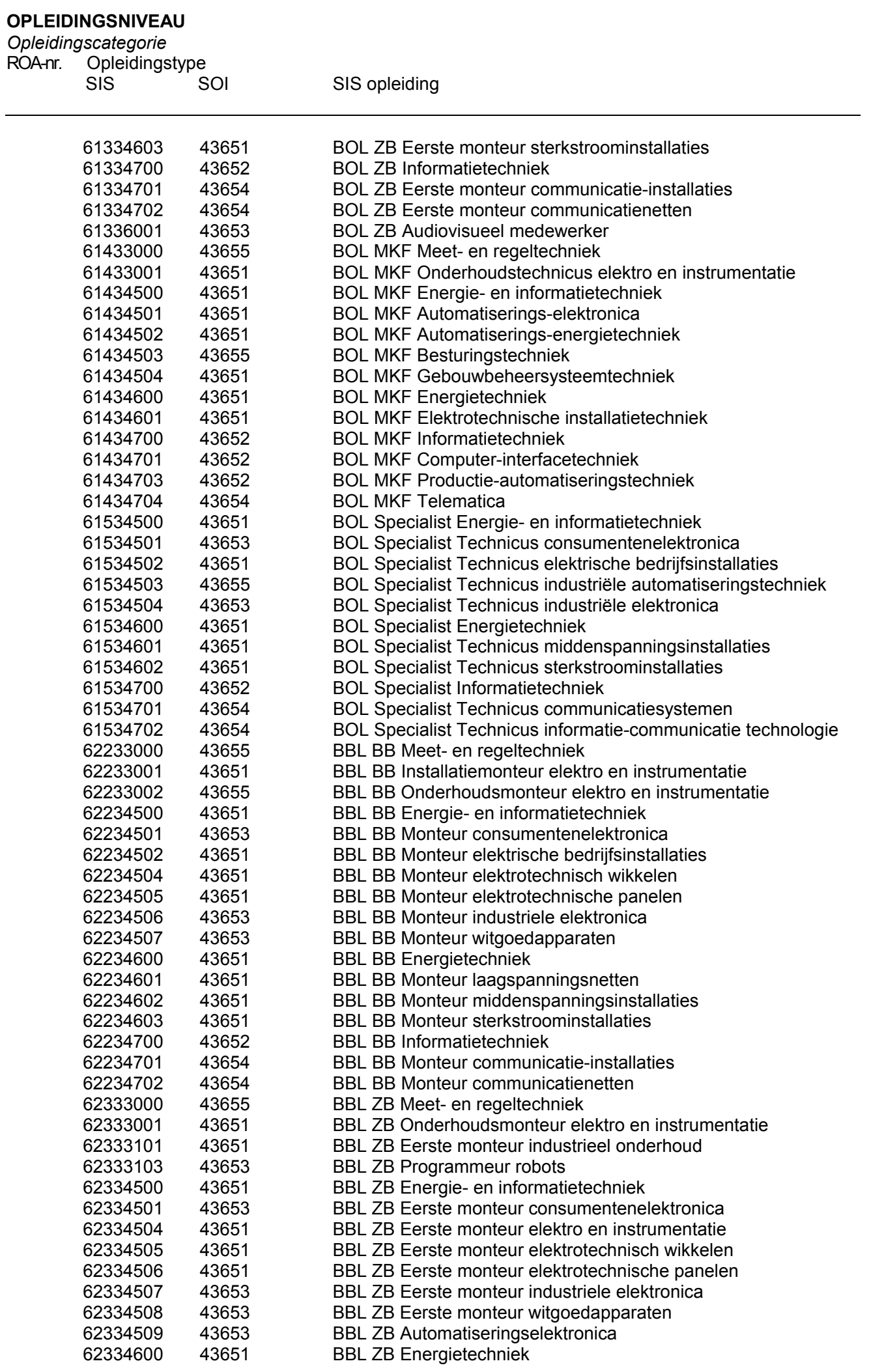




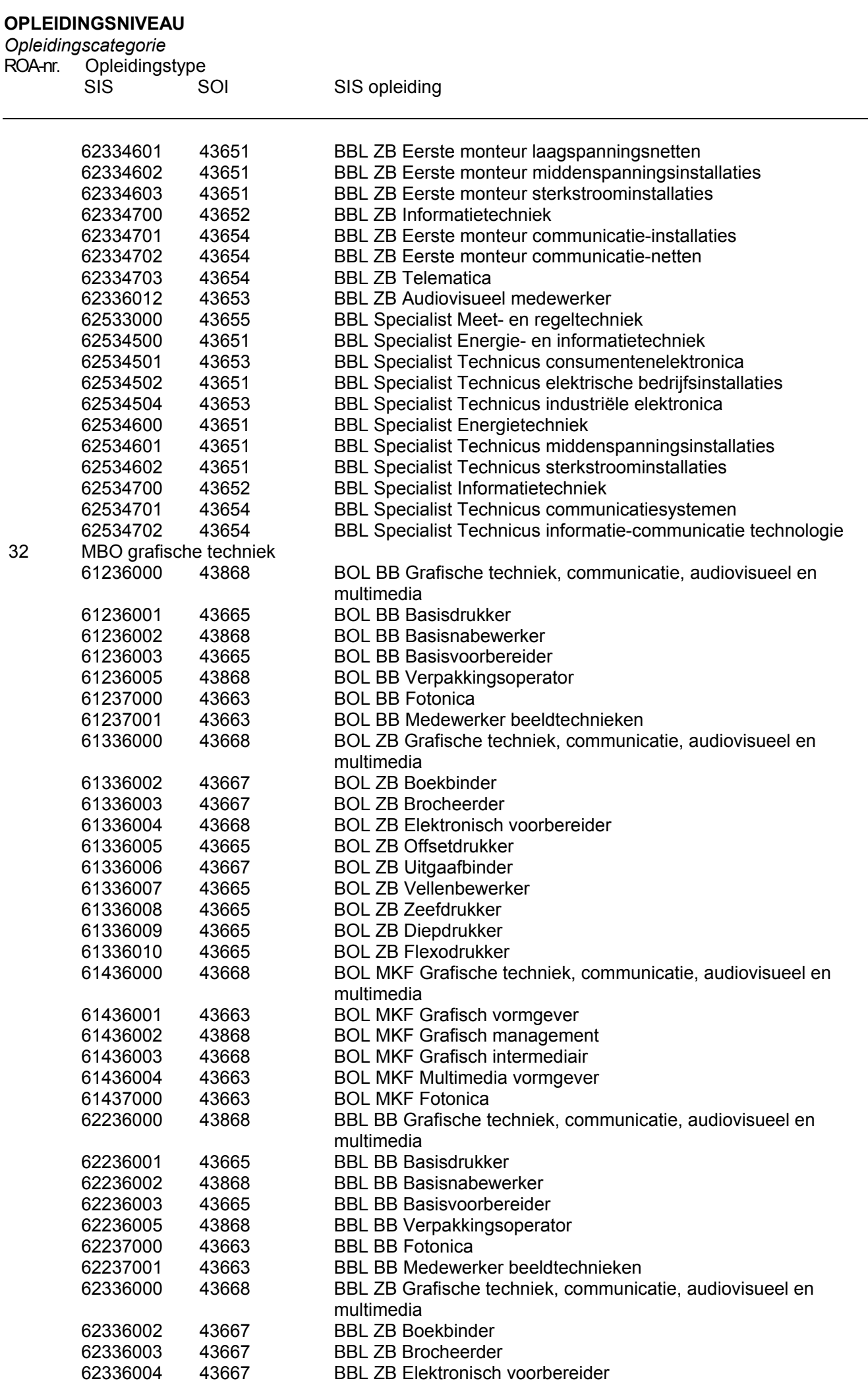




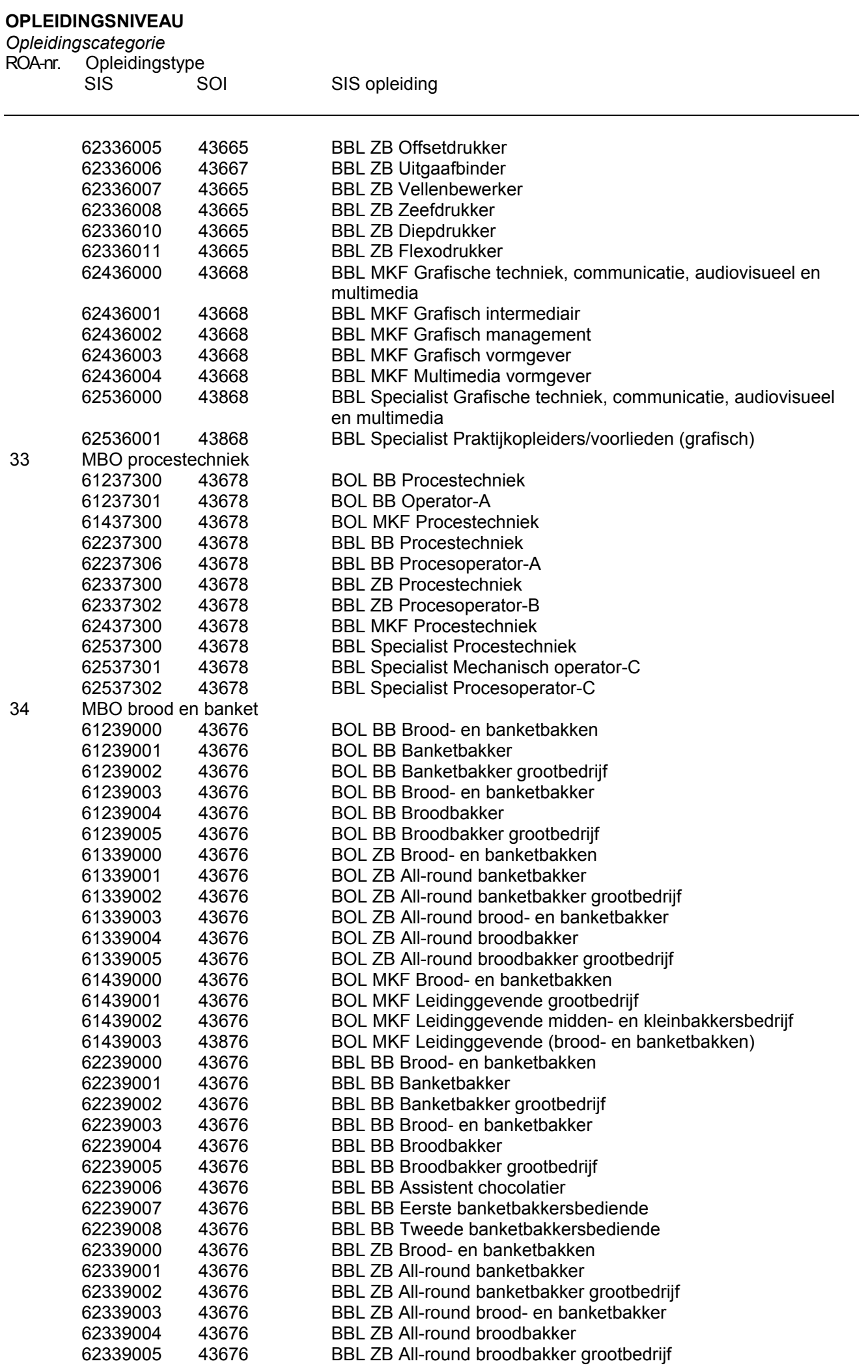




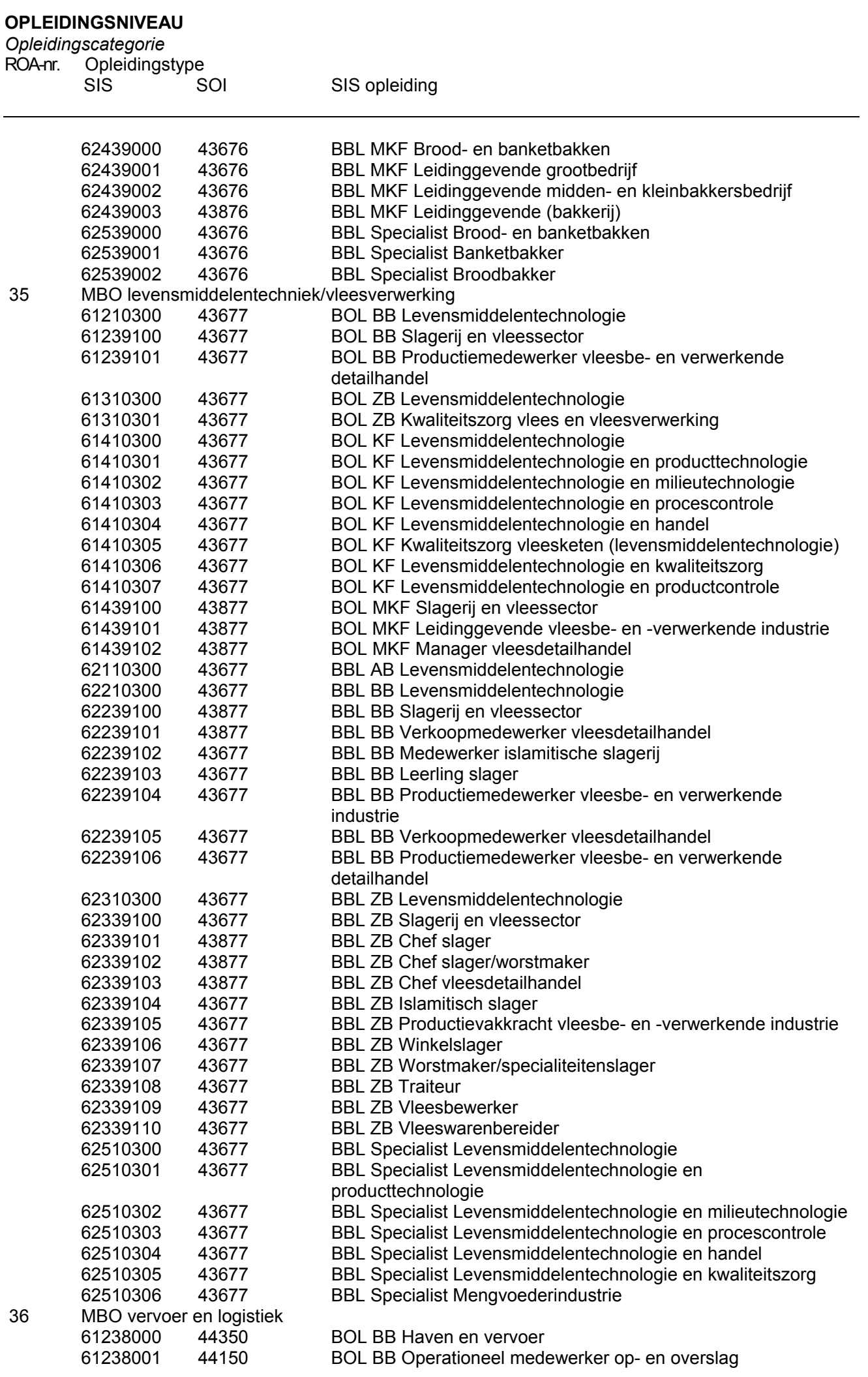




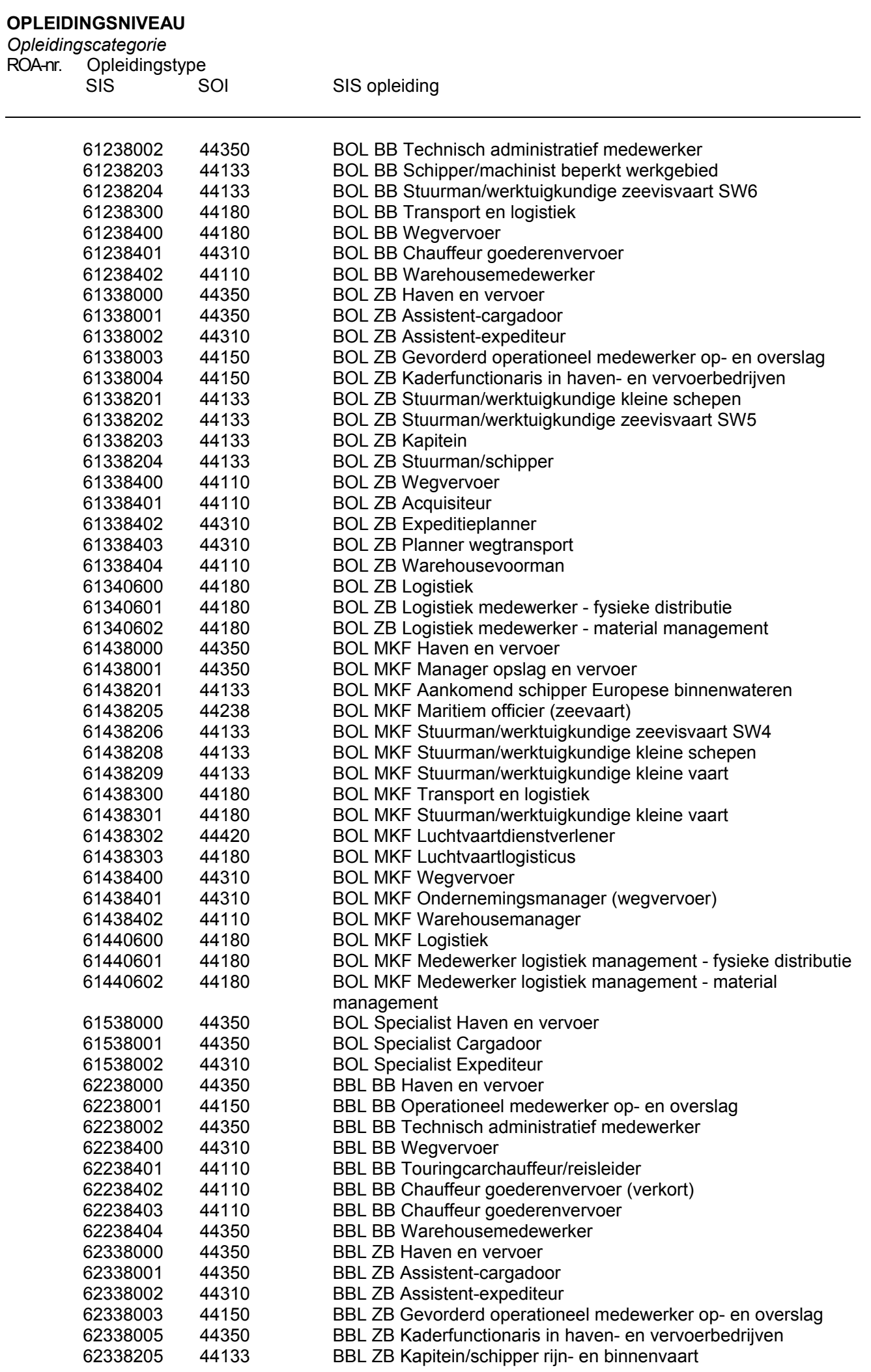




\begin{tabular}{|c|c|c|c|}
\hline \multicolumn{4}{|c|}{$\begin{array}{l}\text { OPLEIDINGSNIVEAU } \\
\text { Opleidingscategorie }\end{array}$} \\
\hline ROA-nr. & Sis & SOI & SIS opleiding \\
\hline & 62338206 & 44133 & BBL ZB Kapitein \\
\hline & 62338207 & 44133 & BBL ZB Stuurman/schipper \\
\hline & 62338400 & 44310 & BBL ZB Wegvervoer \\
\hline & 62338401 & 44310 & BBL ZB Planner wegtransport \\
\hline & 62338403 & 44350 & BBL ZB Warehouse voorman \\
\hline & 62338404 & 44110 & BBL ZB Acquisiteur \\
\hline & 62338405 & 44310 & BBL ZB Expeditieplanner \\
\hline & 62340600 & 44180 & BBL ZB Logistiek \\
\hline & 62340601 & 44180 & BBL ZB Logistiek medewerker - fysieke distributie \\
\hline & 62340602 & 44180 & BBL ZB Logistiek medewerker - material management \\
\hline & 62438400 & 44310 & BBL MKF Wegvervoer \\
\hline & 62438401 & 44310 & BBL MKF Ondernemingsmanager (wegvervoer) \\
\hline & 62438402 & 44110 & BBL MKF Warehousemanager \\
\hline & 62440600 & 44180 & BBL MKF Logistiek \\
\hline & 62440601 & 44180 & BBL MKF Medewerker logistiek management - fysieke distributie \\
\hline & 62440602 & 44180 & $\begin{array}{l}\text { BBL MKF Medewerker logistiek management - material } \\
\text { management }\end{array}$ \\
\hline & 62538000 & 44350 & BBL Specialist Haven en vervoer \\
\hline & 62538001 & 44350 & BBL Specialist Cargadoor \\
\hline & 62538002 & 44310 & BBL Specialist Expediteur \\
\hline & 62538400 & 44310 & BBL Specialist Wegvervoer \\
\hline & 62538401 & 44150 & BBL Specialist Gevaarlijke stoffen \\
\hline \multirow[t]{15}{*}{37} & \multicolumn{3}{|c|}{ MBO techniek overig } \\
\hline & 62235800 & 43688 & BBL BB Pianotechniek \\
\hline & 62235801 & 43688 & BBL BB Assistent pianotechnicus \\
\hline & 62236600 & 43673 & BBL BB Textieltechniek \\
\hline & 62236601 & 43673 & BBL BB Operator filament- en vezelvervaardiging \\
\hline & 62236602 & 43673 & BBL BB Operator garenverwerking \\
\hline & 62236603 & 43673 & BBL BB Operator veredeling \\
\hline & 62236604 & 43673 & BBL BB Operator vezelverwerking \\
\hline & 62236605 & 43673 & BBL BB Operator vliesstofvervaardiging \\
\hline & 62335800 & 43688 & BBL ZB Pianotechniek \\
\hline & 62335801 & 43688 & BBL ZB Gezel pianotechnicus \\
\hline & 62336600 & 43673 & BBL ZB Textieltechniek \\
\hline & 62336601 & 43673 & BBL ZB Monteur mechanische verwerking \\
\hline & 62336602 & 43673 & BBL ZB Specialist mechanische verwerking \\
\hline & 62336603 & 43673 & BBL ZB Specialist veredeling \\
\hline \multicolumn{4}{|c|}{ MBO dienstverlening en gezondheidszorg } \\
\hline \multirow[t]{3}{*}{38} & \multicolumn{3}{|c|}{ MBO dokters-, tandarts- en dierenartsassistent } \\
\hline & 61450101 & 45118 & BOL MKF Doktersassistent \\
\hline & 61450102 & 45138 & BOL MKF Tandartsassistent \\
\hline \multirow[t]{3}{*}{39} & \multicolumn{3}{|c|}{ MBO apothekersassistent } \\
\hline & 61450103 & 45220 & BOL MKF Apothekersassistent \\
\hline & 62450103 & 45220 & BBL MKF Apothekersassistent \\
\hline \multirow[t]{15}{*}{40} & \multicolumn{3}{|c|}{ MBO verpleging } \\
\hline & 61250400 & 45120 & BOL BB Verpleging en verzorging \\
\hline & 61350400 & 45120 & BOL ZB Verpleging en verzorging \\
\hline & 61350401 & 45120 & BOL ZB Verzorgende \\
\hline & 61350402 & 45120 & BOL ZB Verpleegkundige \\
\hline & 61450400 & 45120 & BOL MKF Verpleging en verzorging \\
\hline & 61450401 & 45120 & BOL MKF Verpleegkundige \\
\hline & 61450402 & 45120 & BOL MKF Verzorgende \\
\hline & 62250403 & 45120 & BBL BB Kraamverzorgende \\
\hline & 62450400 & 45120 & BBL MKF Verpleging en verzorging \\
\hline & 62450401 & 45120 & BBL MKF Verpleegkundige \\
\hline & 62450500 & 45120 & BBL MKF Zorg en welzijn \\
\hline & 62650100 & 45120 & In-service Verpleegkundige A \\
\hline & 62650200 & 45120 & In-service Verpleegkundige B \\
\hline & 62650300 & 45120 & In-service Z-verpleegkundige \\
\hline
\end{tabular}




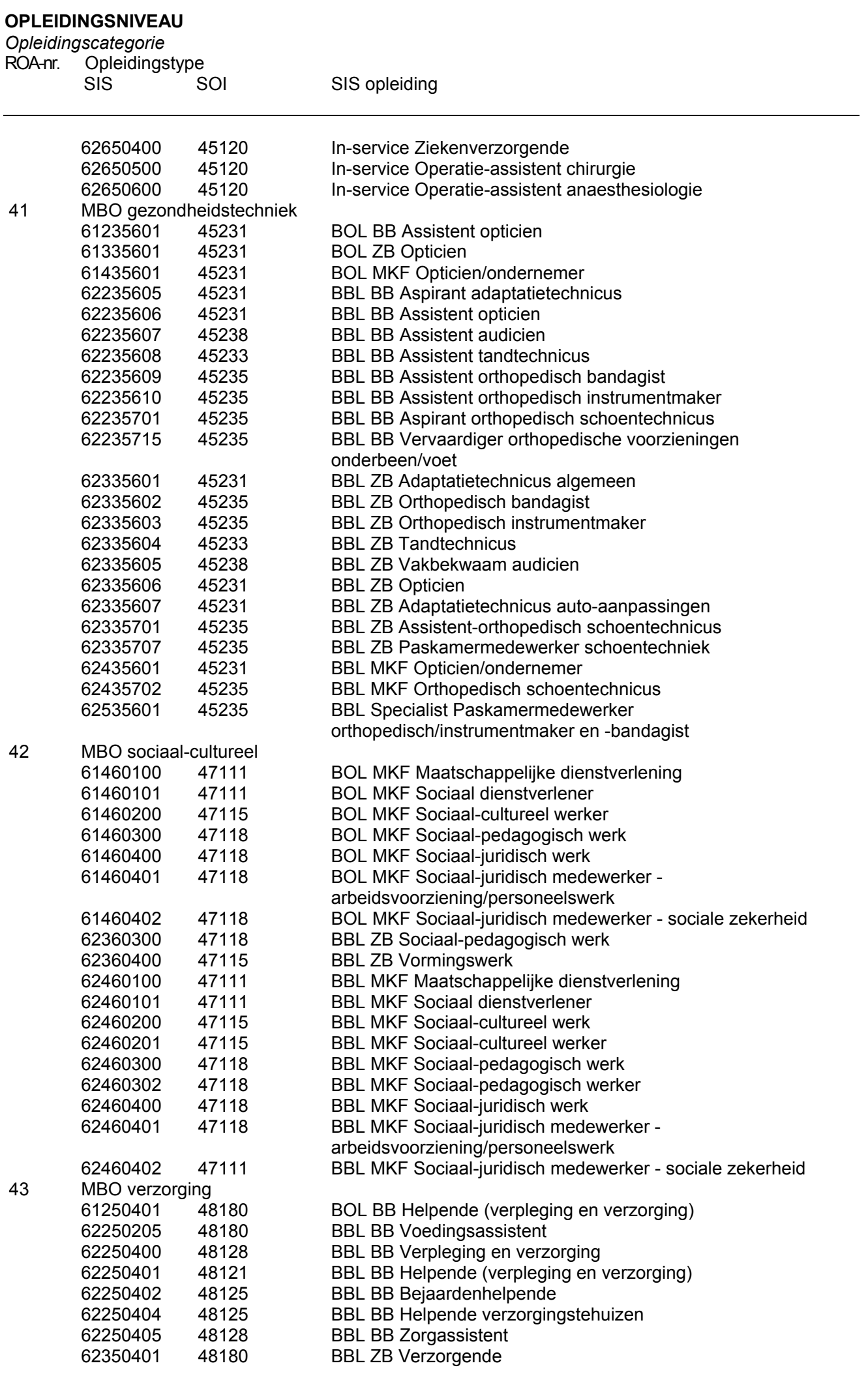




\begin{tabular}{|c|c|c|c|}
\hline \multicolumn{4}{|c|}{$\begin{array}{l}\text { OPLEIDINGSNIVEAU } \\
\text { Opleidingscategorie } \\
\text { ROA-nr. Opleidingstype }\end{array}$} \\
\hline ROA-nr. & \multicolumn{3}{|c|}{$\begin{array}{l}\text { Opleidingstype } \\
\text { SIS SOI }\end{array}$} \\
\hline & 62350402 & 48121 & BBL ZB Verzorgende bij inst. voor gezinsverz. \\
\hline & 62360301 & 48123 & BBL ZB Leidster kindercentra \\
\hline \multirow[t]{17}{*}{44} & \multicolumn{3}{|c|}{ MBO uiterlijke verzorging } \\
\hline & 61251000 & 48130 & BOL BB Uiterlijke verzorging \\
\hline & 61251001 & 48130 & BOL BB Kapper \\
\hline & 61351000 & 48130 & BOL ZB Uiterlijke verzorging \\
\hline & 61351001 & 48130 & BOL ZB All-round kapper \\
\hline & 61351002 & 48130 & BOL ZB Schoonheidsspecialist \\
\hline & 61351003 & 48330 & BOL ZB Voetverzorger \\
\hline & 61351004 & 48130 & BOL ZB Dames- en herenkapper \\
\hline & 62251000 & 48130 & BBL BB Uiterlijke verzorging \\
\hline & 62251001 & 48130 & BBL BB Kapper \\
\hline & 62251002 & 48130 & BBL BB Dameskapper \\
\hline & 62251003 & 48130 & BBL BB Herenkapper \\
\hline & 62251004 & 48130 & BBL BB Dames- en herenkapper \\
\hline & 62351000 & 48130 & BBL ZB Uiterlijke verzorging \\
\hline & 62351001 & 48130 & BBL ZB All-round kapper \\
\hline & 62351002 & 48130 & BBL ZB Dameskappen \\
\hline & 62351003 & 48130 & BBL ZB Herenkappen \\
\hline \multirow[t]{22}{*}{45} & \multicolumn{3}{|c|}{ MBO horeca } \\
\hline & 61242000 & 48340 & BOL BB Horeca, instellingskeuken en contractcatering \\
\hline & 61242001 & 48140 & BOL BB Kok \\
\hline & 61242002 & 48140 & BOL BB Gastheer/-vrouw \\
\hline & 61242003 & 48340 & BOL BB Fastfood-specialist \\
\hline & 61242004 & 48340 & BOL BB Bartender \\
\hline & 61442000 & 48340 & BOL MKF Horeca, instellingskeuken en contractcatering \\
\hline & 61442002 & 48340 & BOL MKF Horecaondernemer café/bar en fastfood \\
\hline & 61442003 & 48340 & BOL MKF Horecaondernemer/-manager \\
\hline & 62242000 & 48340 & BBL BB Horeca, instellingskeuken en contractcatering \\
\hline & 62242001 & 48140 & BBL BB Kok \\
\hline & 62242002 & 48140 & BBL BB Gastheer/-vrouw \\
\hline & 62242003 & 48340 & BBL BB Fastfood-specialist \\
\hline & 62342000 & 48340 & BBL ZB Horeca, instellingskeuken en contractcatering \\
\hline & 62342001 & 48140 & BBL ZB Zelfstandig werkend gastheer/-vrouw \\
\hline & 62342002 & 48140 & BBL ZB Zelfstandig werkend kok \\
\hline & 62442000 & 48340 & BBL MKF Horeca, instellingskeuken en contractcatering \\
\hline & 62442002 & 48340 & BBL MKF Horecaondernemer cafe/bar en fastfood \\
\hline & 62542000 & 48340 & BBL Specialist Horeca, instellingskeuken en contractcatering \\
\hline & 62542001 & 48140 & BBL Specialist Dieetkok \\
\hline & 62542002 & 48140 & BBL Specialist Gespecialiseerd kok \\
\hline & 62542003 & 48140 & BBL Specialist Instellingskok \\
\hline \multirow[t]{7}{*}{46} & \multicolumn{3}{|c|}{ MBO beweging en therapie } \\
\hline & 61450300 & 40667 & BOL MKF Sport en bewegen \\
\hline & 61450301 & 40667 & BOL MKF Sport- en bewegingsleider \\
\hline & 61460301 & 45148 & BOL MKF Activiteitenbegeleider \\
\hline & 61460303 & 45148 & BOL MKF Activiteitenbegeleider (verkort) \\
\hline & 62460301 & 45148 & BBL MKF Activiteitenbegeleider \\
\hline & 62650800 & 45241 & In-service Laborant klinische neurofysiologie \\
\hline \multicolumn{4}{|c|}{ MBO economie } \\
\hline \multirow[t]{10}{*}{47} & \multicolumn{3}{|c|}{ MBO administratie } \\
\hline & 61240000 & 46110 & BOL BB Economie \\
\hline & 61240200 & 46133 & BOL BB Bedrijfsadministratie \\
\hline & 61240201 & 46133 & BOL BB Bedrijfsadministratief medewerker \\
\hline & 61240400 & 46148 & BOL BB Commercieel \\
\hline & 61240401 & 46148 & BOL BB Commercieel administratief medewerker \\
\hline & 61241200 & 46138 & BOL BB Opslag/magazijn \\
\hline & 61241201 & 46138 & BOL BB Magazijnmedewerker \\
\hline & 61340000 & 46110 & BOL ZB Economie \\
\hline & 61340200 & 46133 & BOL ZB Bedrijfsadministratief \\
\hline
\end{tabular}




\begin{tabular}{|c|c|c|c|}
\hline \multicolumn{4}{|c|}{$\begin{array}{l}\text { OPLEIDINGSNIVEAU } \\
\text { Opleidingscategorie }\end{array}$} \\
\hline ROA-nr. & Sis & SOI & SIS opleiding \\
\hline & 61340201 & 46133 & BOL ZB Boekhoudkundig medewerker \\
\hline & 61340400 & 46148 & BOL ZB Commercieel \\
\hline & 61340401 & 46148 & BOL ZB Commercieel medewerker binnendienst \\
\hline & 61341003 & 46148 & BOL ZB Verkoopchef \\
\hline & 61341100 & 46138 & BOL ZB Groothandel/distributie \\
\hline & 61341101 & 46148 & BOL ZB Assistent-exportmanager \\
\hline & 61341102 & 46148 & BOL ZB Commercieel medewerker binnendienst \\
\hline & 61341103 & 46148 & BOL ZB Export medewerker binnendienst \\
\hline & 61341104 & 46148 & BOL ZB Export medewerker buitendienst \\
\hline & 61341105 & 46148 & BOL ZB Medewerker inkoop \\
\hline & 61341106 & 46148 & BOL ZB Vertegenwoordiger \\
\hline & 61341200 & 46138 & BOL ZB Opslag/magazijn \\
\hline & 61341201 & 46138 & BOL ZB Groepsleider magazijn \\
\hline & 61440000 & 46110 & BOL MKF Economie \\
\hline & 61440200 & 46133 & BOL MKF Bedrijfsadministratief \\
\hline & 61440201 & 46133 & BOL MKF Assistent-administrateur \\
\hline & 61440202 & 46133 & BOL MKF Administratie Bestuurlijk \\
\hline & 61440203 & 46133 & BOL MKF Administratie Groothandel \\
\hline & 61440400 & 46148 & BOL MKF Commercieel \\
\hline & 61440500 & 46628 & BOL MKF Economisch-juridisch \\
\hline & 61440501 & 46628 & $\begin{array}{l}\text { BOL MKF Administratief-juridisch medewerker - openbaar } \\
\text { bestuur }\end{array}$ \\
\hline & 61440800 & 46133 & BOL MKF Administratie - vrije richting \\
\hline & 61441004 & 46148 & BOL MKF Internationale handel $(\mathrm{IH})$ \\
\hline & 61441100 & 46138 & BOL MKF Groothandel/distributie \\
\hline & 61441101 & 46148 & BOL MKF Districtsmanager \\
\hline & 61441200 & 46138 & BOL MKF Opslag/magazijn \\
\hline & 61441201 & 46138 & BOL MKF Hoofd magazijn \\
\hline & 62240000 & 46110 & BBL BB Economie \\
\hline & 62240200 & 46133 & BBL BB Bedrijfsadministratief \\
\hline & 62240201 & 46133 & BBL BB Bedrijfsadministratief medewerker \\
\hline & 62240400 & 46148 & BBL BB Commercieel \\
\hline & 62240401 & 46148 & BBL BB Commercieel administratief medewerker \\
\hline & 62240402 & 46148 & BBL BB Telewerker \\
\hline & 62241200 & 46138 & BBL BB Opslag/magazijn \\
\hline & 62241201 & 46138 & BBL BB Magazijnmedewerker \\
\hline & 62340000 & 46110 & BBL ZB Economie \\
\hline & 62340200 & 46133 & BBL ZB Bedrijfsadministratief \\
\hline & 62340201 & 46133 & BBL ZB Boekhoudkundig medewerker \\
\hline & 62340400 & 46148 & BBL ZB Commercieel \\
\hline & 62340401 & 46148 & BBL ZB Commercieel medewerker binnendienst \\
\hline & 62341003 & 46148 & BBL ZB Verkoopchef \\
\hline & 62341100 & 46138 & BBL ZB Groothandel/distributie \\
\hline & 62341101 & 46148 & BBL ZB Assistent-exportmanager \\
\hline & 62341102 & 46148 & BBL ZB Commercieel medewerker binnendienst \\
\hline & 62341103 & 46148 & BBL ZB Export medewerker binnendienst \\
\hline & 62341104 & 46148 & BBL ZB Export medewerker buitendienst \\
\hline & 62341105 & 46148 & BBL ZB Medewerker inkoop \\
\hline & 62341106 & 46148 & BBL ZB Vertegenwoordiger \\
\hline & 62341200 & 46138 & BBL ZB Opslag/magazijn \\
\hline & 62341201 & 46138 & BBL ZB Groepsleider magazijn \\
\hline & 62440000 & 46110 & BBL MKF Economie \\
\hline & 62440200 & 46133 & BBL MKF Bedrijfsadministratief \\
\hline & 62440201 & 46133 & BBL MKF Assistent-administrateur \\
\hline & 62440400 & 46148 & BBL MKF Commercieel \\
\hline & 62440500 & 46628 & BBL MKF Economisch-juridisch \\
\hline & 62440501 & 46628 & $\begin{array}{l}\text { BBL MKF Administratief-juridisch medewerker - openbaar } \\
\text { bestuur }\end{array}$ \\
\hline & 62441100 & 46138 & BBL MKF Groothandel/distributie \\
\hline
\end{tabular}




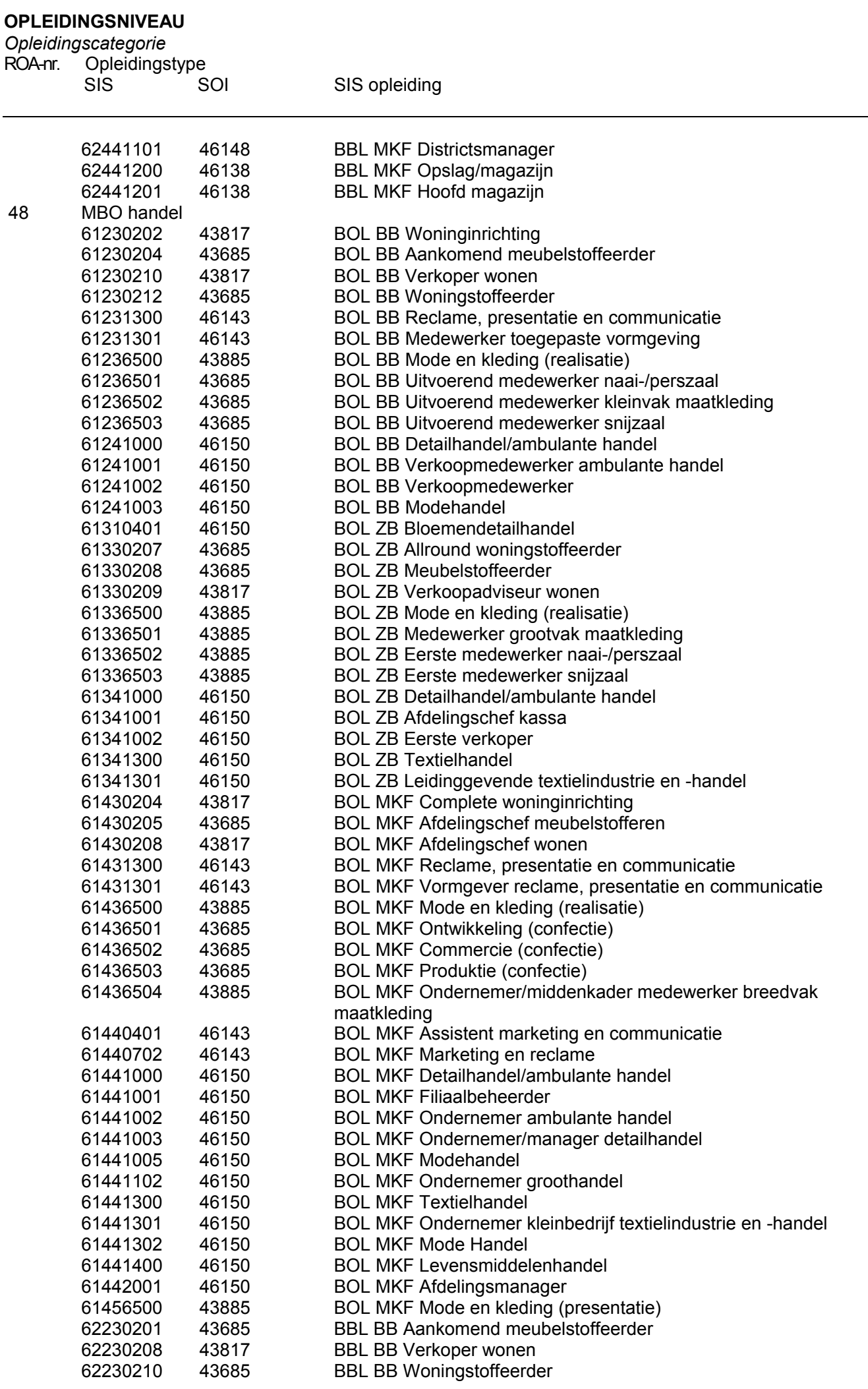




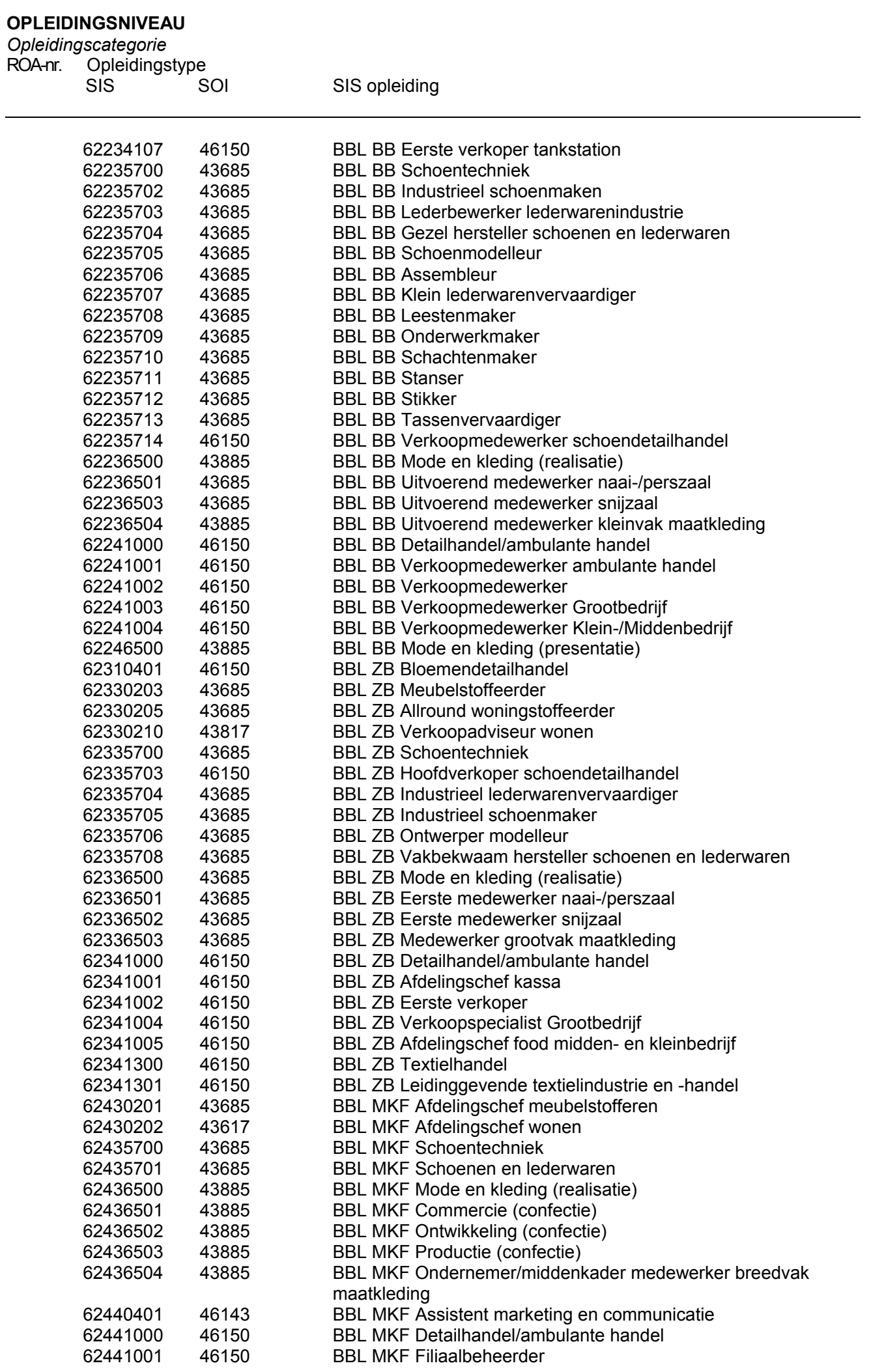




\begin{tabular}{|c|c|c|c|}
\hline \multicolumn{4}{|c|}{$\begin{array}{l}\text { OPLEIDINGSNIVEAU } \\
\text { Opleidingscategorie } \\
\text { ROA-nr. Opleidingstype }\end{array}$} \\
\hline & 62441002 & 46150 & BBL MKF Ondernemer ambulante handel \\
\hline & 62441003 & 46150 & BBL MKF Ondernemer/manager detailhandel \\
\hline & 62441102 & 46150 & BBL MKF Ondernemer groothandel \\
\hline & 62441300 & 46150 & BBL MKF Textielhandel \\
\hline & 62441301 & 46150 & BBL MKF Ondernemer kleinbedrijf textielindustrie en -handel \\
\hline & 62442001 & 46150 & BBL MKF Afdelingsmanager \\
\hline & 62535700 & 43685 & BBL Specialist Schoentechniek \\
\hline \multirow[t]{16}{*}{49} & \multicolumn{3}{|c|}{ MBO secretariaat } \\
\hline & 61240700 & 46131 & BOL BB Secretarieel \\
\hline & 61240701 & 46131 & BOL BB Assistent-secretaresse \\
\hline & 61340700 & 46131 & BOL ZB Secretarieel \\
\hline & 61340701 & 46131 & BOL ZB Secretaresse \\
\hline & 61440700 & 46131 & BOL MKF Secretarieel \\
\hline & 61440701 & 46131 & BOL MKF Directie-secretaresse/management-assistent \\
\hline & 61440703 & 46131 & BOL MKF Internationaal secretariaat (IS) \\
\hline & 61450100 & 45180 & BOL MKF Assistenten gezondheidszorg \\
\hline & 62240700 & 46131 & BBL BB Secretarieel \\
\hline & 62240701 & 46131 & BBL BB Assistent-secretaresse \\
\hline & 62340700 & 46131 & BBL ZB Secretarieel \\
\hline & 62340701 & 46131 & BBL ZB Secretaresse \\
\hline & 62440700 & 46131 & BBL MKF Secretarieel \\
\hline & 62440701 & 46131 & BBL MKF Directiesecretaresse/management-assistent \\
\hline & 62450100 & 45180 & BBL MKF Assistenten gezondheidszorg \\
\hline \multirow[t]{16}{*}{50} & \multicolumn{3}{|c|}{ MBO toerisme en recreatie } \\
\hline & 61242100 & 46142 & BOL BB Toerisme, recreatie en reizen \\
\hline & 61242101 & 46142 & BOL BB Medewerker recreatie \\
\hline & 61242102 & 46142 & BOL BB Medewerker reizen en toeristische informatie \\
\hline & 61342100 & 46142 & BOL ZB Toerisme, recreatie en reizen \\
\hline & 61342101 & 46142 & BOL ZB Zelfstandig werkend medewerker recreatie \\
\hline & 61342102 & 46142 & BOL ZB Zelfstandig werkend medewerker reizen \\
\hline & 61342103 & 46142 & BOL ZB Zelfstandig werkend medewerker toeristische informatie \\
\hline & 61442100 & 46142 & BOL MKF Toerisme, recreatie en reizen \\
\hline & 61442101 & 46142 & BOL MKF Recreatie \\
\hline & 61442102 & 46142 & BOL MKF Reizen \\
\hline & 61442103 & 46142 & BOL MKF Toeristische informatie \\
\hline & 62242100 & 46142 & BBL BB Toerisme, recreatie en reizen \\
\hline & 62242101 & 46142 & BBL BB Medewerker recreatie \\
\hline & 62342100 & 46142 & BBL ZB Toerisme, recreatie en reizen \\
\hline & 62342101 & 46142 & BBL ZB Zelfstandig werkend medewerker recreatie \\
\hline \multirow[t]{7}{*}{51} & \multicolumn{3}{|c|}{ MBO bedrijfskunde } \\
\hline & 61250200 & 46120 & BOL BB Facilitaire dienstverlening \\
\hline & 61250201 & 46120 & BOL BB Medewerker facilitaire dienstverlening \\
\hline & 61440900 & 46120 & BOL MKF Bestuurlijk \\
\hline & 61450200 & 46120 & BOL MKF Facilitaire dienstverlening \\
\hline & 61450201 & 46120 & BOL MKF Medewerker facilitaire dienstverlening \\
\hline & 62250200 & 46120 & BBL BB Facilitaire dienstverlening \\
\hline \multirow[t]{13}{*}{52} & \multicolumn{3}{|c|}{ MBO automatisering } \\
\hline & 61340100 & 46135 & BOL ZB Automatisering \\
\hline & 61340101 & 46135 & BOL ZB Medewerker beheer informatiesystemen \\
\hline & 61434702 & 46135 & BOL MKF Kantoorautomatiseringstechniek \\
\hline & 61440100 & 46135 & BOL MKF Automatisering \\
\hline & 61440101 & 46135 & BOL MKF Applicatiebeheerder \\
\hline & 61440102 & 46135 & BOL MKF Beheerder technische infrastructuur \\
\hline & 61440103 & 46135 & BOL MKF Systeembeheerder MKB \\
\hline & 61540100 & 46135 & BOL Specialist Automatisering \\
\hline & 61540101 & 46135 & BOL Specialist Applicatie-ontwikkelaar \\
\hline & 61540102 & 46135 & BOL Specialist ICT-beheerder \\
\hline & 61540103 & 46135 & BOL Specialist Netwerkbeheerder \\
\hline & 62340100 & 46135 & BBL ZB Automatisering \\
\hline
\end{tabular}




\begin{tabular}{|c|c|c|c|}
\hline \multicolumn{4}{|c|}{$\begin{array}{l}\text { OPLEIDINGSNIVEAU } \\
\text { Opleidingscategorie } \\
\text { ROA-nr. Opleidingstype }\end{array}$} \\
\hline ROA-nr. & Sis & SOI & SIS opleiding \\
\hline & 62340101 & 46135 & BBL ZB Medewerker beheer informatiesystemen \\
\hline & 62440100 & 46135 & BBL MKF Automatisering \\
\hline & 62440101 & 46135 & BBL MKF Applicatiebeheerder \\
\hline & 62440102 & 46135 & BBL MKF Beheerder technische infrastructuur \\
\hline & 62440103 & 46135 & BBL MKF Systeembeheerder MKB \\
\hline & 62540100 & 46135 & BBL Specialist Automatisering \\
\hline & 62540101 & 46135 & BBL Specialist Applicatie-ontwikkelaar \\
\hline & 62540102 & 46135 & BBL Specialist ICT-beheerder \\
\hline & 62540103 & 46135 & BBL Specialist Netwerkbeheerder \\
\hline \multirow[t]{3}{*}{53} & \multicolumn{3}{|c|}{ MBO geld, bank en belastingen } \\
\hline & 61440402 & 46145 & BOL MKF Commercieel medewerker banken \\
\hline & 62440402 & & BBL MKF Commercieel medewerker banken \\
\hline \multirow[t]{3}{*}{54} & \multicolumn{3}{|c|}{ MBO verzekeringswezen } \\
\hline & 61440403 & 46146 & BOL MKF Commercieel medewerker verzekeringen \\
\hline & 62440403 & 46146 & BBL MKF Commercieel medewerker verzekeringen \\
\hline \multicolumn{4}{|c|}{ MBO openbare orde en veiligheid } \\
\hline \multirow[t]{11}{*}{55} & \multicolumn{3}{|c|}{ MBO openbare orde en veiligheid } \\
\hline & 61240300 & 49180 & BOL BB Beveiliging \\
\hline & 61240301 & 49180 & BOL BB Beveiligingsmedewerker \\
\hline & 62080100 & 49110 & MBO Politie \\
\hline & 62080201 & 49150 & MBO Koninklijke landmacht \\
\hline & 62080202 & 49160 & MBO Koninklijke luchtmacht \\
\hline & 62080203 & 49170 & MBO Koninklijke marine \\
\hline & 62080204 & 49110 & MBO Wachtmeester-BBT \\
\hline & 62080205 & 49110 & MBO Marechaussee-BBT \\
\hline & 62240300 & 49180 & BBL BB Beveiliging \\
\hline & 62240301 & 49180 & BBL BB Beveiligingsmedewerker \\
\hline \multicolumn{4}{|c|}{ MBO overig } \\
\hline \multirow[t]{5}{*}{56} & \multicolumn{3}{|c|}{ MBO overig } \\
\hline & 61236004 & 48610 & BOL BB Behoudsmedewerker \\
\hline & 61460305 & 40688 & BOL MKF Onderwijsassistent \\
\hline & 62236004 & 48610 & BBL BB Behoudsmedewerker \\
\hline & 62550401 & 40617 & BBL Specialist Praktijkopleider (verpleging en verzorgende) \\
\hline
\end{tabular}

HBO

HBO onderwijs en tolk en vertaler

\begin{tabular}{|c|c|c|c|}
\hline 57 & HBO lerare & pleiding & derwijs \\
\hline & 71320100 & 50613 & HBO Leraar basisonderwijs \\
\hline & 71320101 & 50613 & HBO Leraar basisonderwijs \\
\hline & 71320102 & 50613 & HBO Leraar speciaal onderwijs \\
\hline & 71320103 & 50613 & HBO Pabo Rotterdam \\
\hline & 71320104 & 50613 & HBO Pabo Heemstede \\
\hline & 71320105 & 50613 & HBO Pabo Den Haag \\
\hline & 71320106 & 50613 & HBO Pabo Dordrecht \\
\hline & 71320107 & 50613 & HBO Pabo Emmen \\
\hline & 71320108 & 50613 & HBO Pabo Groningen \\
\hline & 71320109 & 50613 & HBO Pabo Marienburg \\
\hline & 71320110 & 50613 & HBO Leraar basisonderwijs Montessori \\
\hline & 71320111 & 50613 & HBO Leraar speciaalonderwijs A (gehoorgestoorden) \\
\hline & 71320112 & 50613 & HBO Leraar speciaalonderwijs B (gehoorgestoorden) \\
\hline & 71320114 & 50613 & HBO Pabo Nijmegen \\
\hline & 71320115 & 50613 & HBO Pabo Arnhem \\
\hline & 71320116 & 50613 & HBO Pabo Oegstgeest \\
\hline & 73173000 & 60617 & $\begin{array}{l}\text { HBO 2e fase Pedagogisch-didactische aantekening uitvoerend } \\
\text { musicus }\end{array}$ \\
\hline & 73173100 & 60617 & $\mathrm{HBO} 2 \mathrm{e}$ fase Aantekening begeleider \\
\hline & 73173200 & 60617 & $\mathrm{HBO} 2 \mathrm{e}$ fase Aantekening kamermuziek \\
\hline & HBO lerare & pleiding & \\
\hline
\end{tabular}




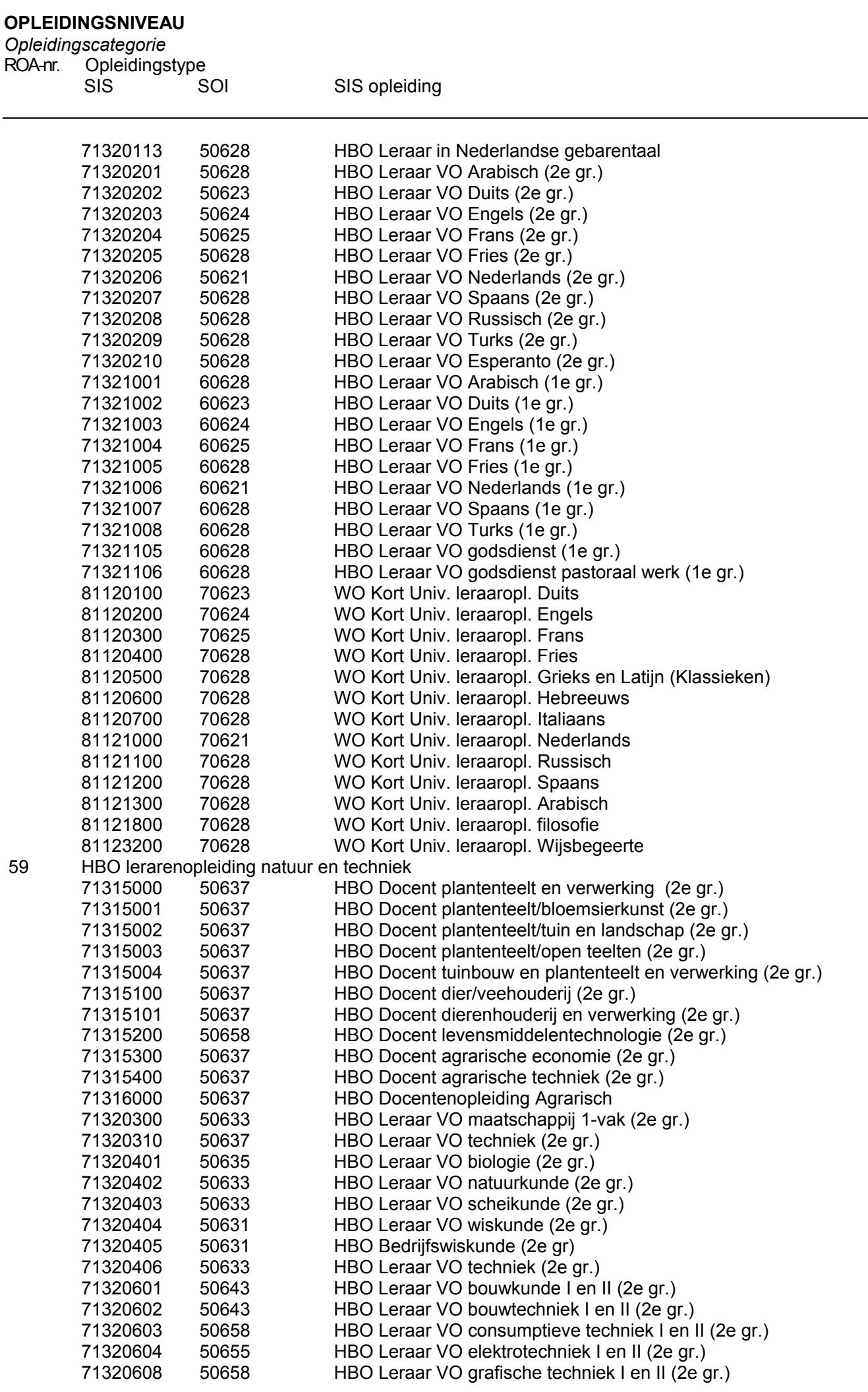




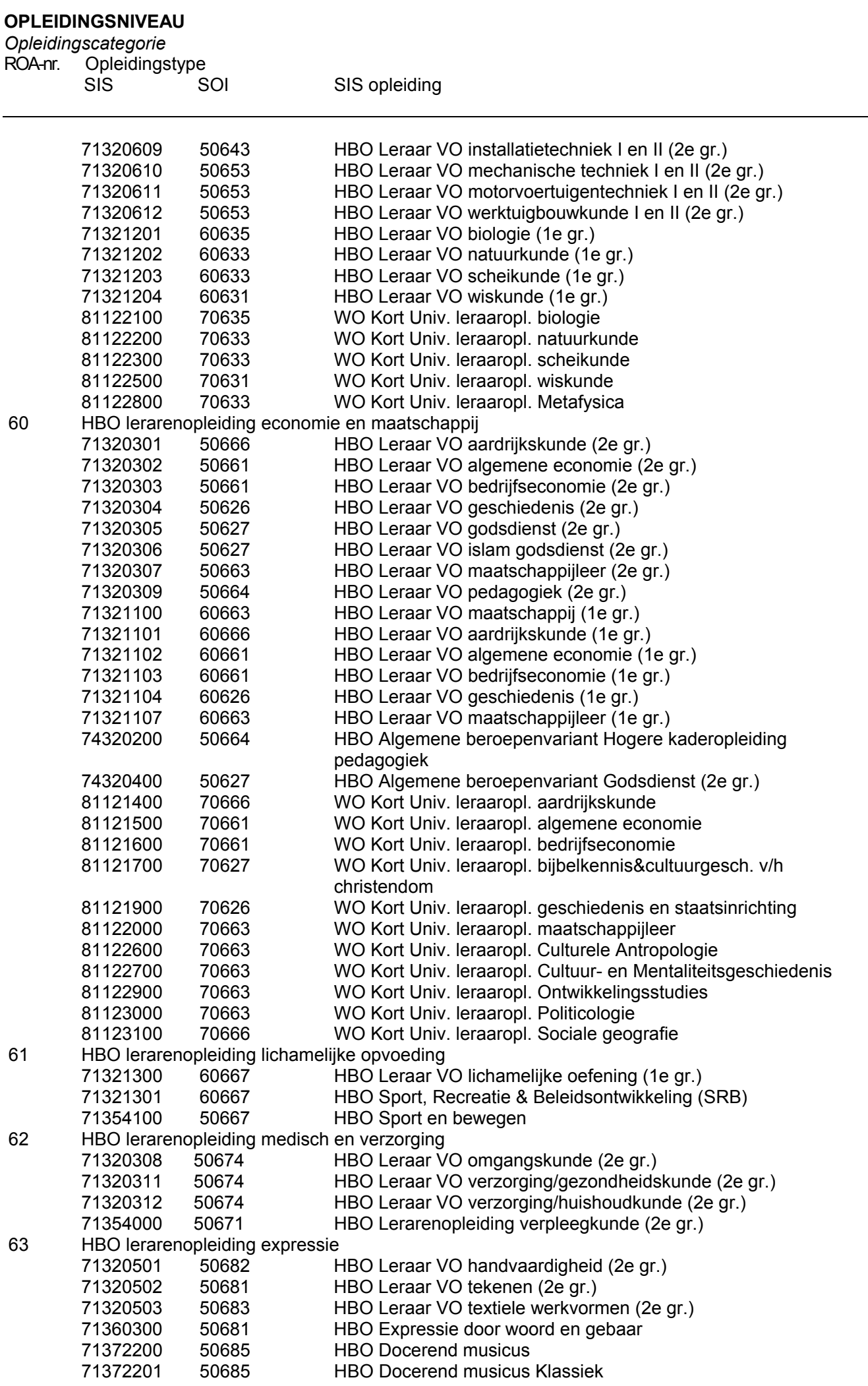




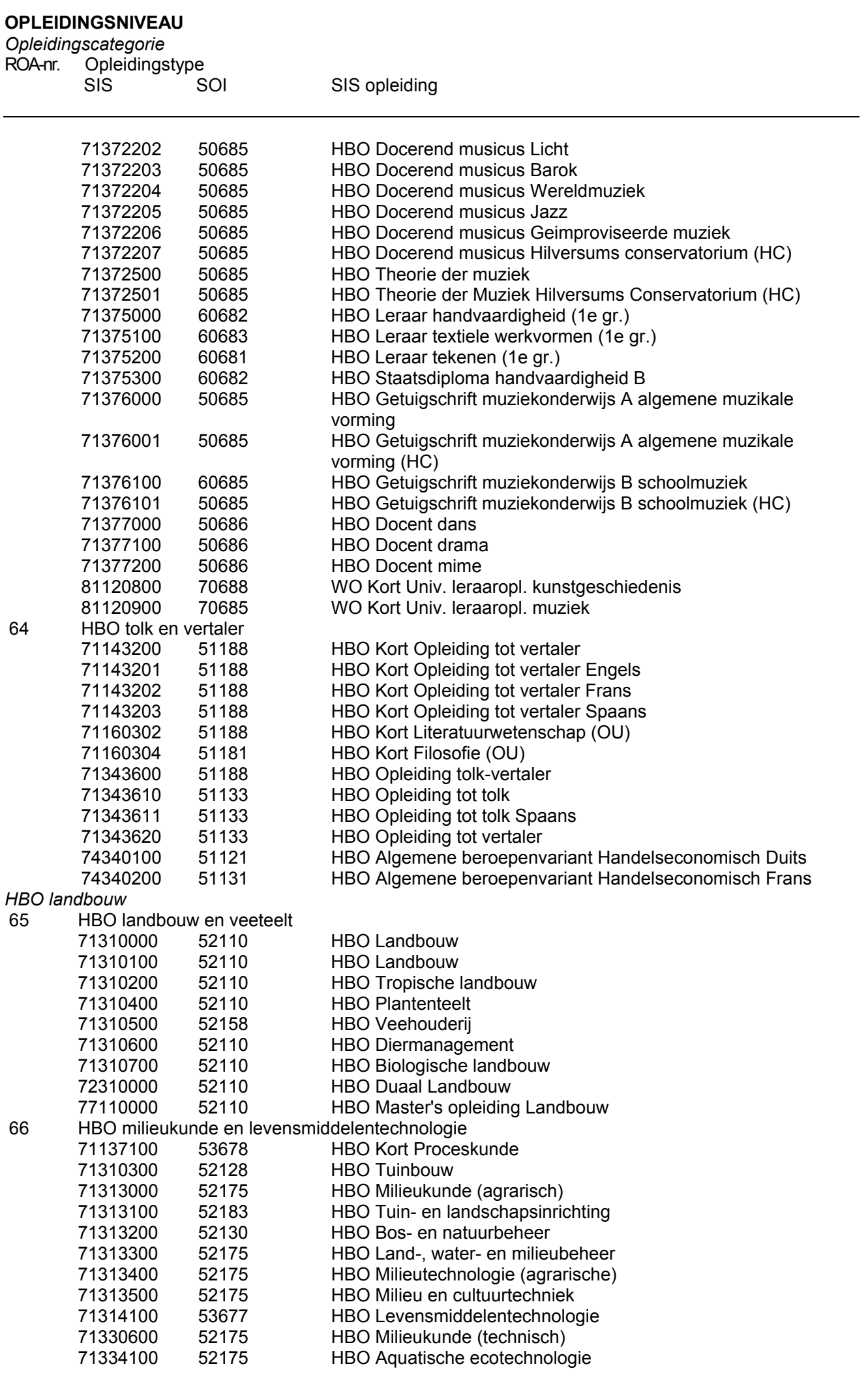




\begin{tabular}{|c|c|c|c|}
\hline \multicolumn{4}{|c|}{$\begin{array}{l}\text { OPLEIDINGSNIVEAU } \\
\text { Opleidingscategorie }\end{array}$} \\
\hline ROA-nr. & SIS & SOI & SIS opleiding \\
\hline & 71334300 & 52175 & HBO Milieutechnologie (technische) \\
\hline & 71343502 & 52188 & HBO Voorlichting \\
\hline & 72314100 & 53677 & HBO Duaal Levensmiddelentechnologie \\
\hline & 72330600 & 52175 & HBO Duaal Milieukunde \\
\hline \multicolumn{4}{|c|}{ HBO techniek } \\
\hline \multirow[t]{12}{*}{67} & \multicolumn{3}{|c|}{ HBO laboratorium } \\
\hline & 71137000 & 53140 & HBO Kort Chemie en laboratorium \\
\hline & 71137200 & 53140 & HBO Kort Analytische methoden \\
\hline & 71314300 & 53160 & HBO Biotechnologie (landbouw) \\
\hline & 71334500 & 53160 & HBO Biotechnologie (technisch) \\
\hline & 71334600 & 53160 & HBO Biologie en medisch laboratoriumonderzoek \\
\hline & 71337000 & 53140 & HBO Analytische proces- en laboratoriuminstrumentatie \\
\hline & 71337100 & 53160 & HBO Biologische laboratoriumopleiding \\
\hline & 71337200 & 53140 & HBO Chemische laboratoriumopleiding \\
\hline & 71337300 & 55210 & HBO Medische laboratoriumopleiding \\
\hline & 72337000 & 53140 & HBO Duaal Analytische proces- en laboratoriuminstrumentatie \\
\hline & 72337200 & 53140 & HBO Duaal Chemische laboratoriumopleiding \\
\hline \multirow[t]{4}{*}{68} & \multicolumn{3}{|c|}{ HBO bouwkunde } \\
\hline & 71330100 & 53618 & HBO Bouwkunde \\
\hline & 71335200 & 53818 & HBO Bouwtechnische bedrijfskunde \\
\hline & 72330100 & 53618 & HBO Duaal Bouwkunde en civiele techniek \\
\hline \multirow[t]{6}{*}{69} & \multicolumn{3}{|c|}{ HBO civiele techniek } \\
\hline & 71131200 & 53623 & HBO Kort Weg- en waterbouwkundig opzichter/uitvoerder \\
\hline & 71330200 & 53623 & HBO Civiele techniek \\
\hline & 71330300 & 53625 & HBO Geodesie \\
\hline & 71330400 & 53623 & HBO Verkeerskunde \\
\hline & 71336200 & 53625 & HBO Hydrografie \\
\hline \multirow[t]{9}{*}{70} & \multicolumn{3}{|c|}{ HBO werktuigbouwkunde } \\
\hline & 71133000 & 53648 & HBO Kort Werktuigbouwkunde \\
\hline & 71133100 & 53648 & HBO Kort Constructeur werktuigbouwkunde \\
\hline & 71133200 & 53648 & HBO Kort Constructeur piping \\
\hline & 71333000 & 53648 & HBO Werktuigbouwkunde \\
\hline & 71333100 & 53841 & HBO Autotechniek \\
\hline & 71333200 & 53645 & HBO Luchtvaarttechnologie \\
\hline & 71333300 & 53643 & HBO Scheepsbouwkunde \\
\hline & 71336000 & 53646 & HBO Algemene operationele technologie \\
\hline \multirow[t]{23}{*}{71} & \multicolumn{3}{|c|}{ HBO elektrotechniek } \\
\hline & 71131002 & 53683 & HBO Kort Wiskunde-onderbouw (OU) \\
\hline & 71132000 & 53653 & HBO Kort Elektrotechniek en technische informatica \\
\hline & 71132100 & 53651 & HBO Kort Elektrotechnisch opzichter \\
\hline & 71190000 & 53120 & HBO Kort Natuurwetenschappen \\
\hline & 71190100 & 53120 & HBO Kort Natuurwetenschappen (OU) \\
\hline & 71190101 & 53120 & HBO Kort Toegepaste oecologie (OU) \\
\hline & 71190102 & 53120 & HBO Kort Milieu en chemie (OU) \\
\hline & 71190103 & 53120 & HBO Kort Milieumanagement (OU) \\
\hline & 71190104 & 53120 & HBO Kort Geosystemen (OU) \\
\hline & 71190105 & 53120 & HBO Kort Ecotoxicologie (OÚ) \\
\hline & 71190106 & 53120 & HBO Kort Biotechnologie (OU) \\
\hline & 71314000 & 53120 & HBO Laboratoriumtechniek \\
\hline & 71314200 & 53120 & HBO Agroproductkunde \\
\hline & 71332000 & 53651 & HBO Elektrotechniek \\
\hline & 71332001 & 53651 & HBO Hoger elektronicus \\
\hline & 71332400 & 53653 & HBO Elektronicatechniek \\
\hline & 71332500 & 53655 & HBO Besturingstechnologie \\
\hline & 71333400 & 53682 & HBO Technische natuurkunde \\
\hline & 71333500 & 53120 & HBO Materiaalkunde \\
\hline & 71334200 & 53120 & HBO Milieugerichte materiaaltechnologie \\
\hline & 71371002 & 53653 & HBO Beeld- en mediatechniek \\
\hline & 72332000 & 53651 & HBO Duaal Elektrotechniek \\
\hline
\end{tabular}




\begin{tabular}{|c|c|c|c|}
\hline \multicolumn{4}{|c|}{$\begin{array}{l}\text { OPLEIDINGSNIVEAU } \\
\text { Opleidingscategorie } \\
\text { ROA-nr. Opleidingstype }\end{array}$} \\
\hline & 74330100 & 53110 & HBO Algemene beroepenvariant Wiskunde \\
\hline & 77190000 & 53120 & HBO Master's opleiding Natuurwetenschappen \\
\hline \multirow[t]{20}{*}{72} & \multicolumn{3}{|c|}{ HBO informatica } \\
\hline & 71131001 & 53652 & HBO Kort Informatica-onderbouw (OU) \\
\hline & 71132200 & 53652 & HBO Kort Informatica \\
\hline & 71132300 & 53652 & HBO Kort Informatica technologie \\
\hline & 71140302 & 56135 & HBO Kort Bestuurlijke informatiekunde (OU) \\
\hline & 71332100 & 53652 & HBO Computertechniek \\
\hline & 71332200 & 53652 & HBO Hogere informatica \\
\hline & 71332300 & 53652 & HBO Informatica en informatiekunde \\
\hline & 71332301 & 53652 & HBO Informatica \\
\hline & 71332302 & 53652 & HBO Technische informatica \\
\hline & 71332303 & 53652 & HBO HTO informatica \\
\hline & 71332304 & 53652 & HBO Hogere opleiding software engineer \\
\hline & 71332305 & 53652 & HBO Hogere opleiding system engineer \\
\hline & 71337400 & 56135 & HBO Laboratoriuminformatica en automatisering \\
\hline & 71341200 & 56135 & HBO Bedrijfskundige informatica \\
\hline & 71341201 & 56135 & HBO Bedrijfsinformatica \\
\hline & 71341502 & 56135 & HBO Management informatica \\
\hline & 71343300 & 56135 & HBO Communicatiesystemen \\
\hline & 72337400 & 56135 & HBO Duaal Laboratoriuminformatica en automatisering \\
\hline & 72341200 & 56135 & HBO Duaal Bedrijfskundige informatica \\
\hline \multirow[t]{5}{*}{73} & \multicolumn{3}{|c|}{ HBO chemische technologie } \\
\hline & 71334000 & 53675 & HBO Chemische technologie \\
\hline & 71334001 & 53675 & HBO Technisch chemicus \\
\hline & 71334700 & 53675 & HBO Chemie \\
\hline & 71335400 & 53673 & HBO Technisch-commerciele textielkunde \\
\hline \multirow[t]{11}{*}{74} & \multicolumn{3}{|c|}{ HBO vervoer en logistiek } \\
\hline & 71130100 & 54180 & HBO Kort Logistiek en facilitair management \\
\hline & 71330700 & 54180 & HBO Logistiek en technische vervoerskunde \\
\hline & 71330701 & 54180 & HBO Logistiek en vervoer \\
\hline & 71330800 & 54121 & HBO Verkeersvlieger (vleugelvliegtuigen) \\
\hline & 71336300 & 54238 & HBO Maritiem officier \\
\hline & 71336301 & 54238 & HBO Maritieme elektronica \\
\hline & 71336400 & 54220 & HBO Vliegtuigoperatie \\
\hline & 71342101 & 54180 & HBO Personenvervoer en verkeer \\
\hline & 71382000 & 54121 & HBO Verkeersvlieger (vleugelvliegtuigen) \\
\hline & 71382100 & 54128 & HBO Verkeersleider \\
\hline \multicolumn{4}{|c|}{ HBO paramedisch } \\
\hline \multirow[t]{10}{*}{75} & \multicolumn{3}{|c|}{ HBO verpleegkunde } \\
\hline & 71141301 & 55380 & HBO Kort Beleid en management gezondheidszorg \\
\hline & 71350100 & 55120 & HBO Opleiding tot verpleegkundige \\
\hline & 71350101 & 55120 & HBO Opleiding tot verpleegkundige met vrijstellingen \\
\hline & 71350200 & 55120 & $\begin{array}{l}\text { HBO Opleiding verpleegkundige maatschappelijke } \\
\text { gezondheidszorg }\end{array}$ \\
\hline & 71350300 & 55120 & HBO Opleiding van kader in de gezondheidszorg \\
\hline & 71351700 & 55120 & HBO Antroposofische gezondheidszorg \\
\hline & 71352200 & 55120 & HBO Operatie-assistent anesthesie \\
\hline & 71352300 & 55120 & HBO Operatie-assistent chirurgie \\
\hline & 72350100 & 55120 & HBO Duaal Opleiding tot verpleegkundige \\
\hline \multirow[t]{9}{*}{76} & \multicolumn{3}{|c|}{ HBO (fysio)therapie } \\
\hline & 71351000 & 55238 & HBO Bewegingstechnologie \\
\hline & 71351200 & 55141 & HBO Fysiotherapie \\
\hline & 71351300 & 55143 & HBO Ergotherapie \\
\hline & 71351400 & 55151 & HBO Logopedie \\
\hline & 71351900 & 55153 & HBO Opleiding tot orthoptist \\
\hline & 71353100 & 55148 & HBO Huidtherapie \\
\hline & 71353200 & 55141 & HBO Opleiding oefentherapeut-Cesar \\
\hline & 71353300 & 55141 & HBO Opleiding oefentherapeut-Mensendieck \\
\hline
\end{tabular}




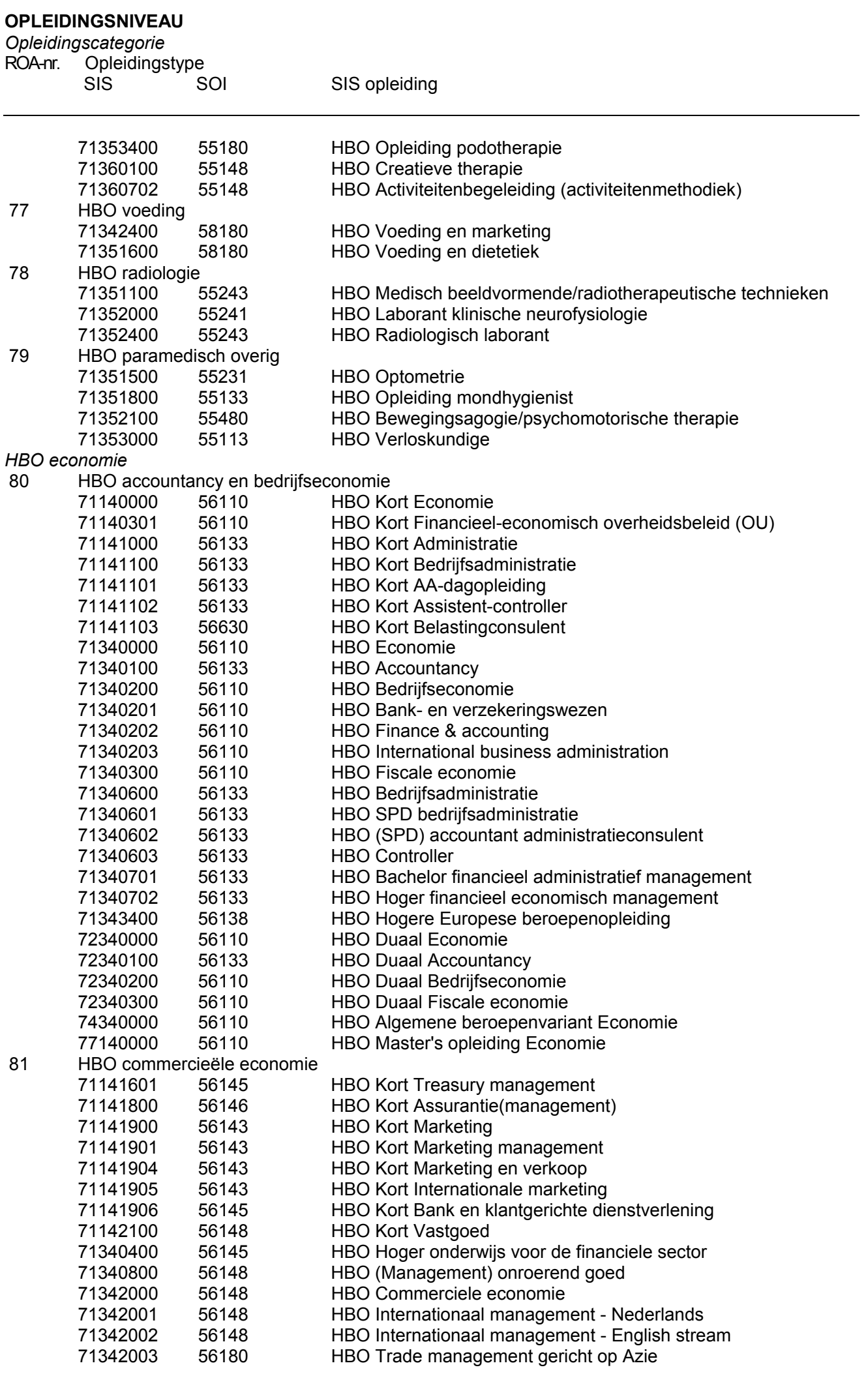




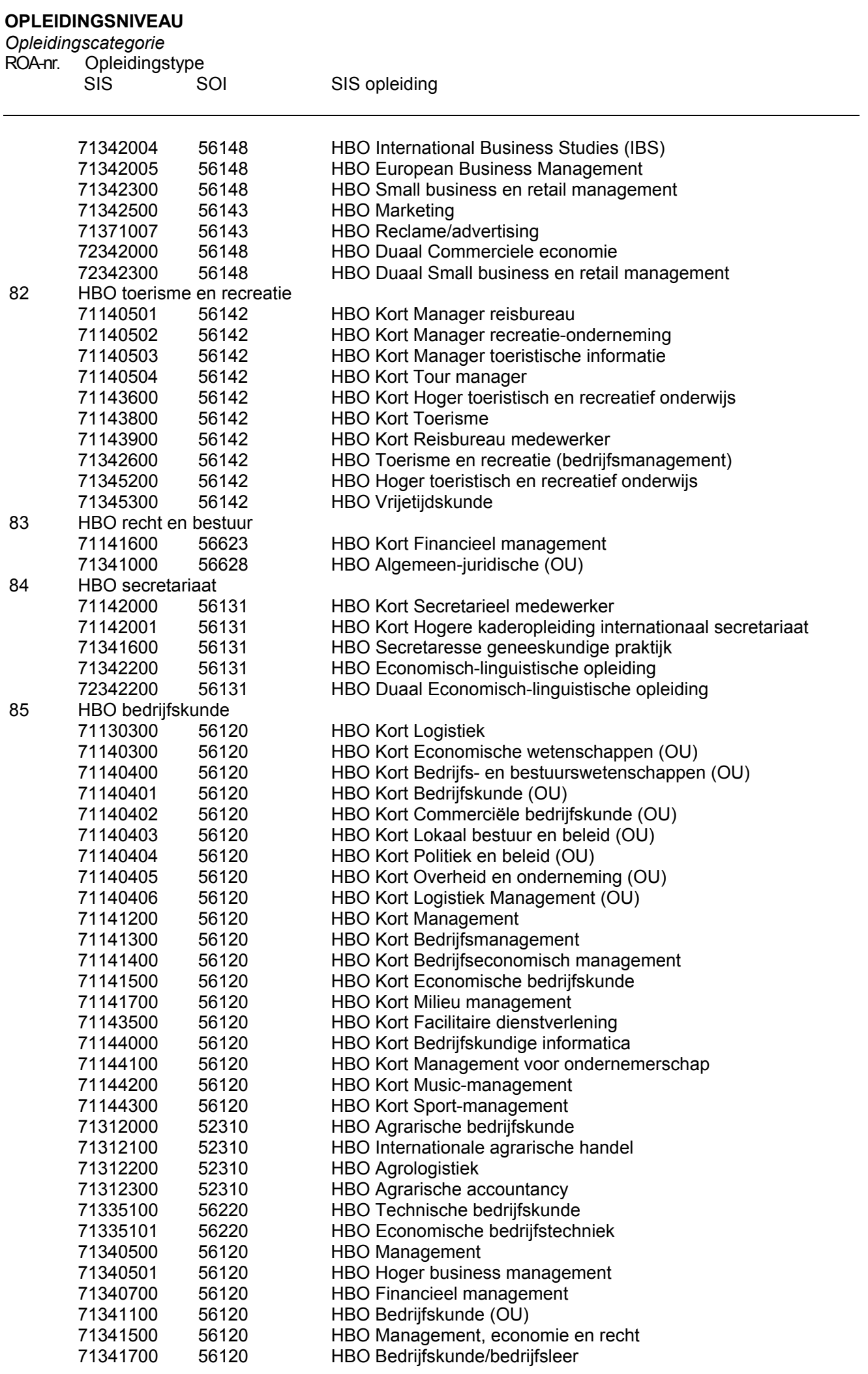




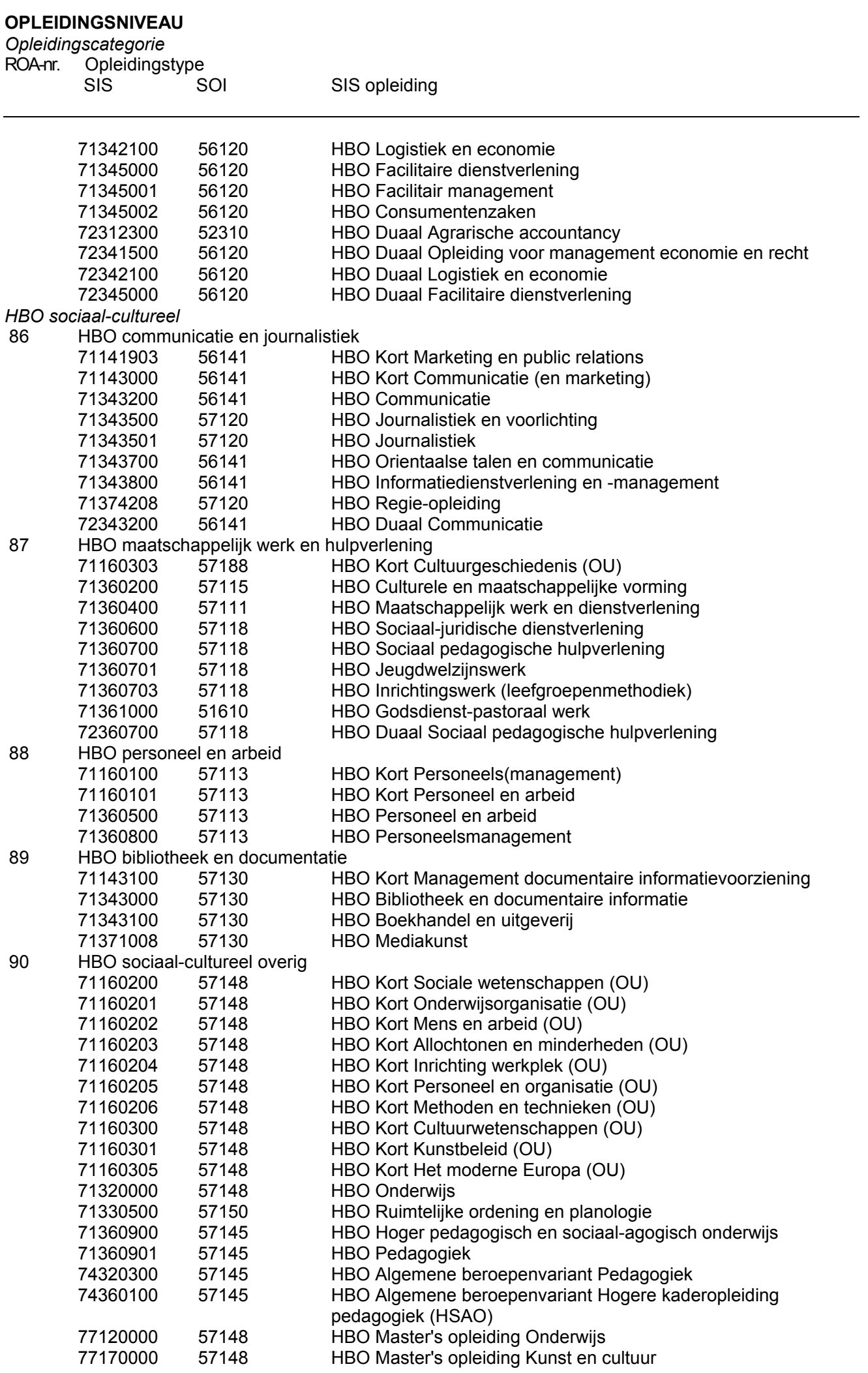




\begin{tabular}{|c|c|c|}
\hline \multicolumn{3}{|c|}{$\begin{array}{l}\text { OPLEIDINGSNIVEAU } \\
\text { Opleidingscategorie } \\
\text { ROA-nr. Opleidingstype }\end{array}$} \\
\hline \multicolumn{3}{|l|}{ HBO kunst } \\
\hline \multicolumn{3}{|c|}{ HBO uitvoerende en beeldende kunsten } \\
\hline 71335300 & 58610 & HBO Mode-, textielvormgeving en styling \\
\hline 71370000 & 58680 & HBO Kunst en cultuur \\
\hline 71370100 & 58610 & HBO Algemene industriele vormgeving \\
\hline 71370200 & 58610 & $\mathrm{HBO}$ Architectonische vormgeving \\
\hline 71370201 & 58610 & HBO Theatervormgeving \\
\hline 71370202 & 58610 & HBO 3D-design \\
\hline 71370203 & 58610 & HBO Binnenhuis \\
\hline 71370204 & 58610 & HBO Stedebouwkunde \\
\hline 71370300 & 58610 & HBO Film- en t.v.-vormgeving \\
\hline 71370301 & 58610 & HBO Film- en t.v.-vormgeving A.V. \\
\hline 71370302 & 58610 & HBO Film- en t.v.-vormgeving Camera \\
\hline 71370303 & 58610 & HBO Film- en t.v.-vormgeving Programmamaker \\
\hline 71370304 & 58610 & HBO Film- en t.v.-vormgeving Fictie \\
\hline 71370305 & 58610 & HBO Film- en t.v.-vormgeving Documentaire \\
\hline 71370306 & 58610 & HBO Film- en t.v.-vormgeving Geluid \\
\hline 71370307 & 58610 & HBO Film- en t.v.-vormgeving Montage \\
\hline 71370308 & 58610 & HBO Film- en t.v.-vormgeving Produktie \\
\hline 71370309 & 58610 & HBO Film- en t.v.-vormgeving Docentenopleiding \\
\hline 71370310 & 58610 & HBO Film- en t.v.-vormgeving Scenario \\
\hline 71370311 & 58610 & HBO Film- en t.v.-vormgeving Regie \\
\hline 71370400 & 58610 & HBO Fotografische vormgeving \\
\hline 71370500 & 58610 & HBO Keramische vormgeving \\
\hline 71370600 & 58610 & HBO Modevormgeving \\
\hline 71370700 & 58610 & HBO Monumentale vormgeving \\
\hline 71370800 & 58610 & HBO Museologie \\
\hline 71370801 & 58610 & HBO Beheer \& behoud \\
\hline 71370802 & 58610 & HBO Museumcommunicatie \\
\hline 71370803 & 58610 & HBO Culturele bedrijfsvoering \\
\hline 71370900 & 58610 & HBO Plastische vormgeving \\
\hline 71371000 & 58610 & HBO Publiciteits- c.q. grafische vormgeving \\
\hline 71371001 & 58610 & HBO Audiovisuele media \\
\hline 71371003 & 58610 & HBO Audiovisuele vormgeving \\
\hline 71371004 & 58610 & HBO Illustratieve vormgeving \\
\hline 71371005 & 58610 & HBO Visuele communicatie \\
\hline 71371006 & 58610 & HBO Gemengde media \\
\hline 71371100 & 58610 & $\begin{array}{l}\text { HBO Schilderkundige vormgev. en vormgev. op gebied vd } \\
\text { grafiek }\end{array}$ \\
\hline 71371200 & 58610 & HBO Textiele vormgeving \\
\hline 71371300 & 58610 & HBO Vormgeving in metalen en kunststoffen \\
\hline 71371400 & 58610 & HBO Beeldende kunst en vormgeving - vrij \\
\hline 71371401 & 58610 & HBO Beeldende kunst en vormgeving - autonoom \\
\hline 71372000 & 58630 & HBO Compositie of compositie/elektronische muziek \\
\hline 71372001 & 58630 & $\begin{array}{l}\text { HBO Compositie of compositie/elektronische muziek Hilversums } \\
\text { conservatorium }(\mathrm{HC})\end{array}$ \\
\hline 71372002 & 58630 & HBO Compositie of compositie/elektronische muziek - klassiek \\
\hline 71372003 & 58630 & HBO Compositie of compositie/elektronische muziek - licht \\
\hline 71372004 & 58630 & HBO Muziektechnologie / Electronische muziek \\
\hline 71372100 & 58630 & HBO Directie koor, orkest of harmonie en fanfare \\
\hline 71372300 & 58630 & HBO Muziek-dramatische opleiding \\
\hline 71372400 & 58680 & HBO Muziekregistratie \\
\hline 71372401 & 58640 & HBO Sonologie \\
\hline 71372402 & 58680 & HBO Beeld \& geluid \\
\hline 71372600 & 58630 & HBO Uitvoerend musicus \\
\hline 71372601 & 58630 & HBO Uitvoerend musicus Klassiek \\
\hline 71372602 & 58630 & HBO Uitvoerend musicus Licht \\
\hline 71372603 & 58630 & HBO Uitvoerend musicus Barok \\
\hline 71372604 & 58630 & HBO Uitvoerend musicus Wereldmuziek \\
\hline
\end{tabular}




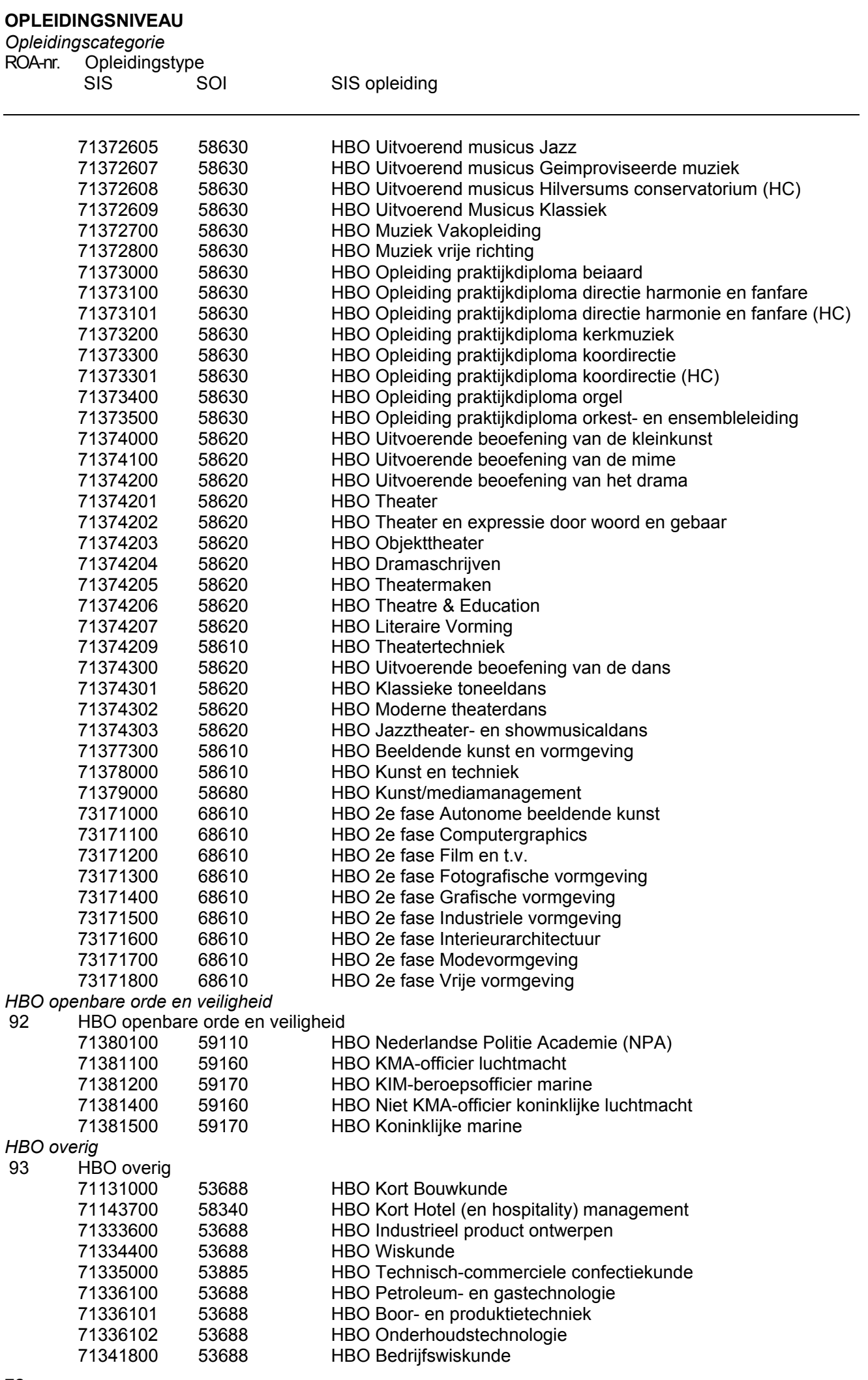




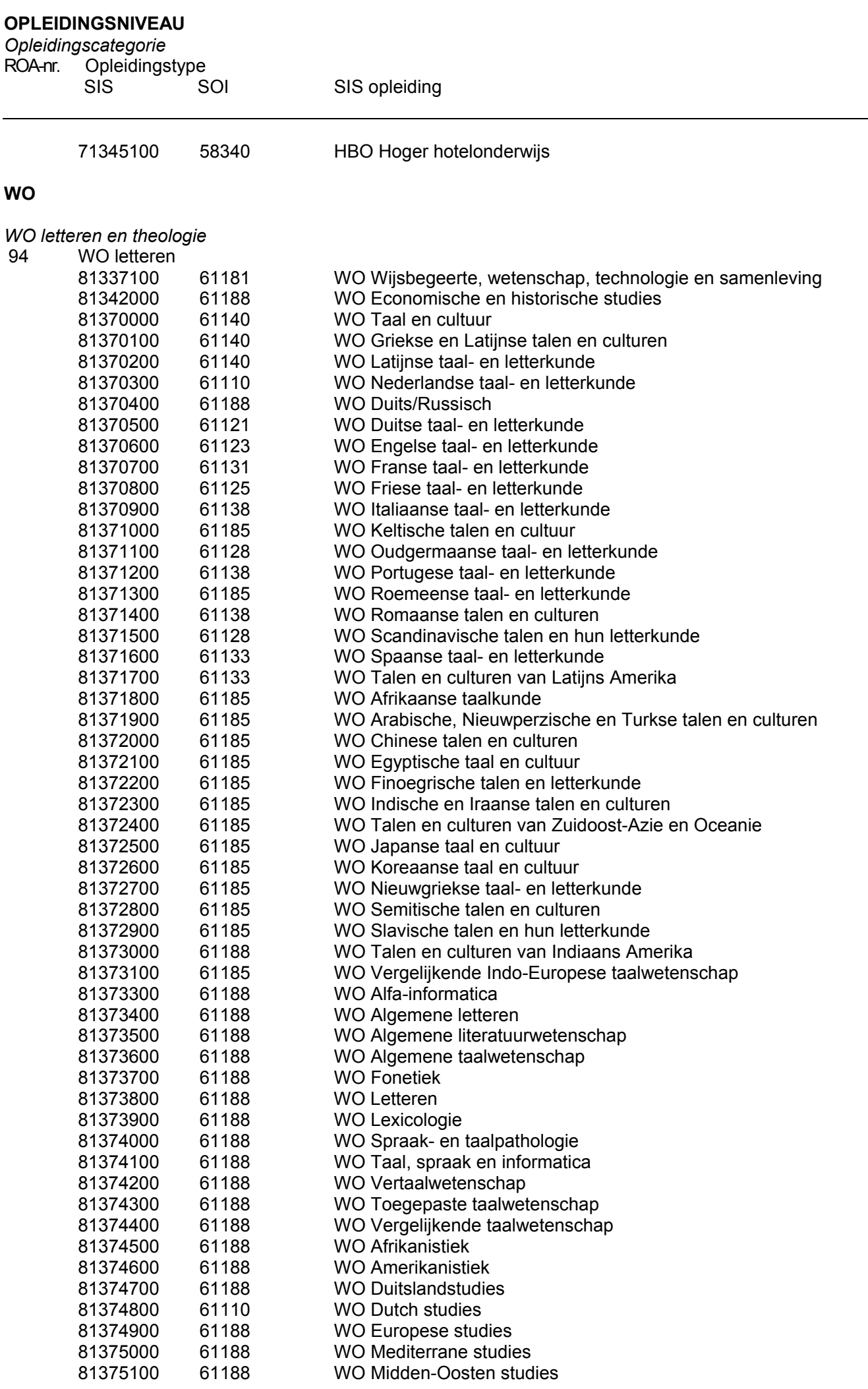




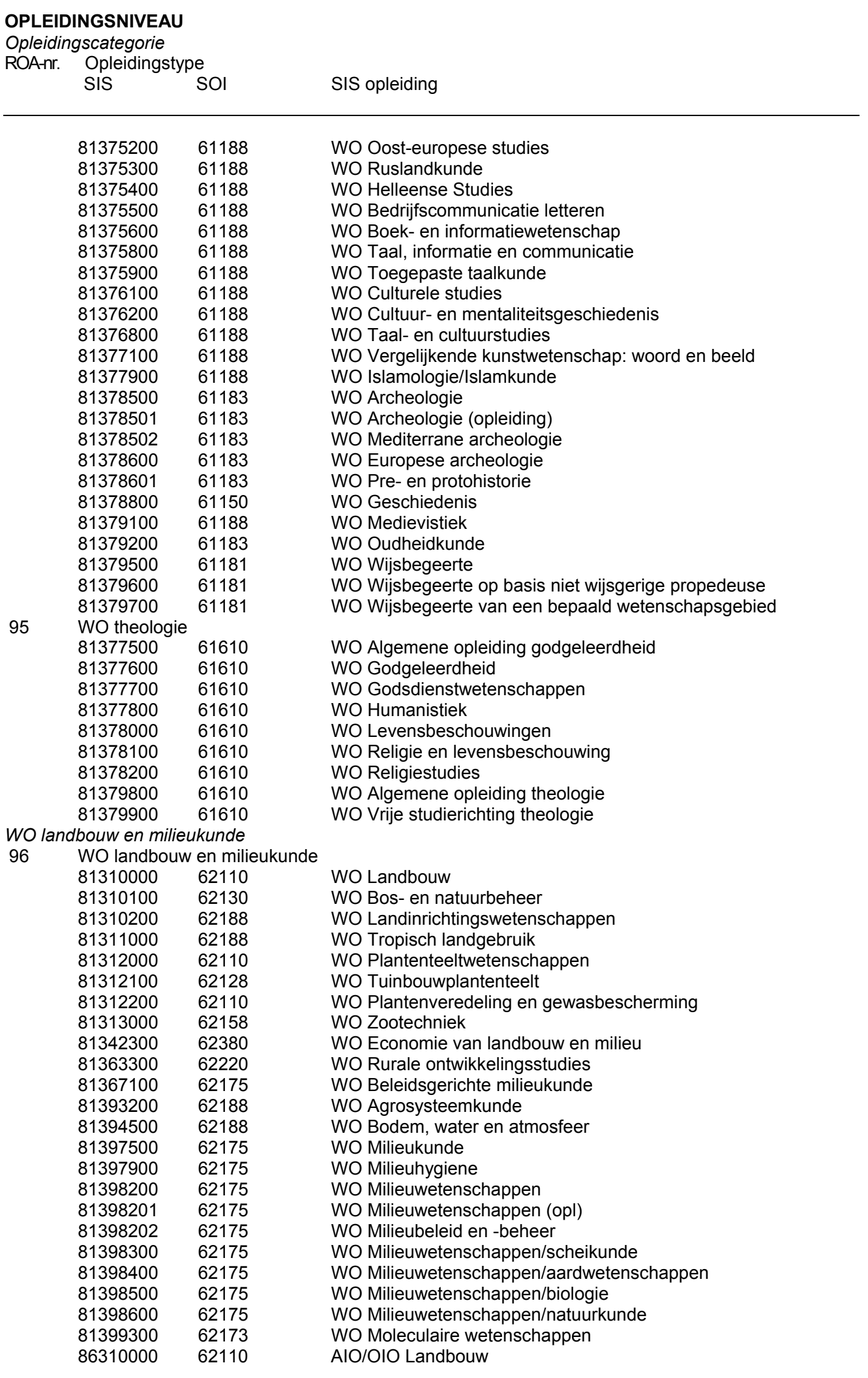




\begin{tabular}{|c|c|c|}
\hline \multicolumn{3}{|c|}{$\begin{array}{l}\text { OPLEIDINGSNIVEAU } \\
\text { Opleidingscategorie } \\
\text { ROA-nr. Opleidingstype }\end{array}$} \\
\hline \multicolumn{3}{|l|}{ WO techniek } \\
\hline $97 \quad$ WO wiskun & en natu & schappen \\
\hline 81330100 & 63688 & WO Technische aardwetenschappen \\
\hline 81330101 & 63688 & WO Grondstoffentechnologie \\
\hline 81330102 & 63688 & WO Petroleumwinning \\
\hline 81330103 & 63688 & WO Technische geofysica \\
\hline 81330104 & 63688 & WO Ingenieursgeologie \\
\hline 81330200 & 63688 & WO Milieutechnologie \\
\hline 81330300 & 63160 & WO Bioprocestechnologie \\
\hline 81330400 & 63675 & WO Scheikundige technologie en bioprocestechnologie \\
\hline 81330401 & 63675 & WO Anorganische chemie en thermodynamica \\
\hline 81330402 & 63675 & WO Organische chemie en katalyse \\
\hline 81330403 & 63675 & WO Technologie van macromoleculaire stoffen \\
\hline 81330404 & 63675 & WO Chemische procestechnologie \\
\hline 81330405 & 63675 & WO Bioprocestechnologie \\
\hline 81330406 & 63675 & WO Microbiologie en enzymologie \\
\hline 81330500 & 63677 & WO Levensmiddelentechnologie \\
\hline 81330600 & 63682 & WO Technische mechanica \\
\hline 81330700 & 63682 & WO Technische natuurkunde \\
\hline 81330701 & 63682 & WO Akoestiek \\
\hline 81330702 & 63682 & WO Deeltjesoptica \\
\hline 81330703 & 63682 & WO Fysische informatica \\
\hline 81330704 & 63682 & WO Optica \\
\hline 81330705 & 63682 & WO Spectroscopie en stralingstechnologie \\
\hline 81330706 & 63682 & WO Theoretische natuurkunde \\
\hline 81330707 & 63682 & WO Technische natuurkunde Transportverschijnselen \\
\hline 81330708 & 63682 & WO Technische natuurkunde Vaste stof \\
\hline 81330709 & 63682 & WO Bedrijfskundige aspecten \\
\hline 81330800 & 63675 & WO Technische scheikunde \\
\hline 81330900 & 63683 & WO Technische wiskunde \\
\hline 81330901 & 63683 & WO Algemene wiskunde \\
\hline 81330902 & 63683 & WO Statistiek, stochastiek en operationele research \\
\hline 81330903 & 63683 & WO Toegepaste analyse \\
\hline 81334200 & 63688 & WO Civiele technologie en management \\
\hline 81334400 & 63688 & WO Installatietechniek \\
\hline 81335000 & 63688 & WO Industrieel ontwerpen \\
\hline 81335001 & 63688 & WO Bedrijfskunde van de produktontwikkeling \\
\hline 81335002 & 63688 & WO Konstruktie \\
\hline 81335003 & 63688 & WO Produkt- en systeemergonomie \\
\hline 81335004 & 63688 & WO Vormgeving \\
\hline 81335400 & 63631 & WO Materiaalkunde \\
\hline 81335401 & 63631 & WO Produktie van materialen \\
\hline 81335402 & 63631 & WO Toepassing en eigenschappen van materialen \\
\hline 81335403 & 63631 & WO Materiaalwetenschappen \\
\hline 81336100 & 63688 & WO Technische bestuurskunde \\
\hline 81336101 & 63688 & WO Transport, infrastructuur en logistiek \\
\hline 81336102 & 63688 & WO Milieumanagement \\
\hline 81336103 & 63688 & WO Informatie- en communicatietechnologie \\
\hline 81390100 & 63110 & WO Bedrijfs- en industriele statistiek \\
\hline 81390200 & 63110 & WO Statistiek \\
\hline 81390300 & 63110 & WO Wiskunde \\
\hline 81391500 & 63683 & WO Computational science \\
\hline 81391700 & 63688 & WO Kennistechnologie \\
\hline 81391701 & 63688 & WO Modelontwerper \\
\hline 81391702 & 63688 & WO Besliskundige kennistechnoloog \\
\hline 81391703 & 63688 & WO Kennissysteemontwerper \\
\hline 81393000 & 63120 & WO Natuurkunde \\
\hline 81393100 & 63130 & WO Sterrrenkunde \\
\hline
\end{tabular}




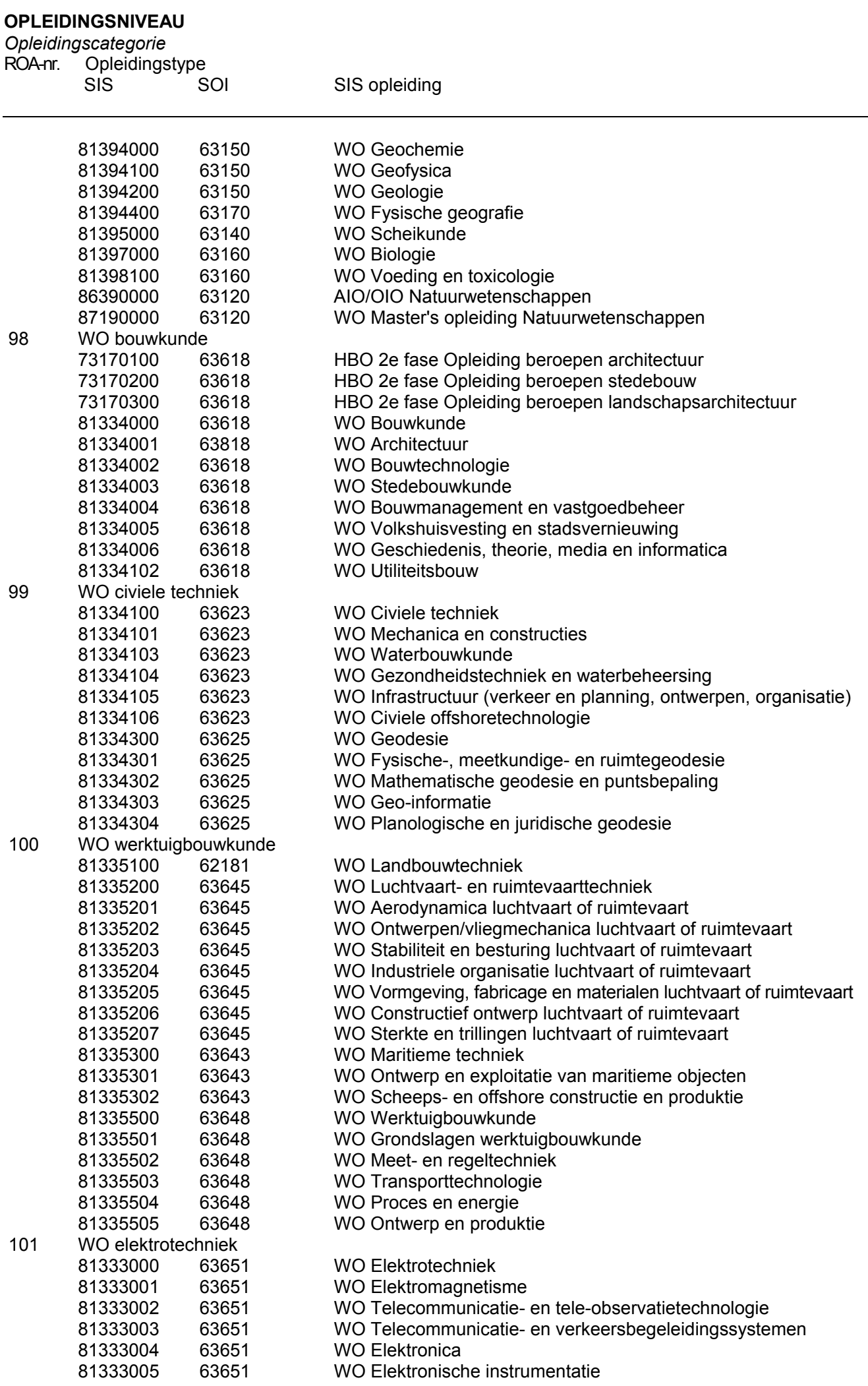




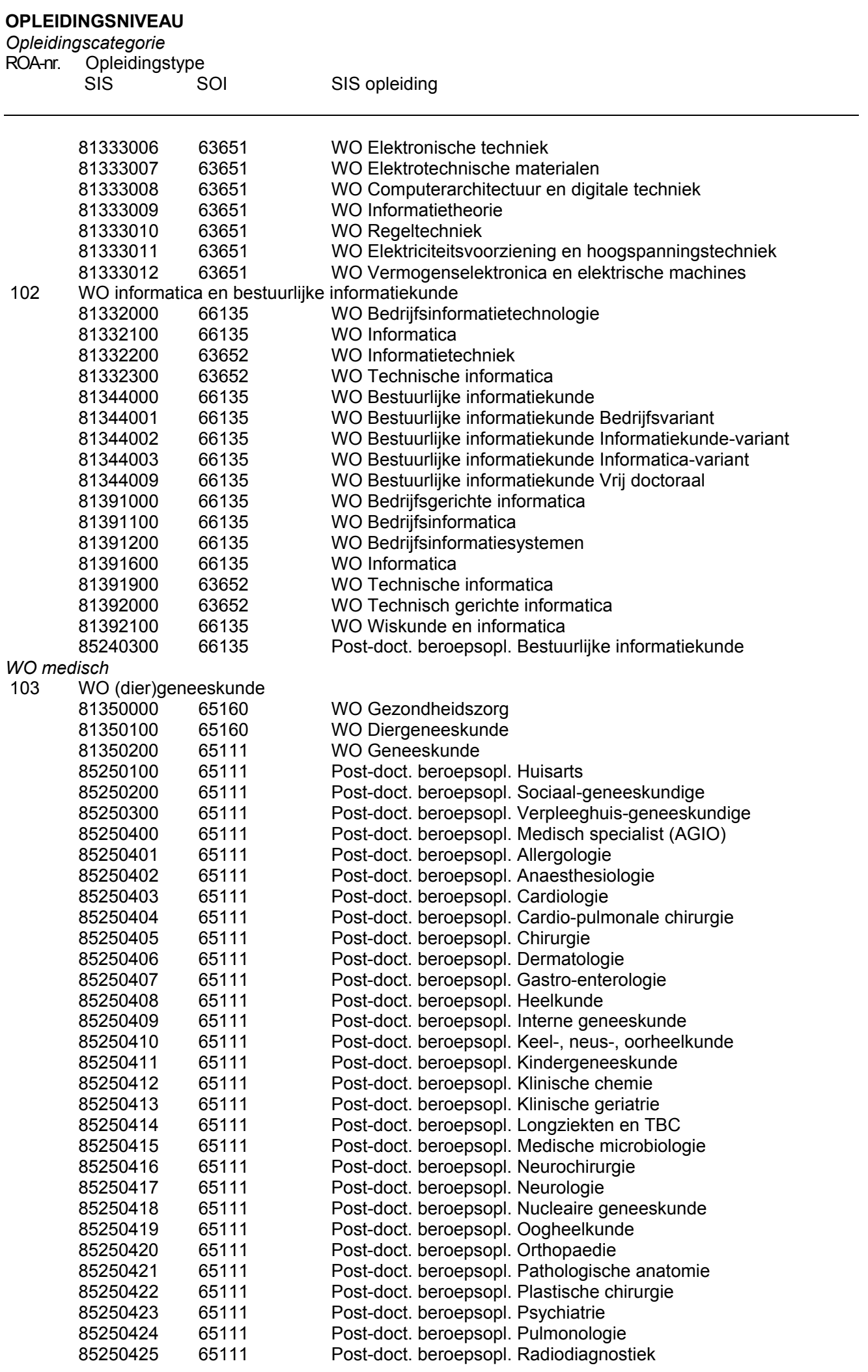




\begin{tabular}{|c|c|c|c|}
\hline \multicolumn{4}{|c|}{$\begin{array}{l}\text { OPLEIDINGSNIVEAU } \\
\text { Opleidingscategorie } \\
\text { ROA-nr. Opleidingstype }\end{array}$} \\
\hline & $\begin{array}{l}85250426 \\
85250427 \\
85250428 \\
85250429 \\
85250430 \\
85250431 \\
85252300\end{array}$ & $\begin{array}{l}65111 \\
65111 \\
65111 \\
65111 \\
65111 \\
65111 \\
65111\end{array}$ & $\begin{array}{l}\text { Post-doct. beroepsopl. Radiotherapie } \\
\text { Post-doct. beroepsopl. Reumatologie } \\
\text { Post-doct. beroepsopl. Revalidatie } \\
\text { Post-doct. beroepsopl. Sportgeneeskunde } \\
\text { Post-doct. beroepsopl. Urologie } \\
\text { Post-doct. beroepsopl. Verloskunde \& gynaecologie } \\
\text { Post-doct. Beroepsopl. Gezondheidszorgpsycholoog }\end{array}$ \\
\hline 104 & $\begin{array}{l}\text { WO tandhe } \\
81350300\end{array}$ & $\begin{array}{l}\text { Ikunde } \\
65131\end{array}$ & WO Tandheelkunde \\
\hline 105 & $\begin{array}{l}\text { WO farmac } \\
81331000 \\
81352500 \\
81352501 \\
81352502 \\
81352600 \\
81352700 \\
81396000 \\
81396100 \\
81396200 \\
81396300 \\
85250000\end{array}$ & $\begin{array}{c}\text { en medi } \\
65280 \\
65280 \\
65280 \\
65280 \\
65280 \\
65280 \\
65220 \\
65220 \\
65220 \\
65220 \\
65280\end{array}$ & $\begin{array}{l}\text { logie } \\
\text { WO Biomedische technologie } \\
\text { WO Medische biologie } \\
\text { WO Medische biologie (natuurwetenschappen) } \\
\text { WO Medische biologie (gezondheidszorg) } \\
\text { WO Medische informatiekunde } \\
\text { WO Medische wetenschappen } \\
\text { WO Biofarmaceutische wetenschappen } \\
\text { WO Farmacie } \\
\text { WO Farmacochemie } \\
\text { WO Technische farmacie } \\
\text { Post-doct. beroepsopl. Gezondheidszorg }\end{array}$ \\
\hline $\begin{array}{l}\text { WO eco } \\
106\end{array}$ & $\begin{array}{l}\text { nomie } \\
\text { WO econo }\end{array}$ & (etr)ie & \\
\hline & $\begin{array}{l}81340000 \\
81340100 \\
81340110 \\
81340111 \\
81340112 \\
81340113 \\
81340114 \\
81340115 \\
81340116 \\
81340117\end{array}$ & $\begin{array}{l}66110 \\
66110 \\
66110 \\
66110 \\
66110 \\
66110 \\
66110 \\
66110 \\
66110 \\
66110\end{array}$ & $\begin{array}{l}\text { WO Economie } \\
\text { WO Economie } \\
\text { WO Algemene economie } \\
\text { WO Alg. economie Macro economie } \\
\text { WO Alg. economie Geld-, krediet en bankwezen } \\
\text { WO Alg. economie Openbare financieen } \\
\text { WO Alg. economie Internationale economisch betrekkingen } \\
\text { WO Alg. economie Economie vd ontwikkelingslanden } \\
\text { WO Alg. economie Politieke economie en mij. orde } \\
\text { WO Alg. economie Regionale economie en economische } \\
\text { geografie }\end{array}$ \\
\hline & 81340118 & 66110 & WO Alg. economie Ruimtelijke economie \\
\hline & 81340119 & 66110 & WO Alg. economie Sociologische economie \\
\hline & $\begin{array}{l}81340120 \\
81340121\end{array}$ & $\begin{array}{l}66110 \\
66110\end{array}$ & $\begin{array}{l}\text { WO Alg. economie Verkeer- en vervoerseconomie } \\
\text { WO Alg. economie Europese integratie }\end{array}$ \\
\hline & 81340122 & 66110 & WO Alg. economie Staatkundige economie \\
\hline & 81340129 & 66110 & WO Alg. economie Vrij doctoraal \\
\hline & 81340130 & 66110 & WO Bedrijfseconomie \\
\hline & 81340131 & 66110 & WO Bedrijfseconomie Kosten, waarde, winst \\
\hline & 81340132 & 66110 & WO Bedrijfseconomie Ondernemingsfinanciering \\
\hline & 81340133 & 66110 & WO Bedrijfseconomie Organisatie vd onderneming \\
\hline & 81340134 & 66110 & WO Bedrijfseconomie Marketing \\
\hline & 81340135 & 66110 & WO Bedrijfseconomie Informatica \\
\hline & 81340136 & 66110 & WO Bedrijfseconomie Agrarische economie \\
\hline & 81340137 & 66110 & $\begin{array}{l}\text { WO Bedrijfseconomie Econ. v. kleine\&middelgrote } \\
\text { ondernemingen }\end{array}$ \\
\hline & 81340138 & 66110 & WO Bedrijfseconomie Berichtgeving \\
\hline & 81340139 & 66110 & WO Bedrijfseconomie Accountancy \\
\hline & 81340140 & 66110 & WO Bedrijfseconomie Financiering en belegging \\
\hline & 81340141 & 66110 & WO Bedrijfseconomie Organisatie \\
\hline & 81340142 & 66110 & WO Bedrijfseconomie Bestuurlijke informatiekunde \\
\hline & 81340143 & 66110 & WO Bedrijfseconomie Bedrijfskundige economie \\
\hline & 81340144 & 66110 & WO Bedrijfseconomie Ruimtelijke bedrijfseconomie \\
\hline & 81340145 & 66110 & WO Bedrijfseconomie Financiele bedrijfseconomie \\
\hline & 81340146 & 66110 & WO Bedrijfseconomie Verzekeringseconomie \\
\hline & 81340147 & 66110 & WO Bedrijfseconomie Kwantitatief \\
\hline
\end{tabular}




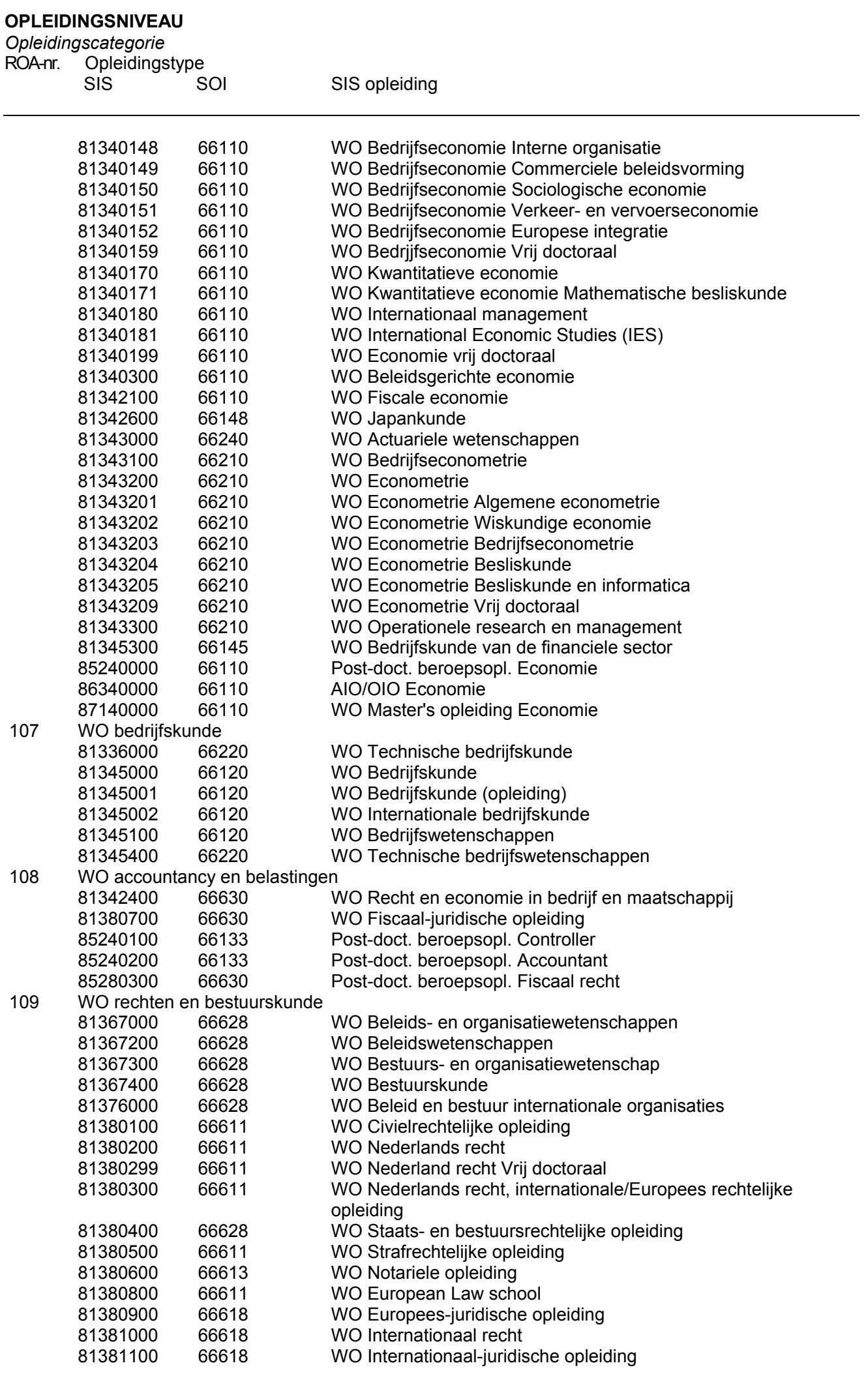




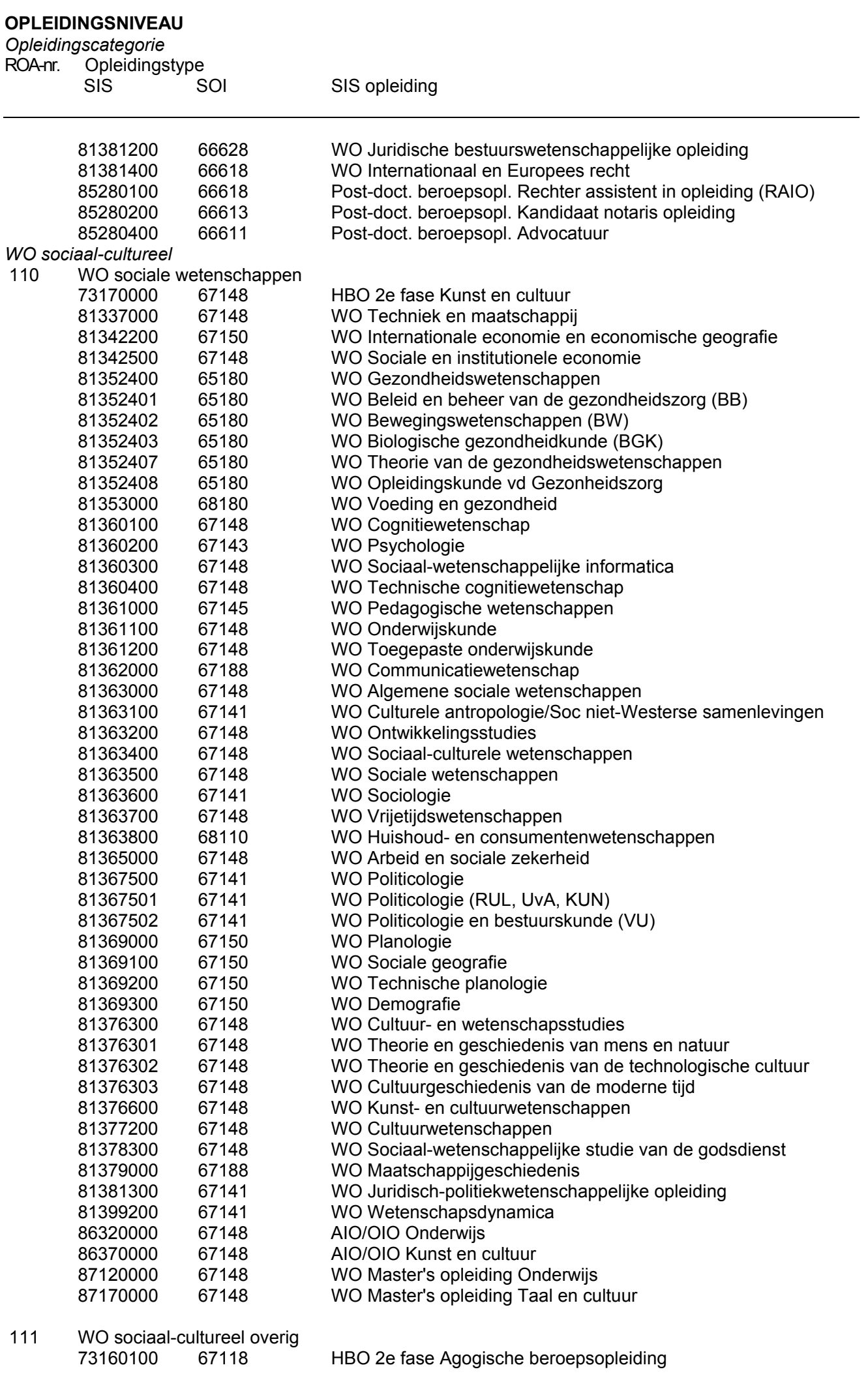


3. Opleidingen per opleidingstype (vervolg)

\begin{tabular}{|c|c|c|c|}
\hline \multicolumn{4}{|c|}{$\begin{array}{l}\text { OPLEIDINGSNIVEAU } \\
\text { Opleidingscategorie }\end{array}$} \\
\hline & 73160200 & 67118 & HBO 2e fase Kaderopleiding opbouwwerk \\
\hline & 81365100 & 67113 & WO Personeelwetenschappen \\
\hline \multicolumn{4}{|c|}{ WO kunst } \\
\hline \multirow[t]{8}{*}{112} & \multicolumn{3}{|c|}{ WO kunstwetenschappen } \\
\hline & 81376400 & 68640 & WO Film- en opvoeringskunsten \\
\hline & 81376500 & 68640 & WO Film- en televisiewetenschappen \\
\hline & 81376700 & 68640 & WO Muziekwetenschap \\
\hline & 81376900 & 68640 & WO Theater-, film- en televisiewetenschappen \\
\hline & 81376901 & 68640 & WO Theater-, film- en televisiewetenschap (UU) \\
\hline & 81376902 & 68640 & WO Theaterwetenschap (UvA) \\
\hline & 81378900 & 68640 & WO Kunstgeschiedenis en archeologie \\
\hline \multicolumn{4}{|c|}{ WO overig } \\
\hline \multirow[t]{9}{*}{113} & WO overig & & \\
\hline & 81352000 & 65380 & WO Beleid en management gezondheidszorg \\
\hline & 81352100 & 65480 & WO Bewegingswetenschappen \\
\hline & 81352200 & 65480 & WO Biomedische gezondheidswetenschappen \\
\hline & 81352300 & 65480 & WO Biomedische wetenschappen \\
\hline & 81352404 & 65480 & WO Geestelijke gezondheidkunde (GGK) \\
\hline & 81352405 & 65480 & WO Gezondheidsvoorlichting (GVO) \\
\hline & 81352406 & 65480 & WO Verplegingswetenschap (VW) \\
\hline & 81352800 & 65380 & WO Milieugezondheidkunde \\
\hline
\end{tabular}





\title{
4. Opleidingstype per opleiding
}

Onderwijstype
SIS SOI ROA-nr. Opleidingstype

\section{Basisonderwijs/Speciaal onderwijs}

$\begin{array}{lll}11300100 & 20112 & 1 \\ 11300201 & 20121 & 1 \\ 11300202 & 20123\end{array}$

\author{
Basisonderwijs
}

IVBO

$\begin{array}{ll}21300000 & 30121 \\ 21300101 & 30121 \\ 21300102 & 30123 \\ 21310000 & 32110 \\ 21310100 & 33677 \\ 21310200 & 32188 \\ 21330100 & 33618 \\ 21330101 & 33611 \\ 21330102 & 33614 \\ 21330103 & 33623 \\ 21330104 & 33615 \\ 21330105 & 33614 \\ 21330106 & 33611 \\ 21330107 & 33685 \\ 21330108 & 33614 \\ 21330109 & 33671 \\ 21330200 & 33638 \\ 21330201 & 33635 \\ 21330300 & 33677 \\ 21330301 & 33676 \\ 21330302 & 33676 \\ 21330303 & 38140 \\ 21330304 & 33677 \\ 21330305 & 34430 \\ 21330400 & 33651 \\ 21340000 & 36110 \\ 21340100 & 36138 \\ 21340200 & 36150 \\ 21350000 & 38100 \\ 21350100 & 38180 \\ 21350200 & 38130 \\ 21350300 & 33685 \\ 21350400 & 37188 \\ 21350500 & 33688\end{array}$

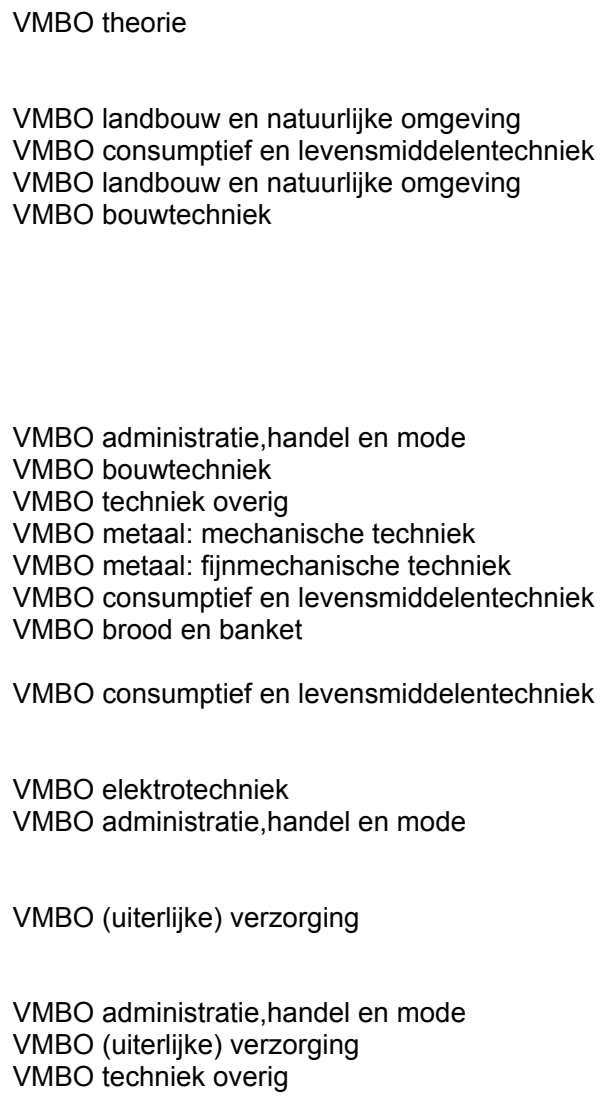

VBO, MAVO, VAVO-MAVO

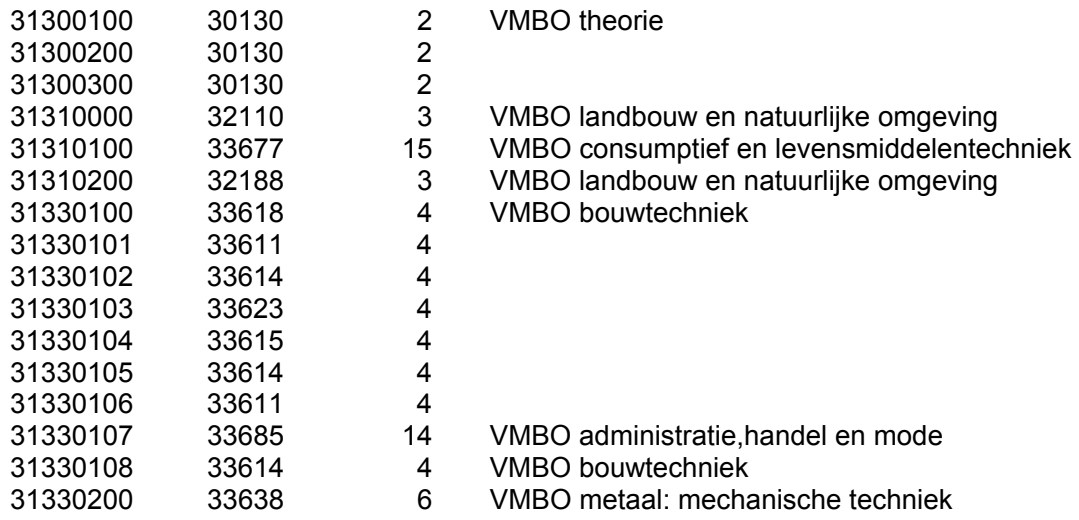


4. Opleidingstype per opleiding (vervolg)

\begin{tabular}{|c|c|c|c|}
\hline \multicolumn{4}{|c|}{ Onderwijstype } \\
\hline 31330201 & 33635 & 7 & VMBO metaal: fijnmechanische techniek \\
\hline 31330202 & 33678 & 13 & VMBO techniek overig \\
\hline 31330203 & 33643 & 13 & \\
\hline 31330204 & 33633 & 6 & VMBO metaal: mechanische techniek \\
\hline 31330205 & 33635 & 7 & VMBO metaal: fijnmechanische techniek \\
\hline 31330206 & 33635 & 7 & \\
\hline 31330207 & 33635 & 7 & \\
\hline 31330208 & 33655 & 9 & VMBO elektrotechniek \\
\hline 31330300 & 33651 & 9 & \\
\hline 31330400 & 33616 & 5 & VMBO installatietechniek \\
\hline 31330500 & 33641 & 8 & VMBO voertuigentechniek \\
\hline 31330501 & 33647 & 13 & VMBO techniek overig \\
\hline 31330502 & 33641 & 8 & VMBO voertuigentechniek \\
\hline 31330600 & 33677 & 15 & VMBO consumptief en levensmiddelentechniek \\
\hline 31330601 & 33676 & 11 & VMBO brood en banket \\
\hline 31330602 & 33676 & 11 & \\
\hline 31330603 & 38140 & 15 & VMBO consumptief en levensmiddelentechniek \\
\hline 31330604 & 33677 & 15 & \\
\hline 31330700 & 33688 & 13 & VMBO techniek overig \\
\hline 31330701 & 33665 & 10 & VMBO grafische techniek \\
\hline 31330702 & 33665 & 10 & \\
\hline 31330703 & 33663 & 10 & \\
\hline 31330801 & 34133 & 12 & VMBO transport en logistiek \\
\hline 31330802 & 34133 & 12 & \\
\hline 31330803 & 34133 & 12 & \\
\hline 31330804 & 34231 & 12 & \\
\hline 31330805 & 33623 & 4 & VMBO bouwtechniek \\
\hline 31330806 & 34131 & 12 & VMBO transport en logistiek \\
\hline 31330807 & 34150 & 12 & \\
\hline 31330808 & 34350 & 12 & \\
\hline 31330809 & 34231 & 12 & \\
\hline 31340000 & 36110 & 14 & VMBO administratie, handel en mode \\
\hline 31340100 & 36138 & 14 & \\
\hline 31340200 & 36150 & 14 & \\
\hline 31340300 & 36150 & 14 & \\
\hline 31350000 & 38100 & 16 & VMBO (uiterlijke) verzorging \\
\hline 31350100 & 38180 & 16 & \\
\hline 31350200 & 38130 & 16 & \\
\hline 31350300 & 33685 & 14 & VMBO administratie, handel en mode \\
\hline 31350301 & 33685 & 14 & \\
\hline 31350302 & 33685 & 14 & \\
\hline 38300100 & 30130 & 2 & VMBO theorie \\
\hline
\end{tabular}

HAVO, HAVO-MBO, VHBO, VAVO-HAVO

$\begin{array}{llll}41300000 & 40100 & 19 & \text { HAVO/NWO } \\ 41300100 & 40150 & 19 & \\ 41300200 & 40158 & 19 & \\ 41300300 & 40180 & 19 & \\ 48300100 & 40150 & 19 & \end{array}$

\section{VWO, VAVO-VWo}

\begin{tabular}{llll}
51300000 & 40100 & 19 & HAVO/NWO \\
51300100 & 40160 & 19 & \\
51300200 & 40170 & 19 & \\
58300000 & 40100 & 19 & \\
& & & \\
MBO & & & \\
61110000 & 32110 & 3 & VMBO landbouw en natuurlijke omgeving \\
61110100 & 32110 & 3 & \\
\hline 4 & & &
\end{tabular}


4. Opleidingstype per opleiding (vervolg)

\begin{tabular}{|c|c|c|c|}
\hline \multicolumn{3}{|c|}{ Onderwijstype } & Opleidingstype \\
\hline 61110300 & 33677 & 35 & MBO levensmiddelentechniek/vleesverwerking \\
\hline 61130200 & 33611 & 23 & MBO bouw \\
\hline 61130201 & 33611 & 23 & \\
\hline 61130202 & 36150 & 14 & VMBO administratie, handel en mode \\
\hline 61130203 & 33611 & 23 & MBO bouw \\
\hline 61130204 & 33611 & 23 & \\
\hline 61130205 & 33611 & 23 & \\
\hline 61132000 & 33633 & 6 & VMBO metaal: mechanische techniek \\
\hline 61132001 & 33633 & 6 & \\
\hline 61132002 & 33633 & 6 & \\
\hline 61132700 & 33633 & 6 & \\
\hline 61132701 & 33633 & 6 & \\
\hline 61132900 & 33638 & 6 & \\
\hline 61132901 & 33638 & 6 & \\
\hline 61133100 & 33638 & 6 & \\
\hline 61133101 & 33638 & 6 & \\
\hline 61134200 & 33641 & 8 & VMBO voertuigentechniek \\
\hline 61134201 & 33641 & 8 & \\
\hline 61134500 & 33651 & 9 & VMBO elektrotechniek \\
\hline 61134501 & 33651 & 9 & \\
\hline 61134502 & 33651 & 9 & \\
\hline 61134503 & 33651 & 9 & \\
\hline 61134600 & 33651 & 9 & \\
\hline 61134601 & 33651 & 9 & \\
\hline 61134602 & 33651 & 9 & \\
\hline 61135000 & 33616 & 25 & MBO installatietechniek \\
\hline 61135001 & 33616 & 25 & \\
\hline 61135002 & 33616 & 25 & \\
\hline 61135100 & 33647 & 13 & VMBO techniek overig \\
\hline 61135101 & 33647 & 13 & \\
\hline 61135600 & 35230 & 41 & MBO gezondheidstechniek \\
\hline 61135601 & 35231 & 16 & VMBO (uiterlijke) verzorging \\
\hline 61136000 & 33668 & 10 & VMBO grafische techniek \\
\hline 61136001 & 33668 & 10 & \\
\hline 61136500 & 33685 & 14 & VMBO administratie, handel en mode \\
\hline 61136501 & 33685 & 14 & \\
\hline 61138000 & 34150 & 12 & VMBO transport en logistiek \\
\hline 61138001 & 34150 & 12 & \\
\hline 61139000 & 33676 & 11 & VMBO brood en banket \\
\hline 61139001 & 33676 & 11 & \\
\hline 61140000 & 36110 & 14 & VMBO administratie, handel en mode \\
\hline 61140300 & 39180 & 17 & VMBO beveiliging \\
\hline 61140301 & 39180 & 17 & \\
\hline 61140302 & 39180 & 17 & \\
\hline 61140700 & 36131 & 14 & VMBO administratie, handel en mode \\
\hline 61140701 & 36131 & 14 & \\
\hline 61140800 & 36150 & 14 & \\
\hline 61140801 & 36150 & 14 & \\
\hline 61140900 & 36138 & 14 & \\
\hline 61140901 & 36138 & 14 & \\
\hline 61141200 & 36138 & 14 & \\
\hline 61141201 & 36138 & 14 & \\
\hline 61142000 & 38140 & 45 & MBO horeca \\
\hline 61142001 & 38140 & 45 & \\
\hline 61210000 & 42110 & 20 & MBO landbouw en veeteelt \\
\hline 61210100 & 42110 & 20 & \\
\hline 61210101 & 42110 & 20 & \\
\hline 61210200 & 42158 & 20 & \\
\hline 61210300 & 43677 & 35 & MBO levensmiddelentechniek/vleesverwerking \\
\hline 61210400 & 42320 & 20 & MBO landbouw en veeteelt \\
\hline 61210500 & 42153 & 20 & \\
\hline 61210501 & 42158 & 20 & \\
\hline
\end{tabular}


4. Opleidingstype per opleiding (vervolg)

\begin{tabular}{|c|c|c|c|}
\hline \multicolumn{3}{|c|}{ Onderwijstype } & Opleidingstype \\
\hline 61210600 & 42110 & 20 & \\
\hline 61210700 & 42158 & 20 & \\
\hline 61210800 & 42183 & 21 & MBO milieu en groene ruimte \\
\hline 61230100 & 43618 & 23 & MBO bouw \\
\hline 61230101 & 43611 & 23 & \\
\hline 61230102 & 43614 & 23 & \\
\hline 61230200 & 43611 & 23 & \\
\hline 61230201 & 43811 & 23 & \\
\hline 61230202 & 43817 & 48 & MBO handel \\
\hline 61230203 & 43811 & 23 & MBO bouw \\
\hline 61230204 & 43685 & 48 & MBO handel \\
\hline 61230205 & 43611 & 23 & MBO bouw \\
\hline 61230206 & 43638 & 26 & MBO werktuigbouw en mechanische techniek \\
\hline 61230207 & 43611 & 23 & MBO bouw \\
\hline 61230208 & 43611 & 23 & \\
\hline 61230209 & 43611 & 23 & \\
\hline 61230210 & 43817 & 48 & MBO handel \\
\hline 61230211 & 43611 & 23 & MBO bouw \\
\hline 61230212 & 43685 & 48 & MBO handel \\
\hline 61231100 & 43815 & 23 & MBO bouw \\
\hline 61231101 & 43615 & 23 & \\
\hline 61231300 & 46143 & 48 & MBO handel \\
\hline 61231301 & 46143 & 48 & \\
\hline 61232000 & 43633 & 26 & MBO werktuigbouw en mechanische techniek \\
\hline 61232001 & 43633 & 26 & \\
\hline 61232900 & 43638 & 26 & \\
\hline 61232901 & 43638 & 26 & \\
\hline 61233000 & 43655 & 31 & MBO elektrotechniek \\
\hline 61233001 & 43651 & 31 & \\
\hline 61233002 & 43655 & 31 & \\
\hline 61233100 & 43638 & 26 & MBO werktuigbouw en mechanische techniek \\
\hline 61233101 & 43638 & 26 & \\
\hline 61233200 & 43646 & 30 & MBO operationele techniek \\
\hline 61233400 & 43645 & 29 & MBO vliegtuigtechniek \\
\hline 61233401 & 43645 & 29 & \\
\hline 61233402 & 43645 & 29 & \\
\hline 61234200 & 43641 & 28 & MBO motorvoertuigentechniek \\
\hline 61234201 & 43641 & 28 & \\
\hline 61234202 & 43641 & 28 & \\
\hline 61234500 & 43651 & 31 & MBO elektrotechniek \\
\hline 61234501 & 43653 & 31 & \\
\hline 61234502 & 43651 & 31 & \\
\hline 61234503 & 43645 & 29 & MBO vliegtuigtechniek \\
\hline 61234504 & 43651 & 31 & MBO elektrotechniek \\
\hline 61234505 & 43651 & 31 & \\
\hline 61234506 & 43653 & 31 & \\
\hline 61234507 & 43653 & 31 & \\
\hline 61234600 & 43651 & 31 & \\
\hline 61234601 & 43651 & 31 & \\
\hline 61234602 & 43651 & 31 & \\
\hline 61234603 & 43651 & 31 & \\
\hline 61234700 & 43652 & 31 & \\
\hline 61234701 & 43654 & 31 & \\
\hline 61234702 & 43654 & 31 & \\
\hline 61234800 & 43616 & 25 & MBO installatietechniek \\
\hline 61234801 & 43648 & 26 & MBO werktuigbouw en mechanische techniek \\
\hline 61234802 & 43616 & 25 & MBO installatietechniek \\
\hline 61234803 & 43616 & 25 & \\
\hline 61234804 & 43616 & 25 & \\
\hline 61235000 & 43616 & 25 & \\
\hline 61235001 & 43616 & 25 & \\
\hline 61235002 & 43616 & 25 & \\
\hline
\end{tabular}


4. Opleidingstype per opleiding (vervolg)

\begin{tabular}{|c|c|c|c|}
\hline \multicolumn{4}{|c|}{ Onderwijstype } \\
\hline 61235003 & 43616 & 25 & \\
\hline 61235004 & 43616 & 25 & \\
\hline 61235500 & 43635 & 27 & MBO fijnmechanische techniek \\
\hline 61235501 & 43835 & 27 & \\
\hline 61235502 & 43835 & 27 & \\
\hline 61235600 & 45230 & 41 & MBO gezondheidstechniek \\
\hline 61235601 & 45231 & 41 & \\
\hline 61235602 & 43835 & 27 & MBO fijnmechanische techniek \\
\hline 61236000 & 43868 & 32 & MBO grafische techniek \\
\hline 61236001 & 43665 & 32 & \\
\hline 61236002 & 43868 & 32 & \\
\hline 61236003 & 43665 & 32 & \\
\hline 61236004 & 48610 & 56 & MBO overig \\
\hline 61236005 & 43868 & 32 & MBO grafische techniek \\
\hline 61236500 & 43885 & 48 & MBO handel \\
\hline 61236501 & 43685 & 48 & \\
\hline 61236502 & 43685 & 48 & \\
\hline 61236503 & 43685 & 48 & \\
\hline 61237000 & 43663 & 32 & MBO grafische techniek \\
\hline 61237001 & 43663 & 32 & \\
\hline 61237100 & 43635 & 27 & MBO fijnmechanische techniek \\
\hline 61237101 & 43635 & 27 & \\
\hline 61237300 & 43678 & 33 & MBO procestechniek \\
\hline 61237301 & 43678 & 33 & \\
\hline 61238000 & 44350 & 36 & MBO vervoer en logistiek \\
\hline 61238001 & 44150 & 36 & \\
\hline 61238002 & 44350 & 36 & \\
\hline 61238200 & 44000 & 36 & \\
\hline 61238201 & 43623 & 24 & MBO grond-, weg- en waterbouw \\
\hline 61238202 & 44130 & 36 & MBO vervoer en logistiek \\
\hline 61238203 & 44133 & 36 & \\
\hline 61238204 & 44133 & 36 & \\
\hline 61238205 & 44231 & 26 & MBO werktuigbouw en mechanische techniek \\
\hline 61238300 & 44180 & 36 & MBO vervoer en logistiek \\
\hline 61238400 & 44180 & 36 & \\
\hline 61238401 & 44310 & 36 & \\
\hline 61238402 & 44110 & 36 & \\
\hline 61239000 & 43676 & 34 & MBO brood en banket \\
\hline 61239001 & 43676 & 34 & \\
\hline 61239002 & 43676 & 34 & \\
\hline 61239003 & 43676 & 34 & \\
\hline 61239004 & 43676 & 34 & \\
\hline 61239005 & 43676 & 34 & \\
\hline 61239100 & 43677 & 35 & MBO levensmiddelentechniek/vleesverwerking \\
\hline 61239101 & 43677 & 35 & \\
\hline 61240000 & 46110 & 47 & MBO administratie \\
\hline 61240200 & 46133 & 47 & \\
\hline 61240201 & 46133 & 47 & \\
\hline 61240300 & 49180 & 55 & MBO openbare orde en veiligheid \\
\hline 61240301 & 49180 & 55 & \\
\hline 61240400 & 46148 & 47 & MBO administratie \\
\hline 61240401 & 46148 & 47 & \\
\hline 61240700 & 46131 & 49 & MBO secretariaat \\
\hline 61240701 & 46131 & 49 & \\
\hline 61241000 & 46150 & 48 & MBO handel \\
\hline 61241001 & 46150 & 48 & \\
\hline 61241002 & 46150 & 48 & \\
\hline 61241003 & 46150 & 48 & \\
\hline 61241200 & 46138 & 47 & MBO administratie \\
\hline 61241201 & 46138 & 47 & \\
\hline 61242000 & 48340 & 45 & MBO horeca \\
\hline 61242001 & 48140 & 45 & \\
\hline
\end{tabular}


4. Opleidingstype per opleiding (vervolg)

\begin{tabular}{|c|c|c|c|}
\hline \multicolumn{3}{|c|}{ Onderwijstype } & Opleidingstype \\
\hline 61242002 & 48140 & 45 & \\
\hline 61242003 & 48340 & 45 & \\
\hline 61242004 & 48340 & 45 & \\
\hline 61242100 & 46142 & 50 & MBO toerisme en recreatie \\
\hline 61242101 & 46142 & 50 & \\
\hline 61242102 & 46142 & 50 & \\
\hline 61250000 & 48100 & 40 & MBO verpleging \\
\hline 61250200 & 46120 & 51 & MBO bedrijfskunde \\
\hline 61250201 & 46120 & 51 & \\
\hline 61250400 & 45120 & 40 & MBO verpleging \\
\hline 61250401 & 48180 & 43 & MBO verzorging \\
\hline 61251000 & 48130 & 44 & MBO uiterlijke verzorging \\
\hline 61251001 & 48130 & 44 & \\
\hline 61310000 & 42110 & 20 & MBO landbouw en veeteelt \\
\hline 61310100 & 42110 & 20 & \\
\hline 61310101 & 42121 & 20 & \\
\hline 61310102 & 42123 & 20 & \\
\hline 61310103 & 42110 & 20 & \\
\hline 61310104 & 42110 & 20 & \\
\hline 61310105 & 42121 & 20 & \\
\hline 61310106 & 42123 & 20 & \\
\hline 61310107 & 42125 & 20 & \\
\hline 61310108 & 42110 & 20 & \\
\hline 61310109 & 42110 & 20 & \\
\hline 61310110 & 42120 & 20 & \\
\hline 61310200 & 42158 & 20 & \\
\hline 61310201 & 42151 & 20 & \\
\hline 61310202 & 42153 & 20 & \\
\hline 61310203 & 42153 & 20 & \\
\hline 61310204 & 42158 & 20 & \\
\hline 61310300 & 43677 & 35 & MBO levensmiddelentechniek/vleesverwerking \\
\hline 61310301 & 43677 & 35 & \\
\hline 61310400 & 42123 & 20 & MBO landbouw en veeteelt \\
\hline 61310401 & 46150 & 48 & MBO handel \\
\hline 61310402 & 42123 & 20 & MBO landbouw en veeteelt \\
\hline 61310403 & 42110 & 20 & \\
\hline 61310404 & 42183 & 21 & MBO milieu en groene ruimte \\
\hline 61310500 & 42158 & 20 & MBO landbouw en veeteelt \\
\hline 61310501 & 42158 & 20 & \\
\hline 61310502 & 42158 & 20 & \\
\hline 61310600 & 42110 & 20 & \\
\hline 61310700 & 42158 & 20 & \\
\hline 61310701 & 42158 & 20 & \\
\hline 61310800 & 42183 & 21 & MBO milieu en groene ruimte \\
\hline 61310801 & 42183 & 21 & \\
\hline 61310802 & 42183 & 21 & \\
\hline 61310803 & 42175 & 21 & \\
\hline 61310804 & 42183 & 21 & \\
\hline 61330200 & 43611 & 23 & MBO bouw \\
\hline 61330201 & 43611 & 23 & \\
\hline 61330202 & 43638 & 26 & MBO werktuigbouw en mechanische techniek \\
\hline 61330203 & 43611 & 23 & MBO bouw \\
\hline 61330204 & 43611 & 23 & \\
\hline 61330205 & 43811 & 23 & \\
\hline 61330206 & 43611 & 23 & \\
\hline 61330207 & 43685 & 48 & MBO handel \\
\hline 61330208 & 43685 & 48 & \\
\hline 61330209 & 43817 & 48 & \\
\hline 61330500 & 43823 & 24 & MBO grond-, weg- en waterbouw \\
\hline 61330501 & 43623 & 24 & \\
\hline 61330502 & 43623 & 24 & \\
\hline 61333000 & 43655 & 31 & MBO elektrotechniek \\
\hline
\end{tabular}


4. Opleidingstype per opleiding (vervolg)

\begin{tabular}{|c|c|c|c|}
\hline \multicolumn{3}{|c|}{ Onderwijstype } & Opleidingstype \\
\hline 61333001 & 43651 & 31 & \\
\hline 61333500 & 43648 & 26 & MBO werktuigbouw en mechanische techniek \\
\hline 61334200 & 43641 & 28 & MBO motorvoertuigentechniek \\
\hline 61334201 & 43641 & 28 & \\
\hline 61334202 & 43641 & 28 & \\
\hline 61334500 & 43651 & 31 & MBO elektrotechniek \\
\hline 61334501 & 43653 & 31 & \\
\hline 61334502 & 43651 & 31 & \\
\hline 61334503 & 43645 & 29 & MBO vliegtuigtechniek \\
\hline 61334504 & 43651 & 31 & MBO elektrotechniek \\
\hline 61334505 & 43651 & 31 & \\
\hline 61334506 & 43651 & 31 & \\
\hline 61334507 & 43653 & 31 & \\
\hline 61334508 & 43653 & 31 & \\
\hline 61334600 & 43651 & 31 & \\
\hline 61334601 & 43651 & 31 & \\
\hline 61334602 & 43651 & 31 & \\
\hline 61334603 & 43651 & 31 & \\
\hline 61334700 & 43652 & 31 & \\
\hline 61334701 & 43654 & 31 & \\
\hline 61334702 & 43654 & 31 & \\
\hline 61334800 & 43616 & 25 & MBO installatietechniek \\
\hline 61334801 & 43618 & 23 & MBO bouw \\
\hline 61334802 & 43616 & 25 & MBO installatietechniek \\
\hline 61334803 & 43616 & 25 & \\
\hline 61334804 & 43616 & 25 & \\
\hline 61334805 & 43616 & 25 & \\
\hline 61334806 & 43616 & 25 & \\
\hline 61335000 & 43616 & 25 & \\
\hline 61335001 & 43616 & 25 & \\
\hline 61335100 & 43648 & 26 & MBO werktuigbouw en mechanische techniek \\
\hline 61335101 & 43648 & 26 & \\
\hline 61335102 & 43648 & 26 & \\
\hline 61335500 & 43835 & 27 & MBO fijnmechanische techniek \\
\hline 61335501 & 43835 & 27 & \\
\hline 61335502 & 43835 & 27 & \\
\hline 61335503 & 43835 & 27 & \\
\hline 61335504 & 43835 & 27 & \\
\hline 61335505 & 43835 & 27 & \\
\hline 61335600 & 45230 & 41 & MBO gezondheidstechniek \\
\hline 61335601 & 45231 & 41 & \\
\hline 61336000 & 43668 & 32 & MBO grafische techniek \\
\hline 61336001 & 43653 & 31 & MBO elektrotechniek \\
\hline 61336002 & 43667 & 32 & MBO grafische techniek \\
\hline 61336003 & 43667 & 32 & \\
\hline 61336004 & 43668 & 32 & \\
\hline 61336005 & 43665 & 32 & \\
\hline 61336006 & 43667 & 32 & \\
\hline 61336007 & 43665 & 32 & \\
\hline 61336008 & 43665 & 32 & \\
\hline 61336009 & 43665 & 32 & \\
\hline 61336010 & 43665 & 32 & \\
\hline 61336500 & 43885 & 48 & MBO handel \\
\hline 61336501 & 43885 & 48 & \\
\hline 61336502 & 43885 & 48 & \\
\hline 61336503 & 43885 & 48 & \\
\hline 61337100 & 43635 & 27 & MBO fijnmechanische techniek \\
\hline 61337101 & 43160 & 22 & MBO laboratorium \\
\hline 61337102 & 43635 & 27 & MBO fijnmechanische techniek \\
\hline 61337103 & 43140 & 22 & MBO laboratorium \\
\hline 61337104 & 45210 & 22 & \\
\hline 61338000 & 44350 & 36 & MBO vervoer en logistiek \\
\hline
\end{tabular}


4. Opleidingstype per opleiding (vervolg)

\begin{tabular}{|c|c|c|c|}
\hline \multicolumn{3}{|c|}{ Onderwijstype } & Opleidingstype \\
\hline 61338001 & 44350 & 36 & \\
\hline 61338002 & 44310 & 36 & \\
\hline 61338003 & 44150 & 36 & \\
\hline 61338004 & 44150 & 36 & \\
\hline 61338200 & 44000 & 36 & \\
\hline 61338201 & 44133 & 36 & \\
\hline 61338202 & 44133 & 36 & \\
\hline 61338203 & 44133 & 36 & \\
\hline 61338204 & 44133 & 36 & \\
\hline 61338400 & 44110 & 36 & \\
\hline 61338401 & 44110 & 36 & \\
\hline 61338402 & 44310 & 36 & \\
\hline 61338403 & 44310 & 36 & \\
\hline 61338404 & 44110 & 36 & \\
\hline 61339000 & 43676 & 34 & MBO brood en banket \\
\hline 61339001 & 43676 & 34 & \\
\hline 61339002 & 43676 & 34 & \\
\hline 61339003 & 43676 & 34 & \\
\hline 61339004 & 43676 & 34 & \\
\hline 61339005 & 43676 & 34 & \\
\hline 61340000 & 46110 & 47 & MBO administratie \\
\hline 61340100 & 46135 & 52 & MBO automatisering \\
\hline 61340101 & 46135 & 52 & \\
\hline 61340200 & 46133 & 47 & MBO administratie \\
\hline 61340201 & 46133 & 47 & \\
\hline 61340400 & 46148 & 47 & \\
\hline 61340401 & 46148 & 47 & \\
\hline 61340600 & 44180 & 36 & MBO vervoer en logistiek \\
\hline 61340601 & 44180 & 36 & \\
\hline 61340602 & 44180 & 36 & \\
\hline 61340700 & 46131 & 49 & MBO secretariaat \\
\hline 61340701 & 46131 & 49 & \\
\hline 61341000 & 46150 & 48 & MBO handel \\
\hline 61341001 & 46150 & 48 & \\
\hline 61341002 & 46150 & 48 & \\
\hline 61341003 & 46148 & 47 & MBO administratie \\
\hline 61341100 & 46138 & 47 & \\
\hline 61341101 & 46148 & 47 & \\
\hline 61341102 & 46148 & 47 & \\
\hline 61341103 & 46148 & 47 & \\
\hline 61341104 & 46148 & 47 & \\
\hline 61341105 & 46148 & 47 & \\
\hline 61341106 & 46148 & 47 & \\
\hline 61341200 & 46138 & 47 & \\
\hline 61341201 & 46138 & 47 & \\
\hline 61341300 & 46150 & 48 & MBO handel \\
\hline 61341301 & 46150 & 48 & \\
\hline 61342100 & 46142 & 50 & MBO toerisme en recreatie \\
\hline 61342101 & 46142 & 50 & \\
\hline 61342102 & 46142 & 50 & \\
\hline 61342103 & 46142 & 50 & \\
\hline 61350400 & 45120 & 40 & MBO verpleging \\
\hline 61350401 & 45120 & 40 & \\
\hline 61350402 & 45120 & 40 & \\
\hline 61351000 & 48130 & 44 & MBO uiterlijke verzorging \\
\hline 61351001 & 48130 & 44 & \\
\hline 61351002 & 48130 & 44 & \\
\hline 61351003 & 48330 & 44 & \\
\hline 61351004 & 48130 & 44 & \\
\hline 61410000 & 42110 & 20 & MBO landbouw en veeteelt \\
\hline 61410100 & 42110 & 20 & \\
\hline 61410101 & 42110 & 20 & \\
\hline
\end{tabular}


4. Opleidingstype per opleiding (vervolg)

\begin{tabular}{|c|c|c|c|}
\hline \multicolumn{3}{|c|}{ Onderwijstype } & Opleidingstype \\
\hline 61410102 & 42110 & 20 & \\
\hline 61410103 & 42110 & 20 & \\
\hline 61410200 & 42158 & 20 & \\
\hline 61410201 & 42158 & 20 & \\
\hline 61410202 & 42158 & 20 & \\
\hline 61410203 & 42158 & 20 & \\
\hline 61410204 & 42158 & 20 & \\
\hline 61410300 & 43677 & 35 & MBO levensmiddelentechniek/vleesverwerking \\
\hline 61410301 & 43677 & 35 & \\
\hline 61410302 & 43677 & 35 & \\
\hline 61410303 & 43677 & 35 & \\
\hline 61410304 & 43677 & 35 & \\
\hline 61410305 & 43677 & 35 & \\
\hline 61410306 & 43677 & 35 & \\
\hline 61410307 & 43677 & 35 & \\
\hline 61410308 & 42158 & 20 & MBO landbouw en veeteelt \\
\hline 61410400 & 42123 & 20 & \\
\hline 61410500 & 42153 & 20 & \\
\hline 61410501 & 42158 & 20 & \\
\hline 61410502 & 42158 & 20 & \\
\hline 61410600 & 42110 & 20 & \\
\hline 61410700 & 42158 & 20 & \\
\hline 61410701 & 42158 & 20 & \\
\hline 61410702 & 42158 & 20 & \\
\hline 61410800 & 42183 & 21 & MBO milieu en groene ruimte \\
\hline 61410801 & 42183 & 21 & \\
\hline 61410802 & 42175 & 21 & \\
\hline 61410803 & 42130 & 21 & \\
\hline 61410804 & 42130 & 21 & \\
\hline 61410805 & 42183 & 21 & \\
\hline 61410900 & 42175 & 21 & \\
\hline 61430100 & 43618 & 23 & MBO bouw \\
\hline 61430101 & 43618 & 23 & \\
\hline 61430102 & 43618 & 23 & \\
\hline 61430103 & 43618 & 23 & \\
\hline 61430200 & 43611 & 23 & \\
\hline 61430201 & 43611 & 23 & \\
\hline 61430202 & 43611 & 23 & \\
\hline 61430203 & 43611 & 23 & \\
\hline 61430204 & 43817 & 48 & MBO handel \\
\hline 61430205 & 43685 & 48 & \\
\hline 61430206 & 43811 & 23 & MBO bouw \\
\hline 61430207 & 43811 & 23 & \\
\hline 61430208 & 43817 & 48 & MBO handel \\
\hline 61430209 & 43811 & 23 & MBO bouw \\
\hline 61430210 & 43811 & 23 & \\
\hline 61430212 & 43811 & 23 & \\
\hline 61430213 & 43611 & 23 & \\
\hline 61430214 & 43611 & 23 & \\
\hline 61430500 & 43623 & 24 & MBO grond-, weg- en waterbouw \\
\hline 61430501 & 43623 & 24 & \\
\hline 61430502 & 43625 & 24 & \\
\hline 61430503 & 43823 & 24 & \\
\hline 61431100 & 43815 & 23 & MBO bouw \\
\hline 61431101 & 43815 & 23 & \\
\hline 61431300 & 46143 & 48 & MBO handel \\
\hline 61431301 & 46143 & 48 & \\
\hline 61432300 & 43645 & 29 & MBO vliegtuigtechniek \\
\hline 61432301 & 43635 & 27 & MBO fijnmechanische techniek \\
\hline 61432302 & 43635 & 27 & \\
\hline 61432303 & 43635 & 27 & \\
\hline 61432304 & 43645 & 29 & MBO vliegtuigtechniek \\
\hline
\end{tabular}


4. Opleidingstype per opleiding (vervolg)

\begin{tabular}{|c|c|c|c|}
\hline \multicolumn{3}{|c|}{ Onderwijstype } & Opleidingstype \\
\hline 61432500 & 43635 & 27 & MBO fijnmechanische techniek \\
\hline 61432600 & 42110 & 20 & MBO landbouw en veeteelt \\
\hline 61432701 & 43631 & 26 & MBO werktuigbouw en mechanische techniek \\
\hline 61433000 & 43655 & 31 & MBO elektrotechniek \\
\hline 61433001 & 43651 & 31 & \\
\hline 61433200 & 43646 & 30 & MBO operationele techniek \\
\hline 61433400 & 43645 & 29 & MBO vliegtuigtechniek \\
\hline 61433401 & 43645 & 29 & \\
\hline 61433402 & 43645 & 29 & \\
\hline 61433403 & 43645 & 29 & \\
\hline 61433500 & 43648 & 26 & MBO werktuigbouw en mechanische techniek \\
\hline 61433600 & 43647 & 26 & \\
\hline 61434100 & 43841 & 28 & MBO motorvoertuigentechniek \\
\hline 61434101 & 43841 & 28 & \\
\hline 61434102 & 43841 & 28 & \\
\hline 61434103 & 43841 & 28 & \\
\hline 61434104 & 43841 & 28 & \\
\hline 61434105 & 43841 & 28 & \\
\hline 61434106 & 43841 & 28 & \\
\hline 61434107 & 43841 & 28 & \\
\hline 61434108 & 43841 & 28 & \\
\hline 61434109 & 43841 & 28 & \\
\hline 61434200 & 43841 & 28 & \\
\hline 61434500 & 43651 & 31 & MBO elektrotechniek \\
\hline 61434501 & 43651 & 31 & \\
\hline 61434502 & 43651 & 31 & \\
\hline 61434503 & 43655 & 31 & \\
\hline 61434504 & 43651 & 31 & \\
\hline 61434505 & 43645 & 29 & MBO vliegtuigtechniek \\
\hline 61434600 & 43651 & 31 & MBO elektrotechniek \\
\hline 61434601 & 43651 & 31 & \\
\hline 61434700 & 43652 & 31 & \\
\hline 61434701 & 43652 & 31 & \\
\hline 61434702 & 46135 & 52 & MBO automatisering \\
\hline 61434703 & 43652 & 31 & MBO elektrotechniek \\
\hline 61434704 & 43654 & 31 & \\
\hline 61434800 & 43643 & 26 & MBO werktuigbouw en mechanische techniek \\
\hline 61435500 & 43635 & 27 & MBO fijnmechanische techniek \\
\hline 61435501 & 43635 & 27 & \\
\hline 61435502 & 43635 & 27 & \\
\hline 61435503 & 43835 & 27 & \\
\hline 61435504 & 43635 & 27 & \\
\hline 61435505 & 43835 & 27 & \\
\hline 61435600 & 45230 & 40 & MBO verpleging \\
\hline 61435601 & 45231 & 41 & MBO gezondheidstechniek \\
\hline 61436000 & 43668 & 32 & MBO grafische techniek \\
\hline 61436001 & 43663 & 32 & \\
\hline 61436002 & 43868 & 32 & \\
\hline 61436003 & 43668 & 32 & \\
\hline 61436004 & 43663 & 32 & \\
\hline 61436500 & 43885 & 48 & MBO handel \\
\hline 61436501 & 43685 & 48 & \\
\hline 61436502 & 43685 & 48 & \\
\hline 61436503 & 43685 & 48 & \\
\hline 61436504 & 43885 & 48 & \\
\hline 61437000 & 43663 & 32 & MBO grafische techniek \\
\hline 61437100 & 43635 & 27 & MBO fijnmechanische techniek \\
\hline 61437101 & 45210 & 22 & MBO laboratorium \\
\hline 61437102 & 43140 & 22 & \\
\hline 61437103 & 43160 & 22 & \\
\hline 61437104 & 43635 & 27 & MBO fijnmechanische techniek \\
\hline 61437200 & 42175 & 21 & MBO milieu en groene ruimte \\
\hline
\end{tabular}


4. Opleidingstype per opleiding (vervolg)

\begin{tabular}{|c|c|c|c|}
\hline \multicolumn{4}{|c|}{ Onderwijstype } \\
\hline 61437300 & 43678 & 33 & MBO procestechniek \\
\hline 61438000 & 44350 & 36 & MBO vervoer en logistiek \\
\hline 61438001 & 44350 & 36 & \\
\hline 61438200 & 44000 & 36 & \\
\hline 61438201 & 44133 & 36 & \\
\hline 61438202 & 43623 & 24 & MBO grond-, weg- en waterbouw \\
\hline 61438203 & 43623 & 24 & \\
\hline 61438204 & 43623 & 24 & \\
\hline 61438205 & 44238 & 36 & MBO vervoer en logistiek \\
\hline 61438206 & 44133 & 36 & \\
\hline 61438208 & 44133 & 36 & \\
\hline 61438209 & 44133 & 36 & \\
\hline 61438300 & 44180 & 36 & \\
\hline 61438301 & 44180 & 36 & \\
\hline 61438302 & 44420 & 36 & \\
\hline 61438303 & 44180 & 36 & \\
\hline 61438304 & 44300 & 36 & \\
\hline 61438305 & 44300 & 36 & \\
\hline 61438400 & 44310 & 36 & \\
\hline 61438401 & 44310 & 36 & \\
\hline 61438402 & 44110 & 36 & \\
\hline 61439000 & 43676 & 34 & MBO brood en banket \\
\hline 61439001 & 43676 & 34 & \\
\hline 61439002 & 43676 & 34 & \\
\hline 61439003 & 43876 & 34 & \\
\hline 61439100 & 43877 & 35 & MBO levensmiddelentechniek/vleesverwerking \\
\hline 61439101 & 43877 & 35 & \\
\hline 61439102 & 43877 & 35 & \\
\hline 61440000 & 46110 & 47 & MBO administratie \\
\hline 61440100 & 46135 & 52 & MBO automatisering \\
\hline 61440101 & 46135 & 52 & \\
\hline 61440102 & 46135 & 52 & \\
\hline 61440103 & 46135 & 52 & \\
\hline 61440200 & 46133 & 47 & MBO administratie \\
\hline 61440201 & 46133 & 47 & \\
\hline 61440202 & 46133 & 47 & \\
\hline 61440203 & 46133 & 47 & \\
\hline 61440400 & 46148 & 47 & \\
\hline 61440401 & 46143 & 48 & MBO handel \\
\hline 61440402 & 46145 & 53 & MBO geld, bank en belastingen \\
\hline 61440403 & 46146 & 54 & MBO verzekeringswezen \\
\hline 61440500 & 46628 & 47 & MBO administratie \\
\hline 61440501 & 46628 & 47 & \\
\hline 61440600 & 44180 & 36 & MBO vervoer en logistiek \\
\hline 61440601 & 44180 & 36 & \\
\hline 61440602 & 44180 & 36 & \\
\hline 61440700 & 46131 & 49 & MBO secretariaat \\
\hline 61440701 & 46131 & 49 & \\
\hline 61440702 & 46143 & 48 & MBO handel \\
\hline 61440703 & 46131 & 49 & MBO secretariaat \\
\hline 61440800 & 46133 & 47 & MBO administratie \\
\hline 61440900 & 46120 & 51 & MBO bedrijfskunde \\
\hline 61441000 & 46150 & 48 & MBO handel \\
\hline 61441001 & 46150 & 48 & \\
\hline 61441002 & 46150 & 48 & \\
\hline 61441003 & 46150 & 48 & \\
\hline 61441004 & 46148 & 47 & MBO administratie \\
\hline 61441005 & 46150 & 48 & MBO handel \\
\hline 61441100 & 46138 & 47 & MBO administratie \\
\hline 61441101 & 46148 & 47 & \\
\hline 61441102 & 46150 & 48 & MBO handel \\
\hline 61441200 & 46138 & 47 & MBO administratie \\
\hline
\end{tabular}


4. Opleidingstype per opleiding (vervolg)

\begin{tabular}{|c|c|c|c|}
\hline \multicolumn{3}{|c|}{ Onderwijstype } & Opleidingstype \\
\hline 61441201 & 46138 & 47 & \\
\hline 61441300 & 46150 & 48 & MBO handel \\
\hline 61441301 & 46150 & 48 & \\
\hline 61441302 & 46150 & 48 & \\
\hline 61441400 & 46150 & 48 & \\
\hline 61442000 & 48340 & 45 & MBO horeca \\
\hline 61442001 & 46150 & 48 & MBO handel \\
\hline 61442002 & 48340 & 45 & MBO horeca \\
\hline 61442003 & 48340 & 45 & \\
\hline 61442004 & 43618 & 23 & MBO bouw \\
\hline 61442100 & 46142 & 50 & MBO toerisme en recreatie \\
\hline 61442101 & 46142 & 50 & \\
\hline 61442102 & 46142 & 50 & \\
\hline 61442103 & 46142 & 50 & \\
\hline 61450000 & 48100 & 40 & MBO verpleging \\
\hline 61450101 & 45118 & 38 & MBO dokters-, tandarts- en dierenartsassistent \\
\hline 61450102 & 45138 & 38 & \\
\hline 61450103 & 45220 & 39 & MBO apothekersassistent \\
\hline 61450200 & 46120 & 51 & MBO bedrijfskunde \\
\hline 61450201 & 46120 & 51 & \\
\hline 61450300 & 40667 & 46 & MBO beweging en therapie \\
\hline 61450301 & 40667 & 46 & \\
\hline 61450400 & 45120 & 40 & MBO verpleging \\
\hline 61450401 & 45120 & 40 & \\
\hline 61450402 & 45120 & 40 & \\
\hline 61456500 & 43885 & 48 & MBO handel \\
\hline 61460000 & 47140 & 42 & MBO sociaal-cultureel \\
\hline 61460100 & 47111 & 42 & \\
\hline 61460101 & 47111 & 42 & \\
\hline 61460200 & 47115 & 42 & \\
\hline 61460300 & 47118 & 42 & \\
\hline 61460301 & 45148 & 46 & MBO beweging en therapie \\
\hline 61460302 & 47140 & 42 & MBO sociaal-cultureel \\
\hline 61460303 & 45148 & 46 & MBO beweging en therapie \\
\hline 61460305 & 40688 & 56 & MBO overig \\
\hline 61460400 & 47118 & 42 & MBO sociaal-cultureel \\
\hline 61460401 & 47118 & 42 & \\
\hline 61460402 & 47118 & 42 & \\
\hline 61534500 & 43651 & 31 & MBO elektrotechniek \\
\hline 61534501 & 43653 & 31 & \\
\hline 61534502 & 43651 & 31 & \\
\hline 61534503 & 43655 & 31 & \\
\hline 61534504 & 43653 & 31 & \\
\hline 61534600 & 43651 & 31 & \\
\hline 61534601 & 43651 & 31 & \\
\hline 61534602 & 43651 & 31 & \\
\hline 61534700 & 43652 & 31 & \\
\hline 61534701 & 43654 & 31 & \\
\hline 61534702 & 43654 & 31 & \\
\hline 61538000 & 44350 & 36 & MBO vervoer en logistiek \\
\hline 61538001 & 44350 & 36 & \\
\hline 61538002 & 44310 & 36 & \\
\hline 61540100 & 46135 & 52 & MBO automatisering \\
\hline 61540101 & 46135 & 52 & \\
\hline 61540102 & 46135 & 52 & \\
\hline 61540103 & 46135 & 52 & \\
\hline 62080100 & 49110 & 55 & MBO openbare orde en veiligheid \\
\hline 62080200 & 49100 & 55 & \\
\hline 62080201 & 49150 & 55 & \\
\hline 62080202 & 49160 & 55 & \\
\hline 62080203 & 49170 & 55 & \\
\hline 62080204 & 49110 & 55 & \\
\hline
\end{tabular}


4. Opleidingstype per opleiding (vervolg)

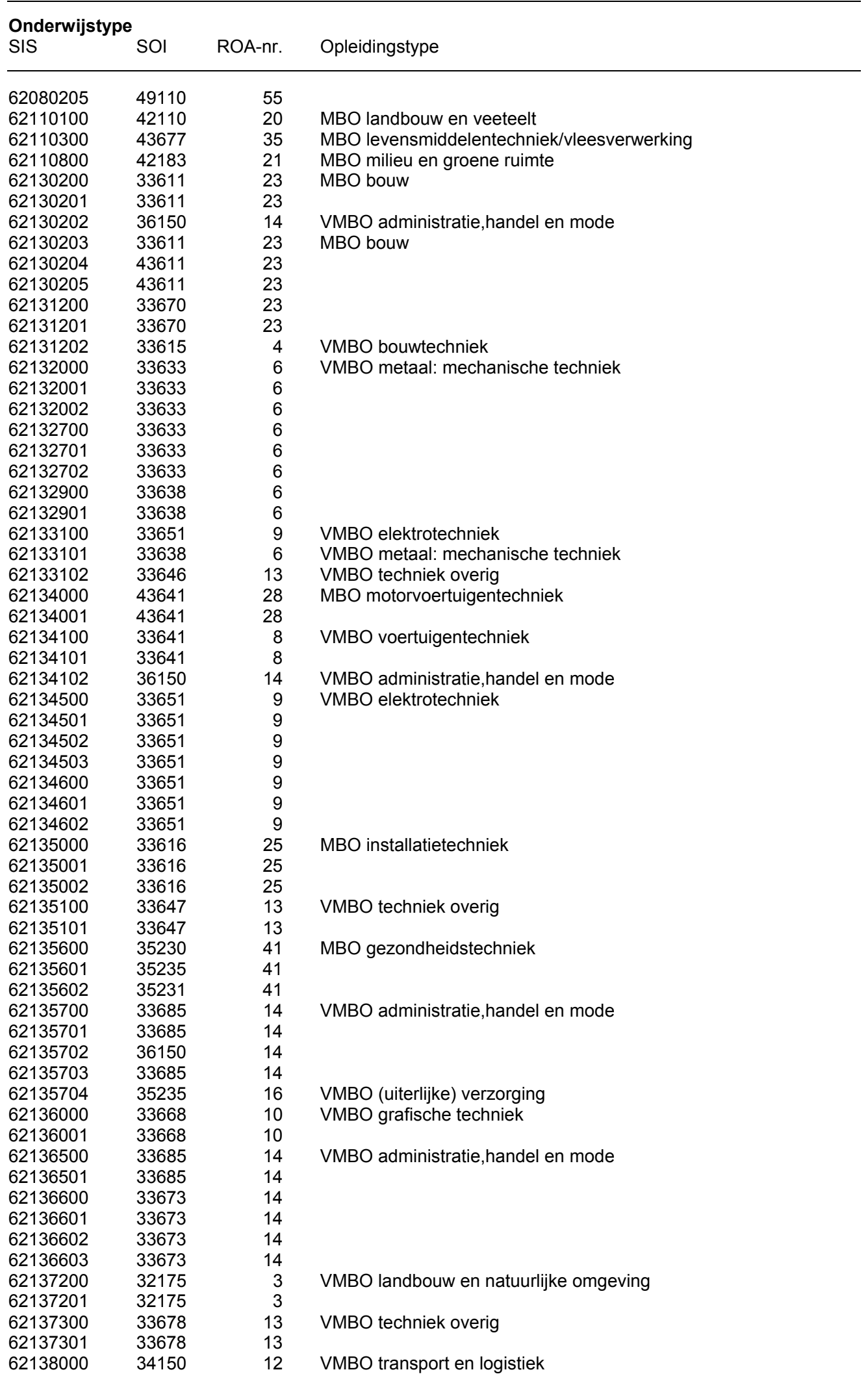


4. Opleidingstype per opleiding (vervolg)

\begin{tabular}{|c|c|c|c|}
\hline \multicolumn{3}{|c|}{ Onderwijstype } & Opleidingstype \\
\hline 62138001 & 34150 & 12 & \\
\hline 62138400 & 34110 & 12 & \\
\hline 62138401 & 34180 & 12 & \\
\hline 62139000 & 33870 & 34 & MBO brood en banket \\
\hline 62139001 & 33870 & 34 & \\
\hline 62139100 & 33677 & 35 & MBO levensmiddelentechniek/vleesverwerking \\
\hline 62139101 & 33677 & 35 & \\
\hline 62139102 & 33677 & 35 & \\
\hline 62140300 & 39180 & 17 & VMBO beveiliging \\
\hline 62140301 & 39180 & 17 & \\
\hline 62140302 & 39180 & 17 & \\
\hline 62140700 & 36131 & 14 & VMBO administratie, handel en mode \\
\hline 62140701 & 36131 & 14 & \\
\hline 62141000 & 36150 & 14 & \\
\hline 62141001 & 36150 & 14 & \\
\hline 62141100 & 36138 & 14 & \\
\hline 62141101 & 36138 & 14 & \\
\hline 62141200 & 36138 & 14 & \\
\hline 62141201 & 36138 & 14 & \\
\hline 62142000 & 38140 & 45 & MBO horeca \\
\hline 62142001 & 38140 & 45 & \\
\hline 62210000 & 42110 & 20 & MBO landbouw en veeteelt \\
\hline 62210100 & 42110 & 20 & \\
\hline 62210101 & 42110 & 20 & \\
\hline 62210200 & 42158 & 20 & \\
\hline 62210300 & 43677 & 35 & MBO levensmiddelentechniek/vleesverwerking \\
\hline 62210400 & 42320 & 20 & MBO landbouw en veeteelt \\
\hline 62210500 & 42153 & 20 & \\
\hline 62210501 & 42153 & 20 & \\
\hline 62210600 & 42110 & 20 & \\
\hline 62210700 & 42158 & 20 & \\
\hline 62210800 & 42183 & 21 & MBO milieu en groene ruimte \\
\hline 62230100 & 43618 & 23 & MBO bouw \\
\hline 62230101 & 43611 & 23 & \\
\hline 62230102 & 43614 & 23 & \\
\hline 62230103 & 43613 & 23 & \\
\hline 62230104 & 43614 & 23 & \\
\hline 62230105 & 43614 & 23 & \\
\hline 62230106 & 43614 & 23 & \\
\hline 62230107 & 43618 & 23 & \\
\hline 62230108 & 43616 & 25 & MBO installatietechniek \\
\hline 62230109 & 43614 & 23 & MBO bouw \\
\hline 62230110 & 43611 & 23 & \\
\hline 62230111 & 43611 & 23 & \\
\hline 62230112 & 43613 & 23 & \\
\hline 62230113 & 43613 & 23 & \\
\hline 62230200 & 43611 & 23 & \\
\hline 62230201 & 43685 & 48 & MBO handel \\
\hline 62230202 & 43611 & 23 & MBO bouw \\
\hline 62230203 & 43638 & 26 & MBO werktuigbouw en mechanische techniek \\
\hline 62230204 & 43611 & 23 & MBO bouw \\
\hline 62230205 & 43611 & 23 & \\
\hline 62230206 & 43811 & 23 & \\
\hline 62230207 & 43611 & 23 & \\
\hline 62230208 & 43817 & 48 & MBO handel \\
\hline 62230209 & 43611 & 23 & MBO bouw \\
\hline 62230210 & 43685 & 48 & MBO handel \\
\hline 62230500 & 43623 & 24 & MBO grond-, weg- en waterbouw \\
\hline 62230501 & 43623 & 24 & \\
\hline 62230502 & 43623 & 24 & \\
\hline 62230503 & 43623 & 24 & \\
\hline 62230504 & 43623 & 24 & \\
\hline
\end{tabular}


4. Opleidingstype per opleiding (vervolg)

\begin{tabular}{|c|c|c|c|}
\hline \multicolumn{4}{|c|}{ Onderwijstype } \\
\hline 62230505 & 43623 & 24 & \\
\hline 62230506 & 43623 & 24 & \\
\hline 62230507 & 43623 & 24 & \\
\hline 62231000 & 43618 & 23 & MBO bouw \\
\hline 62231001 & 43613 & 23 & \\
\hline 62231002 & 43613 & 23 & \\
\hline 62231003 & 43611 & 23 & \\
\hline 62231004 & 43614 & 23 & \\
\hline 62231100 & 43815 & 23 & \\
\hline 62231101 & 43615 & 23 & \\
\hline 62231105 & 43615 & 23 & \\
\hline 62231200 & 43670 & 23 & \\
\hline 62231201 & 43670 & 23 & \\
\hline 62231202 & 43670 & 23 & \\
\hline 62231203 & 43615 & 23 & \\
\hline 62232000 & 43633 & 26 & MBO werktuigbouw en mechanische techniek \\
\hline 62232001 & 43633 & 26 & \\
\hline 62232005 & 43633 & 26 & \\
\hline 62232006 & 43633 & 26 & \\
\hline 62232007 & 43633 & 26 & \\
\hline 62232008 & 43633 & 26 & \\
\hline 62232009 & 43638 & 26 & \\
\hline 62232010 & 43633 & 26 & \\
\hline 62232100 & 43631 & 26 & \\
\hline 62232101 & 43631 & 26 & \\
\hline 62232102 & 43631 & 26 & \\
\hline 62232200 & 43635 & 27 & MBO fijnmechanische techniek \\
\hline 62232201 & 43635 & 27 & \\
\hline 62232300 & 43635 & 27 & \\
\hline 62232301 & 43635 & 27 & \\
\hline 62232600 & 42210 & 26 & MBO werktuigbouw en mechanische techniek \\
\hline 62232601 & 43647 & 26 & \\
\hline 62232602 & 42210 & 26 & \\
\hline 62232700 & 43633 & 26 & \\
\hline 62232701 & 43633 & 26 & \\
\hline 62232702 & 43633 & 26 & \\
\hline 62232703 & 43633 & 26 & \\
\hline 62232704 & 43633 & 26 & \\
\hline 62232900 & 43638 & 26 & \\
\hline 62232901 & 43638 & 26 & \\
\hline 62232905 & 43638 & 26 & \\
\hline 62232906 & 43638 & 26 & \\
\hline 62232907 & 43638 & 26 & \\
\hline 62232908 & 43635 & 27 & MBO fijnmechanische techniek \\
\hline 62232909 & 43638 & 26 & MBO werktuigbouw en mechanische techniek \\
\hline 62232910 & 43638 & 26 & \\
\hline 62233000 & 43655 & 31 & MBO elektrotechniek \\
\hline 62233001 & 43651 & 31 & \\
\hline 62233002 & 43655 & 31 & \\
\hline 62233100 & 43638 & 26 & MBO werktuigbouw en mechanische techniek \\
\hline 62233101 & 43638 & 26 & \\
\hline 62233105 & 43647 & 26 & \\
\hline 62233106 & 43646 & 30 & MBO operationele techniek \\
\hline 62233300 & 43643 & 26 & MBO werktuigbouw en mechanische techniek \\
\hline 62233301 & 43643 & 26 & \\
\hline 62233302 & 43643 & 26 & \\
\hline 62233400 & 43645 & 29 & MBO vliegtuigtechniek \\
\hline 62233405 & 43645 & 29 & \\
\hline 62233406 & 43645 & 29 & \\
\hline 62233407 & 43645 & 29 & \\
\hline 62233500 & 43648 & 26 & MBO werktuigbouw en mechanische techniek \\
\hline 62233501 & 43648 & 26 & \\
\hline
\end{tabular}


4. Opleidingstype per opleiding (vervolg)

\begin{tabular}{|c|c|c|c|}
\hline \multicolumn{3}{|c|}{ Onderwijstype } & Opleidingstype \\
\hline 62234000 & 43641 & 28 & MBO motorvoertuigentechniek \\
\hline 62234001 & 43641 & 28 & \\
\hline 62234002 & 43641 & 28 & \\
\hline 62234003 & 43641 & 28 & \\
\hline 62234004 & 43641 & 28 & \\
\hline 62234005 & 43641 & 28 & \\
\hline 62234100 & 43641 & 28 & \\
\hline 62234101 & 43647 & 26 & MBO werktuigbouw en mechanische techniek \\
\hline 62234102 & 43641 & 28 & MBO motorvoertuigentechniek \\
\hline 62234103 & 43641 & 28 & \\
\hline 62234104 & 43641 & 28 & \\
\hline 62234105 & 43641 & 28 & \\
\hline 62234106 & 43647 & 26 & MBO werktuigbouw en mechanische techniek \\
\hline 62234107 & 46150 & 48 & MBO handel \\
\hline 62234108 & 43641 & 28 & MBO motorvoertuigentechniek \\
\hline 62234109 & 43641 & 28 & \\
\hline 62234110 & 43641 & 28 & \\
\hline 62234111 & 43641 & 28 & \\
\hline 62234112 & 43641 & 28 & \\
\hline 62234113 & 43641 & 28 & \\
\hline 62234500 & 43651 & 31 & MBO elektrotechniek \\
\hline 62234501 & 43653 & 31 & \\
\hline 62234502 & 43651 & 31 & \\
\hline 62234503 & 43645 & 29 & MBO vliegtuigtechniek \\
\hline 62234504 & 43651 & 31 & MBO elektrotechniek \\
\hline 62234505 & 43651 & 31 & \\
\hline 62234506 & 43653 & 31 & \\
\hline 62234507 & 43653 & 31 & \\
\hline 62234600 & 43651 & 31 & \\
\hline 62234601 & 43651 & 31 & \\
\hline 62234602 & 43651 & 31 & \\
\hline 62234603 & 43651 & 31 & \\
\hline 62234700 & 43652 & 31 & \\
\hline 62234701 & 43654 & 31 & \\
\hline 62234702 & 43654 & 31 & \\
\hline 62234800 & 43616 & 25 & MBO installatietechniek \\
\hline 62234801 & 43648 & 26 & MBO werktuigbouw en mechanische techniek \\
\hline 62234802 & 43616 & 25 & MBO installatietechniek \\
\hline 62234803 & 43616 & 25 & \\
\hline 62234804 & 43616 & 25 & \\
\hline 62234900 & 43647 & 26 & MBO werktuigbouw en mechanische techniek \\
\hline 62234901 & 43647 & 26 & \\
\hline 62234902 & 43647 & 26 & \\
\hline 62235000 & 43616 & 25 & MBO installatietechniek \\
\hline 62235001 & 43616 & 25 & \\
\hline 62235002 & 43616 & 25 & \\
\hline 62235005 & 43616 & 25 & \\
\hline 62235006 & 43616 & 25 & \\
\hline 62235007 & 43616 & 25 & \\
\hline 62235008 & 43616 & 25 & \\
\hline 62235100 & 43648 & 26 & MBO werktuigbouw en mechanische techniek \\
\hline 62235101 & 43648 & 26 & \\
\hline 62235500 & 43635 & 27 & MBO fijnmechanische techniek \\
\hline 62235505 & 43635 & 27 & \\
\hline 62235506 & 43635 & 27 & \\
\hline 62235600 & 45230 & 41 & MBO gezondheidstechniek \\
\hline 62235605 & 45231 & 41 & \\
\hline 62235606 & 45231 & 41 & \\
\hline 62235607 & 45238 & 41 & \\
\hline 62235608 & 45233 & 41 & \\
\hline 62235609 & 45235 & 41 & \\
\hline 62235610 & 45235 & 41 & \\
\hline
\end{tabular}


4. Opleidingstype per opleiding (vervolg)

\begin{tabular}{|c|c|c|c|}
\hline \multicolumn{4}{|c|}{ Onderwijstype } \\
\hline 62235700 & 43685 & 48 & MBO handel \\
\hline 62235701 & 45235 & 41 & MBO gezondheidstechniek \\
\hline 62235702 & 43685 & 48 & MBO handel \\
\hline 62235703 & 43685 & 48 & \\
\hline 62235704 & 43685 & 48 & \\
\hline 62235705 & 43685 & 48 & \\
\hline 62235706 & 43685 & 48 & \\
\hline 62235707 & 43685 & 48 & \\
\hline 62235708 & 43685 & 48 & \\
\hline 62235709 & 43685 & 48 & \\
\hline 62235710 & 43685 & 48 & \\
\hline 62235711 & 43685 & 48 & \\
\hline 62235712 & 43685 & 48 & \\
\hline 62235713 & 43685 & 48 & \\
\hline 62235714 & 46150 & 48 & \\
\hline 62235715 & 45235 & 41 & MBO gezondheidstechniek \\
\hline 62235800 & 43688 & 37 & MBO techniek overig \\
\hline 62235801 & 43688 & 37 & \\
\hline 62236000 & 43868 & 32 & MBO grafische techniek \\
\hline 62236001 & 43665 & 32 & \\
\hline 62236002 & 43868 & 32 & \\
\hline 62236003 & 43665 & 32 & \\
\hline 62236004 & 48610 & 56 & MBO overig \\
\hline 62236500 & 43885 & 48 & MBO handel \\
\hline 62236501 & 43685 & 48 & \\
\hline 62236503 & 43685 & 48 & \\
\hline 62236504 & 43885 & 48 & \\
\hline 62236600 & 43673 & 37 & MBO techniek overig \\
\hline 62236601 & 43673 & 37 & \\
\hline 62236602 & 43673 & 37 & \\
\hline 62236603 & 43673 & 37 & \\
\hline 62236604 & 43673 & 37 & \\
\hline 62236605 & 43673 & 37 & \\
\hline 62237000 & 43663 & 32 & MBO grafische techniek \\
\hline 62237001 & 43663 & 32 & \\
\hline 62237100 & 43635 & 27 & MBO fijnmechanische techniek \\
\hline 62237105 & 43635 & 27 & \\
\hline 62237300 & 43678 & 33 & MBO procestechniek \\
\hline 62237305 & 43646 & 30 & MBO operationele techniek \\
\hline 62237306 & 43678 & 33 & MBO procestechniek \\
\hline 62238000 & 44350 & 36 & MBO vervoer en logistiek \\
\hline 62238001 & 44150 & 36 & \\
\hline 62238002 & 44350 & 36 & \\
\hline 62238003 & 44250 & 26 & MBO werktuigbouw en mechanische techniek \\
\hline 62238200 & 44000 & 36 & MBO vervoer en logistiek \\
\hline 62238201 & 43623 & 24 & MBO grond-, weg- en waterbouw \\
\hline 62238202 & 44130 & 36 & MBO vervoer en logistiek \\
\hline 62238205 & 44130 & 36 & \\
\hline 62238400 & 44310 & 36 & \\
\hline 62238401 & 44110 & 36 & \\
\hline 62238402 & 44110 & 36 & \\
\hline 62238403 & 44110 & 36 & \\
\hline 62238404 & 44350 & 36 & \\
\hline 62239000 & 43676 & 34 & MBO brood en banket \\
\hline 62239001 & 43676 & 34 & \\
\hline 62239002 & 43676 & 34 & \\
\hline 62239003 & 43676 & 34 & \\
\hline 62239004 & 43676 & 34 & \\
\hline 62239005 & 43676 & 34 & \\
\hline 62239006 & 43676 & 34 & \\
\hline 62239007 & 43676 & 34 & \\
\hline 62239008 & 43676 & 34 & \\
\hline
\end{tabular}


4. Opleidingstype per opleiding (vervolg)

\begin{tabular}{|c|c|c|c|}
\hline \multicolumn{3}{|c|}{ Onderwijstype } & Opleidingstype \\
\hline 62239100 & 43877 & 35 & MBO levensmiddelentechniek/vleesverwerking \\
\hline 62239101 & 43877 & 35 & \\
\hline 62239102 & 43677 & 35 & \\
\hline 62239103 & 43677 & 35 & \\
\hline 62239104 & 43677 & 35 & \\
\hline 62239105 & 43677 & 35 & \\
\hline 62239106 & 43677 & 35 & \\
\hline 62240000 & 46110 & 47 & MBO administratie \\
\hline 62240200 & 46133 & 47 & \\
\hline 62240201 & 46133 & 47 & \\
\hline 62240300 & 49180 & 55 & MBO openbare orde en veiligheid \\
\hline 62240301 & 49180 & 55 & \\
\hline 62240400 & 46148 & 47 & MBO administratie \\
\hline 62240401 & 46148 & 47 & \\
\hline 62240402 & 46148 & 47 & \\
\hline 62240700 & 46131 & 49 & MBO secretariaat \\
\hline 62240701 & 46131 & 49 & \\
\hline 62241000 & 46150 & 48 & MBO handel \\
\hline 62241001 & 46150 & 48 & \\
\hline 62241002 & 46150 & 48 & \\
\hline 62241003 & 46150 & 48 & \\
\hline 62241004 & 46150 & 48 & \\
\hline 62241200 & 46138 & 47 & MBO administratie \\
\hline 62241201 & 46138 & 47 & \\
\hline 62242000 & 48340 & 45 & MBO horeca \\
\hline 62242001 & 48140 & 45 & \\
\hline 62242002 & 48140 & 45 & \\
\hline 62242003 & 48340 & 45 & \\
\hline 62242005 & 43841 & 47 & MBO administratie \\
\hline 62242100 & 46142 & 50 & MBO toerisme en recreatie \\
\hline 62242101 & 46142 & 50 & \\
\hline 62246500 & 43885 & 48 & MBO handel \\
\hline 62250000 & 48100 & 40 & MBO verpleging \\
\hline 62250200 & 46120 & 51 & MBO bedrijfskunde \\
\hline 62250205 & 48180 & 43 & MBO verzorging \\
\hline 62250400 & 48128 & 43 & \\
\hline 62250401 & 48121 & 43 & \\
\hline 62250402 & 48125 & 43 & \\
\hline 62250403 & 45120 & 40 & \\
\hline 62250404 & 48125 & 43 & \\
\hline 62250405 & 48128 & 43 & \\
\hline 62251000 & 48130 & 44 & MBO uiterlijke verzorging \\
\hline 62251001 & 48130 & 44 & \\
\hline 62251002 & 48130 & 44 & \\
\hline 62251003 & 48130 & 44 & \\
\hline 62251004 & 48130 & 44 & \\
\hline 62310000 & 42110 & 20 & MBO landbouw en veeteelt \\
\hline 62310100 & 42110 & 20 & \\
\hline 62310101 & 42121 & 20 & \\
\hline 62310102 & 42123 & 20 & \\
\hline 62310103 & 42110 & 20 & \\
\hline 62310104 & 42110 & 20 & \\
\hline 62310105 & 42121 & 20 & \\
\hline 62310106 & 42123 & 20 & \\
\hline 62310107 & 42125 & 20 & \\
\hline 62310108 & 42110 & 20 & \\
\hline 62310109 & 42110 & 20 & \\
\hline 62310110 & 42120 & 20 & \\
\hline 62310200 & 42158 & 20 & \\
\hline 62310201 & 42151 & 20 & \\
\hline 62310202 & 42153 & 20 & \\
\hline 62310203 & 42153 & 20 & \\
\hline
\end{tabular}


4. Opleidingstype per opleiding (vervolg)

\begin{tabular}{|c|c|c|c|}
\hline \multicolumn{4}{|c|}{ Onderwijstype } \\
\hline 62310300 & 43677 & 35 & MBO levensmiddelentechniek/vleesverwerking \\
\hline 62310400 & 42123 & 20 & MBO landbouw en veeteelt \\
\hline 62310401 & 46150 & 48 & MBO handel \\
\hline 62310402 & 42123 & 20 & MBO landbouw en veeteelt \\
\hline 62310403 & 42110 & 20 & \\
\hline 62310404 & 42183 & 21 & MBO milieu en groene ruimte \\
\hline 62310500 & 42158 & 20 & MBO landbouw en veeteelt \\
\hline 62310501 & 42158 & 20 & \\
\hline 62310502 & 42158 & 20 & \\
\hline 62310600 & 42110 & 20 & \\
\hline 62310700 & 42158 & 20 & \\
\hline 62310701 & 42158 & 20 & \\
\hline 62310702 & 42250 & 20 & \\
\hline 62310800 & 42183 & 21 & MBO milieu en groene ruimte \\
\hline 62310801 & 42183 & 21 & \\
\hline 62310802 & 42183 & 21 & \\
\hline 62310803 & 42175 & 21 & \\
\hline 62330100 & 43618 & 23 & MBO bouw \\
\hline 62330101 & 43618 & 23 & \\
\hline 62330102 & 43618 & 23 & \\
\hline 62330103 & 43616 & 25 & MBO installatietechniek \\
\hline 62330104 & 43614 & 23 & MBO bouw \\
\hline 62330105 & 43611 & 23 & \\
\hline 62330200 & 43611 & 23 & \\
\hline 62330201 & 43611 & 23 & \\
\hline 62330202 & 43611 & 23 & \\
\hline 62330203 & 43685 & 48 & MBO handel \\
\hline 62330204 & 43611 & 23 & MBO bouw \\
\hline 62330205 & 43685 & 48 & MBO handel \\
\hline 62330206 & 43611 & 23 & MBO bouw \\
\hline 62330207 & 43638 & 26 & MBO werktuigbouw en mechanische techniek \\
\hline 62330208 & 43611 & 23 & MBO bouw \\
\hline 62330209 & 43611 & 23 & \\
\hline 62330210 & 43817 & 48 & MBO handel \\
\hline 62330500 & 43623 & 24 & MBO grond-, weg- en waterbouw \\
\hline 62330505 & 43623 & 24 & \\
\hline 62330506 & 43623 & 24 & \\
\hline 62330507 & 43623 & 24 & \\
\hline 62330508 & 43646 & 30 & MBO operationele techniek \\
\hline 62330509 & 43646 & 30 & \\
\hline 62330510 & 43623 & 24 & MBO grond-, weg- en waterbouw \\
\hline 62330511 & 43623 & 24 & \\
\hline 62330512 & 43623 & 24 & \\
\hline 62330513 & 43623 & 24 & \\
\hline 62330514 & 43623 & 24 & \\
\hline 62330515 & 43623 & 24 & \\
\hline 62330516 & 43623 & 24 & \\
\hline 62331000 & 43618 & 23 & MBO bouw \\
\hline 62331001 & 43614 & 23 & \\
\hline 62331100 & 43815 & 23 & \\
\hline 62331101 & 43615 & 23 & \\
\hline 62331102 & 43615 & 23 & \\
\hline 62331200 & 43670 & 23 & \\
\hline 62331201 & 43670 & 23 & \\
\hline 62331202 & 43670 & 23 & \\
\hline 62332000 & 43633 & 26 & MBO werktuigbouw en mechanische techniek \\
\hline 62332001 & 43633 & 26 & \\
\hline 62332002 & 43647 & 26 & \\
\hline 62332003 & 43633 & 26 & \\
\hline 62332300 & 43635 & 27 & MBO fijnmechanische techniek \\
\hline 62332301 & 43635 & 27 & \\
\hline 62332400 & 43635 & 27 & \\
\hline
\end{tabular}


4. Opleidingstype per opleiding (vervolg)

\begin{tabular}{|c|c|c|c|}
\hline \multicolumn{3}{|c|}{ Onderwijstype } & Opleidingstype \\
\hline 62332600 & 42210 & 26 & MBO werktuigbouw en mechanische techniek \\
\hline 62332601 & 42210 & 26 & \\
\hline 62332700 & 43633 & 26 & \\
\hline 62332701 & 43633 & 26 & \\
\hline 62332900 & 43638 & 26 & \\
\hline 62332901 & 43638 & 26 & \\
\hline 62332902 & 43638 & 26 & \\
\hline 62332903 & 43638 & 26 & \\
\hline 62333000 & 43655 & 31 & MBO elektrotechniek \\
\hline 62333001 & 43651 & 31 & \\
\hline 62333100 & 43638 & 26 & MBO werktuigbouw en mechanische techniek \\
\hline 62333101 & 43651 & 31 & MBO elektrotechniek \\
\hline 62333102 & 43646 & 30 & MBO operationele techniek \\
\hline 62333103 & 43653 & 31 & MBO elektrotechniek \\
\hline 62333300 & 43643 & 26 & MBO werktuigbouw en mechanische techniek \\
\hline 62333400 & 43645 & 29 & MBO vliegtuigtechniek \\
\hline 62333401 & 43645 & 29 & \\
\hline 62333500 & 43648 & 26 & MBO werktuigbouw en mechanische techniek \\
\hline 62333505 & 43648 & 26 & \\
\hline 62334000 & 43641 & 28 & MBO motorvoertuigentechniek \\
\hline 62334001 & 43641 & 28 & \\
\hline 62334002 & 43641 & 28 & \\
\hline 62334003 & 43641 & 28 & \\
\hline 62334004 & 43641 & 28 & \\
\hline 62334100 & 43641 & 28 & \\
\hline 62334101 & 43647 & 26 & MBO werktuigbouw en mechanische techniek \\
\hline 62334102 & 43641 & 28 & MBO motorvoertuigentechniek \\
\hline 62334103 & 43641 & 28 & \\
\hline 62334104 & 43841 & 28 & \\
\hline 62334105 & 43841 & 28 & \\
\hline 62334106 & 43841 & 28 & \\
\hline 62334107 & 43841 & 28 & \\
\hline 62334500 & 43651 & 31 & MBO elektrotechniek \\
\hline 62334501 & 43653 & 31 & \\
\hline 62334502 & 43645 & 29 & MBO vliegtuigtechniek \\
\hline 62334503 & 43645 & 29 & \\
\hline 62334504 & 43651 & 31 & MBO elektrotechniek \\
\hline 62334505 & 43651 & 31 & \\
\hline 62334506 & 43651 & 31 & \\
\hline 62334507 & 43653 & 31 & \\
\hline 62334508 & 43653 & 31 & \\
\hline 62334509 & 43653 & 31 & \\
\hline 62334600 & 43651 & 31 & \\
\hline 62334601 & 43651 & 31 & \\
\hline 62334602 & 43651 & 31 & \\
\hline 62334603 & 43651 & 31 & \\
\hline 62334700 & 43652 & 31 & \\
\hline 62334701 & 43654 & 31 & \\
\hline 62334702 & 43654 & 31 & \\
\hline 62334703 & 43654 & 31 & \\
\hline 62334800 & 43616 & 25 & MBO installatietechniek \\
\hline 62334801 & 43618 & 23 & MBO bouw \\
\hline 62334802 & 43618 & 23 & \\
\hline 62334803 & 43616 & 25 & MBO installatietechniek \\
\hline 62334804 & 43616 & 25 & \\
\hline 62334805 & 43616 & 25 & \\
\hline 62334806 & 43616 & 25 & \\
\hline 62334900 & 43647 & 26 & MBO werktuigbouw en mechanische techniek \\
\hline 62334901 & 43647 & 26 & \\
\hline 62334902 & 43647 & 26 & \\
\hline 62335000 & 43616 & 25 & MBO installatietechniek \\
\hline 62335001 & 43616 & 25 & \\
\hline
\end{tabular}


4. Opleidingstype per opleiding (vervolg)

\begin{tabular}{|c|c|c|c|}
\hline \multicolumn{3}{|c|}{ Onderwijstype } & Opleidingstype \\
\hline 62335005 & 43616 & 25 & \\
\hline 62335006 & 43616 & 25 & \\
\hline 62335007 & 43616 & 25 & \\
\hline 62335008 & 43616 & 25 & \\
\hline 62335009 & 43616 & 25 & \\
\hline 62335010 & 43616 & 25 & \\
\hline 62335011 & 43616 & 25 & \\
\hline 62335100 & 43648 & 26 & MBO werktuigbouw en mechanische techniek \\
\hline 62335101 & 43648 & 26 & \\
\hline 62335102 & 43616 & 25 & MBO installatietechniek \\
\hline 62335500 & 43635 & 27 & MBO fijnmechanische techniek \\
\hline 62335501 & 43635 & 27 & \\
\hline 62335600 & 45230 & 41 & MBO gezondheidstechniek \\
\hline 62335601 & 45231 & 41 & \\
\hline 62335602 & 45235 & 41 & \\
\hline 62335603 & 45235 & 41 & \\
\hline 62335604 & 45233 & 41 & \\
\hline 62335605 & 45238 & 41 & \\
\hline 62335606 & 45231 & 41 & \\
\hline 62335607 & 45231 & 41 & \\
\hline 62335700 & 43685 & 48 & MBO handel \\
\hline 62335701 & 45235 & 41 & MBO gezondheidstechniek \\
\hline 62335703 & 46150 & 48 & MBO handel \\
\hline 62335704 & 43685 & 48 & \\
\hline 62335705 & 43685 & 48 & \\
\hline 62335706 & 43685 & 48 & \\
\hline 62335707 & 45235 & 41 & MBO gezondheidstechniek \\
\hline 62335708 & 43685 & 48 & MBO handel \\
\hline 62335800 & 43688 & 37 & MBO techniek overig \\
\hline 62335801 & 43688 & 37 & \\
\hline 62336000 & 43668 & 32 & MBO grafische techniek \\
\hline 62336002 & 43667 & 32 & \\
\hline 62336003 & 43667 & 32 & \\
\hline 62336004 & 43667 & 32 & \\
\hline 62336005 & 43665 & 32 & \\
\hline 62336006 & 43667 & 32 & \\
\hline 62336007 & 43665 & 32 & \\
\hline 62336008 & 43665 & 32 & \\
\hline 62336010 & 43665 & 32 & \\
\hline 62336011 & 43665 & 32 & \\
\hline 62336012 & 43653 & 31 & MBO elektrotechniek \\
\hline 62336500 & 43685 & 48 & MBO handel \\
\hline 62336501 & 43685 & 48 & \\
\hline 62336502 & 43685 & 48 & \\
\hline 62336503 & 43685 & 48 & \\
\hline 62336600 & 43673 & 37 & MBO techniek overig \\
\hline 62336601 & 43673 & 37 & \\
\hline 62336602 & 43673 & 37 & \\
\hline 62336603 & 43673 & 37 & \\
\hline 62337300 & 43678 & 33 & MBO procestechniek \\
\hline 62337301 & 43646 & 30 & MBO operationele techniek \\
\hline 62337302 & 43678 & 33 & MBO procestechniek \\
\hline 62338000 & 44350 & 36 & MBO vervoer en logistiek \\
\hline 62338001 & 44350 & 36 & \\
\hline 62338002 & 44310 & 36 & \\
\hline 62338003 & 44150 & 36 & \\
\hline 62338005 & 44350 & 36 & \\
\hline 62338200 & 44000 & 36 & \\
\hline 62338205 & 44133 & 36 & \\
\hline 62338206 & 44133 & 36 & \\
\hline 62338207 & 44133 & 36 & \\
\hline 62338400 & 44310 & 36 & \\
\hline
\end{tabular}


4. Opleidingstype per opleiding (vervolg)

\begin{tabular}{|c|c|c|c|}
\hline \multicolumn{3}{|c|}{ Onderwijstype } & Opleidingstype \\
\hline 62338401 & 44310 & 36 & \\
\hline 62338403 & 44350 & 36 & \\
\hline 62338404 & 44110 & 36 & \\
\hline 62338405 & 44310 & 36 & \\
\hline 62339000 & 43676 & 34 & MBO brood en banket \\
\hline 62339001 & 43676 & 34 & \\
\hline 62339002 & 43676 & 34 & \\
\hline 62339003 & 43676 & 34 & \\
\hline 62339004 & 43676 & 34 & \\
\hline 62339005 & 43676 & 34 & \\
\hline 62339100 & 43677 & 35 & MBO levensmiddelentechniek/vleesverwerking \\
\hline 62339101 & 43877 & 35 & \\
\hline 62339102 & 43877 & 35 & \\
\hline 62339103 & 43877 & 35 & \\
\hline 62339104 & 43677 & 35 & \\
\hline 62339105 & 43677 & 35 & \\
\hline 62339106 & 43677 & 35 & \\
\hline 62339107 & 43677 & 35 & \\
\hline 62339108 & 43677 & 35 & \\
\hline 62339109 & 43677 & 35 & \\
\hline 62339110 & 43677 & 35 & \\
\hline 62340000 & 46110 & 47 & MBO administratie \\
\hline 62340100 & 46135 & 52 & MBO automatisering \\
\hline 62340101 & 46135 & 52 & \\
\hline 62340200 & 46133 & 47 & MBO administratie \\
\hline 62340201 & 46133 & 47 & \\
\hline 62340400 & 46148 & 47 & \\
\hline 62340401 & 46148 & 47 & \\
\hline 62340600 & 44180 & 36 & MBO vervoer en logistiek \\
\hline 62340601 & 44180 & 36 & \\
\hline 62340602 & 44180 & 36 & \\
\hline 62340700 & 46131 & 49 & MBO secretariaat \\
\hline 62340701 & 46131 & 49 & \\
\hline 62341000 & 46150 & 48 & MBO handel \\
\hline 62341001 & 46150 & 48 & \\
\hline 62341002 & 46150 & 48 & \\
\hline 62341003 & 46148 & 47 & MBO administratie \\
\hline 62341004 & 46150 & 48 & MBO handel \\
\hline 62341005 & 46150 & 48 & \\
\hline 62341100 & 46138 & 47 & MBO administratie \\
\hline 62341101 & 46148 & 47 & \\
\hline 62341102 & 46148 & 47 & \\
\hline 62341103 & 46148 & 47 & \\
\hline 62341104 & 46148 & 47 & \\
\hline 62341105 & 46148 & 47 & \\
\hline 62341106 & 46148 & 47 & \\
\hline 62341200 & 46138 & 47 & \\
\hline 62341201 & 46138 & 47 & \\
\hline 62341300 & 46150 & 48 & MBO handel \\
\hline 62341301 & 46150 & 48 & \\
\hline 62342000 & 48340 & 45 & MBO horeca \\
\hline 62342001 & 48140 & 45 & \\
\hline 62342002 & 48140 & 45 & \\
\hline 62342100 & 46142 & 50 & MBO toerisme en recreatie \\
\hline 62342101 & 46142 & 50 & \\
\hline 62350000 & 48100 & 40 & MBO verpleging \\
\hline 62350400 & 48100 & 40 & \\
\hline 62350401 & 48180 & 43 & MBO verzorging \\
\hline 62350402 & 48121 & 43 & \\
\hline 62351000 & 48130 & 44 & MBO uiterlijke verzorging \\
\hline 62351001 & 48130 & 44 & \\
\hline 62351002 & 48130 & 44 & \\
\hline
\end{tabular}


4. Opleidingstype per opleiding (vervolg)

\begin{tabular}{|c|c|c|c|}
\hline \multicolumn{4}{|c|}{ Onderwijstype } \\
\hline 62351003 & 48130 & 44 & \\
\hline 62360000 & 47100 & 42 & MBO sociaal-cultureel \\
\hline 62360300 & 47118 & 42 & \\
\hline 62360301 & 48123 & 43 & MBO verzorging \\
\hline 62360400 & 47115 & 42 & MBO sociaal-cultureel \\
\hline 62410000 & 42110 & 20 & MBO landbouw en veeteelt \\
\hline 62430100 & 43618 & 23 & MBO bouw \\
\hline 62430105 & 43618 & 23 & \\
\hline 62430107 & 43618 & 23 & \\
\hline 62430200 & 43611 & 23 & \\
\hline 62430201 & 43685 & 48 & MBO handel \\
\hline 62430202 & 43617 & 48 & \\
\hline 62430203 & 43611 & 23 & MBO bouw \\
\hline 62430204 & 43611 & 23 & \\
\hline 62430210 & 43611 & 23 & \\
\hline 62431000 & 43618 & 23 & \\
\hline 62431001 & 43623 & 24 & MBO grond-, weg- en waterbouw \\
\hline 62431200 & 43670 & 23 & MBO bouw \\
\hline 62431201 & 43670 & 23 & \\
\hline 62432700 & 43633 & 26 & MBO werktuigbouw en mechanische techniek \\
\hline 62432701 & 43633 & 26 & \\
\hline 62432702 & 43633 & 26 & \\
\hline 62434100 & 43841 & 28 & MBO motorvoertuigentechniek \\
\hline 62434101 & 43841 & 28 & \\
\hline 62435600 & 45230 & 40 & MBO verpleging \\
\hline 62435601 & 45231 & 41 & MBO gezondheidstechniek \\
\hline 62435700 & 43685 & 48 & MBO handel \\
\hline 62435701 & 43685 & 48 & \\
\hline 62435702 & 45235 & 41 & MBO gezondheidstechniek \\
\hline 62436000 & 43668 & 32 & MBO grafische techniek \\
\hline 62436001 & 43668 & 32 & \\
\hline 62436002 & 43668 & 32 & \\
\hline 62436003 & 43668 & 32 & \\
\hline 62436004 & 43668 & 32 & \\
\hline 62436500 & 43885 & 48 & MBO handel \\
\hline 62436501 & 43885 & 48 & \\
\hline 62436502 & 43885 & 48 & \\
\hline 62436503 & 43885 & 48 & \\
\hline 62436504 & 43885 & 48 & \\
\hline 62437300 & 43678 & 33 & MBO procestechniek \\
\hline 62438300 & 44200 & 36 & MBO vervoer en logistiek \\
\hline 62438301 & 44300 & 36 & \\
\hline 62438400 & 44310 & 36 & \\
\hline 62438401 & 44310 & 36 & \\
\hline 62438402 & 44110 & 36 & \\
\hline 62439000 & 43676 & 34 & MBO brood en banket \\
\hline 62439001 & 43676 & 34 & \\
\hline 62439002 & 43676 & 34 & \\
\hline 62439003 & 43876 & 34 & \\
\hline 62440000 & 46110 & 47 & MBO administratie \\
\hline 62440100 & 46135 & 52 & MBO automatisering \\
\hline 62440101 & 46135 & 52 & \\
\hline 62440102 & 46135 & 52 & \\
\hline 62440103 & 46135 & 52 & \\
\hline 62440200 & 46133 & 47 & MBO administratie \\
\hline 62440201 & 46133 & 47 & \\
\hline 62440400 & 46148 & 47 & \\
\hline 62440401 & 46143 & 48 & MBO handel \\
\hline 62440402 & 46145 & 53 & MBO geld, bank en belastingen \\
\hline 62440403 & 46146 & 54 & MBO verzekeringswezen \\
\hline 62440500 & 46628 & 47 & MBO administratie \\
\hline 62440501 & 46628 & 47 & \\
\hline
\end{tabular}


4. Opleidingstype per opleiding (vervolg)

\begin{tabular}{|c|c|c|c|}
\hline \multicolumn{3}{|c|}{ Onderwijstype } & Opleidingstype \\
\hline 62440600 & 44180 & 36 & MBO vervoer en logistiek \\
\hline 62440601 & 44180 & 36 & \\
\hline 62440602 & 44180 & 36 & \\
\hline 62440700 & 46131 & 49 & MBO secretariaat \\
\hline 62440701 & 46131 & 49 & \\
\hline 62441000 & 46150 & 48 & MBO handel \\
\hline 62441001 & 46150 & 48 & \\
\hline 62441002 & 46150 & 48 & \\
\hline 62441003 & 46150 & 48 & \\
\hline 62441100 & 46138 & 47 & MBO administratie \\
\hline 62441101 & 46148 & 47 & \\
\hline 62441102 & 46150 & 48 & MBO handel \\
\hline 62441200 & 46138 & 47 & MBO administratie \\
\hline 62441201 & 46138 & 47 & \\
\hline 62441300 & 46150 & 48 & MBO handel \\
\hline 62441301 & 46150 & 48 & \\
\hline 62442000 & 48340 & 45 & MBO horeca \\
\hline 62442001 & 46150 & 48 & MBO handel \\
\hline 62442002 & 48340 & 45 & MBO horeca \\
\hline 62442003 & 43618 & 23 & MBO bouw \\
\hline 62450000 & 48100 & 40 & MBO verpleging \\
\hline 62450103 & 45220 & 39 & MBO apothekersassistent \\
\hline 62450400 & 45120 & 40 & MBO verpleging \\
\hline 62450401 & 45120 & 40 & \\
\hline 62450500 & 45120 & 40 & \\
\hline 62460000 & 47100 & 42 & MBO sociaal-cultureel \\
\hline 62460100 & 47111 & 42 & \\
\hline 62460101 & 47111 & 42 & \\
\hline 62460200 & 47115 & 42 & \\
\hline 62460201 & 47115 & 42 & \\
\hline 62460300 & 47118 & 42 & \\
\hline 62460301 & 45148 & 46 & MBO beweging en therapie \\
\hline 62460302 & 47118 & 42 & MBO sociaal-cultureel \\
\hline 62460400 & 47118 & 42 & \\
\hline 62460401 & 47118 & 42 & \\
\hline 62460402 & 47111 & 42 & \\
\hline 62510000 & 42110 & 20 & MBO landbouw en veeteelt \\
\hline 62510100 & 42110 & 20 & \\
\hline 62510101 & 42110 & 20 & \\
\hline 62510102 & 42110 & 20 & \\
\hline 62510103 & 42110 & 20 & \\
\hline 62510104 & 42110 & 20 & \\
\hline 62510200 & 42158 & 20 & \\
\hline 62510201 & 42158 & 20 & \\
\hline 62510202 & 42158 & 20 & \\
\hline 62510203 & 42158 & 20 & \\
\hline 62510300 & 43677 & 35 & MBO levensmiddelentechniek/vleesverwerking \\
\hline 62510301 & 43677 & 35 & \\
\hline 62510302 & 43677 & 35 & \\
\hline 62510303 & 43677 & 35 & \\
\hline 62510304 & 43677 & 35 & \\
\hline 62510305 & 43677 & 35 & \\
\hline 62510306 & 43677 & 35 & \\
\hline 62510400 & 42320 & 20 & MBO landbouw en veeteelt \\
\hline 62510401 & 42320 & 20 & \\
\hline 62510500 & 42153 & 20 & \\
\hline 62510501 & 42158 & 20 & \\
\hline 62510502 & 42158 & 20 & \\
\hline 62510700 & 42158 & 20 & \\
\hline 62510701 & 42158 & 20 & \\
\hline 62510702 & 42158 & 20 & \\
\hline 62510800 & 42183 & 21 & MBO milieu en groene ruimte \\
\hline
\end{tabular}


4. Opleidingstype per opleiding (vervolg)

\begin{tabular}{|c|c|c|c|}
\hline \multicolumn{4}{|c|}{ Onderwijstype } \\
\hline 62510801 & 42183 & 21 & \\
\hline 62510802 & 42175 & 21 & \\
\hline 62510803 & 42130 & 21 & \\
\hline 62530100 & 43618 & 23 & MBO bouw \\
\hline 62530101 & 43611 & 23 & \\
\hline 62530102 & 43614 & 23 & \\
\hline 62530103 & 43814 & 23 & \\
\hline 62530104 & 43618 & 23 & \\
\hline 62531000 & 43618 & 23 & \\
\hline 62531001 & 43614 & 23 & \\
\hline 62531100 & 43815 & 23 & \\
\hline 62531101 & 43615 & 23 & \\
\hline 62531102 & 43615 & 23 & \\
\hline 62532700 & 43633 & 26 & MBO werktuigbouw en mechanische techniek \\
\hline 62533000 & 43655 & 31 & MBO elektrotechniek \\
\hline 62533001 & 43647 & 26 & MBO werktuigbouw en mechanische techniek \\
\hline 62533500 & 43648 & 26 & \\
\hline 62533501 & 43647 & 26 & \\
\hline 62533502 & 43648 & 26 & \\
\hline 62533700 & 43647 & 26 & \\
\hline 62533701 & 43647 & 26 & \\
\hline 62533702 & 43647 & 26 & \\
\hline 62534000 & 43841 & 28 & MBO motorvoertuigentechniek \\
\hline 62534001 & 43841 & 28 & \\
\hline 62534002 & 43841 & 28 & \\
\hline 62534100 & 43841 & 28 & \\
\hline 62534101 & 43841 & 28 & \\
\hline 62534102 & 43841 & 28 & \\
\hline 62534103 & 43641 & 28 & \\
\hline 62534104 & 43841 & 28 & \\
\hline 62534105 & 43841 & 28 & \\
\hline 62534106 & 43841 & 28 & \\
\hline 62534107 & 43841 & 28 & \\
\hline 62534108 & 43841 & 28 & \\
\hline 62534109 & 43841 & 28 & \\
\hline 62534500 & 43651 & 31 & MBO elektrotechniek \\
\hline 62534501 & 43653 & 31 & \\
\hline 62534502 & 43651 & 31 & \\
\hline 62534504 & 43653 & 31 & \\
\hline 62534600 & 43651 & 31 & \\
\hline 62534601 & 43651 & 31 & \\
\hline 62534602 & 43651 & 31 & \\
\hline 62534700 & 43652 & 31 & \\
\hline 62534701 & 43654 & 31 & \\
\hline 62534702 & 43654 & 31 & \\
\hline 62535000 & 43616 & 25 & MBO installatietechniek \\
\hline 62535001 & 43647 & 26 & MBO werktuigbouw en mechanische techniek \\
\hline 62535600 & 45230 & 41 & MBO gezondheidstechniek \\
\hline 62535601 & 45235 & 41 & \\
\hline 62535700 & 43685 & 48 & MBO handel \\
\hline 62536000 & 43868 & 32 & MBO grafische techniek \\
\hline 62536001 & 43868 & 32 & \\
\hline 62537300 & 43678 & 33 & MBO procestechniek \\
\hline 62537301 & 43678 & 33 & \\
\hline 62537302 & 43678 & 33 & \\
\hline 62538000 & 44350 & 36 & MBO vervoer en logistiek \\
\hline 62538001 & 44350 & 36 & \\
\hline 62538002 & 44310 & 36 & \\
\hline 62538400 & 44310 & 36 & \\
\hline 62538401 & 44150 & 36 & \\
\hline 62539000 & 43676 & 34 & MBO brood en banket \\
\hline 62539001 & 43676 & 34 & \\
\hline
\end{tabular}


4. Opleidingstype per opleiding (vervolg)

\begin{tabular}{|c|c|c|c|}
\hline \multicolumn{3}{|c|}{ Onderwijstype } & Opleidingstype \\
\hline 62539002 & 43676 & 34 & \\
\hline 62540100 & 46135 & 52 & MBO automatisering \\
\hline 62540101 & 46135 & 52 & \\
\hline 62540102 & 46135 & 52 & \\
\hline 62540103 & 46135 & 52 & \\
\hline 62542000 & 48340 & 45 & MBO horeca \\
\hline 62542001 & 48140 & 45 & \\
\hline 62542002 & 48140 & 45 & \\
\hline 62542003 & 48140 & 45 & \\
\hline 62550000 & 48100 & 40 & MBO verpleging \\
\hline 62550400 & 45210 & 22 & MBO laboratorium \\
\hline 62550401 & 40617 & 56 & MBO overig \\
\hline 62650100 & 45120 & 40 & MBO verpleging \\
\hline 62650200 & 45120 & 40 & \\
\hline 62650300 & 45120 & 40 & \\
\hline 62650400 & 45120 & 40 & \\
\hline 62650500 & 45120 & 40 & \\
\hline 62650600 & 45120 & 40 & \\
\hline 62650700 & 45243 & 40 & \\
\hline 62650800 & 45241 & 40 & \\
\hline \multicolumn{4}{|l|}{ HBO } \\
\hline 71130100 & 54180 & 74 & HBO vervoer en logistiek \\
\hline 71130300 & 56120 & 85 & HBO bedrijfskunde \\
\hline 71131000 & 53688 & 93 & HBO overig \\
\hline 71131001 & 53652 & 72 & HBO informatica \\
\hline 71131002 & 53683 & 71 & HBO elektrotechniek \\
\hline 71131100 & 53168 & 68 & HBO bouwkunde \\
\hline 71131200 & 53623 & 69 & HBO civiele techniek \\
\hline 71132000 & 53653 & 71 & HBO elektrotechniek \\
\hline 71132100 & 53651 & 71 & \\
\hline 71132200 & 53652 & 72 & HBO informatica \\
\hline 71132300 & 53652 & 72 & \\
\hline 71133000 & 53648 & 70 & HBO werktuigbouwkunde \\
\hline 71133100 & 53648 & 70 & \\
\hline 71133200 & 53648 & 70 & \\
\hline 71137000 & 53140 & 67 & HBO laboratorium \\
\hline 71137100 & 53678 & 66 & HBO milieukunde en levensmiddelentechnologie \\
\hline 71137200 & 53140 & 67 & HBO laboratorium \\
\hline 71140000 & 56110 & 80 & HBO accountancy en bedrijfseconomie \\
\hline 71140300 & 56120 & 85 & HBO bedrijfskunde \\
\hline 71140301 & 56110 & 80 & HBO accountancy en bedrijfseconomie \\
\hline 71140302 & 56135 & 72 & $\mathrm{HBO}$ informatica \\
\hline 71140400 & 56120 & 85 & HBO bedrijfskunde \\
\hline 71140401 & 56120 & 85 & \\
\hline 71140402 & 56120 & 85 & \\
\hline 71140403 & 56120 & 85 & \\
\hline 71140404 & 56120 & 85 & \\
\hline 71140405 & 56120 & 85 & \\
\hline 71140406 & 56120 & 85 & \\
\hline 71140501 & 56142 & 82 & HBO toerisme en recreatie \\
\hline 71140502 & 56142 & 82 & \\
\hline 71140503 & 56142 & 82 & \\
\hline 71140504 & 56142 & 82 & \\
\hline 71141000 & 56133 & 80 & HBO accountancy en bedrijfseconomie \\
\hline 71141100 & 56133 & 80 & \\
\hline 71141101 & 56133 & 80 & \\
\hline 71141102 & 56133 & 80 & \\
\hline 71141103 & 56630 & 80 & \\
\hline 71141200 & 56120 & 85 & HBO bedrijfskunde \\
\hline 71141300 & 56120 & 85 & \\
\hline
\end{tabular}


4. Opleidingstype per opleiding (vervolg)

\begin{tabular}{|c|c|c|c|}
\hline \multicolumn{4}{|c|}{ Onderwijstype } \\
\hline 71141301 & 55380 & 75 & HBO verpleegkunde \\
\hline 71141400 & 56120 & 85 & HBO bedrijfskunde \\
\hline 71141500 & 56120 & 85 & \\
\hline 71141600 & 56623 & 83 & HBO recht en bestuur \\
\hline 71141601 & 56145 & 81 & HBO commerciële economie \\
\hline 71141700 & 56120 & 85 & HBO bedrijfskunde \\
\hline 71141800 & 56146 & 81 & HBO commerciële economie \\
\hline 71141900 & 56143 & 81 & \\
\hline 71141901 & 56143 & 81 & \\
\hline 71141903 & 56141 & 86 & HBO communicatie en journalistiek \\
\hline 71141904 & 56143 & 81 & HBO commerciële economie \\
\hline 71141905 & 56143 & 81 & \\
\hline 71141906 & 56145 & 81 & \\
\hline 71142000 & 56131 & 84 & HBO secretariaat \\
\hline 71142001 & 56131 & 84 & \\
\hline 71142100 & 56148 & 81 & HBO commerciële economie \\
\hline 71143000 & 56141 & 86 & HBO communicatie en journalistiek \\
\hline 71143100 & 57130 & 89 & HBO bibliotheek en documentatie \\
\hline 71143200 & 51188 & 64 & HBO tolk en vertaler \\
\hline 71143201 & 51188 & 64 & \\
\hline 71143202 & 51188 & 64 & \\
\hline 71143203 & 51188 & 64 & \\
\hline 71143500 & 56120 & 85 & HBO bedrijfskunde \\
\hline 71143600 & 56142 & 82 & HBO toerisme en recreatie \\
\hline 71143700 & 58340 & 93 & HBO overig \\
\hline 71143800 & 56142 & 82 & HBO toerisme en recreatie \\
\hline 71143900 & 56142 & 82 & \\
\hline 71144000 & 56120 & 85 & HBO bedrijfskunde \\
\hline 71144100 & 56120 & 85 & \\
\hline 71144200 & 56120 & 85 & \\
\hline 71144300 & 56120 & 85 & \\
\hline 71160100 & 57113 & 88 & HBO personeel en arbeid \\
\hline 71160101 & 57113 & 88 & \\
\hline 71160200 & 57148 & 90 & HBO sociaal-cultureel overig \\
\hline 71160201 & 57148 & 90 & \\
\hline 71160202 & 57148 & 90 & \\
\hline 71160203 & 57148 & 90 & \\
\hline 71160204 & 57148 & 90 & \\
\hline 71160205 & 57148 & 90 & \\
\hline 71160206 & 57148 & 90 & \\
\hline 71160300 & 57148 & 90 & \\
\hline 71160301 & 57148 & 90 & \\
\hline 71160302 & 51188 & 64 & HBO tolk en vertaler \\
\hline 71160303 & 57188 & 87 & HBO maatschappelijk werk en hulpverlening \\
\hline 71160304 & 51181 & 64 & HBO tolk en vertaler \\
\hline 71160305 & 57148 & 90 & HBO sociaal-cultureel overig \\
\hline 71190000 & 53120 & 71 & HBO elektrotechniek \\
\hline 71190100 & 53120 & 71 & \\
\hline 71190101 & 53120 & 71 & \\
\hline 71190102 & 53120 & 71 & \\
\hline 71190103 & 53120 & 71 & \\
\hline 71190104 & 53120 & 71 & \\
\hline 71190105 & 53120 & 71 & \\
\hline 71190106 & 53120 & 71 & \\
\hline 71310000 & 52110 & 65 & HBO landbouw en veeteelt \\
\hline 71310100 & 52110 & 65 & \\
\hline 71310200 & 52110 & 65 & \\
\hline 71310300 & 52128 & 66 & HBO milieukunde en levensmiddelentechnologie \\
\hline 71310400 & 52110 & 65 & HBO landbouw en veeteelt \\
\hline 71310500 & 52158 & 65 & \\
\hline 71310600 & 52110 & 65 & \\
\hline 71310700 & 52110 & 65 & \\
\hline
\end{tabular}


4. Opleidingstype per opleiding (vervolg)

\begin{tabular}{|c|c|c|c|}
\hline \multicolumn{3}{|c|}{ Onderwijstype } & Opleidingstype \\
\hline 71312000 & 52310 & 85 & HBO bedrijfskunde \\
\hline 71312100 & 52310 & 85 & \\
\hline 71312200 & 52310 & 85 & \\
\hline 71312300 & 52310 & 85 & \\
\hline 71313000 & 52175 & 66 & HBO milieukunde en levensmiddelentechnologie \\
\hline 71313100 & 52183 & 66 & \\
\hline 71313200 & 52130 & 66 & \\
\hline 71313300 & 52175 & 66 & \\
\hline 71313400 & 52175 & 66 & \\
\hline 71313500 & 52175 & 66 & \\
\hline 71314000 & 53120 & 71 & HBO elektrotechniek \\
\hline 71314100 & 53677 & 66 & HBO milieukunde en levensmiddelentechnologie \\
\hline 71314200 & 53120 & 71 & HBO elektrotechniek \\
\hline 71314300 & 53160 & 67 & HBO laboratorium \\
\hline 71315000 & 50637 & 59 & HBO lerarenopleiding natuur en techniek \\
\hline 71315001 & 50637 & 59 & \\
\hline 71315002 & 50637 & 59 & \\
\hline 71315003 & 50637 & 59 & \\
\hline 71315004 & 50637 & 59 & \\
\hline 71315100 & 50637 & 59 & \\
\hline 71315101 & 50637 & 59 & \\
\hline 71315200 & 50658 & 59 & \\
\hline 71315300 & 50637 & 59 & \\
\hline 71315400 & 50637 & 59 & \\
\hline 71316000 & 50637 & 59 & \\
\hline 71320000 & 57148 & 90 & HBO sociaal-cultureel overig \\
\hline 71320100 & 50613 & 57 & HBO lerarenopleiding basisonderwijs \\
\hline 71320101 & 50613 & 57 & \\
\hline 71320102 & 50613 & 57 & \\
\hline 71320103 & 50613 & 57 & \\
\hline 71320104 & 50613 & 57 & \\
\hline 71320105 & 50613 & 57 & \\
\hline 71320106 & 50613 & 57 & \\
\hline 71320107 & 50613 & 57 & \\
\hline 71320108 & 50613 & 57 & \\
\hline 71320109 & 50613 & 57 & \\
\hline 71320110 & 50613 & 57 & \\
\hline 71320111 & 50613 & 57 & \\
\hline 71320112 & 50613 & 57 & \\
\hline 71320113 & 50628 & 58 & HBO lerarenopleiding talen \\
\hline 71320114 & 50613 & 57 & HBO lerarenopleiding basisonderwijs \\
\hline 71320115 & 50613 & 57 & \\
\hline 71320116 & 50613 & 57 & \\
\hline 71320201 & 50628 & 58 & HBO lerarenopleiding talen \\
\hline 71320202 & 50623 & 58 & \\
\hline 71320203 & 50624 & 58 & \\
\hline 71320204 & 50625 & 58 & \\
\hline 71320205 & 50628 & 58 & \\
\hline 71320206 & 50621 & 58 & \\
\hline 71320207 & 50628 & 58 & \\
\hline 71320208 & 50628 & 58 & \\
\hline 71320209 & 50628 & 58 & \\
\hline 71320210 & 50628 & 58 & \\
\hline 71320300 & 50633 & 59 & HBO lerarenopleiding natuur en techniek \\
\hline 71320301 & 50666 & 60 & HBO lerarenopleiding economie en maatschappij \\
\hline 71320302 & 50661 & 60 & \\
\hline 71320303 & 50661 & 60 & \\
\hline 71320304 & 50626 & 60 & \\
\hline 71320305 & 50627 & 60 & \\
\hline 71320306 & 50627 & 60 & \\
\hline 71320307 & 50663 & 60 & \\
\hline 71320308 & 50674 & 62 & HBO lerarenopleiding medisch en verzorging \\
\hline
\end{tabular}


4. Opleidingstype per opleiding (vervolg)

\begin{tabular}{|c|c|c|c|}
\hline $\begin{array}{l}\text { Onderwijstype } \\
\text { SIS }\end{array}$ & SOI & ROA-nr. & Opleidingstype \\
\hline 71320309 & 50664 & 60 & HBO lerarenopleiding economie en maatschappij \\
\hline 71320310 & 50637 & 59 & HBO lerarenopleiding natuur en techniek \\
\hline 71320311 & 50674 & 62 & HBO lerarenopleiding medisch en verzorging \\
\hline 71320312 & 50674 & 62 & \\
\hline 71320401 & 50635 & 59 & HBO lerarenopleiding natuur en techniek \\
\hline 71320402 & 50633 & 59 & \\
\hline 71320403 & 50633 & 59 & \\
\hline 71320404 & 50631 & 59 & \\
\hline 71320405 & 50631 & 59 & \\
\hline 71320406 & 50633 & 59 & \\
\hline 71320501 & 50682 & 63 & HBO lerarenopleiding expressie \\
\hline 71320502 & 50681 & 63 & \\
\hline 71320503 & 50683 & 63 & \\
\hline 71320601 & 50643 & 59 & HBO lerarenopleiding natuur en techniek \\
\hline 71320602 & 50643 & 59 & \\
\hline 71320603 & 50658 & 59 & \\
\hline 71320604 & 50655 & 59 & \\
\hline 71320608 & 50658 & 59 & \\
\hline 71320609 & 50643 & 59 & \\
\hline 71320610 & 50653 & 59 & \\
\hline 71320611 & 50653 & 59 & \\
\hline 71320612 & 50653 & 59 & \\
\hline 71321001 & 60628 & 58 & HBO lerarenopleiding talen \\
\hline 71321002 & 60623 & 58 & \\
\hline 71321003 & 60624 & 58 & \\
\hline 71321004 & 60625 & 58 & \\
\hline 71321005 & 60628 & 58 & \\
\hline 71321006 & 60621 & 58 & \\
\hline 71321007 & 60628 & 58 & \\
\hline 71321008 & 60628 & 58 & \\
\hline 71321100 & 60663 & 60 & HBO lerarenopleiding economie en maatschappij \\
\hline 71321101 & 60666 & 60 & \\
\hline 71321102 & 60661 & 60 & \\
\hline 71321103 & 60661 & 60 & \\
\hline 71321104 & 60626 & 60 & \\
\hline 71321105 & 60628 & 58 & HBO lerarenopleiding talen \\
\hline 71321106 & 60628 & 58 & \\
\hline 71321107 & 60663 & 60 & HBO lerarenopleiding economie en maatschappij \\
\hline 71321108 & 50670 & 62 & HBO lerarenopleiding medisch en verzorging \\
\hline 71321201 & 60635 & 59 & HBO lerarenopleiding natuur en techniek \\
\hline 71321202 & 60633 & 59 & \\
\hline 71321203 & 60633 & 59 & \\
\hline 71321204 & 60631 & 59 & \\
\hline 71321300 & 60667 & 61 & HBO lerarenopleiding lichamelijke opvoeding \\
\hline 71321301 & 60667 & 61 & \\
\hline 71330100 & 53618 & 68 & HBO bouwkunde \\
\hline 71330101 & 53168 & 85 & HBO bedrijfskunde \\
\hline 71330102 & 53168 & 98 & WO bouwkunde \\
\hline 71330200 & 53623 & 69 & HBO civiele techniek \\
\hline 71330300 & 53625 & 69 & \\
\hline 71330400 & 53623 & 69 & \\
\hline 71330500 & 57150 & 90 & HBO sociaal-cultureel overig \\
\hline 71330600 & 52175 & 66 & HBO milieukunde en levensmiddelentechnologie \\
\hline 71330700 & 54180 & 74 & HBO vervoer en logistiek \\
\hline 71330701 & 54180 & 74 & \\
\hline 71330800 & 54121 & 74 & \\
\hline 71332000 & 53651 & 71 & HBO elektrotechniek \\
\hline 71332001 & 53651 & 71 & \\
\hline 71332100 & 53652 & 72 & HBO informatica \\
\hline 71332200 & 53652 & 72 & \\
\hline 71332300 & 53652 & 72 & \\
\hline 71332301 & 53652 & 72 & \\
\hline
\end{tabular}


4. Opleidingstype per opleiding (vervolg)

\begin{tabular}{|c|c|c|c|}
\hline \multicolumn{4}{|c|}{ Onderwijstype } \\
\hline 71332302 & 53652 & 72 & \\
\hline 71332303 & 53652 & 72 & \\
\hline 71332304 & 53652 & 72 & \\
\hline 71332305 & 53652 & 72 & \\
\hline 71332400 & 53653 & 71 & HBO elektrotechniek \\
\hline 71332500 & 53655 & 71 & \\
\hline 71333000 & 53648 & 70 & HBO werktuigbouwkunde \\
\hline 71333100 & 53841 & 70 & \\
\hline 71333200 & 53645 & 70 & \\
\hline 71333300 & 53643 & 70 & \\
\hline 71333400 & 53682 & 71 & HBO elektrotechniek \\
\hline 71333500 & 53120 & 71 & \\
\hline 71333600 & 53688 & 93 & HBO overig \\
\hline 71334000 & 53675 & 73 & HBO chemische technologie \\
\hline 71334001 & 53675 & 73 & \\
\hline 71334002 & 53675 & 73 & \\
\hline 71334100 & 52175 & 66 & HBO milieukunde en levensmiddelentechnologie \\
\hline 71334200 & 53120 & 71 & HBO elektrotechniek \\
\hline 71334300 & 52175 & 66 & HBO milieukunde en levensmiddelentechnologie \\
\hline 71334400 & 53688 & 93 & HBO overig \\
\hline 71334500 & 53160 & 67 & HBO laboratorium \\
\hline 71334600 & 53160 & 67 & \\
\hline 71334700 & 53675 & 73 & HBO chemische technologie \\
\hline 71335000 & 53885 & 93 & HBO overig \\
\hline 71335100 & 56220 & 85 & HBO bedrijfskunde \\
\hline 71335101 & 56220 & 85 & \\
\hline 71335200 & 53818 & 68 & HBO bouwkunde \\
\hline 71335300 & 58610 & 91 & HBO uitvoerende en beeldende kunsten \\
\hline 71335400 & 53673 & 73 & HBO chemische technologie \\
\hline 71336000 & 53646 & 70 & HBO werktuigbouwkunde \\
\hline 71336100 & 53688 & 93 & HBO overig \\
\hline 71336101 & 53688 & 93 & \\
\hline 71336102 & 53688 & 93 & \\
\hline 71336200 & 53625 & 69 & HBO civiele techniek \\
\hline 71336300 & 54238 & 74 & HBO vervoer en logistiek \\
\hline 71336301 & 54238 & 74 & \\
\hline 71336400 & 54220 & 74 & \\
\hline 71337000 & 53140 & 67 & HBO laboratorium \\
\hline 71337100 & 53160 & 67 & \\
\hline 71337200 & 53140 & 67 & \\
\hline 71337300 & 55210 & 67 & \\
\hline 71337400 & 56135 & 72 & HBO informatica \\
\hline 71340000 & 56110 & 80 & HBO accountancy en bedrijfseconomie \\
\hline 71340100 & 56133 & 80 & \\
\hline 71340200 & 56110 & 80 & \\
\hline 71340201 & 56110 & 80 & \\
\hline 71340202 & 56110 & 80 & \\
\hline 71340203 & 56110 & 80 & \\
\hline 71340300 & 56110 & 80 & \\
\hline 71340400 & 56145 & 81 & HBO commerciële economie \\
\hline 71340500 & 56120 & 85 & HBO bedrijfskunde \\
\hline 71340501 & 56120 & 85 & \\
\hline 71340600 & 56133 & 80 & HBO accountancy en bedrijfseconomie \\
\hline 71340601 & 56133 & 80 & \\
\hline 71340602 & 56133 & 80 & \\
\hline 71340603 & 56133 & 80 & \\
\hline 71340700 & 56120 & 85 & HBO bedrijfskunde \\
\hline 71340701 & 56133 & 80 & HBO accountancy en bedrijfseconomie \\
\hline 71340702 & 56133 & 80 & \\
\hline 71340800 & 56148 & 81 & HBO commerciële economie \\
\hline 71341000 & 56628 & 83 & HBO recht en bestuur \\
\hline 71341100 & 56120 & 85 & HBO bedrijfskunde \\
\hline
\end{tabular}


4. Opleidingstype per opleiding (vervolg)

\begin{tabular}{|c|c|c|c|}
\hline \multicolumn{4}{|c|}{ Onderwijstype } \\
\hline 71341200 & 56135 & 72 & HBO informatica \\
\hline 71341201 & 56135 & 72 & \\
\hline 71341300 & 56620 & 83 & HBO recht en bestuur \\
\hline 71341400 & 56620 & 83 & \\
\hline 71341500 & 56120 & 85 & HBO bedrijfskunde \\
\hline 71341502 & 56135 & 72 & HBO informatica \\
\hline 71341600 & 56131 & 84 & HBO secretariaat \\
\hline 71341700 & 56120 & 85 & HBO bedrijfskunde \\
\hline 71341800 & 53688 & 93 & $\mathrm{HBO}$ overig \\
\hline 71342000 & 56148 & 81 & HBO commerciële economie \\
\hline 71342001 & 56148 & 81 & \\
\hline 71342002 & 56148 & 81 & \\
\hline 71342003 & 56180 & 81 & \\
\hline 71342004 & 56148 & 81 & \\
\hline 71342005 & 56148 & 81 & \\
\hline 71342100 & 56120 & 85 & HBO bedrijfskunde \\
\hline 71342101 & 54180 & 74 & HBO vervoer en logistiek \\
\hline 71342200 & 56131 & 84 & HBO secretariaat \\
\hline 71342300 & 56148 & 81 & HBO commerciële economie \\
\hline 71342400 & 58180 & 77 & HBO voeding \\
\hline 71342500 & 56143 & 81 & HBO commerciële economie \\
\hline 71342600 & 56142 & 82 & HBO toerisme en recreatie \\
\hline 71343000 & 57130 & 89 & HBO bibliotheek en documentatie \\
\hline 71343100 & 57130 & 89 & \\
\hline 71343200 & 56141 & 86 & HBO communicatie en journalistiek \\
\hline 71343300 & 56135 & 72 & HBO informatica \\
\hline 71343400 & 56138 & 80 & HBO accountancy en bedrijfseconomie \\
\hline 71343500 & 57120 & 86 & HBO communicatie en journalistiek \\
\hline 71343501 & 57120 & 86 & \\
\hline 71343502 & 52188 & 66 & HBO milieukunde en levensmiddelentechnologie \\
\hline 71343600 & 51188 & 64 & HBO tolk en vertaler \\
\hline 71343610 & 51133 & 64 & \\
\hline 71343611 & 51133 & 64 & \\
\hline 71343620 & 51133 & 64 & \\
\hline 71343700 & 56141 & 86 & HBO communicatie en journalistiek \\
\hline 71343800 & 56141 & 86 & \\
\hline 71345000 & 56120 & 85 & HBO bedrijfskunde \\
\hline 71345001 & 56120 & 85 & \\
\hline 71345002 & 56120 & 85 & \\
\hline 71345100 & 58340 & 93 & HBO overig \\
\hline 71345200 & 56142 & 82 & HBO toerisme en recreatie \\
\hline 71345300 & 56142 & 82 & \\
\hline 71350100 & 55120 & 75 & HBO verpleegkunde \\
\hline 71350101 & 55120 & 75 & \\
\hline 71350200 & 55120 & 75 & \\
\hline 71350300 & 55120 & 75 & \\
\hline 71351000 & 55238 & 76 & HBO (fysio)therapie \\
\hline 71351100 & 55243 & 78 & HBO radiologie \\
\hline 71351200 & 55141 & 76 & HBO (fysio)therapie \\
\hline 71351300 & 55143 & 76 & \\
\hline 71351400 & 55151 & 76 & \\
\hline 71351500 & 55231 & 79 & HBO paramedisch overig \\
\hline 71351600 & 58180 & 77 & HBO voeding \\
\hline 71351700 & 55120 & 75 & HBO verpleegkunde \\
\hline 71351800 & 55133 & 79 & HBO paramedisch overig \\
\hline 71351900 & 55153 & 76 & HBO (fysio)therapie \\
\hline 71352000 & 55241 & 78 & $\mathrm{HBO}$ radiologie \\
\hline 71352100 & 55480 & 79 & HBO paramedisch overig \\
\hline 71352200 & 55120 & 75 & $\mathrm{HBO}$ verpleegkunde \\
\hline 71352300 & 55120 & 75 & \\
\hline 71352400 & 55243 & 78 & $\mathrm{HBO}$ radiologie \\
\hline 71353000 & 55113 & 79 & HBO paramedisch overig \\
\hline
\end{tabular}


4. Opleidingstype per opleiding (vervolg)

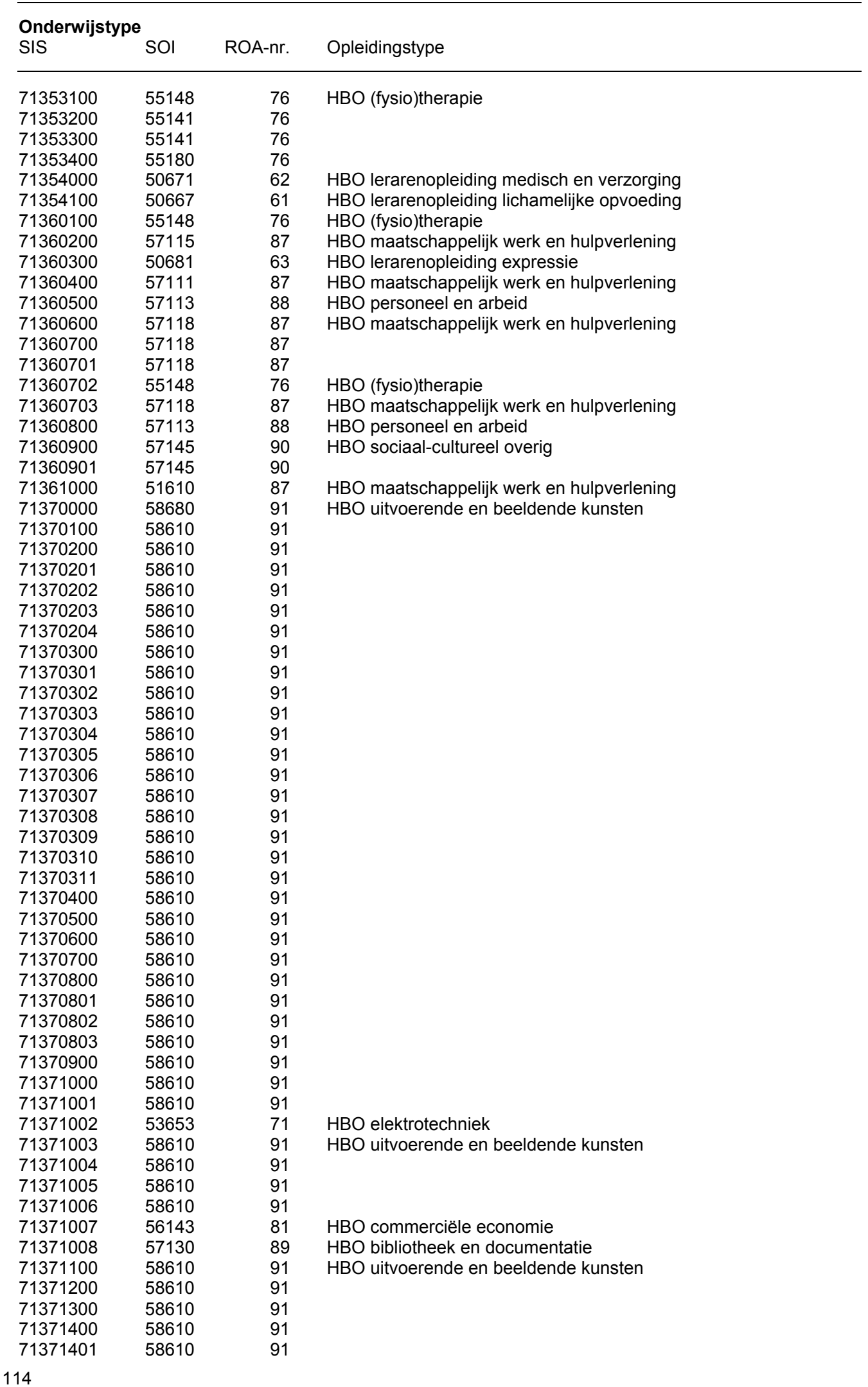


4. Opleidingstype per opleiding (vervolg)

\begin{tabular}{|c|c|c|c|}
\hline \multicolumn{4}{|c|}{ Onderwijstype } \\
\hline 71372000 & 58630 & 91 & \\
\hline 71372001 & 58630 & 91 & \\
\hline 71372002 & 58630 & 91 & \\
\hline 71372003 & 58630 & 91 & \\
\hline 71372004 & 58630 & 91 & \\
\hline 71372100 & 58630 & 91 & \\
\hline 71372200 & 50685 & 63 & HBO lerarenopleiding expressie \\
\hline 71372201 & 50685 & 63 & \\
\hline 71372202 & 50685 & 63 & \\
\hline 71372203 & 50685 & 63 & \\
\hline 71372204 & 50685 & 63 & \\
\hline 71372205 & 50685 & 63 & \\
\hline 71372206 & 50685 & 63 & \\
\hline 71372207 & 50685 & 63 & \\
\hline 71372300 & 58630 & 91 & HBO uitvoerende en beeldende kunsten \\
\hline 71372400 & 58680 & 91 & \\
\hline 71372401 & 58640 & 91 & \\
\hline 71372402 & 58680 & 91 & \\
\hline 71372500 & 50685 & 63 & HBO lerarenopleiding expressie \\
\hline 71372501 & 50685 & 63 & \\
\hline 71372600 & 58630 & 91 & HBO uitvoerende en beeldende kunsten \\
\hline 71372601 & 58630 & 91 & \\
\hline 71372602 & 58630 & 91 & \\
\hline 71372603 & 58630 & 91 & \\
\hline 71372604 & 58630 & 91 & \\
\hline 71372605 & 58630 & 91 & \\
\hline 71372607 & 58630 & 91 & \\
\hline 71372608 & 58630 & 91 & \\
\hline 71372609 & 58630 & 91 & \\
\hline 71372700 & 58630 & 91 & \\
\hline 71372800 & 58630 & 91 & \\
\hline 71373000 & 58630 & 91 & \\
\hline 71373100 & 58630 & 91 & \\
\hline 71373101 & 58630 & 91 & \\
\hline 71373200 & 58630 & 91 & \\
\hline 71373300 & 58630 & 91 & \\
\hline 71373301 & 58630 & 91 & \\
\hline 71373400 & 58630 & 91 & \\
\hline 71373500 & 58630 & 91 & \\
\hline 71374000 & 58620 & 91 & \\
\hline 71374100 & 58620 & 91 & \\
\hline 71374200 & 58620 & 91 & \\
\hline 71374201 & 58620 & 91 & \\
\hline 71374202 & 58620 & 91 & \\
\hline 71374203 & 58620 & 91 & \\
\hline 71374204 & 58620 & 91 & \\
\hline 71374205 & 58620 & 91 & \\
\hline 71374206 & 58620 & 91 & \\
\hline 71374207 & 58620 & 91 & \\
\hline 71374208 & 57120 & 86 & HBO communicatie en journalistiek \\
\hline 71374209 & 58610 & 91 & HBO uitvoerende en beeldende kunsten \\
\hline 71374300 & 58620 & 91 & \\
\hline 71374301 & 58620 & 91 & \\
\hline 71374302 & 58620 & 91 & \\
\hline 71374303 & 58620 & 91 & \\
\hline 71375000 & 60682 & 63 & HBO lerarenopleiding expressie \\
\hline 71375100 & 60683 & 63 & \\
\hline 71375200 & 60681 & 63 & \\
\hline 71375300 & 60682 & 63 & \\
\hline 71376000 & 50685 & 63 & \\
\hline 71376001 & 50685 & 63 & \\
\hline 71376100 & 60685 & 63 & \\
\hline
\end{tabular}


4. Opleidingstype per opleiding (vervolg)

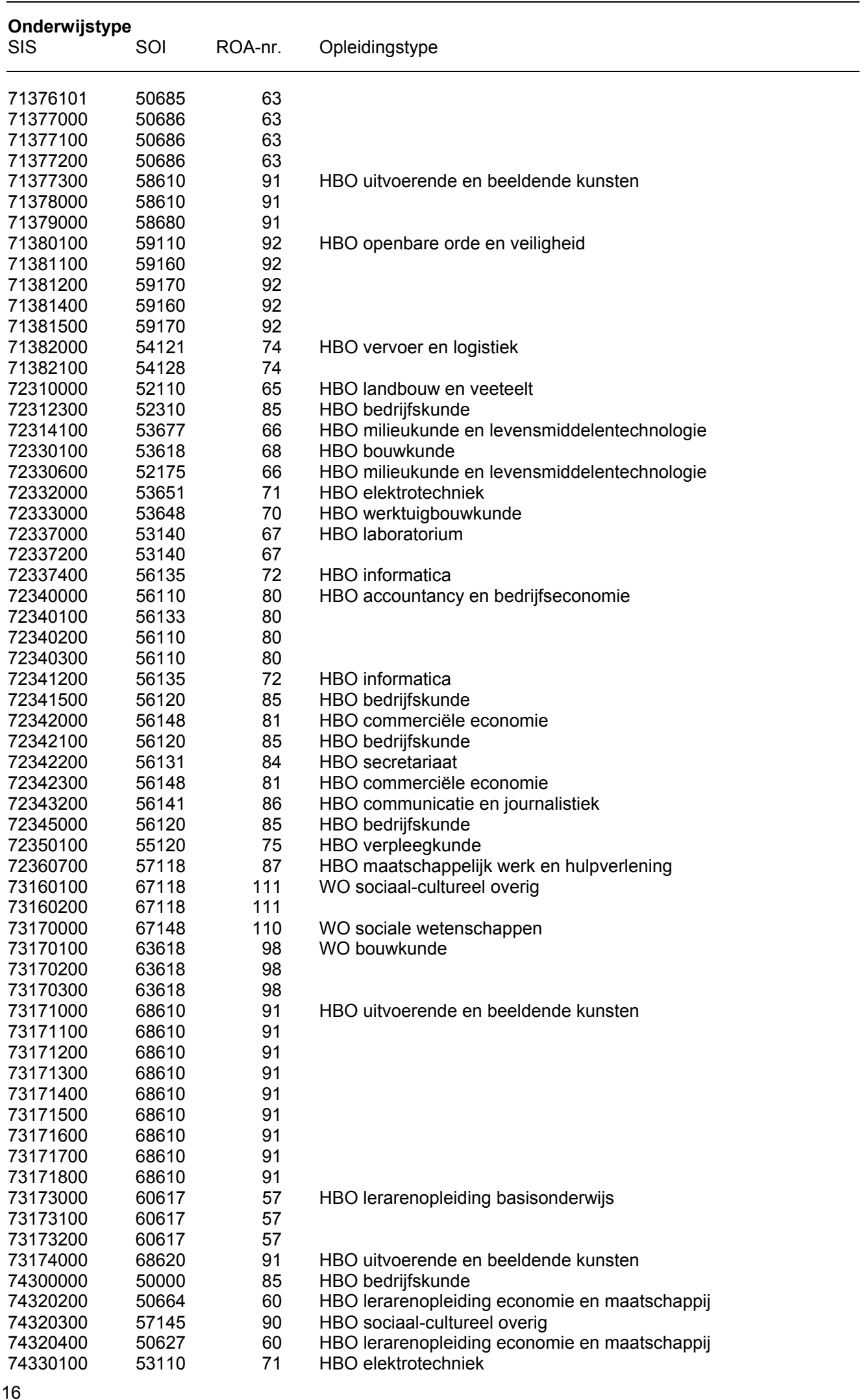


4. Opleidingstype per opleiding (vervolg)

\begin{tabular}{|c|c|c|c|}
\hline \multicolumn{4}{|c|}{ Onderwijstype } \\
\hline SIS & SOI & ROA-nr. & Opleidingstype \\
\hline 74340000 & 56110 & 80 & HBO accountancy en bedrijfseconomie \\
\hline 74340100 & 51121 & 64 & HBO tolk en vertaler \\
\hline 74340200 & 51131 & 64 & \\
\hline 74360100 & 57145 & 90 & HBO sociaal-cultureel overig \\
\hline 77110000 & 52110 & 65 & HBO landbouw en veeteelt \\
\hline 77120000 & 57148 & 90 & HBO sociaal-cultureel overig \\
\hline 77140000 & 56110 & 80 & HBO accountancy en bedrijfseconomie \\
\hline 77170000 & 57148 & 90 & HBO sociaal-cultureel overig \\
\hline 77190000 & 53120 & 71 & HBO elektrotechniek \\
\hline \multicolumn{4}{|l|}{ wo } \\
\hline 81120100 & 70623 & 58 & HBO lerarenopleiding talen \\
\hline 81120200 & 70624 & 58 & \\
\hline 81120300 & 70625 & 58 & \\
\hline 81120400 & 70628 & 58 & \\
\hline 81120500 & 70628 & 58 & \\
\hline 81120600 & 70628 & 58 & \\
\hline 81120700 & 70628 & 58 & \\
\hline 81120800 & 70688 & 63 & HBO lerarenopleiding expressie \\
\hline 81120900 & 70685 & 63 & \\
\hline 81121000 & 70621 & 58 & HBO lerarenopleiding talen \\
\hline 81121100 & 70628 & 58 & \\
\hline 81121200 & 70628 & 58 & \\
\hline 81121300 & 70628 & 58 & \\
\hline 81121400 & 70666 & 60 & HBO lerarenopleiding economie en maatschappij \\
\hline 81121500 & 70661 & 60 & \\
\hline 81121600 & 70661 & 60 & \\
\hline 81121700 & 70627 & 60 & \\
\hline 81121800 & 70628 & 58 & HBO lerarenopleiding talen \\
\hline 81121900 & 70626 & 60 & HBO lerarenopleiding economie en maatschappij \\
\hline 81122000 & 70663 & 60 & \\
\hline 81122100 & 70635 & 59 & HBO lerarenopleiding natuur en techniek \\
\hline 81122200 & 70633 & 59 & \\
\hline 81122300 & 70633 & 59 & \\
\hline 81122400 & 70638 & 97 & WO wiskunde en natuurwetenschappen \\
\hline 81122500 & 70631 & 59 & HBO lerarenopleiding natuur en techniek \\
\hline 81122600 & 70663 & 60 & HBO lerarenopleiding economie en maatschappij \\
\hline 81122700 & 70663 & 60 & \\
\hline 81122800 & 70633 & 59 & HBO lerarenopleiding natuur en techniek \\
\hline 81122900 & 70663 & 60 & HBO lerarenopleiding economie en maatschappij \\
\hline 81123000 & 70663 & 60 & \\
\hline 81123100 & 70666 & 60 & \\
\hline 81123200 & 70628 & 58 & HBO lerarenopleiding talen \\
\hline 81310000 & 62110 & 96 & WO landbouw en milieukunde \\
\hline 81310100 & 62130 & 96 & \\
\hline 81310200 & 62188 & 96 & \\
\hline 81311000 & 62188 & 96 & \\
\hline 81312000 & 62110 & 96 & \\
\hline 81312100 & 62128 & 96 & \\
\hline 81312200 & 62110 & 96 & \\
\hline 81313000 & 62158 & 96 & \\
\hline 81330000 & 63500 & 101 & WO elektrotechniek \\
\hline 81330100 & 63688 & 97 & WO wiskunde en natuurwetenschappen \\
\hline 81330101 & 63688 & 97 & \\
\hline 81330102 & 63688 & 97 & \\
\hline 81330103 & 63688 & 97 & \\
\hline 81330104 & 63688 & 97 & \\
\hline 81330200 & 63688 & 97 & \\
\hline 81330300 & 63160 & 97 & \\
\hline 81330400 & 63675 & 97 & \\
\hline 81330401 & 63675 & 97 & \\
\hline
\end{tabular}


4. Opleidingstype per opleiding (vervolg)

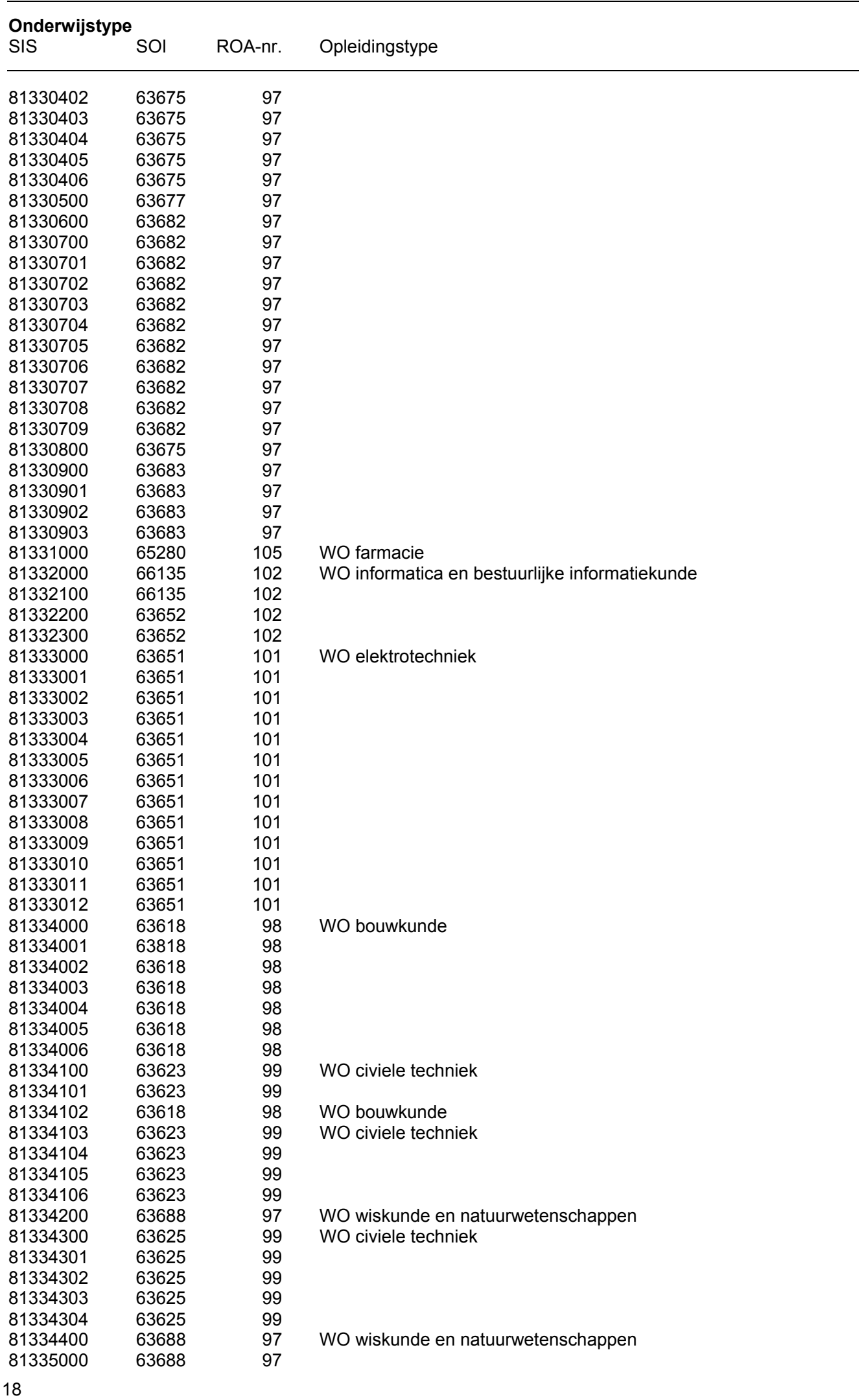


4. Opleidingstype per opleiding (vervolg)

\begin{tabular}{|c|c|c|c|}
\hline \multicolumn{4}{|c|}{ Onderwijstype } \\
\hline 81335001 & 63688 & 97 & \\
\hline 81335002 & 63688 & 97 & \\
\hline 81335003 & 63688 & 97 & \\
\hline 81335004 & 63688 & 97 & \\
\hline 81335100 & 62181 & 100 & WO werktuigbouwkunde \\
\hline 81335200 & 63645 & 100 & \\
\hline 81335201 & 63645 & 100 & \\
\hline 81335202 & 63645 & 100 & \\
\hline 81335203 & 63645 & 100 & \\
\hline 81335204 & 63645 & 100 & \\
\hline 81335205 & 63645 & 100 & \\
\hline 81335206 & 63645 & 100 & \\
\hline 81335207 & 63645 & 100 & \\
\hline 81335300 & 63643 & 100 & \\
\hline 81335301 & 63643 & 100 & \\
\hline 81335302 & 63643 & 100 & \\
\hline 81335400 & 63631 & 97 & WO wiskunde en natuurwetenschappen \\
\hline 81335401 & 63631 & 97 & \\
\hline 81335402 & 63631 & 97 & \\
\hline 81335403 & 63631 & 97 & \\
\hline 81335500 & 63648 & 100 & WO werktuigbouwkunde \\
\hline 81335501 & 63648 & 100 & \\
\hline 81335502 & 63648 & 100 & \\
\hline 81335503 & 63648 & 100 & \\
\hline 81335504 & 63648 & 100 & \\
\hline 81335505 & 63648 & 100 & \\
\hline 81335600 & 65230 & 105 & WO farmacie \\
\hline 81336000 & 66220 & 107 & WO bedrijfskunde \\
\hline 81336100 & 63688 & 97 & WO wiskunde en natuurwetenschappen \\
\hline 81336101 & 63688 & 97 & \\
\hline 81336102 & 63688 & 97 & \\
\hline 81336103 & 63688 & 97 & \\
\hline 81337000 & 67148 & 110 & WO sociale wetenschappen \\
\hline 81337100 & 61181 & 94 & WO letteren \\
\hline 81340000 & 66110 & 106 & WO econom(etr)ie \\
\hline 81340100 & 66110 & 106 & \\
\hline 81340110 & 66110 & 106 & \\
\hline 81340111 & 66110 & 106 & \\
\hline 81340112 & 66110 & 106 & \\
\hline 81340113 & 66110 & 106 & \\
\hline 81340114 & 66110 & 106 & \\
\hline 81340115 & 66110 & 106 & \\
\hline 81340116 & 66110 & 106 & \\
\hline 81340117 & 66110 & 106 & \\
\hline 81340118 & 66110 & 106 & \\
\hline 81340119 & 66110 & 106 & \\
\hline 81340120 & 66110 & 106 & \\
\hline 81340121 & 66110 & 106 & \\
\hline 81340122 & 66110 & 106 & \\
\hline 81340129 & 66110 & 106 & \\
\hline 81340130 & 66110 & 106 & \\
\hline 81340131 & 66110 & 106 & \\
\hline 81340132 & 66110 & 106 & \\
\hline 81340133 & 66110 & 106 & \\
\hline 81340134 & 66110 & 106 & \\
\hline 81340135 & 66110 & 106 & \\
\hline 81340136 & 66110 & 106 & \\
\hline 81340137 & 66110 & 106 & \\
\hline 81340138 & 66110 & 106 & \\
\hline 81340139 & 66110 & 106 & \\
\hline 81340140 & 66110 & 106 & \\
\hline 81340141 & 66110 & 106 & \\
\hline
\end{tabular}


4. Opleidingstype per opleiding (vervolg)

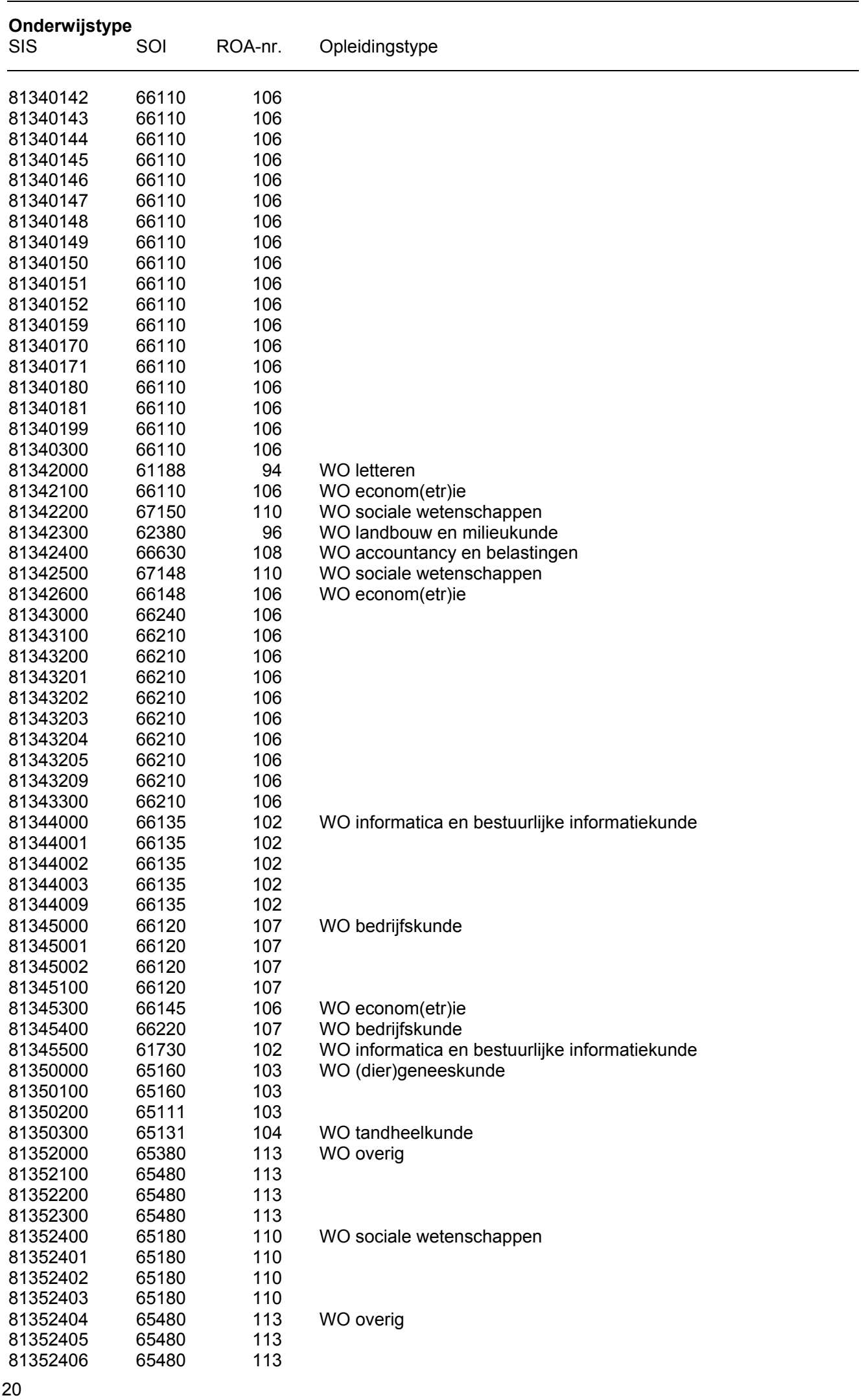


4. Opleidingstype per opleiding (vervolg)

\begin{tabular}{|c|c|c|c|}
\hline \multicolumn{4}{|c|}{ Onderwijstype } \\
\hline 81352407 & 65180 & 110 & WO sociale wetenschappen \\
\hline 81352408 & 65180 & 110 & \\
\hline 81352500 & 65280 & 105 & WO farmacie \\
\hline 81352501 & 65280 & 105 & \\
\hline 81352502 & 65280 & 105 & \\
\hline 81352600 & 65280 & 105 & \\
\hline 81352700 & 65280 & 105 & \\
\hline 81352800 & 65380 & 113 & WO overig \\
\hline 81353000 & 68180 & 110 & WO sociale wetenschappen \\
\hline 81360100 & 67148 & 110 & \\
\hline 81360200 & 67143 & 110 & \\
\hline 81360300 & 67148 & 110 & \\
\hline 81360400 & 67148 & 110 & \\
\hline 81361000 & 67145 & 110 & \\
\hline 81361100 & 67148 & 110 & \\
\hline 81361200 & 67148 & 110 & \\
\hline 81362000 & 67188 & 110 & \\
\hline 81362100 & 66140 & 106 & WO econom(etr)ie \\
\hline 81363000 & 67148 & 110 & WO sociale wetenschappen \\
\hline 81363100 & 67141 & 110 & \\
\hline 81363200 & 67148 & 110 & \\
\hline 81363300 & 62220 & 96 & WO landbouw en milieukunde \\
\hline 81363400 & 67148 & 110 & WO sociale wetenschappen \\
\hline 81363500 & 67148 & 110 & \\
\hline 81363600 & 67141 & 110 & \\
\hline 81363700 & 67148 & 110 & \\
\hline 81363800 & 68110 & 110 & \\
\hline 81365000 & 67148 & 110 & \\
\hline 81365100 & 67113 & 111 & WO sociaal-cultureel overig \\
\hline 81366000 & 66610 & 109 & WO rechten en bestuurskunde \\
\hline 81367000 & 66628 & 109 & \\
\hline 81367100 & 62175 & 96 & WO landbouw en milieukunde \\
\hline 81367200 & 66628 & 109 & WO rechten en bestuurskunde \\
\hline 81367300 & 66628 & 109 & \\
\hline 81367400 & 66628 & 109 & \\
\hline 81367500 & 67141 & 110 & WO sociale wetenschappen \\
\hline 81367501 & 67141 & 110 & \\
\hline 81367502 & 67141 & 110 & \\
\hline 81369000 & 67150 & 110 & \\
\hline 81369100 & 67150 & 110 & \\
\hline 81369200 & 67150 & 110 & \\
\hline 81369300 & 67150 & 110 & \\
\hline 81370000 & 61140 & 94 & WO letteren \\
\hline 81370100 & 61140 & 94 & \\
\hline 81370200 & 61140 & 94 & \\
\hline 81370300 & 61110 & 94 & \\
\hline 81370400 & 61188 & 94 & \\
\hline 81370500 & 61121 & 94 & \\
\hline 81370600 & 61123 & 94 & \\
\hline 81370700 & 61131 & 94 & \\
\hline 81370800 & 61125 & 94 & \\
\hline 81370900 & 61138 & 94 & \\
\hline 81371000 & 61185 & 94 & \\
\hline 81371100 & 61128 & 94 & \\
\hline 81371200 & 61138 & 94 & \\
\hline 81371300 & 61185 & 94 & \\
\hline 81371400 & 61138 & 94 & \\
\hline 81371500 & 61128 & 94 & \\
\hline 81371600 & 61133 & 94 & \\
\hline 81371700 & 61133 & 94 & \\
\hline 81371800 & 61185 & 94 & \\
\hline 81371900 & 61185 & 94 & \\
\hline
\end{tabular}


4. Opleidingstype per opleiding (vervolg)

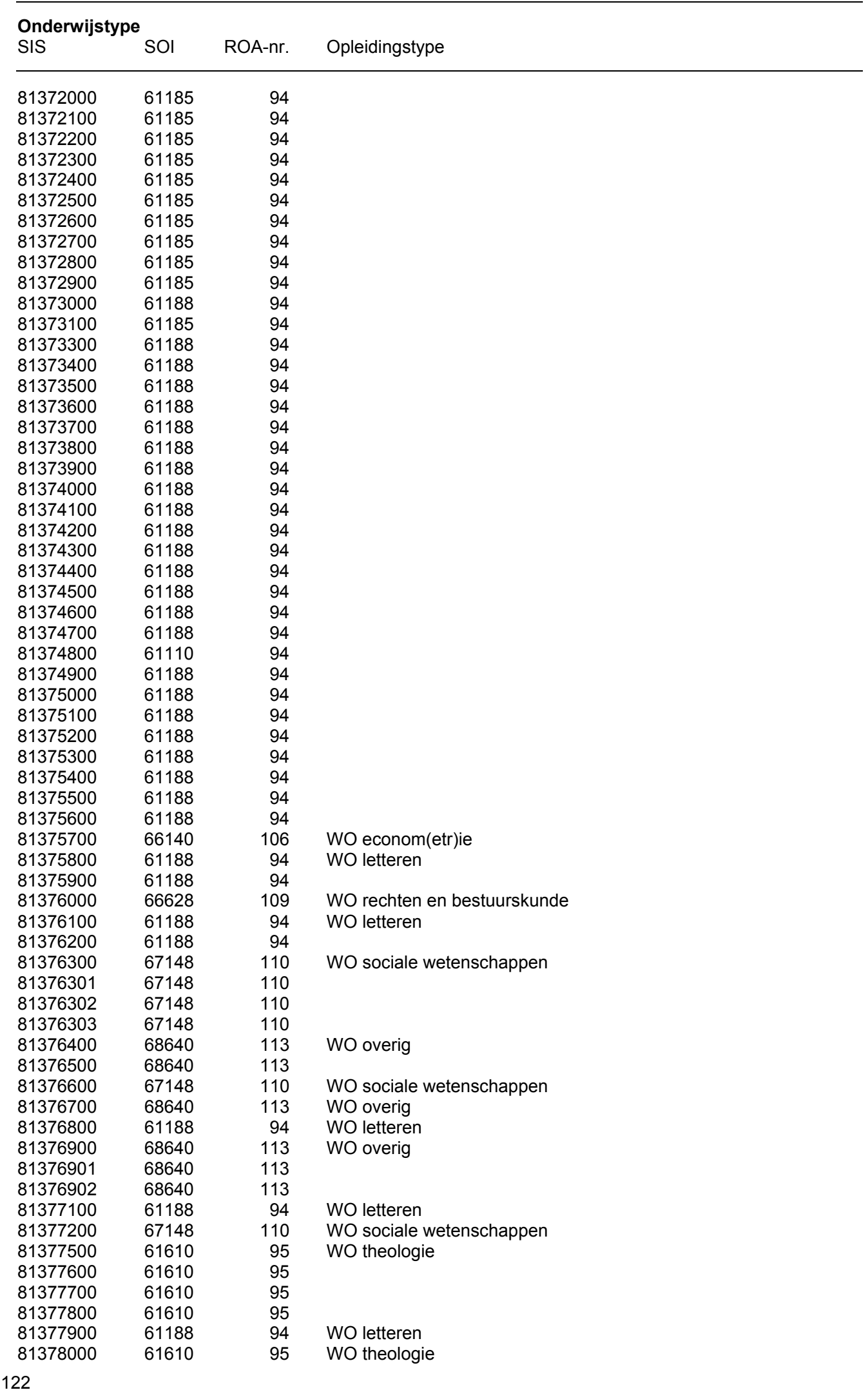


4. Opleidingstype per opleiding (vervolg)

\begin{tabular}{|c|c|c|c|}
\hline \multicolumn{4}{|c|}{ Onderwijstype } \\
\hline 81378100 & 61610 & 95 & \\
\hline 81378200 & 61610 & 95 & \\
\hline 81378300 & 67148 & 110 & WO sociale wetenschappen \\
\hline 81378500 & 61183 & 94 & WO letteren \\
\hline 81378501 & 61183 & 94 & \\
\hline 81378502 & 61183 & 94 & \\
\hline 81378600 & 61183 & 94 & \\
\hline 81378601 & 61183 & 94 & \\
\hline 81378800 & 61150 & 94 & \\
\hline 81378900 & 68640 & 113 & WO overig \\
\hline 81379000 & 67188 & 110 & WO sociale wetenschappen \\
\hline 81379100 & 61188 & 94 & WO letteren \\
\hline 81379200 & 61183 & 94 & \\
\hline 81379500 & 61181 & 94 & \\
\hline 81379600 & 61181 & 94 & \\
\hline 81379700 & 61181 & 94 & \\
\hline 81379800 & 61610 & 95 & WO theologie \\
\hline 81379900 & 61610 & 95 & \\
\hline 81380100 & 66611 & 109 & WO rechten en bestuurskunde \\
\hline 81380200 & 66611 & 109 & \\
\hline 81380299 & 66611 & 109 & \\
\hline 81380300 & 66611 & 109 & \\
\hline 81380400 & 66628 & 109 & \\
\hline 81380500 & 66611 & 109 & \\
\hline 81380600 & 66613 & 109 & \\
\hline 81380700 & 66630 & 108 & WO accountancy en belastingen \\
\hline 81380800 & 66611 & 109 & WO rechten en bestuurskunde \\
\hline 81380900 & 66618 & 109 & \\
\hline 81381000 & 66618 & 109 & \\
\hline 81381100 & 66618 & 109 & \\
\hline 81381200 & 66628 & 109 & \\
\hline 81381300 & 67141 & 110 & WO sociale wetenschappen \\
\hline 81381400 & 66618 & 109 & WO rechten en bestuurskunde \\
\hline 81390000 & 63120 & 97 & WO wiskunde en natuurwetenschappen \\
\hline 81390100 & 63110 & 97 & \\
\hline 81390200 & 63110 & 97 & \\
\hline 81390300 & 63110 & 97 & \\
\hline 81391000 & 66135 & 102 & WO informatica en bestuurlijke informatiekunde \\
\hline 81391100 & 66135 & 102 & \\
\hline 81391200 & 66135 & 102 & \\
\hline 81391300 & 63180 & 97 & WO wiskunde en natuurwetenschappen \\
\hline 81391400 & 63180 & 97 & \\
\hline 81391500 & 63683 & 97 & \\
\hline 81391600 & 66135 & 102 & WO informatica en bestuurlijke informatiekunde \\
\hline 81391700 & 63688 & 97 & WO wiskunde en natuurwetenschappen \\
\hline 81391701 & 63688 & 97 & \\
\hline 81391702 & 63688 & 97 & \\
\hline 81391703 & 63688 & 97 & \\
\hline 81391800 & 63180 & 97 & \\
\hline 81391900 & 63652 & 102 & WO informatica en bestuurlijke informatiekunde \\
\hline 81392000 & 63652 & 102 & \\
\hline 81392100 & 66135 & 102 & \\
\hline 81393000 & 63120 & 97 & WO wiskunde en natuurwetenschappen \\
\hline 81393100 & 63130 & 97 & \\
\hline 81393200 & 62188 & 96 & WO landbouw en milieukunde \\
\hline 81394000 & 63150 & 97 & WO wiskunde en natuurwetenschappen \\
\hline 81394100 & 63150 & 97 & \\
\hline 81394200 & 63150 & 97 & \\
\hline 81394300 & 63180 & 97 & \\
\hline 81394400 & 63170 & 97 & \\
\hline 81394500 & 62188 & 96 & WO landbouw en milieukunde \\
\hline 81395000 & 63140 & 97 & WO wiskunde en natuurwetenschappen \\
\hline
\end{tabular}


4. Opleidingstype per opleiding (vervolg)

\begin{tabular}{|c|c|c|c|}
\hline \multicolumn{3}{|c|}{ Onderwijstype } & Opleidingstype \\
\hline 81396000 & 65220 & 105 & WO farmacie \\
\hline 81396100 & 65220 & 105 & \\
\hline 81396200 & 65220 & 105 & \\
\hline 81396300 & 65220 & 105 & \\
\hline 81397000 & 63160 & 97 & WO wiskunde en natuurwetenschappen \\
\hline 81397100 & 63180 & 97 & \\
\hline 81397400 & 63180 & 97 & \\
\hline 81397500 & 62175 & 96 & WO landbouw en milieukunde \\
\hline 81397900 & 62175 & 96 & \\
\hline 81398000 & 63180 & 97 & WO wiskunde en natuurwetenschappen \\
\hline 81398100 & 63160 & 97 & \\
\hline 81398200 & 62175 & 96 & WO landbouw en milieukunde \\
\hline 81398201 & 62175 & 96 & \\
\hline 81398202 & 62175 & 96 & \\
\hline 81398300 & 62175 & 96 & \\
\hline 81398400 & 62175 & 96 & \\
\hline 81398500 & 62175 & 96 & \\
\hline 81398600 & 62175 & 96 & \\
\hline 81399000 & 63180 & 97 & WO wiskunde en natuurwetenschappen \\
\hline 81399001 & 63180 & 97 & \\
\hline 81399002 & 63180 & 97 & \\
\hline 81399200 & 67141 & 110 & WO sociale wetenschappen \\
\hline 81399300 & 62173 & 96 & WO landbouw en milieukunde \\
\hline 85240000 & 66110 & 106 & WO econom(etr)ie \\
\hline 85240100 & 66133 & 108 & WO accountancy en belastingen \\
\hline 85240200 & 66133 & 108 & \\
\hline 85240300 & 66135 & 102 & WO informatica en bestuurlijke informatiekunde \\
\hline 85250000 & 65280 & 105 & WO farmacie \\
\hline 85250100 & 65111 & 103 & WO (dier)geneeskunde \\
\hline 85250200 & 65111 & 103 & \\
\hline 85250300 & 65111 & 103 & \\
\hline 85250400 & 65111 & 103 & \\
\hline 85250401 & 65111 & 103 & \\
\hline 85250402 & 65111 & 103 & \\
\hline 85250403 & 65111 & 103 & \\
\hline 85250404 & 65111 & 103 & \\
\hline 85250405 & 65111 & 103 & \\
\hline 85250406 & 65111 & 103 & \\
\hline 85250407 & 65111 & 103 & \\
\hline 85250408 & 65111 & 103 & \\
\hline 85250409 & 65111 & 103 & \\
\hline 85250410 & 65111 & 103 & \\
\hline 85250411 & 65111 & 103 & \\
\hline 85250412 & 65111 & 103 & \\
\hline 85250413 & 65111 & 103 & \\
\hline 85250414 & 65111 & 103 & \\
\hline 85250415 & 65111 & 103 & \\
\hline 85250416 & 65111 & 103 & \\
\hline 85250417 & 65111 & 103 & \\
\hline 85250418 & 65111 & 103 & \\
\hline 85250419 & 65111 & 103 & \\
\hline 85250420 & 65111 & 103 & \\
\hline 85250421 & 65111 & 103 & \\
\hline 85250422 & 65111 & 103 & \\
\hline 85250423 & 65111 & 103 & \\
\hline 85250424 & 65111 & 103 & \\
\hline 85250425 & 65111 & 103 & \\
\hline 85250426 & 65111 & 103 & \\
\hline 85250427 & 65111 & 103 & \\
\hline 85250428 & 65111 & 103 & \\
\hline 85250429 & 65111 & 103 & \\
\hline 85250430 & 65111 & 103 & \\
\hline
\end{tabular}


4. Opleidingstype per opleiding (vervolg)

\begin{tabular}{|c|c|c|c|}
\hline \multicolumn{4}{|c|}{ Onderwijstype } \\
\hline 85250431 & 65111 & 103 & \\
\hline 85252300 & 65111 & 103 & \\
\hline 85280200 & 66613 & 109 & WO rechten en bestuurskunde \\
\hline 85280300 & 66630 & 108 & WO accountancy en belastingen \\
\hline 85280400 & 66611 & 109 & WO rechten en bestuurskunde \\
\hline 86310000 & 62110 & 96 & WO landbouw en milieukunde \\
\hline 86320000 & 67148 & 110 & WO sociale wetenschappen \\
\hline 86330000 & 63500 & 101 & WO elektrotechniek \\
\hline 86330100 & 63500 & 101 & \\
\hline 86340000 & 66110 & 106 & WO econom(etr)ie \\
\hline 86370000 & 67148 & 110 & WO sociale wetenschappen \\
\hline 86390000 & 63120 & 97 & WO wiskunde en natuurwetenschappen \\
\hline 87110000 & 62110 & 96 & WO landbouw en milieukunde \\
\hline 87120000 & 67148 & 110 & WO sociale wetenschappen \\
\hline 87130000 & 63500 & 101 & WO elektrotechniek \\
\hline 87140000 & 66110 & 106 & WO econom(etr)ie \\
\hline 87170000 & 67148 & 110 & WO sociale wetenschappen \\
\hline 87190000 & 63120 & 97 & WO wiskunde en natuurwetenschappen \\
\hline
\end{tabular}





\section{BEROEPEN}



ROA-beroepsklasse

ROA-nr. SBC ROA-beroepsgroep

\section{PEDAGOGISCHE BEROEPEN}

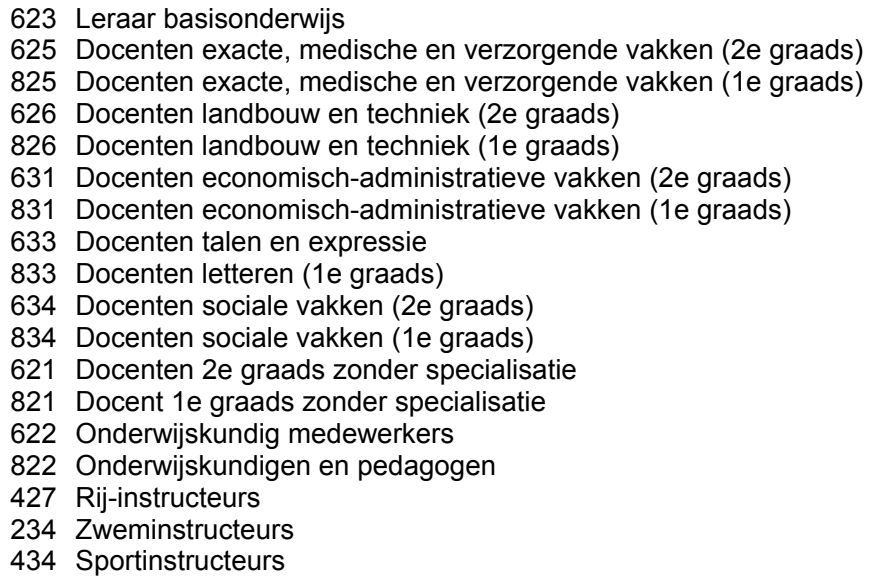

\section{CULTURELE BEROEPEN}

19752 Tolken, vertalers en schrijvers

20553 Bibliotheekassistenten

21753 Bibliothecarissen

$22 \quad 554$ Grafisch ontwerpers

$23 \quad 754$ Kunstenaars

24762 Geestelijk verzorgers

25962 Geestelijken

26764 Journalisten

27964 Taalkundigen

\section{AGRARISCHE BEROEPEN}

28104 Agrarische hulparbeiders

29242 Agrarische arbeiders

30442 Agrarische vakkrachten

31642 Milieuhygiënisten en agrarisch vertegenwoordigers

$32 \quad 842$ Landbouwkundigen

243 Landbouwmachinebestuurders en vissers

444 Agrarische bedrijfshoofden

\section{TECHNISCHE, AMBACHTS- EN INDUSTRIEBEROEPEN}

$\begin{array}{lll}35 & 106 & \text { Productiemedewerkers } \\ 36 & 251 & \text { Laboratorium-assistenten } \\ 37 & 451 & \text { Laboranten } \\ 38 & 651 & \text { Technisch analisten } \\ 39 & 851 & \text { Natuurwetenschappers } \\ 40 & 261 & \text { Conciërges } \\ 41 & 461 & \text { Hoofden technische dienst } \\ 42 & 861 & \text { Werktuigbouwkundigen } \\ 43 & 262 & \text { Bouwvakkers } \\ 44 & 462 & \text { Aannemers en installateurs } \\ 45 & 662 & \text { Architecten en bouwkundig projectleiders } \\ 46 & 862 & \text { Weg- en waterbouwkundigen } \\ 47 & 263 & \text { Weg- en waterbouwkundige arbeiders } \\ 48 & 463 & \text { Weg- en waterbouwkundige vakkrachten } \\ 49 & 663 & \text { Weg- en waterbouwkundig ontwerpers en projectleiders } \\ 50 & 264 & \text { Metaalarbeiders }\end{array}$


ROA-beroepsklasse

ROA-nr. SBC ROA-beroepsgroep

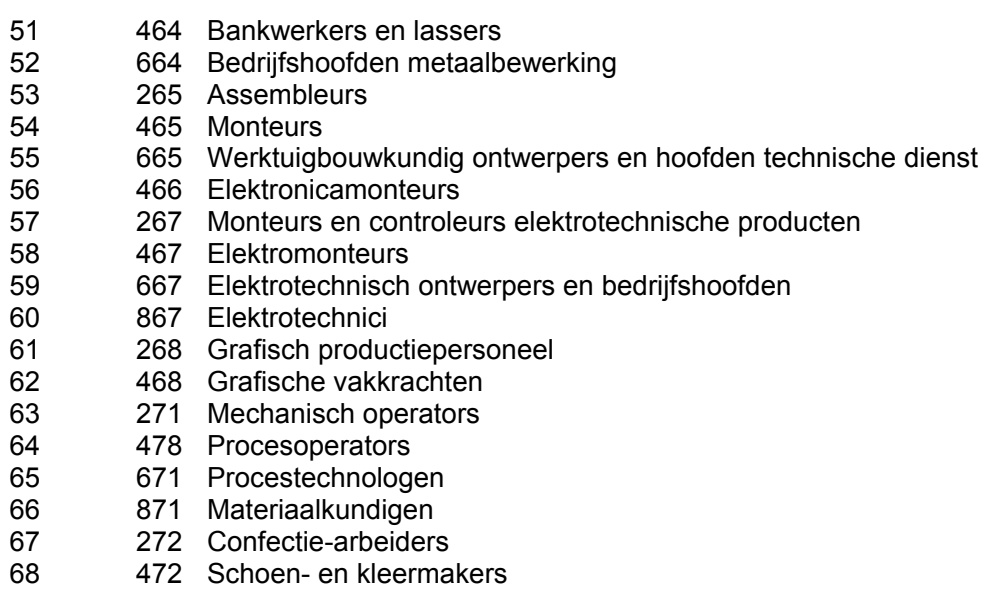

\section{TRANSPORTBEROEPEN}

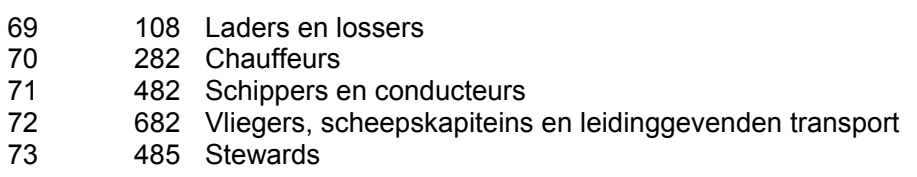

\section{MEDISCHE EN PARAMEDISCHE BEROEPEN}

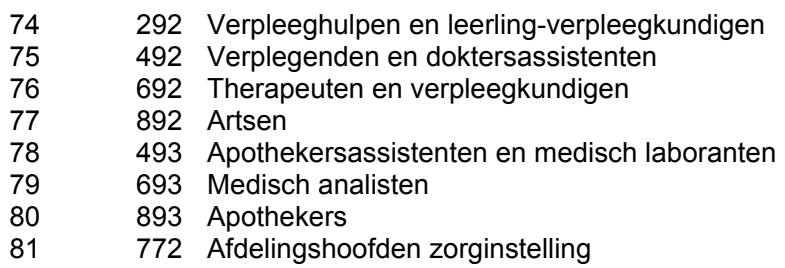

\section{ECONOMISCH-ADMINISTRATIEVE BEROEPEN}

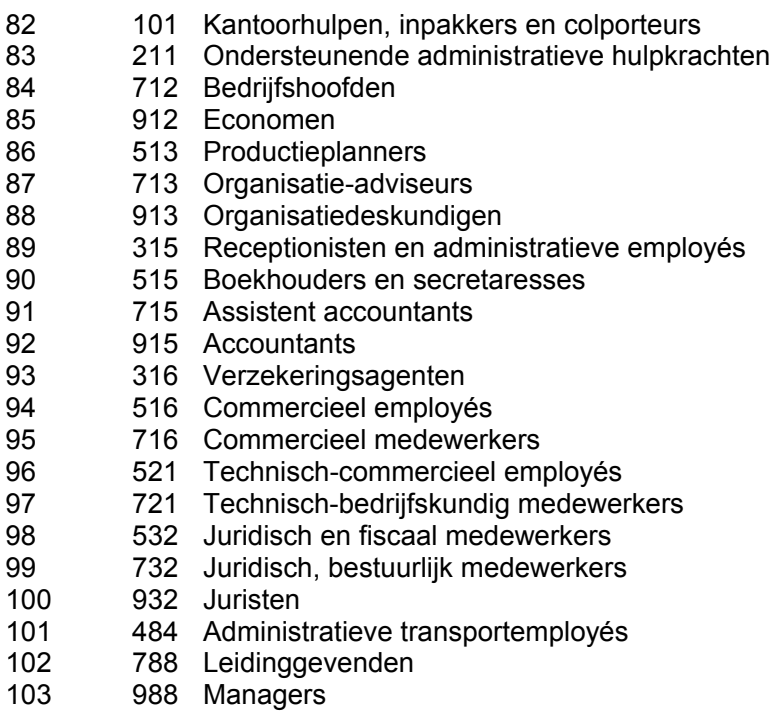


5. Beroepsgroepen, volgorde ROA (vervolg)

ROA-beroepsklasse

ROA-nr. SBC ROA-beroepsgroep

104494 Medisch secretaresses

\section{INFORMATICA BEROEPEN}

$\begin{array}{lll}105 & 514 & \text { Programmeurs } \\ 106 & 714 & \text { Systeemanalisten } \\ 107 & 914 & \text { Informatici } \\ 108 & 666 & \text { Technisch systeemanalisten }\end{array}$

\section{SOCIAAL-CULTURELE BEROEPEN}

109563 Activiteitenbegeleiders en medewerkers arbeidsbemiddeling

110763 Medewerkers sociaal-cultureel werk en personeel en arbeid

111963 Hoofden sociaal-cultureel werk en personeel en arbeid

112765 Sociaal-wetenschappelijk medewerkers

113965 Sociaal-wetenschappelijk onderzoekers

\section{VERZORGENDE EN DIENSTVERLENENDE BEROEPEN}

$\begin{array}{lll}114 & 112 & \text { Vakkenvullers } \\ 115 & 117 & \text { Interieurverzorgers } \\ 116 & 317 & \text { Verkopers } \\ 117 & 517 & \text { Winkeliers } \\ 118 & 372 & \text { Hulpkrachten horeca en verzorging } \\ 119 & 495 & \text { Ziekenverzorgenden } \\ 120 & 572 & \text { Verzorgend personeel } \\ 121 & 373 & \text { Café- en snackbarhouders } \\ 122 & 573 & \text { Bedrijfshoofden horeca } \\ 123 & 479 & \text { Bakkers en slagers }\end{array}$

\section{OPENBARE ORDE- EN VEILIGHEIDSBEROEPEN}

124342 Aspirant politieagenten, soldaten en beveiligingshulpkrachten

125542 Politieagenten, onderofficieren en beveiligingsemployés

126742 Politie-inspecteurs en officieren

$127 \quad 473$ Brandweerlieden 

SBC-beroepsklasse

SBC ROA-nr. SBC-beroepsgroep

11 ELEMENTAIRE BEROEPEN

10182 Algemene elementaire beroepen

$104 \quad 28$ Elementaire agrarische beroepen

$106 \quad 35$ Elementaire technische beroepen

10869 Elementaire transportberoepen

$112 \quad 114$ Elementaire administratieve, commerciële beroepen

$117 \quad 115$ Elementaire verzorgende beroepen

LAGERE NIET-SPECIALISTISCHE BEROEPEN

83 Lagere niet-specialistische beroepen

\section{LAGERE DOCENTEN SPORTVAKKEN}

17 Lagere docenten sportvakken

\section{LAGERE AGRARISCHE BEROEPEN}

29 Lagere algemeen agrarische beroepen

33 Lagere technisch-agrarische beroepen

\section{LAGERE TECHNISCHE BEROEPEN}

40 Lagere technische beroepen (ongeacht specialisatie)

43 Lagere bouwkundige beroepen

47 Lagere weg- en waterbouwkundige beroepen

50 Lagere metaalkundige beroepen

53 Lagere werktuigbouwkundige beroepen ed.

57 Lagere elektrotechnische beroepen

61 Lagere grafische beroepen

63 Lagere procestechnische beroepen

67 Lagere technische beroepen NEG

\section{LAGERE TRANSPORTBEROEPEN}

70 Lagere algemene transportberoepen

\section{LAGERE (PARA)MEDISCHE BEROEPEN}

74 Lagere (para)medische beroepen

\section{Lagere administratieve beroepen}

93 Lagere (technisch-) commerciële beroepen

116 Lagere verkoopberoepen

\section{LAGERE BEVEILGINGSBEROEPEN}

124 Lagere beveiligingsberoepen

427

\section{LAGERE VERZORGENDE BEROEPEN}

118 Lagere algemeen verzorgende beroepen ed.

121 Lagere commercieel-verzorgende beroepen

\section{4}

MIDDELBARE DOCENTEN TRANSPORT-,SPORTVAKKEN

16 Middelbare docenten transportvakken

18 Middelbare docenten sportvakken 


\section{Beroepsgroepen, volgorde SBC '92 (vervolg)}

SBC-beroepsklasse

SBC ROA-nr. SBC-beroepsgroep

46

461

462

463

464

465

466

467

468

472

473

478

479

48

482

484

485

49

492

493

494

495

51

513

514

515

516

517

521

53

532

542

55

553

554

56

563

57

572

573

62

621

622

623

625

626

631

633

634

64

642
MIDDELBARE TECHNISCHE BEROEPEN

41 Middelbare technische beroepen (ongeacht specialisatie)

44 Middelbare bouwkundige beroepen

48 Middelbare weg- en waterbouwkundige beroepen

Middelbare metaalkundige beroepen

Middelbare werktuigbouwkundige beroepen ed.

Middelbare elektrotechnische beroepen (automatisering ed.)

Middelbare elektrotechnische beroepen (excl. automatisering ed.)

Middelbare grafische beroepen ed.

Middelbare technische beroepen NEG

Middelbare technische beveiligingsberoepen

Middelbare procestechnische beroepen (procesoperators)

Middelbare procestechnische beroepen (bakkers en slagers)

\section{MIDDELBARE TRANSPORTBEROEPEN ED}

Middelbare algemene transportberoepen

Middelbare economisch-administratieve transportberoepen

Middelbare verzorgende transportberoepen

MIDDELBARE (PARA)MEDISCHE BEROEPEN

Middelbare algemene (para)medische beroepen

Middelbare technisch-(para)medische beroepen

Middelbare economisch-administratieve (para)medische beroepen

Middelbare verzorgend-(para)medische beroepen

\section{MIDDELBARE ADMINISTRATIEVE,COMMERCIËLE BEROEPEN ED}

86 Middelbare bedrijfskundige beroepen

105 Middelbare administratieve beroepen (automatisering ed.) ed.

90 Middelbare administratieve beroepen (excl. automatisering ed.) ed.

94 Middelbare commerciële beroepen ed.

117 Middelbare verkoopberoepen

96 Middelbare technisch-, wiskundig- commerciële, administratieve beroepen

MIDDELBARE JURIDISCHE,BESTUURLIJKE BEVEILIGINGSBEROEPEN

98 Middelbare juridische, bestuurlijke beroepen

125 Middelbare beveiligingsberoepen

MIDDELBARE TAALKUNDIGE,CULTURELE BEROEPEN

20 Middelbare taalkundige beroepen ed.

22 Middelbare kunstzinnige beroepen

109 Middelbare sociaal-maatschappelijke beroepen ed.

\section{MIDDELBARE VERZORGENDE BEROEPEN ED}

120 Middelbare algemeen verzorgende beroepen

122 Middelbare commercieel-verzorgende beroepen ed.

HOGERE PEDAGOGISCHE BEROEPEN

12 Hogere pedagogische beroepen (ongeacht specialisatie)

14 Hogere onderwijskundige, pedagogische beroepen

1 Docenten basisonderwijs, algemeen vormende vakken

2 Docenten exacte, (para)medische, verzorgende vakken (2e en $3 e$ gr.)

4 Docenten agrarische, technische, transportvakken (2e en $3 e$ gr.)

6 Docenten economische, administratieve, juridische vakken (2e en $3 \mathrm{e}$ gr.)

8 Docenten taalkundige, culturele vakken ed. (2e en $3 \mathrm{e}$ gr.)

10 Docenten sociale, psychologische vakken (2e en 3e gr.)

HOGEREN LANDBOUWKUNDIGE BEROEPEN

31 Hogere landbouwkundige beroepen 
SBC-beroepsklasse

SBC ROA-nr. SBC-beroepsgroep

65

HOGERE WISKUNDIGE,NATUURWETENSCHAPPELIJKE BEROEPEN

38 Hogere wiskundige, natuurwetenschappelijke beroepen

HOGERE TECHNISCHE BEROEPEN

45 Hogere bouwkundigen, technische beveiligingsberoepen

49 Hogere weg- en waterbouwkundigen

52 Hogere metaalkundige beroepen

55 Hogere werktuigbouwkundige beroepen ed.

108 Hogere elektrotechnische beroepen (automatisering ed.)

59 Hogere elektrotechnische beroepen (excl. automatisering ed.)

65 Hogere procestechnische beroepen ed.

\section{HOGERE TRANSPORTBEROEPEN}

72 Hogere transportberoepen (excl. technisch)

\section{HOGERE (PARA)MEDISCHE BEROEPEN}

76 Hogere algemene, verzorgende (para)medische beroepen

79 Hogere technisch-(para)medische beroepen

\section{HOGERE ADMINISTRATIEVE,COMMERCIËLE,ECONOMISCHE BEROEPEN}

84 Hogere algemeen economische beroepen

87 Hogere bedrijfskundige beroepen ed.

106 Hogere administratieve beroepen (automatisering ed.)

91 Hogere administratieve beroepen (excl. automatisering ed.)

95 Hogere commerciële beroepen ed.

97 Hogere technisch-, wiskundig- commerciële, administratieve beroepen

\section{HOGERE JURIDISCHE,BESTUURLIJKE,BEVEILIGINGSBEROEPEN}

99 Hogere juridische, bestuurlijke beroepen

126 Hogere algemene beveiligingsberoepen

HOGERE TAALKUNDIGE,CULTURELE BEROEPEN

19 Hogere taalkundige beroepen

21 Hogere bibliotheek-, documentatieberoepen

23 Hogere kunstzinnige beroepen

\section{HOGERE BEROEPEN MBT GEDRAG EN MAATSCHAPPIJ ED}

24 Hogere theologische beroepen

110 Hogere sociaal-maatschappelijke beroepen

26 Hogere beroepen in de journalistiek

112 Hogere sociaal-wetenschappelijke beroepen ed.

\section{HOGERE VERZORGENDE BEROEPEN}

81 Hogere verzorgende beroepen

\section{MANAGERS (HBO WERK- EN DENKNIVEAU) ED}

102 Managers (HBO werk- en denkniveau) ed.

\section{WETENSCHAPPELIJKE PEDAGOGISCHE BEROEPEN}

13 Wetenschappelijke pedagogische beroepen (ongeacht specialisatie)

15 Wetenschappelijke onderwijskundige, pedagogische beroepen

3 Docenten exacte, (para)medische, verzorgende vakken (1e gr. en WO)

5 Docenten agrarische, technische, transportvakken (1e gr. en WO)

7 Docenten economische, administratieve, juridische vakken (1e gr. en WO)

9 Docenten taalkundige, culturele vakken (1e gr. en WO)

11 Docenten sociale, psychologische vakken (1e gr. en WO)

\section{WETENSCHAPPELIJKE LANDBOUWKUNDIGE BEROEPEN}

32 Wetenschappelijke landbouwkundige beroepen

\section{WETENSCH WISKUNDIGE,NATUURWETENSCHAPPELIJKE BEROEPEN}

39 Wetenschappelijke wiskundige, natuurwetenschappelijke beroepen 
SBC-beroepsklasse

SBC ROA-nr. SBC-beroepsgroep

\begin{tabular}{|c|c|c|}
\hline \multicolumn{2}{|l|}{86} & WETENSCHAPPELIJKE TECHNISCHE BEROEPEN \\
\hline 861 & 42 & Wetenschappelijke technische (ongeacht specialisatie), werktuigbouwkundige beroepen \\
\hline 862 & 46 & Wetenschappelijke (weg- en waterbouw-)bouwkundige beroepen ed. \\
\hline 867 & 60 & Wetenschappelijke elektrotechnische beroepen \\
\hline 871 & 66 & Wetenschappelijke materiaalkundige, procestechnische beroepen ed. \\
\hline 89 & & WETENSCHAPPELIJKE (PARA)MEDISCHE BEROEPEN ED \\
\hline 892 & 77 & Wetenschappelijke (para)medische beroepen (excl. technisch) ed. \\
\hline 893 & 80 & Wetenschappelijke technisch (para)medische beroepen \\
\hline 91 & & WETENSCHAPPELIJKE ECONOMISCHE,ADMINISTRATIEVE BEROEPEN ED \\
\hline 912 & 85 & Wetenschappelijke algemeen-economische, commerciële beroepen ed. \\
\hline 913 & 88 & Wetenschappelijke (technisch-) bedrijfskundige, wiskundig-economische beroepen \\
\hline 914 & 107 & Wetenschappelijke administratieve beroepen (automatisering ed.) \\
\hline 915 & 92 & Wetenschappelijke administratieve beroepen (excl. automatisering ed.) \\
\hline 93 & & WETENSCHAPPELIJKE JURIDISCHE,BESTUURLIJKE BEROEPEN \\
\hline 932 & 100 & Wetenschappelijke juridische, bestuurlijke beroepen \\
\hline 96 & & WETENSCHAPPELIJKE BEROEPEN MBT GEDRAG EN MAATSCHAPPIJ ED \\
\hline 962 & 25 & Wetenschappelijke theologische beroepen \\
\hline 963 & 111 & Wetenschappelijke sociaal-maatschappelijke beroepen \\
\hline 964 & 27 & Wetenschappelijke journalistieke, taalkundige, culturele beroepen \\
\hline 965 & 113 & Wetenschappelijke sociaal-wetenschappelijke beroepen \\
\hline 98 & & MANAGERS (WETENSCHAPPELIJK WERK- EN DENKNIVEAU) \\
\hline 988 & 103 & Managers (wetenschappelijk werk- en denkniveau) \\
\hline
\end{tabular}


SBC-beroepsklasse

SBC-nr. SBC-beroepsgroep/ ROA-nr. ROA-beroepsgroep Beroep

\section{ELEMENTAIRE BEROEPEN}

101 Algemene elementaire beroepen / 82 Kantoorhulpen, inpakkers en colporteurs

11119 Inpakker handmatig

11128 Kantoorhulp (kopiëren, bezorgen interne post e.d.)

11123 Colporteur kranten, tijdschriften, folders, wasgoed

11126 Opruimer-schoonmaker

11132 Bewaker, wachter (element)

104 Elementaire agrarische beroepen / 28 Agrarische hulparbeiders

11101 Hulparbeider tuinbouw

11102 Hulparbeider groen-, terreinverzorging

11103 Hulparbeider akkerbouw

106 Elementaire technische beroepen / 35 Productiemedewerkers

11117 Productiemedewerker industrie (eenvoudige machine bedienen)

11125 Sjouwer, opperman

11134 Postsorteerder PTT, grondstof-, productensorteerder, meteropnemer water-, energiebedrijf

11118 Productiemedewerker industrie (samenstellen; geen houtwaren, plastic-, rubberartikelen)

11111 Schoonmaker machines, gebouwen, installaties, produkten (geen walserij-, gieterij-produkten)

11115 Assistent onderhoudsmedewerker (schilder-, metsel-, timmerwerk, eigen gebouw; elementair)

11110 Hulparbeider wegenbouw, grondwerk

11120 Sloper van gebouwen

11114 Constructieschilder, aardewerkspuiter, dompelaar, wegmarkeerder

11116 Textielproduktenmaker (excl. textielproduktiemachines bedienen)

11112 Schoonmaker laboratoriummateriaal en -glaswerk

108 Elementaire transportberoepen / 69 Laders en lossers

11122 Lader, losser, pakhuis-, magazijnknecht, verhuizer

11109 Reinigingsdienstarbeider, dekpersoneel binnenvaart

11124 Bezorger, koerier

11127 Trekkerchauffeur intern transport (excl. landbouw), bouwliftbediener

112 Elementaire administratieve, commerciële beroepen / 114 Vakkenvullers

11121 Vakkenvuller winkel, garderobejuffrouw

11131 Verkoper kiosk, benzinelaadstation (afrekenen drukwerk, ijs, benzine e.d.)

11130 Hulpverkoper, leerling-verkoper detailhandel

117 Elementaire verzorgende beroepen / 115 Interieurverzorgers

11133 Glazenwasser, interieurverzorger, keukenknecht, medewerker huishoudelijke dienst

11108 Buffetbediende, barbediende

11107 Oliebollen-, poffertjesbakker, snackbarbediende (frituur)

11106 Assistent restaurant, cafetaria (schoonmaken en bedienen)

\section{LAGERE NIET-SPECIALISTISCHE BEROEPEN}

211 Lagere niet-specialistische beroepen / 83 Ondersteunende administratieve hulpkrachten

21102 Enquêteur, codeur, verkeersteller

21103 Ondersteunende administratieve functies: kantoormachines bedienen

21106 Diskjockey

21108 Beroepssporter (excl. denksporten)

21104 Afvalopkoper-afvalverkoper (incl. oud metaal)

\section{LAGERE DOCENTEN SPORTVAKKEN}

234 Lagere docenten sportvakken / 17 Zweminstructeurs

23401 Zweminstructeur 
SBC-beroepsklasse

SBC-nr. SBC-beroepsgroep/ ROA-nr. ROA-beroepsgroep

Beroep

\section{LAGERE AGRARISCHE BEROEPEN}

242 Lagere algemeen agrarische beroepen / 29 Agrarische arbeiders

24203 Arbeider tuinbouw

24207 Arbeider veeteelt

24205 Arbeider akkerbouw

24206 Arbeider landbouw gemengd bedrijf

24208 Arbeider bosbouw

24213 Controleur, keurder agrarische produkten op veiling

24210 Dierenverzorger kinderboerderij, asiel, laboratorium, bosbouw

24211 Bloemschikker, bloemsierkunstenaar (lager)

24214 Selecteur zaad, bollen, planten

24212 Jachtopziener, jachtopzichter

24201 Tekenaar tuin- en landschap

243 Lagere technisch-agrarische beroepen / 33 Landbouwmachinebestuurders en vissers

24301 Landbouwmachinebestuurder

24303 Visser, vis-, schaaldierenkweker

24304 Landbouw-, hoefsmid

24302 Stuurman-visser

25 LAGERE WISKUNDIGE, NATUURWETENSCHAPPELIJKE BEROEPEN

251 Lagere wiskundige, natuurwetenschappelijke beroepen / 36 Laboratorium-assistenten

25102 Sterilisatie-assistent (laboratorium, operatiekamer)

25101 Scheikundig laboratoriumbediende, leerling-analist, laborant melkcontrole

\section{LAGERE TECHNISCHE BEROEPEN}

261 Lagere technische beroepen (ongeacht specialisatie) / 40 Conciërges

26107 Conciërge, huisbewaarder (beveiligen en schoonmaken), koster

26101 Conciërge, huisbewaarder (beveiligen, schoonmaken, technisch onderhoud)

26102 Autowasserettehouder, objectleider schoonmaakdienst, filterreiniger procesindustrie

26106 Conciërge, huisbewaarder (beveiligen), kustlichtwachter

26104 Borstel-, manden-, mattenmaker (machinaal); delfstoffenbewerker neg

262

26211

26217

26208

26214

26209

26210

26219

26213

26207

26216

26218

26205

26221

26220

26203

26224

26206

26225

26215

Lagere bouwkundige beroepen / 43 Bouwvakkers

Betontimmerman, parketvloerenlegger, monteur systeembouw; bouwvaktimmerman (lager)

Huisschilder, verfspuiter (excl. constructiewerk, wegmarkering, auto's, decoratie aardewerk)

Metselaar, tegelzetter, voeger, steenbewerker

Houtwarensamensteller

Stukadoor, beton-, cement-, terrazzovloerenlegger, -afwerker

Betonwerker, -produktenmaker, -ijzervlechter; cement- e.a. minerale produktenmaker

Dakdekker

Machinaal houtbewerker

Steigermaker

Schilder-behanger

Glazenmaker, glaszetter

Isoleerder: isolatiewerker bouwnijverheid

Algemeen onderhoudsman: timmeren, gas, water, elektro (eigen gebouw; lager)

Onderhoudstimmerman-metselaar (woningbouwvereniging; lager)

Algemeen onderhoudsman-hovenier (excl. bouwnijverheid)

Kunststof ramen-, kozijnenmaker

Assistent loodgieter, -installateur (excl. dakdekken)

Controleur-keurder houten produkten

Behanger; vloerlegger rubber, kurk 


\section{Beroepen per beroepsgroep (vervolg)}

\section{SBC-beroepsklasse \\ SBC-nr. SBC-beroepsgroep/ ROA-nr. ROA-beroepsgroep Beroep}

26212 Grafkisten-, rietmeubelmaker, kuiper, stoelenmatter

26204 Assistent loodgieter, -installateur (incl. dakdekken)

263 Lagere weg- en waterbouwkundige beroepen / 47 Weg- en waterbouwkundige arbeiders

26305 Wegenbouwarbeider, grondwerker bouw, straatmaker

26304 Kabelwerker, gasleidinglegger

26306 Laadschopbestuurder (bouwnijverheid), heier

26302 Kantonnier

26303 Baggermolenarbeider (sjouwen, schoonmaken)

264 Lagere metaalkundige beroepen / 50 Metaalarbeiders

26410 Soldeerder, metaalbrander, -snijder, -sloper; lasser (lager)

26412 Machinaal metaalbewerker (excl. bankwerk)

26409 Plaat werker (excl. scheeps-, vliegtuigplaatwerker)

26403 Machinaal verspaner metaal, metaalfrezer

26404 Constructiebankwerker (incl. samenbouwen; lager)

26414 Samensteller metaalwaren

26411 Constructiesamenbouwer; stalen, aluminium ramen-, kozijnenmaker (lager)

26415 Controleur, tester metaalwaren (excl. voertuigen, machines)

26407 Burgersmid; metaalbuiger, -forceur, -perser, -walser (excl. plaatwerk, automaatbediende)

26401 Schoonmaker, poetser, reiniger walserij-, gieterij-produkten

26402 Vormer, kernmaker, glas- e.a. mineralenbewerker

26406 Glasgraveur, -etser; diamant-, edelsteen- en edelmetaalbewerker (lager)

26413 Ovenman voorverwarmings-, gloei-, normaliseer-, temperoven, smelter inductieoven

26405 Gereedschapsmaker (lager)

265 Lagere werktuigbouwkundige beroepen / 53 Assembleurs

26511 Samensteller voertuigen, kantoormachines (excl. elektro); voertuigbekleder

26505 Rijwiel-, motorrijwiel-, bromfietshersteller, hulpautomonteur

28302 Motordrijver (scheepvaart)

26504 Landbouwwerktuigenhersteller (lager)

26512 Controleur, tester voertuigen, machines (excl. elektro; lager)

26507 Scheepsschilder

26503 Boorpersoneel (geen boorder)

26501 Smeerder (excl. schepen)

26508 Machinist transport-, koelmachines

26509 Omsteller cokesbereiding, spindoppenmonteur

267 Lagere elektrotechnische beroepen / 57 Monteurs en controleurs elektrotechnische producten 26701 Elektrotechnisch bankwerker, monteur, installateur (sterkstroom); elektromonteur huishoudelijke apparaten (lager)

26706 Controleur, tester elektrotechnische apparaten en onderdelen (excl. meet- en regeltechniek)

26704 Elektronicamonteur (nieuwbouw, onderhoud; excl. computer-, meet- en regeltechnische, medische apparatuur; lager)

26705 Wikkelaar ankers, spoelen; samensteller elektronische apparatuur

26703 Elektrotechnisch monteur, installateur (zwakstroom)

26601 Meet- en regeltechnisch monteur (lager)

26702 Audio-visueel onderwijstechnicus, studio-elektricien, belichter (lager)

268 Lagere grafische beroepen / 61 Grafisch productiepersoneel

26801 Zetters; drukwerkvoorbereiders grafische industrie (lager)

26804 Papierwaren-, dozenmaker, kartonnagewerker; papiervernisser drukkerij

26802 Lichtdrukker, drukker aardewerkmotieven, zeefdrukker

26803 Binderijpersoneel (geen boekbinder)

26805 Fotolaboratoriumbediende (geen laborant); tweede camera-assistent 
SBC-beroepsklasse

SBC-nr. SBC-beroepsgroep/ ROA-nr. ROA-beroepsgroep

Beroep

271 Lagere procestechnische beroepen / 63 Mechanisch operators

27112 Mechanisch operator glas-, aardewerk-, papier-, textiel-, voedings- en genotmiddelen-, procesindustrie

27109 Machinebediende glas-, aardewerk-, papier-, textiel-, voedings- en genotmiddelen-, procesindustrie

27107 Slachter, slachterij-arbeider, worst-vleeswarenmaker; visfileerder, -snijder, schaaldierenpeller

27101 Slager-verkoper (lager)

27113 Samensteller rubber-, plasticartikelen

27108 Brood-, koek-, banketbakker, chocolademaker (ambachtelijk; excl. in-, verkoop; lager)

27116 Controleur, keurder procesindustrie (excl. delfstoffen, olie en gas), sigaren

27102 Rubber- en plasticvormer; buitenbandenvulcaniseur; steen-, tegel-, dakpannenvormer

27115 Sigarenmaker, glas- en aardewerkschilder, nettenboeter (handmatig)

27106 Huid-, leerbewerker

27110 Machinesteller spinnerij, inrijger breimachine, kaartenzetter weverij

27104 Banden-, riemen-, cilindermaker spinmachines

272 Lagere technische beroepen NEG / 67 Confectie-arbeiders

27204 Confectie-, woning- en meubelstoffennaaister; kleermaker, zeil-, tenten, markiezen-, dekkledenmaker (excl. patroontekenen, in-, verkoop)

27203 Meubelstoffeerder; woningstoffeerder (excl. in-, verkoop)

27202 Hoofd wasserij, wasser, perser, ontvlekker wasserij

27206 Schoenfabrieksarbeider; schoenhersteller, lederwarenmaker (excl. kleding, in-, verkoop)

27209 Controleur, keurder, completeerder confectie

27207 Stanser, snijder lederwaren

27208 Bioscoopoperateur

\section{LAGERE TRANSPORTBEROEPEN}

Lagere algemene transportberoepen / 70 Chauffeurs

28209 Vrachtwagenchauffeur

28211 Heftruckchauffeur, lier-, winchdrijver

28215 Buschauffeur (lijn- of stadsdienst)

28208 Postbesteller ptt

28205 Taxi-chauffeur

28214 Chauffeur bibliotheek-, informatiebus; chauffeur znd

28210 Bezorger-chauffeur bestelauto

28213 Metro-, trambestuurder, rangeerder; treinmachinist (excl. ns)

28207 Bootsman havenbedrijf, bootsman zeevaart

28216 Chauffeur personenbusje (klein rijbewijs); directie-, particulier chauffeur

28217 Brug-, overweg-, seinhuis-, sluiswachter

28204 Buschauffeur groepsvervoer binnen- en buitenland

28206 Postexpediteur PTT

28202 Matroos (zeevaart, zeesleepvaart)

28201 Vrachtwagenchauffeur meubelen, woninginrichting

28212 Pontschipper

29 LAGERE (PARA)MEDISCHE BEROEPEN

Lagere (para)medische beroepen / 74 Verpleeghulpen en leerling-verpleegkundigen

Verpleeghulp; leerling-ziekenverzorgende

Leerling-verpleegkundige a en b

Ambulancebegeleider (excl. verpleegkundige); leerling-kraamverzorger 
SBC-beroepsklasse

SBC-nr. SBC-beroepsgroep/ ROA-nr. ROA-beroepsgroep Beroep

315 Lagere administratieve beroepen / 89 Receptionisten en administratieve employés

31504 Facturist; assistent boekhouder, bedrijfskassier, loonadministrateur (lager)

31509 Administratief employ, (eenvoudige repetitieve, administratieve werkzaamheden, lager)

31515 Receptionist, baliemedewerker

31511 Typist, data-typist

31510 Postbediende (interne post); verzekeringsemploy, (administratieve ondersteuning)

31502 Magazijnbediende (administratief; lager)

31503 Stenotypist; secretaresse (excl. directie- en medisch; lager)

31517 Telefonist

31513 Administratief medewerker bibliotheek, archief (lager)

31512 Typist-telefonist-receptionist

31514 Bode-bezorger (kantoor)

31508 Incasseerder, kwitantieloper, (huur)inner

31506 Personeelsadministratie-employ,: personeels- en loonadministratie (lager)

31518 Weger, meter

31516 Hotelportier (lager)

Lagere (technisch-)commerciële beroepen / 93 Verzekeringsagenten

31603

31604

Berekenaar premies, uitkeringen (verzekeringen)

31606 Demonstrateur

31601 Reclametekenaar

32101 Etaleur (lager)

31605 Hostess felicitatiedienst

317 Lagere verkoopberoepen / 116 Verkopers

31701 Winkelbediende, markt-, straatverkoper (excl. kiosk, vlees); debitant staatsloterij

31703 Kassamedewerker

31702 Bloemschikker-verkoper

342 Lagere beveiligingsberoepen / 124 Aspirant politieagenten, soldaten en beveiligingshulpkrachten

34202 Aspirant agent politie; militair lagere rangen dan onderofficier; portier (excl. hotel); bewaker (lager)

34201 Parketwacht politie

\section{LAGERE VERZORGENDE BEROEPEN}

Lagere algemeen verzorgende beroepen ed. / 118 Hulpkrachten horeca en verzorging Kelner, serveerster Alpha-hulp; gezins-, bejaardenverzorgende thuiszorg, inrichtingsassistente (lager) Leerling-verpleegkundige z, kinderverzorgende particulieren; bejaarden-, zwakzinnigenverzorgende (lager)

Hulpkok, keukenassistent (koken en schoonmaken) Kok (lager)

Huishoudhulp in inrichting, tehuis

Manicure, pedicure, kappershulp, schoonheidsmasseur sauna

Hoofd linnenkamer hotel, inrichting, schip

Hulp in de particuliere huishouding

Huishoudster, butler, valet

373

Assistent peuterwerker 
7. Beroepen per beroepsgroep (vervolg)

SBC-beroepsklasse

SBC-nr. SBC-beroepsgroep/ ROA-nr. ROA-beroepsgroep Beroep

37301 Snackbarhouder

37303 Begrafenispersoneel (excl. ondernemer)

42 MIDDELBARE DOCENTEN TRANSPORT-, SPORTVAKKEN

427 Middelbare docenten transportvakken / 16 Rij-instructeurs

42701 Autorij-instructeur

42702 Rij-examinator

434 Middelbare docenten sportvakken / 18 Sportinstructeurs

43401 Sportinstructeur (excl. zweminstructeur)

44 MIDDELBARE AGRARISCHE BEROEPEN

442 Middelbare (technisch-) agrarische beroepen / 30 Agrarische vakkrachten

44211 Chef plantsoendienst, opzichter tuinonderhoud

44209 Bloemschikker, bloemsierkunstenaar (middelbaar)

44205 Boomchirurg, bosbaas, boswachter

44207 Vee-inseminator, veeverloskundige

44201 Assistent-onderzoeker tuinbouwkundig onderzoek

44202 Assistent-onderzoeker landbouwkundig onderzoek

44208 Dierentrainer; dierenverzorger, -oppasser dierentuin, safaripark

44210 Keurmeester, controleur land-, tuin-, bosbouw, veeteelt (middelbaar)

44203 Assistent-onderzoeker veeteeltkundig onderzoek

44212 Leidinggevend boswachter

44302 Opzichter cultuurtechnische werken

44303 Leidinggevend opzichter cultuurtechnische werken

44301 Bodemkundig onderzoeker, karteerder, cultuurtechnicus (middelbaar)

444 Middelbare commercieel-agrarische beroepen / 34 Agrarische bedrifshoofden

44407 Bedrijfshoofd kleine (pluim)veehouderij

44403 Bedrijfshoofd klein tuinbouwbedrijf

44405 Bedrijfshoofd klein akkerbouwbedrijf

44406 Bedrijfshoofd klein gemengd landbouwbedrijf

44414 Bedrijfshoofd middelgroot tuinbouwbedrijf

44404 Bedrijfshoofd klein hoveniersbedrijf

44409 Hondentrimmer, dierenasielhouder

44415 Bedrijfshoofd middelgroot hoveniersbedrijf

44418 Bedrijfshoofd middelgrote (pluim)veehouderij

44402 Bedrijfshoofd klein landbouwloonbedrijf

44413 Werkmeester sociale hulpverlening bloemisterij, tuinderij

44408 Bedrijfshoofd kleine manege

44411 Bedrijfshoofd middelgroot tuinbouwloonbedrijf

44412 Bedrijfshoofd middelgroot landbouwloonbedrijf

44401 Bedrijfshoofd klein tuinbouwloonbedrijf

44410 Bedrijfshoofd middelgrote manege

44417 Bedrijfshoofd middelgroot gemengd landbouwbedrijf

451 Middelbare wiskundige, natuurwetenschappelijke beroepen / 37 Laboranten

45103 Biologisch, zo"logisch, botanisch, natuurkundig, scheikundig laborant

45105 Statistisch employ,

45101 Statistisch analist (middelbaar)

45102 Geologisch, meteorologisch assistent, -waarnemer 
SBC-beroepsklasse

SBC-nr. SBC-beroepsgroep/ ROA-nr. ROA-beroepsgroep

Beroep

46

MIDDELBARE TECHNISCHE BEROEPEN

461 Middelbare technische beroepen (ongeacht specialisatie) / 41 Hoofden technische dienst

46101 Hoofd kleine technische dienst (middelbaar)

46106 Werkmeester werkplaats, inrichting, gevangenis, sociale werkplaats

46105 Pianostemmer

46102 Muziekinstrumentenmaker, -reparateur (incl. in-, verkoop)

46103 Muziekinstrumentenmaker, -reparateur (excl. in-, verkoop)

46104 Toneelmeester

462 Middelbare bouwkundige beroepen / 44 Aannemers en installateurs

46211 Sanitair-, verwarmingsinstallateur (aanleg en onderhoud); gas-, pijpfitter

46213 Decor-, markiezen-, rolluikentimmerman; bouwvaktimmerman (middelbaar)

46208 Aannemer timmerwerk (klein bedrijf)

46204 Meubelmaker (ambachtelijk)

46226 Uitvoerder bouw en -installatiewerk

46229 Bedrijfshoofd middelgroot bouw-, bouwinstallatiebedrijf (excl. elektrotechnisch)

46203 Bouwkundig, meubeltekenaar; bouwkundig tekenaar-constructeur (middelbaar)

46202 Bouwcalculator (middelbaar)

46220 Onderhoudsloodgieter, verwarmingsonderhoudsmonteur

46225 Werkmeester luchtbehandelingsinstallatiebouw, timmerfabriek, houtbewerking,

kwaliteitscontroledienst meubelen, bouwproducten

46223 Bouwkundig opzichter (middelbaar)

46209 Allround loodgieter

46205 Assistent uitvoerder bouw; bouwkundig werkvoorbereider (middelbaar)

46206 Bedrijfshoofd klein installatiebedrijf (excl. elektrotechnisch)

46218 Onderhoudstimmerman-metselaar (woningbouwvereniging; middelbaar)

46219 Algemeen onderhoudsman: timmeren, gas, water, elektro (eigen gebouw; middelbaar)

46207 Aannemer metselwerk (klein bedrijf)

46227 Leidinggevend bouwkundig opzichter (middelbaar)

46212 Voorman-metselaar, fabrieksschoorsteenbouwer, oven- en ketelmetselaar

46221 Betonmolenbaas bouwnijverheid

46224 Bestekzoeker, besteksorteerder

46216 Voorman-timmerman (timmerfabriek)

46215 Allround machinaal houtbewerker

46222 Insteller houtbewerkingsmachines

46217 Glas in lood-zetter

463 Middelbare weg- en waterbouwkundige beroepen / 48 Weg- en waterbouwkundige vakkrachten

46307 Hei-, grondverzet-, wegenbouwmachinist

46302 Landmeettechnicus, weg- en waterbouwk tekenaar; cartografisch, landmeetk tekenaar, weg- en waterbouwk tekenaar- constructeur (middelbaar)

46311 Uitvoerder weg- en waterbouw

46308 Baggermachinist

46304 Bedrijfshoofd klein weg- en waterbouw-, grondwerkbedrijf

46314 Bedrijfshoofd middelgroot weg- en waterbouw-, grondwerkbedrijf

46309 Weg- en waterbouwkundig opzichter (middelbaar)

46312 Leidinggevend weg- en waterbouwkundig opzichter (middelbaar)

46303 Assistent uitvoerder weg- en waterbouw

46301 Weg- en waterbouwkundig calculator (middelbaar)

46305 Steenzetter waterbouwkundige werken

46306 Betonmolenbaas, asfaltmolenbaas weg- en waterbouw

46310 Duiker, onderwaterwerker

46315 Leidinggevend baggermachinist 
SBC-beroepsklasse

SBC-nr. SBC-beroepsgroep/ ROA-nr. ROA-beroepsgroep

Beroep

464 Middelbare metaalkundige beroepen / 51 Bankwerkers en lassers

46411 Fijnbankwerker, uurwerkmaker, -reparateur, optisch glasslijper, (glas)instrumentmaker; gereedschapsmaker (middelbaar)

46416 Lasser (metaal; middelbaar)

46410 Constructiebankwerker (incl. samenbouwen; middelbaar)

46409 Allround machinebankwerker, modelmaker metaal

46423 Werkmeester metaal(waren)productie, glasblazerij

46417 Vliegtuigrompensamenbouwer; constructiesamenbouwer; stalen, aluminium ramen-, kozijnenmaker (middelbaar)

46404 Amanuensis, practicum onderwijsassistent (middelbaar)

46407 Metaalgieter, gietmachinebediener

46405 Bedrijfshoofd klein metaalbewerkingsbedrijf

46415 Scheeps-, vliegtuigplaatwerker

46408 Cnc-programmeur-verspaner, -polijster, -schuurder

46419 Procesoperator smelten erts, staal, non-ferro

46421 Goud- en zilversmid (massafabricage)

46418 Galvaniseur metaal (elektrolytisch)

46403 Houtmodelmaker

46401 Afschrijver, aftekenaar, traceur metaal

46420 Glasblazer (hand; massafabricage)

46412 Diamant-, edelsteen- en edelmetaalbewerker (middelbaar)

46413 Gereedschapssmid, vormenmaker, modelmaker gips

$465 \quad$ Middelbare werktuigbouwkundige beroepen ed. / 54 Monteurs

46519 Automonteur (onderhoud, reparatie)

46514 Monteur lift-, boorinstallaties, machines, werktuigen (excl. installatietechniek)

46529 Werkmeester afd werktuigbouw, onderhoud produktie-apparaten, gas-, waterdistributie

46505 Machinebankwerker-monteur machines, werktuigen, fabrieksinstallaties (excl. motoren, elektro)

46511 Monteur fabrieksinstallaties (procestechniek; incl. installatietechniek excl. elektro)

46516 Onderhoudsmonteur kantoor-, huishoudnaaimachines, motoren; motormonteur, tuiger, takelaar

46526 Kraan-, hijsmachinist (excl. grondverzet)

46501 Tekenaar werktuigbouw (excl. liften); tekenaar-constructeur (excl. liften; middelbaar)

46504 Bedrijfshoofd kleine machine-, voertuig-, vliegtuigfabriek, scheepswerf

46523 Auto-, rijtuigspuiter

46525 Machinist stationaire machines

48302 Treinbestuurder NS

46503 Technisch calculator (excl. bouw, grafische-, machine-, proces- en textielind)

46522 Scheepstimmerman, scheepsbeschieter (excl. varend)

46506 Machinebankwerker-motormonteur (excl. elektro)

46518 Storingsmonteur, onderhoudsmonteur materieel spoorwegen

46517 Landbouwwerktuigenhersteller (middelbaar)

46521 Auto-, vliegtuigelektricien

46524 Bank-, stempel-, walsinsteller, cnc-programmeur (instellen)

46528 Controleur, tester voertuigen, machines (excl. elektro; middelbaar)

46520 Scheepselektricien

46509 Autoplaatwerker en -spuiter

46527 Inspecteur, controleur gas- en waterleidingbedrijf (middelbaar)

46515 Boormachinist, bronboorder

48301 Scheepswerktuigkundige khv

46513 Carrosseriebouwer, wagenmaker (houtbouw); vliegtuigtimmerman

46507 Fijnbankwerker-monteur machines, werktuigen, fabrieksinstallaties (excl. motoren, elektro)

48303 Radarwaarnemer

46530 Hoofd tekenkamer werktuigbouwkunde (middelbaar)

466 Middelbare elektrotechnische beroepen (automatisering ed.) / 56 Elektronicamonteurs

46603 Elektronicamonteur (nieuwbouw, onderhoud computer-, meet- en regeltechnische apparatuur; 
SBC-beroepsklasse

SBC-nr. SBC-beroepsgroep/ ROA-nr. ROA-beroepsgroep

Beroep

middelbaar)

46605 Werkmeester afd meet- en regeltechnische apparatuur (bouw, installatie, kwaliteitscontroledienst; middelbaar)

46604 Controleur, tester meet- en regeltechnische apparatuur

46602 Productiebegeleider automatisering (technische toepassingen; middelbaar)

46601 Tekenaar meet- en regel-, informatietechniek; tekenaar-constructeur meet- en regel-, informatietechniek (middelbaar)

467 Middelbare elektrotechnische beroepen (excl. automatisering ed.) / 58 Elektromonteurs

46707 Elektricien-installateur (bouwnijverheid), elektrotechnisch bankwerker-monteur (motoren); elektromonteur huish elektr apparaten (middelbaar)

46708 Onderhoudselektricien bedrijfsinstallaties, elektrotechnisch bankwerker-monteur (transformatoren, schakelapparatuur)

46711 Elektronicamonteur (nieuwbouw, onderhoud; excl. computer-, meet- en regeltechnische apparatuur; middelbaar)

46710 Telefoon-, telecommunicatiemonteur (excl. (aan)leggen kabels)

46717 Werkmeester elektriciteitsdistributie, kwaliteitscontrole; elektrotechn dienst, produktie elektrotechn app (middelbaar)

46701 Tekenaar elektrotechniek; tekenaar-constructeur elektrotechniek (excl. meet- en regel-, informatietechniek; middelbaar)

46714 Zend-, geluids-, beeldapparatuurbedieners

46704 Bedrijfshoofd klein bedrijf bouw en reparatie elektrische apparatuur, elektrotechnisch installatiebedrijf

46706 Bedrijfshoofd klein bedrijf bouw en reparatie elektronica (excl. computers)

46709 Audio-visueel onderwijstechnicus, studio-elektricien, belichter (middelbaar)

46715 Elektrotechnisch opzichter (middelbaar)

46718 Leidinggevend elektrotechnisch opzichter (middelbaar)

46712 Onderhoudselektricien bouwnijverheid

46719 Hoofd tekenkamer elektrotechniek (middelbaar)

46703 Radiograaf

46716 Controleur, tester elektrische installaties

46713 Schakelbordwachter elektrische centrale

468 Middelbare grafische beroepen ed. / 62 Grafische vakkrachten

46803 Bedrijfshoofd kleine drukkerij

46812 Fotograaf, film- en tv-camera-operateur, film-editor, -monteur, fotolaborant

46808 Hoog-, diep-, offset-, blok-, textieldrukker

46813 Bedrijfshoofd middelgroot fotolaboratorium, -ontwikkelcentrale; werkmeester grafische industrie

46809 Boekbinder

66801 Bedrijfshoofd middelgrote drukkerij, binderij

46802 Technisch calculator (grafische industrie)

46806 Drukwerkvoorbereiders grafische industrie (middelbaar)

46801 Lithografisch, reproductietekenaar, technisch illustrator

46810 Bedrijfshoofd klein fotolaboratorium, -ontwikkelcentrale

46815 Leidinggevend drukker

46807 Stereotypeur, stypengalvaniseur (grafische industrie)

472 Middelbare technische beroepen NEG / 68 Schoen- en kleermakers

47208 Schoenhersteller, lederwarenmaker (excl. kleding, incl. in-, verkoop)

47206 Woningstoffeerder (incl. in-, verkoop)

47211 Modelnaaister, patroonmaker (kleding)

47213 Werkmeester kleding-, schoenfabricage, kwaliteitscontroledienst kleding, schoeisel

47207 Bontkleermaker, zeil-, tenten-, markiezen-, dekkledenmaker (excl. patroontekenen, incl. in-, verkoop)

47214 Bedrijfshoofd middelgroot bedrijf confectie-industrie

47202 Patroontekenaar kleding, schoeisel

47204 Kleermaker (excl. bont), zeil-, tenten-, markiezen-, dekkledenmaker (incl. patroontekenen, excl. 
SBC-beroepsklasse

SBC-nr. SBC-beroepsgroep/ ROA-nr. ROA-beroepsgroep

Beroep

in-, verkoop)

47209 Bedrijfshoofd klein bedrijf textielindustrie

47201 Technisch natuurkundige (middelbaar)

47203 (Bont)kleermaker, zeil-, tenten-, markiezen-, dekkledenmaker (incl. patroontekenen, in-, verkoop)

473 Middelbare technische beveiligingsberoepen / 127 Brandweerlieden

47302 Brandwacht

47301 Brandveiligheidsdeskundige (middelbaar)

47304 Brandmeester

47305 Brandweeronderofficier, chef bedrijfsbrandweer

$478 \quad$ Procesoperators / 64 Procesoperators

47110 Procesoperator glas-, aardewerk-, papier-, textiel-, voedings- en genotmiddelen-, procesindustrie (middelbaar)

47112 Werkmeester afd glas-, aardewerk-, papier-, textiel-, voedings- en genotmiddelen-, (petro)chemische industrie

47103 Kunststoffen-, textiellaborant

47111 Keurmeester voedingsmiddelen (excl. vee en vlees; middelbaar)

47102 Technisch calculator (proces- en textielindustrie)

47108 Handwever (stof, tapijt, kant)

47109 Weefmachinesteller, breimachinesteller

479 Bakkers en slagers / 123 Bakkers en slagers

47104 Bedrijfshoofd, filiaalhouder kleine slagerij

47106 Slager-verkoper (middelbaar)

47107 Brood-, koek-, banketbakker, chocolademaker (ambachtelijk; excl. in-, verkoop; middelbaar)

47105 Brood-banketbakker (ambachtelijk; incl. in-, verkoop)

47115 Leidinggevend slager-verkoper

47114 Leidinggevend brood-banketbakker (ambachtelijk; incl. in-, verkoop)

47113 Bedrijfshoofd, filiaalhouder middelgrote slagerij

Middelbare algemene transportberoepen / 71 Schippers en conducteurs

48204 Schipper binnenvaart, kapitein sleepdienst, stuurman khv, loods binnenvaart

48201 Ladingmeester, stuwadoor; dienstleider, opzichter vervoersdiensten (middelbaar)

48205 Conducteur trein, tram, bus

48208 Dokmeester, loodschef, pakhuischef, terreinchef; hoofd besteldienst ptt

48203 Assistent-treindienstleider

48202 Havenmeester binnenhaven, kanaalmeester

48206 Perronopzichter ns, stationschef autobusvervoer

484 Middelbare economisch-administratieve transportberoepen / 101 Administratieve transportemployés

48401 Transportplanner, administratief employ, bevrachting

48402 Expediënt, waterklerk

48413 Bedrijfshoofd middelgroot transport-, expeditie-, stuwadoorsbedrijf

48406 Bedrijfshoofd klein transport-, expeditiebedrijf

48408 Controleur haven-, transportbedrijf

48405 Bedrijfshoofd klein binnenvaart-, zeevaartbedrijf

48407 Bedrijfshoofd klein taxibedrijf

48411 Bedrijfshoofd middelgroot taxibedrijf; districtschef wegenwacht

48410 Weger, meter scheepsladingen

48403 Bedrijfshoofd klein touringcarbedrijf

48412 Bedrijfshoofd middelgroot touringcarbedrijf 
SBC-beroepsklasse

SBC-nr. SBC-beroepsgroep/ ROA-nr. ROA-beroepsgroep

Beroep

$485 \quad$ Middelbare verzorgende transportberoepen / 73 Stewards

48501 Steward, stewardess luchtvaart

48503 Grondsteward, grondstewardess

48502 Scheepskok

49 MIDDELBARE (PARA)MEDISCHE BEROEPEN

492 Middelbare algemene (para)medische beroepen / 75 Verplegenden en doktersassistenten

49208 Ambulanceverpleegkundige; verpleegkundige (psychiatrisch) ziekenhuis (middelbaar)

49202 Doktersassistent

49209 Kraamverzorgende

49206 Operatieassistent

49207 Sociaal, sociaal-psychiatrisch verpleegkundige

49203 Dierenartsassistent

49211 Keurmeester vee en vlees

49204 Chiropractic-, kruidendokter, magnetiseur, osteopaat

49210 Arbeidstherapeut (middelbaar)

49201 Ambulancechauffeur-verpleegkundige

49205 Verbandmeester, fysiotherapie-assistent, leerling-verloskundige

Middelbare technisch-(para)medische beroepen / 78 Apothekersassistenten en medisch laboranten

49310 Apothekersassistent

49302 Medisch laborant

49311 Eeg-, ecg-, hart-, longfunctieassistent (middelbaar); leerling-radiologisch laborant; audicien, opticien (excl. in-, verkoop)

49305 Tandtechnicus

49304 Medisch instrumentmaker (excl. elektrotechnisch), orthopedisch bandagist

49309 Audicien, opticien (incl. in-, verkoop)

49301 Orthopedisch instrumentmaker

49308 Orthopedisch schoenmaker

49303 Bedrijfshoofd klein tandtechnisch laboratorium, orthopedische schoenmakerij, optische glasmakerij

49307 Medisch assistent elektronica

Middelbare economisch-administratieve (para)medische beroepen / 104 Medisch secretaresses

49401 Medisch secretaresse

49402 Beheerder medisch archief

495 Middelbare verzorgend-(para)medische beroepen / 119 Ziekenverzorgenden

49501 Ziekenverzorgende

49502 Sociotherapeut (incl. leerling)

51 MIDDELBARE ADMINISTRATIEVE, COMMERCIËLE BEROEPEN ED.

$513 \quad$ Middelbare bedrijfskundige beroepen / 86 Productieplanners

51301 Productieplannen, werkvoorbereider (administratief, excl. bijdrage begroting; middelbaar)

51302 Productieplannen, werkvoorbereider (administratief, incl. bijdrage begroting; middelbaar)

514 Middelbare administratieve beroepen (automatisering ed.) / 105 Programmeurs

51402 Programmeur (geen systeem-, wetens-), computeroperator, systeembeheerder, netwerkbeheerder (middelbaar)

31401 Computeroperator (lager)

51401 Productiebegeleider automatisering (administratieve toepassingen; middelbaar) 


\section{Beroepen per beroepsgroep (vervolg)}

SBC-beroepsklasse

SBC-nr. SBC-beroepsgroep/ ROA-nr. ROA-beroepsgroep

Beroep

515 Middelbare administratieve beroepen (excl. automatisering ed.) / 90 Boekhouders en secretaresses

51507 Assistent-boekhouder, boekhouder, bedrijfskassier, loonadministrateur (middelbaar)

51506 Vergaderstenograaf, -notulist; secretaresse (excl. directie- en medisch; middelbaar)

51510 Handelscorrespondent, secretariaatsmedewerker studentenadministratie; administratief employ, (middelbaar)

51516 Hoofd secretariaat, tekstverwerking, post- en archiefzaken; office manager (middelbaar)

51502 Directiesecretaresse, directie-assistent (middelbaar)

51505 Magazijnbediende (administratief; middelbaar)

51504 Kostprijscalculator, begrotingscalculator (administratief; middelbaar)

51508 Administratief medewerker behandeling declaraties, pensioen-, subsidiestudiefinancieringaanvragen (middelbaar)

51512 Commercieel-administratief medewerker inkoopafdeling

51503 Voorraadadministrateur

51519 Leidinggevend magazijnbeheerder (administratief)

51201 Assistent-onderzoeker economisch onderzoek (middelbaar)

51518 Leidinggevend boekhouder (middelbaar)

51517 Office manager (tevens directie-assistent; middelbaar)

51509 Personeelsadministratie-employ,: personeels- en loonadministratie (middelbaar)

51511 Administratief medewerker bibliotheek en archief (middelbaar)

51501 Begeleider administratiesysteem (ondersteuning en voorlichting)

51514 Hotelportier (middelbaar)

51513 Archiefemploy,: verhuurt goederen uit archief

51202 Bedrijfshoofd kleine bioscoop

51515 Telegrafist, telexist

$516 \quad$ Middelbare commerciële beroepen / 94 Commercieel employés

51618 Advertentie-, reclameacquisiteur; verkoper groothandel, produktiebedrijf, zakelijke diensten

51607 Bank-, spaarbankemploy, (geen balie-, loketwerk); bank-, wisselkassier, marketingassistent

51616 Vertegenwoordiger artikelen en producten neg

51619 Lokettist postkantoor, spoorwegen; baliemedewerker bank

51611 Commercieel-administratief medewerker verkoopafdeling

51610 Verzekeringsagent

51617 Acquisiteurs van zakelijke diensten (geen advertenties, reclame, verzekeringen)

51615 Inkoper (middelbaar)

51608 Acceptant, schadecorrespondent verzekeringen

51602 Makelaar onroerend goed, onroerend goed deskundige (middelbaar)

51613 Balie-employé, reisbureau, reisverkoper

51601 Bijkantoorhouder bank, postkantoor

51603 Public relations adviseur, voorlichtingsfunctionaris (middelbaar)

51621 Schadetaxateur, -expert

51609 Controleur buitendienst sociale verzekeringen, documentencontroleur bank

51605 Reisprogrammeur reisorganisatie

51612 Toeristisch informant (geen reisverkoper)

51622 Verkoopchef groothandel (binnendienst)

51801 Uitgever (middelbaar), bedrijfshoofd kleine uitgeverij (excl. bladen)

51604 Reisleider, museumgids

51620 Tekstschrijver reclame (middelbaar)

517

51705

51708

51706

51701

51709

51707

51703

\section{Middelbare verkoopberoepen / 117 Winkeliers}

Detailhandelaar (geen slagerij, vis, auto's, rijwielen; klein bedrijf)

Detailhandelaar middelgroot bedrijf (excl. slagerij)

Eerste verkoper detailhandel

Detailhandelaar auto's, rijwielen (klein bedrijf)

Leidinggevend verkoper detailhandel

Eerste caissière 
SBC-beroepsklasse

SBC-nr. SBC-beroepsgroep/ ROA-nr. ROA-beroepsgroep

Beroep

51702 Detailhandelaar vis (klein bedrijf)

51704 Veilinghouder, afslager

521 Middelbare technisch-, wiskundig-, commerciële-, administratieve beroepen / 96

Technisch-commercieel employés

52105 Vertegenwoordiger technische producten (excl. automatisering; middelbaar)

52101 Technisch werkvoorbereider, planner (excl. bouwnijverheid; middelbaar)

52104 Inkoper technische producten: machines, apparaten (excl. automatisering; middelbaar)

52102 Reclame-, decoratieschilder

52106 Etaleur (middelbaar)

52103 Actuarieel rekenaar, actuarieel assistent (middelbaar)

53 MIDDELBARE JURIDISCHE, BESTUURLIJKE BEVEILIGINGSBEROEPEN

532 Middelbare juridische, bestuurlijke beroepen / 98 Juridisch en fiscaal medewerkers

53203 Belastingambtenaar, -assistent, douaneambtenaar

53204 Administratief medewerker notaris, advocaat, rechtbank

53206 Buitendienstmedewerker sociale voorzieningen ed, reinigingspolitie

53205 Deurwaarder (excl. gerechtsdeurwaarder)

53201 Belastingconsulent (middelbaar)

542 Middelbare beveiligingsberoepen / 125 Politieagenten, onderofficieren en beveiligingsemployés

54203 Politieagent, wachtmeester

54201 Bedrijfspolitieagent, -rechercheur, particulier detective; militair onderofficier

54205 Leidinggevend beveiligingsbeambte, militair onderofficier

54202 Rechercheur (excl. bedrijfsrecherche; middelbaar)

54204 Adjudant, wachtcommandant, postcommandant (politie)

55

\section{MIDDELBARE TAALKUNDIGE, CULTURELE BEROEPEN}

553

Middelbare taalkundige beroepen ed. / 20 Bibliotheekassistenten

55302 Bibliotheekassistent (excl. uitleen); archivaris, archiefmedewerker, literatuuronderzoeker (middelbaar)

55301 Bibliotheekassistent (incl. uitleen)

55202 Lector uitgeverij

55201 Redacteur, assistent-redacteur (uitgeverij boeken; middelbaar)

41103 Corrector, collationist

41101 Nieuwslezer, programma-aankondiger

55303 Leidinggevend archivaris (middelbaar)

$554 \quad$ Middelbare kunstzinnige beroepen / 22 Grafisch ontwerpers

55401 Boekillustrator, sneltekenaar; decor-, reclame-, grafisch ontwerper (middelbaar)

56 MIDDELBARE BEROEPEN MBT. GEDRAG EN MAATSCHAPPIJ

563 Middelbare sociaal-maatschappelijke beroepen ed. / 109 Activiteitenbegeleiders en medewerkers arbeidsbemiddeling

56306 Recreatie-, activiteitenleider

56304 Administratief medewerker arbeidsbemiddeling; personeelsfunctionaris werving, selectie, studievoorlichting (middelbaar)

56307 Maatschappelijk, sociaal-cultureel werker (excl. recreatie-, activiteitenleider; middelbaar)

57401 Penitentiair inrichtingswerker

56201 Pastoraal werker

56302 Maatschappelijk werker kinderbescherming, voogdij (middelbaar)

56305 Beheerder buurthuis (geen conciërge)

56303 Consulent opbouwwerk (middelbaar) 
SBC-beroepsklasse

SBC-nr. SBC-beroepsgroep/ ROA-nr. ROA-beroepsgroep Beroep

57 MIDDELBARE VERZORGENDE BEROEPEN ED.

572 Middelbare algemeen verzorgende beroepen / 120 Verzorgend personeel

57210 Crècheleidster; bejaarden-, zwakzinnigenverzorgende (middelbaar)

57212 Kapper, pruikenmaker, grimeur, schoonheidsspecialist

57208 Gezins-, bejaardenverzorgende thuiszorg, inrichtingsassistent (middelbaar)

57207 Instellings-, dieetkok; kok (middelbaar)

57201 Hoofd kleine afd huishouding, verzorging inrichting, hotel

57204 Chef-kok kleine keuken

57202 Peuterwerker

57213 Hoofd middelgrote afd huishouding, verzorging inrichting (middelbaar)

57203 Bedrijfshoofd (tevens kok) klein restaurant

57214 Chef-kok grote keuken, bedrijfshoofd (tevens kok) middelgroot restaurant

57215 Bedrijfshoofd middelgroot schoonmaakbedrijf, wasserij, kapperszaak

57211 Bedrijfshoofd klein schoonmaakbedrijf

57206 Oberkelner

57209 Chiropodist

57205 Bedrijfshoofd kleine wasserij

573

Middelbare commercieel-verzorgende beroepen ed. / 122 Bedrijfshoofden horeca

57302

57308

57304

57303

57306

57307

77301

57305

57301

Bedrijfshoofd klein restaurant, kantine

Bedrijfshoofd middelgroot hotel, pension, vakantiecentrum, restaurant, kantine, café, bar, snackbar

Bedrijfshoofd klein hotel, pension, vakantiecentrum

Croupier

Saunahouder

Bedrijfshoofd middelgrote begrafenisonderneming

Hofmeester passagiersschip, scheepspurser koopvaardij

Bedrijfshoofd kamerverhuurbedrijf

Bedrijfshoofd kleine begrafenisonderneming

62

HOGERE PEDAGOGISCHE BEROEPEN

Hogere pedagogische beroepen (ongeacht specialisatie) / 12 Docenten $2 e$ en $3 e$ graads zonder specialisatie

62101 Docent twee of meer vakken van verschillende vakgebieden (2e en $3 e$ graads)

62102 Examinator, gecommitteerde (hoger)

Hogere onderwijskundige, pedagogische beroepen / 14 Onderwijskundig medewerkers

62203

62205

62204

62202

Coördinator, consulent onderwijs (hoger)

Onderwijskundig medewerker (ontwikkelen les-, cursusmateriaal; hoger)

Schoolbegeleider (hoger)

62201 Beleidsambtenaar onderwijs en wetenschappen, onderwijszaken (hoger)

623 Docenten basisonderwijs, algemeen vormende vakken / 1 Leraar basisonderwijs

62301 Docent basisonderwijs, algemeen vormende vakken

62302 Docent speciaal onderwijs

625 Docenten exacte, (para)medische, verzorgende vakken (2e en 3 e gr.) / 2 Docenten exacte, medische en verzorgende vakken (2e en 3 e gr.)

62501 Docent wiskunde, natuurwetenschappen, statistiek, laboratoriumtechniek (2e en $3 e$ graads); instructeur denksport

62802 Verpleegkundige-docent

63501 Docent huishoudkunde, koksvak (2e en 3e graads)

62801 Docent paramedische praktijkvakken, leidster-docente kraamcentrum 
SBC-beroepsklasse

SBC-nr. SBC-beroepsgroep/ ROA-nr. ROA-beroepsgroep Beroep

43501 Docent kappersvak

42801 Instructeur ehbo

626 Docenten agrarische, technische, transportvakken (2e en 3e gr.) / 4 Docenten landbouw en techniek (2e en 3e gr.)

62601 Docent technische wetenschappen en praktijkvakken (2e en 3e graads)

42601 Bedrijfsleermeester technische praktijkvakken

62401 Docent agrarische economie, agrarische wetenschappen en praktijkvakken (2e en $3 \mathrm{e}$ graads)

62701 Docent transportvakken (2e en 3e graads); instructeur verkeersdienstsimulator, linktrainer

631 Docenten economische, administratieve, juridische vakken (2e en 3e gr.) / 6 Docenten economisch-administratieve vakken (2e en 3 e gr.)

63101 Docent economie, commerciële en adm vakken, handelswetenschappen (2e en 3e graads); docent handelscorrespondentie (geen praktijkdiploma)

43101 Docent praktijkdiploma handelscorrespondentie

63201 Docent openbare orde en veiligheid; recht, bestuurskunde (2e en $3 e$ graads)

633 Docenten taalkundige, culturele vakken ed. / 8 Docenten talen en expressie

63301 Docent humaniora, muziek, toneel, handwerken, godsdienst, bibliotheek en archief (2e en $3 e$ graads)

43301 Dansleraar ballroom, volksdansen

634 Docenten sociale, psychologische vakken (2e en 3e gr.) / 10 Docenten sociale vakken (2e en 3e gr.)

63401 Docent aardrijkskunde, opvoedkunde, lichamelijke opvoeding, sociale wetenschappen (2e en $3 e$ graads)

\section{HOGERE LANDBOUWKUNDIGE BEROEPEN}

642 Hogere landbouwkundige beroepen / 31 Milieuhygiënisten en agrarisch vertegenwoordigers

64204 Milieuhygiënist

64404 Vertegenwoordiger agrarische produkten (incl. zaai-, pootgoed)

64208 Keurmeester, controleur land-, tuin-, bosbouw, veeteelt (hoger); technisch ambtenaar milieuzaken (inspectie)

64207 Technisch-agrarisch voorlichter, consulent (hoger)

64206 Tuin- en landschapsarchitect (hoger)

64205 Land-, tuin-, bosbouwkundige, plantenteeltdeskundige, milieu-onderzoeker bodemgebruik landbouw (hoger)

64201 Beleidsmedewerker milieuzaken, beleidsambtenaar natuur-, landbouwmilieubeheer, openluchtrecreatie (hoger)

64302 Bodemkundig onderzoeker, karteerder, cultuurtechnicus (hoger)

64403 Inkoper agrarische produkten (incl. zaai-, pootgoed)

64402 Voorlichter, consulent agrarische bedrijfskunde (hoger)

64401 Beleidsambtenaar akkerbouw-, tuinbouw-, veeteelt-, voedselvoorziening-, visserijbeleid (hoger)

64203 Landbouwkundige tropische planten-, veeteelt (hoger)

64209 Leidinggevend beheerder natuurmonumenten

64301 Beleidsambtenaar beheer, landinrichting landelijke gebieden (hoger)

64202 Beleidsmedewerker bos- en landschapsbouw (excl. rijk, provincie, gemeente)

\section{HOGERE WISKUNDIGE, NATUURWETENSCHAPPELIJKE BEROEPEN}

651 Hogere wiskundige, natuurwetenschappelijke beroepen / 38 Technisch analisten

65104 Biologisch, zoologisch, botanisch, natuurkundig, scheikundig analist

65103 Statistisch analist, statisticus (hoger)

65101 Beleidsambtenaar milieubeheer: afvalstoffen, luchtkwaliteit, bodemgebruik industrie, bouw (hoger)

65109 Leidinggevend scheikundig, chemisch analist 


\title{
7. Beroepen per beroepsgroep (vervolg)
}

\author{
SBC-beroepsklasse \\ SBC-nr. SBC-beroepsgroep/ ROA-nr. ROA-beroepsgroep \\ Beroep
}

65102 Milieu-onderzoeker afvalstoffen, luchtkwaliteit, bodemgebruik industrie, bouw (hoger)

65105 Wiskundig rekenaar, wiskundig assistent (hoger)

\section{HOGERE TECHNISCHE BEROEPEN}

662 Hogere bouwkundigen, technische beveiligingsberoepen / 45 Architecten en bouwkundig projectleiders

66204 Binnenhuisarchitect; architect, bouwkundig ontwerper-constructeur (hoger)

66209 Bouwkundig projectleider (incl. ontwerp; middelgrote projecten; hoger)

67301 Brandveiligheidsdeskundige (hoger)

66202 Bouwcalculator (hoger)

66203 Bouwkundig adviseur (hoger)

66208 Hoofduitvoerder bouw (middelgrote projecten; hoger)

66206 Bouwkundig werkvoorbereider (hoger)

66205 Bouwkundig tekenaar-constructeur (hoger), bouwkundig bestekschrijver

66207 Bouwkundig opzichter (hoger)

66201 Bouwkundig beleidsmedewerker; beleidsambtenaar bouw, stadsvernieuwing (hoger)

66211 Leidinggevend bouwkundig ontwerper-constructeur (hoger)

67304 Brandweercommandant middelgrote brandweer

66210 Leidinggevend bouwkundig opzichter (hoger)

663 Hogere bouwkundigen, technische beveiligingsberoepen / 49 Weg- en waterbouwkundig ontwerpers en projectleiders

66305 Weg- en waterbouwkundig ontwerper-constructeur, verkeersplanoloog (hoger)

66304 Verkeersonderzoeker; landmeetkundige (hoger)

66314 Leidinggevend weg- en waterbouwkundig ontwerper-constructeur, verkeersplanoloog (hoger)

66311 Projectleider weg- en waterbouw (incl. ontwerp; hoger)

66303 Weg-en waterbouwkundig calculator (hoger)

66309 Technisch hoofdambtenaar kadaster; weg- en waterbouwkundig opzichter (hoger)

66310 Hoofduitvoerder weg- en waterbouw (middelgrote projecten; hoger)

66307 Weg- en waterbouwkundig tekenaar-constructeur (hoger)

66312 Leidinggevend weg- en waterbouwkundig opzichter (hoger)

664

66406

66402

66403

66401

66404
Hogere metaalkundige beroepen / 52 Bedrijfshoofden metaalbewerking

Bedrijfshoofd middelgroot metaalbewerkingsbedrijf

Amanuensis, practicum onderwijsassistent (hoger)

Lasinspecteur

Metaalkundige, gieterijtechnicus, lastechnicus (hoger)

Werkmeester kwaliteitscontroledienst ketelbouw, fijnmechanische produkten

Hogere werktuigbouwkundige beroepen ed. / 55 Werktuigbouwkundig ontwerpers en hoofden technische dienst

Ontwerper-constructeur werktuigbouw (excl. liften; hoger)

Hoofd middelgrote technische dienst (hoger)

Bedrijfshoofd middelgrote machine-, voertuig-, vliegtuigfabriek, scheepswerf

Scheepswerktuigkundige ghv, marine

Werkmeester gas-, water-, elektriciteitsproduktie, afd offshore-industrie

Technisch tekstschrijver

Boordwerktuigkundige

Hoofd kleine technische dienst (hoger)

Tekenaar-constructeur werktuigbouw (excl. liften; hoger)

Hoofdwerktuigkundige ghv

Inspecteur, controleur gas- en waterleidingbedrijf (hoger)

Technisch calculator (machinefabriek)

Marconist, radiotelegrafist

Beleidsambtenaar arbeidsomstandigheden, geluidshinder (hoger)

Technisch ambtenaar geluidshinder 


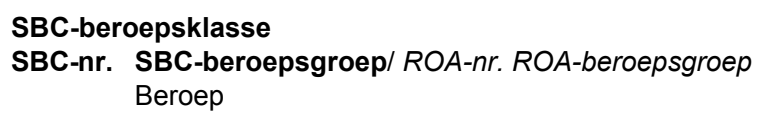

666 Hogere elektrotechnische beroepen (automatisering ed.) / 108 Technisch systeemanalisten

66601 Systeemanalist, systeemontwerper, probleemanalist, informatie-analist; programmeur (wetenschappelijke toepassingen; technisch; hoger)

66603 Ontwerper-constructeur informatie-, meet- en regeltechniek (hoger)

66604 Bedrijfshoofd klein bedrijf bouw en reparatie computers, meet- en regeltechnische apparaten

667 Hogere elektrotechnische beroepen (excl. automatisering ed.) / 59 Electrotechnisch ontwerpers en bedrijfshoofden

66702 Ontwerper-constructeur energie-, telecommunicatietechniek, elektromotoren, elektronica (hoger)

66709 Bedrijfshoofd middelgroot elektrotechnisch installatiebedrijf, bouw en reparatie elektrische apparatuur en elektronica (excl. computers)

66705 Werkmeester productie elektrotechnische apparaten, elektrotechnische dienst (hoger)

66707 Leidinggevend ontwerper-constructeur energie-, telecommunicatietechniek, elektromotoren, elektronica (hoger)

66704 Elektrotechnisch opzichter (hoger)

66703 Tekenaar-constructeur elektrotechniek (excl. meet- en regel-, informatietechniek; hoger)

66701 Meettechnicus ontwikkeling en bewaking elektrotechnische meetstandaarden

66706 Leidinggevend elektrotechnisch opzichter (hoger)

Hogere procestechnische beroepen ed. / 65 Procestechnologen

67101 Chemisch, hout-, keramisch, papier-, textiel-, voedingsmiddelentechnoloog (hoger)

67103 Bedrijfshoofd klein bedrijf voedingsmiddelen-, (petro-)chemische, procesindustrie

67105 Vertegenwoordiger chemische producten (procesindustrie; excl. farmacie)

67203 Bedrijfshoofd middelgroot bedrijf leer-, schoeisel-, textielindustrie

67201 Technisch natuurkundige, mijnbouwkundige, confectie-, ledertechnoloog (hoger)

67107 Leidinggevend chemisch, hout-, keramisch, papier-, textiel-, voedingsmiddelentechnoloog (hoger)

67102 Bedrijfshoofd klein ingenieursbureau procestechnologie

67106 Keurmeester voedingsmiddelen (excl. vee en vlees; hoger)

67104 Inkoper chemische producten (procesindustrie; excl. farmacie)

\section{HOGERE TRANSPORTBEROEPEN}

Hogere transportberoepen (excl. technisch) / 72 Vliegers, scheepskapiteins en leidinggevenden transport

68403 Leidinggevende transport, expeditie en opslag

68204 Vlieger, vlieger-navigator

68205 Kapitein kustvaart, 2e en lagere stuurlieden ghv, loods zeescheepvaart

68202 Luchtverkeersleider; dienstleider, opzichter vervoersdiensten (hoger)

68207 Scheepskapitein ghv

68208 1e Stuurman ghv, kapitein grote zeesleepvaart, kapitein khv

68404 Bedrijfshoofd middelgroot openbaar vervoers-, vlieg-, binnenvaart-, zeevaartbedrijf

68402 Controleur vervoer gevaarlijke stoffen

68201 Beleidsambtenaar transport, vervoer (hoger)

68206 Chef nautische dienst (waldienst) 
SBC-beroepsklasse

SBC-nr. SBC-beroepsgroep/ ROA-nr. ROA-beroepsgroep

Beroep

69 HOGERE (PARA)MEDISCHE BEROEPEN

692 Hogere algemene, verzorgende (para)medische beroepen / 76 Therapeuten en verpleegkundigen

69205 Fysio-, bewegingstherapeut, akoepedist, logopedist, orthoptist

69206 Wijk-, school-, particulier verpleegkundige; verpleegkundige ziekenhuis (hoger)

69210 Hoofdverpleegkundige ziekenhuis

69207 Arbeids-, bezigheids-, creatief, muziek-, speltherapeut (hoger)

69203 Mondhygiënist, verloskundige, homeopaat (excl. arts)

69501 Diëtist

69204 Anesthesie-assistent

69201 Districtsverpleegkundige; beleidsmedewerker, beleidsambtenaar gezondheidszorg (hoger)

69209 Hoofdverpleegkundige ambulancedienst

69202 Bedrijfsverpleegkundige

693 Hogere technisch-(para)medische beroepen / 79 Medisch analisten

69303 Medisch, bacteriologisch-medisch, zoologisch-medisch analist

69305 Radiologisch laborant; eeg-, ecg-, hartfunctie-, dialyse-, beademingsassistent (hoger)

69304 Orthopedisch maatnemer en modelmaker

69306 Bedrijfshoofd middelgroot tandtechnisch laboratorium, orthopedische schoenmakerij, optische glasmakerij

69301 Arbeidshygiënist, ergonoom

69302 Ziekenhuishygiënist

\section{HOGERE ADMINISTRATIEVE, COMMERCIËLE, ECONOMISCHE BEROEPEN}

712 Hogere algemeen economische beroepen / 84 Bedrijfshoofden

71204 Bedrijfshoofd algemene leiding klein bedrijf (excl. handel, horeca, landbouw)

71203 Bedrijfshoofd klein uitzendbureau

71201 Beleidsambtenaar financiële, economische zaken (excl. fiscale zaken; hoger)

71206 Bedrijfshoofd middelgroot uitzendbureau

713 Hogere bedrijfskundige beroepen ed. / 87 Organisatie-adviseurs

71301 Bedrijfsorganisatiedeskundige (excl. technisch), personeelsorganisatie-adviseur (hoger)

71303 Productieplannen, werkvoorbereider (administratief, excl. bijdrage begroting; hoger)

71305 Leidinggevend bedrijfsorganisatiedeskundige (excl. technisch)

71302 Bedrijfsorganisatiedeskundige (planning en begroting)

71304 Productieplannen, werkvoorbereider (administratief, incl. bijdrage begroting; hoger)

714 Hogere administratieve beroepen (automatisering ed.) / 106 Systeemanalisten

71401 Informatie-, systeemanalist, systeemontwerper, -programmeur; programmeur (wetenschappelijke toepassingen; administratief; hoger)

71404 Systeem-, netwerkbeheerder (hoger)

71402 Programmeur (administratieve toepassingen; hoger; excl. systeemprogrammeur, excl. wetenschappelijke toepassingen)

71407 Leidinggevende automatisering (administratieve toepassingen; hoger)

71406 Vertegenwoordiger computers, randapparatuur, automatiseringsmiddelen

71403 Productiebegeleider automatisering (administratieve toepassingen; hoger)

71405 Inkoper computers, randapparatuur, automatiseringsmiddelen

71408 Leidinggevend inkoper automatiseringsmiddelen

715 Hogere administratieve beroepen (excl. automatisering ed.) / 91 Assistent accountants

71505 Administratief medewerker behandeling declaraties, pensioen-, subsidie-, studiefinancieringaanvragen (hoger); assistent accountant

71504 Boekhouder (hoger)

71502 Directiesecretaresse, directie-assistent (hoger)

71511 Leidinggevend boekhouder (hoger); leidinggevende financieel-economische zaken 
SBC-beroepsklasse

SBC-nr. SBC-beroepsgroep/ ROA-nr. ROA-beroepsgroep

Beroep

71508 Bedrijfshoofd middelgroot boekhoud-, administratiekantoor; office manager (hoger)

71507 Accountant-administratieconsulent

71510 Office manager (tevens directie-assistent; hoger)

71503 Kostprijscalculator, begrotingscalculator (excl. technisch; hoger)

71501 Beleidsambtenaar fiscale zaken (hoger)

71509 Hoofd afdeling administratie (leiding aan uitvoerenden; beleidsvoorbereiding; hoger)

71506 Personeelsadministratie-employ; personeels- en loonadministratie (hoger)

716 Hogere commerciële beroepen ed. / 95 Commercieel medewerkers

71611 Groothandelaar, makelaar in roerende goederen, effectenarbitrageant, hoofd kleine afd verkoop, export, inkoop

71601 Beleggings-, krediet-, financieel adviseur; kredietanalist, kredietbeoordelaar

71618 Leidinggevend groothandelaar, hoofd middelgrote afdeling verkoop, export, inkoop

71604 Marketingadviseur, -specialist (geen onderzoek)

71615 Bedrijfshoofd middelgroot assurantiekantoor, makelaardij, vvv; algemene leiding middelgroot bedrijf (excl. landbouw, handel, horeca)

71602 Marketing-onderzoeker (hoger)

71612 Inkoper znd (hoger)

71608 Public relations adviseur, voorlichtingsfunctionaris (hoger)

71616 Bedrijfshoofd middelgrote bank-, verzekeringsmaatschappij, bijkantoor bank, postkantoor

69402 Artsen-, dierenartsenbezoeker; vertegenwoordiger farmaceutische prod

71606 Reclamedeskundige, reclamecampagne-adviseur

71610 Verzekeringsinspecteur

71603 Verzekeringsdeskundige (excl. agent, inspecteur)

71617 Leidinggevende marketingadviseur, -specialist, reclamedeskundige, -adviseur

71607 Makelaar onroerend goed, onroerend goed deskundige (hoger)

71605 Commissionair in effecten

71614 Tekstschrijver reclame (hoger)

71619 Leidinggevend inkoper znd

71613 Bedrijfshoofd klein reisbureau, -organisatie

71801 Uitgever (hoger)

69401 Inkoper farmaceutische producten

71609 Bedrijfshoofd kleine vvv

71802 Bedrijfshoofd middelgrote uitgeverij (huis- aan huisbladen, boeken)

71620 Bedrijfshoofd middelgroot reisbureau, -organisatie

721 Hogere technisch-, wiskundig-commerciële, administratieve beroepen / 97 Technischbedrijfskundig medewerkers

72102 Bedrijfsorganisatiedeskundige (technisch; hoger)

72106 Vertegenwoordiger technische producten (excl. automatisering; hoger)

72101 Arbeidsanalist, arbeidskundige

72108 Leidinggevend bedrijfsorganisatiedeskundige (technisch; hoger)

72105 Inkoper technische producten: machines, apparaten (excl. automatisering; hoger)

72103 Technisch werkvoorbereider, planner (excl. bouwnijverheid; hoger)

72107 Hoofd arbeid werkplaats(en) in instelling, tehuis, gevangenis

72109 Leidinggevend inkoper technische producten: machines, apparaten (excl. automatisering)

72104 Actuarieel rekenaar, actuarieel assistent (hoger)

\section{HOGERE JURIDISCHE, BESTUURLIJKE, BEVEILIGINGSBEROEPEN}

732 Hogere juridische, bestuurlijke beroepen / 99 Juridisch, bestuurlijk medewerkers

73803 Leidinggevende afd arbeidsaangelegenheden, sociaal-culturele zaken, volkshuisvesting, ruimtelijke ordening (overheid)

73205 Belastingconsulent (hoger)

73702 Leidinggevende afd algemene zaken, bevolkingsadministratie overheid

73201 Beleidsambtenaar juridische zaken, sociale zekerheid, openbare orde en veiligheid (hoger)

73402 Leidinggevende afd landbouw, visserij, milieuhygiëne 
SBC-beroepsklasse

SBC-nr. SBC-beroepsgroep/ ROA-nr. ROA-beroepsgroep Beroep

73209 Hoofdcontroleur, -verificateur belastingen; gemeentesecretaris kleine gemeente

73801 Beleidsambtenaar sportzaken (hoger)

73207 Opsporingsambtenaar sociale voorzieningen e.d. (excl. buitendienst)

73203 Beleidsmedewerker juridische zaken (excl. rijk, provincie, gemeente; hoger)

73202 Secretaris overheidsdiensten, organisaties (juridisch; hoger)

73302 Leidinggevende afd onderwijs en culturele zaken overheid

73701 Secretaris overheidsdiensten, organisaties (economisch, administratief; hoger)

73206 Gerechtsdeurwaarder

73210 Verkeersinspecteur, vervoersinspecteur

73301 Secretaris overheidsdiensten, organisaties (onderwijs; hoger)

73401 Secretaris overheidsdiensten, organisaties (landbouw; hoger)

73204 Sportofficial

742 Hogere algemene beveiligingsberoepen / 126 Politie-inspecteurs en officieren

$74201 \quad$ Militair officier (kapitein of lager)

74204 Leidinggevend militair officier (kapitein of lager)

74203 Politie-inspecteur

74205 Adjunct-directeur gevangenis, hoofd veiligheidsdienst overheid

75 HOGERE TAALKUNDIGE, CULTURELE BEROEPEN

$752 \quad$ Hogere taalkundige beroepen / 19 Tolken, vertalers en schrijvers

75204 Auteur, scenarioschrijver, tolk, vertaler

75203 Redacteur (uitgeverij boeken; hoger)

75201 Gidsenschrijver

Hogere bibliotheek-, documentatieberoepen / 21 Bibliothecarissen

75303 Archivaris, literatuuronderzoeker, bibliothecaris (excl. jeugd-, muziekbibliotheek; hoger)

75304 Leidinggevend archivaris, bibliothecaris (hoger)

75301 Beleidsambtenaar documentatie, bibliotheek, informatievoorziening (hoger)

$754 \quad$ Hogere kunstzinnige beroepen / 23 Kunstenaars

75415 Beeldend kunstenaar; museummedewerker presentaties; mode-ontwerper; decor-, reclamegrafisch ontwerper (hoger)

75414 Instrumentalist, componist, dirigent (excl. koor), songwriter

75411 Acteur, cabaretier, vari,t,-artiest, zanger opera, operette, revue, musical

75416 Bedrijfshoofd middelgrote kunstgalerij, museum, instelling voor kunstbeoefening; productieleider uitvoerende kunst

75403 Bedrijfshoofd kleine kunstgalerij, museum, instelling voor kunstbeoefening

75418 Regisseur toneel, film

75412 Balletdanser, ballroomdanser

75404 Impresario, theateragent

75409 Bedrijfshoofd klein grafisch ontwerpbureau

75408 Kunstgalerij-, museumconservator (hoger)

75401 Beleidsambtenaar culturele zaken, kunsten (hoger)

75413 Zanger (excl. opera, operette, revue, musical), koordirigent

75406 Choreograaf

75405 Filmer, cineast

75402 Educatief medewerker museum (hoger)

75407 Archiefemployé, museumarchief

76 HOGERE BEROEPEN MBT. GEDRAG EN MAATSCHAPPIJ ED.

762 Hogere theologische beroepen / 24 Geestelijk verzorgers

76201 Bedienaar eredienst (hoger) 
SBC-beroepsklasse

SBC-nr. SBC-beroepsgroep/ ROA-nr. ROA-beroepsgroep

Beroep

763 Hogere sociaal-maatschappelijke beroepen / 110 Sociaal-cultureel werkers

76313 Sociaal-cultureel werker, maatschappelijk werker (excl. kinderbescherming, voogdij, reclassering; hoger)

76310 Arbeidsbemiddelaar; personeelsfunctionaris werving, selectie, studievoorlichting (hoger)

76315 Leidinggevende afd personeels-, sociale zaken

76306 Maatschappelijk werker reclassering; kinderbescherming, voogdij (hoger)

76302 Beleidsmedewerker personeelszaken, arbeidsvoorwaarden

76311 Coördinator maatschappelijk, sociaal-cultureel werk (hoger)

76308 Studie- en beroepskeuzeadviseur; school-, studentendecaan (hoger)

76314 Bedrijfshoofd middelgrote instelling voor maatschappelijk werk

76317 Leidinggevend personeelsfunctionaris werving, selectie, studievoorlichting

76305 Sociaal raadsman (hoger)

76303 Functie-analist

76304 Adviseur, consulent sociaal-cultureel werk (hoger)

76301 Beleidsmedewerker maatschappelijk werk (excl. rijk, provincie, gemeente)

76319 Leidinggevend maatschappelijk werker (hoger)

76307 Consulent opbouwwerk (hoger)

764 Hogere sociaal-wetenschappelijke beroepen ed. / 26 Journalisten

76401 Journalist, recensent, criticus; redacteur (uitgeverij bladen; hoger)

76403 Hoofdredacteur, algemeen redactiechef (uitgeverij bladen; hoger)

76404 Regisseur radio, tv

765 Hogere sociaal-wetenschappelijke beroepen ed. / 112 Sociaal-wetenschappelijk medewerkers

76501 Beleidsambtenaar ruimtelijke ordening, welzijnsbeleid (hoger)

76502 Assistent-onderzoeker planologisch, psychologisch onderzoek (hoger)

76504 Psychotherapeut (hoger)

56501 Assistent-onderzoeker planologisch, psychologisch onderzoek (middelbaar)

76503 Assistent-onderzoeker sociologisch, demografisch onderzoek

\section{HOGERE VERZORGENDE BEROEPEN}

$772 \quad$ Hogere verzorgende beroepen / 81 Afdelingshoofden zorginstelling

77203 Bedrijfshoofd middelgroot bejaardentehuis, gezinsverzorgingsinstelling; leidinggevende gezinszorg; hoofdverpleegkundige zwakzinnigenzorg

77202 Hoofd middelgrote afd huishouding, verzorging inrichting (hoger)

78 MANAGERS (HBO WERK- EN DENKNIVEAU) ED.

788 Managers (HBO werk- en denkniveau) ed. / 102 Leidinggevenden

78801 Manager groot-, detailhandel, bankbijkantoren, bioscoop, afd verkoop, afd inkoop

78501 Manager bouw, bouwinstallatiebedrijven, bewakingsdienst; manager industriële produktie, wegen waterbouw (hoger)

79101 Manager politie, sport-, vakbond, deurwaarderskantoor

78202 Directeur basis-, speciaal onderwijs (niet lesgevend)

78601 Manager transport- (geen taxibedrijf), expeditie-, cargadoors-, stuwadoors-, vliegbedrijf, binnenpleziervaartbedrijf

79401 Manager hotel, restaurant, congres-, vakantiecentrum, schoonmaakbedrijf, wasserij, kapperszaak

78301 Manager agrarisch bedrijf, plantsoendienst, manege; rentmeester

78802 Secretaris vereniging, stichting

78602 Havenmeester scheepvaart

58601 Manager taxibedrijf

59401 Manager caf,, bar, snackbar, kantine, begrafenisonderneming

78502 Brandweercommandant grote brandweer 
SBC-beroepsklasse

SBC-nr. SBC-beroepsgroep/ ROA-nr. ROA-beroepsgroep Beroep

82 WETENSCHAPPELIJKE PEDAGOGISCHE BEROEPEN

821 Wetenschappelijke pedagogische beroepen (ongeacht specialisatie) / 13 Docent 1e graads zonder specialisatie

82101 Docent twee of meer vakken van verschillende vakgebieden (1e graads)

822 Wetenschappelijke onderwijskundige, pedagogische beroepen / 15 Onderwijskundigen en pedagogen

82206 Cursusleider, cursuscoördinator (lesgevend)

82208 Orthopedagoog (excl. wetens onderzoek)

82209 Leidinggevend coördinator, consulent onderwijs

82201 Beleidsmedewerker; beleidsambtenaar onderwijszaken (wetens)

82203 Wetens onderzoeker onderwijskunde

82204 Coördinator, consulent onderwijs (wetens)

82205 Pedagogisch adviseur; schoolbegeleider (wetens)

82207 Onderwijskundig medewerker (ontwikkelen les-, cursusmateriaal; wetens)

82202 Wetens onderzoeker (ortho-)pedagogiek

82210 Leidinggevende onderwijskundig onderzoek

825 Docenten exacte, (para)medische, verzorgende vakken (1e gr. en WO) / 3 Docenten exacte, medische en verzorgende vakken (1e gr. en WO)

82502 Docent wiskunde, natuurwetenschappen, statistiek, laboratoriumtechniek (1e graads)

82501 Docent wetens onderwijs wiskunde, natuurwetenschappen, statistiek

82802 Docent (dier)geneeskunde, farmacie (1e graads)

82801 Docent wetens onderwijs (dier)geneeskunde, farmacie

83501 Docent wetens onderwijs (landbouw)huishoudkunde

83502 Docent huishoudkunde, koksvak (1e graads)

826 Docenten agrarische, technische, transportvakken (1e gr. en WO) / 5 Docenten landbouw en techniek (1e gr. en WO)

82602 Docent technische wetenschappen en praktijkvakken (1e graads)

82601 Docent wetens onderwijs technische wetenschappen

82402 Docent agrarische economie, agrarische wetenschappen en praktijkvakken (1e graads)

831 Docenten economische, administratieve, juridische vakken (1e gr. en WO) / 7 Docenten economisch-administratieve vakken (1e gr. en WO)

83102 Docent actuariële wetenschappen; docent economie, commerciële en administratieve vakken, handelswetenschappen (1e graads)

83101 Docent wetens onderwijs economie, administratieve en commerciële vakken, actuariële wetenschappen

83202 Docent recht, bestuurskunde (1e graads)

83201 Docent wetens onderwijs recht, bestuurskunde

833 Docenten taalkundige, culturele vakken (1e gr. en WO) / 9 Docenten letteren (1e gr. en WO)

83302 Docent humaniora, muziek, toneel, handwerken, godsdienst, bibliotheek en archief (1e graads)

83301 Docent wetens onderwijs humaniora, (kunst)geschiedenis, theologie

834 Docenten sociale, psychologische vakken (1e gr. en WO) / 11 Docenten sociale vakken (1e gr. en WO)

83402 Docent aardrijkskunde, opvoedkunde, lichamelijke opvoeding, sociale wetenschappen (1e graads)

83401 Docent wetens onderwijs aardrijkskunde, opvoedkunde, didactiek, sociale wetenschappen

84 WETENSCHAPPELIJKE LANDBOUWKUNDIGE BEROEPEN

842 Wetenschappelijke landbouwkundige beroepen / 32 Landbouwkundigen

84203 Land-, tuin-, bosbouwkundige, plantenteeltdeskundige, milieu-onderzoeker landbouw (wetens) 
SBC-beroepsklasse

SBC-nr. SBC-beroepsgroep/ ROA-nr. ROA-beroepsgroep

Beroep

84205 Tuin- en landschapsarchitect (wetens)

84201 Beleidsmedewerker milieuzaken, beleidsambtenaar natuur-, landbouwmilieubeheer, openluchtrecreatie (wetens)

84204 Wetens onderzoeker land-, tuin-, bosbouw; milieu-onderzoeker bodemgebruik landbouw

84303 Bodemkundig onderzoeker, cultuurtechnicus (wetens)

84401 Beleidsambtenaar akkerbouw-, tuinbouw-, veeteelt-, voedselvoorziening-, visserijbeleid (wetens)

84403 Voorlichter, consulent agrarische bedrijfskunde (wetens)

84206 Technisch-agrarisch voorlichter, consulent (wetens)

84207 Leidinggevende landbouwproefstation, veredelingsbedrijf, afd landbouwkundig, milieukundig onderzoek landbouw

84402 Wetens onderzoeker agrarische economie

85 WETENSCH. WISKUNDIGE, NATUURWETENSCHAPPELIJKE BEROEPEN

851 Wetenschappelijke wiskundige, natuurwetenschappelijke beroepen / 39

Natuurwetenschappers

85102 Wiskundige, natuurwetenschapper; milieu-onderzoeker afvalstoffen, luchtkwaliteit, bodemgebruik industrie, bouw (wetens)

85103 Wetens onderzoeker schei-, natuurkunde, biochemie, biologie, geologie, geografie, wiskunde, statistiek

85105 Leidinggevende wiskundig en natuurwetenschappelijk onderzoek

85104 Statisticus (wetens)

85101 Beleidsambtenaar milieubeheer: afvalstoffen, luchtkwaliteit, bodemgebruik industrie, bouw (wetens)

861 Wetenschappelijke technische (ongeacht specialisatie), werktuigbouwkundige beroepen / 42 Werktuigbouwkundigen

86104 Leidinggevende afd research, productontwikkeling

86502 Ontwerper-constructeur werktuigbouw (excl. liften; wetens)

86503 Inspecteur werktuigbouw (excl. gas- en waterinstallaties)

86505 Leidinggevend ontwerper-constructeur werktuigbouw (excl. liften; wetens)

86103 Hoofd middelgrote technische dienst (wetens)

86101 Beleidsambtenaar arbeidsomstandigheden, geluidshinder (wetens)

86501 Wetens onderzoeker scheeps-, vliegtuig-, werktuigbouwkunde

862 Wetenschappelijke (weg- en waterbouw-)bouwkundige beroepen ed. / 46 (Weg-en water)bouwkundigen

86204 Stedenbouwkundige; architect, bouwkundig ontwerper-constructeur (wetens)

86304 Weg- en waterbouwkundig ontwerper-constructeur, verkeersplanoloog (wetens)

86205 Bouwkundig inspecteur

86207 Bouwkundig projectleider (incl. ontwerp; middelgrote projecten; wetens)

86201 Beleidsambtenaar bouw, stadsvernieuwing (wetens)

86308 Leidinggevend weg-en waterbouwkundig ontwerper-constructeur, verkeersplanoloog (wetens)

86309 Bedrijfshoofd middelgroot ingenieursbureau weg- en waterbouw

86303 Wetens onderzoeker geodesie, cartografie, verkeerskunde, weg- en waterbouwkunde

86208 Leidinggevend bouwkundig ontwerper-constructeur (wetens)

86202 Bouwkundig adviseur (wetens)

86306 Projectleider weg- en waterbouw (incl. ontwerp; wetens)

86305 Hoofduitvoerder weg- en waterbouw (middelgrote projecten; wetens)

86302 Geodeet, cartograaf; landmeetkundige (wetens)

86301 Beleidsmedewerker verkeers- en stedebouwkunde, beleidsambtenaar kadaster, infrastructuur (wetens)

867 Wetenschappelijke elektrotechnische beroepen / 60 Elektrotechnici

86601 Programmeur (technisch; wetenschappelijke toepassingen; wetens) 
SBC-beroepsklasse

SBC-nr. SBC-beroepsgroep/ ROA-nr. ROA-beroepsgroep Beroep

86702 Ontwerper-constructeur energie-, telecommunicatietechniek, elektromotoren, elektronica (wetens)

86602 Ontwerper-constructeur informatie-, meet- en regeltechniek (wetens)

86701 Wetens onderzoeker elektrotechniek

86606 Bedrijfshoofd middelgroot bedrijf bouw, installatie en reparatie computers, meet- en regeltechnische apparatuur

871 Wetenschappelijke materiaalkundige, procestechnische beroepen ed. / 66 Materiaalkundigen

87102 Chemisch, textiel-, voedingsmiddelentechnoloog (wetens)

87104 Bedrijfshoofd middelgroot bedrijf voedingsmiddelen-, (petro-)chemische, procesindustrie

87206 Industrieel vormgever, industrieel ontwerper

87203 Technisch natuurkundige, mijnbouwkundige (wetens)

87202 Wetens onderzoeker toegepaste wiskunde, ertskunde, mijnbouwkunde, technische natuurkunde, industriële vormgeving

87101 Wetens onderzoeker chemische technologie, voedingsmiddelentechnologie

87103 Leidinggevend chemisch-, textiel-, voedingsmiddelentechnoloog (wetens)

87201 Wiskundig ingenieur; ertskundige; opsporingsingenieur aardgas, aardolie, mineralen, delfstoffen

86402 Metaalkundige (wetens)

87205 Bedrijfshoofd ingenieursbureau industriële vormgeving

Wetenschappelijke (para)medische beroepen (excl. technisch) ed. / 77 Artsen

89206 Huis-, bedrijfs-, consultatiebureau-, schoolarts; arts-specialist (excl. psychiater, seksuoloog, anesthesist); tandarts, tandarts- specialist

89209 Dierenarts (incl. specialist); geneeskundige veterinaire gezondheidszorg

89207 Psychiater, seksuoloog

89203 Wetens onderzoeker (dier)geneeskunde, tandheelkunde

89202 Arbeidsfysioloog, bacterioloog, patholoog, seroloog, viroloog

89201 Beleidsmedewerker, beleidsambtenaar gezondheidszorg (wetens)

89208 Anesthesist

89205 Medisch adviseur: opleidingsadvies in speciaal onderwijs

89501 Gezondheidsvoorlichting- en opvoedingsconsulent

97203 Voedingsvoorlichter

89211 Bedrijfshoofd middelgrote medische kliniek, gezondheidscentrum, kruisvereniging

89210 Leidinggevende afd medisch onderzoek

89204 Medisch adviseur (verzekeringsmaatschappij)

97204 Leidinggevende huishoudkundig, voedingsgewoonten onderzoek

97202 Wetens onderzoeker voeding van de mens

893 Wetenschappelijke technisch (para)medische beroepen / 80 Apothekers

89307 Apotheker

89311 Leidinggevend apotheker

89309 Leidinggevende medisch laboratorium

89302 Farmacoloog, klinisch chemicus

89303 Wetens onderzoeker farmacie

89310 Bedrijfshoofd middelgroot bedrijf farmaceutische industrie

89301 Gezondheidsfysicus, klinisch fysicus

91 WETENSCHAPPELIJKE ECONOMISCHE, ADMINISTRATIEVE BEROEPEN ED.

912 Wetenschappelijke algemeen-economische, commerciële beroepen ed. / 85 Economen

91203 Wetens onderzoeker (bedrijfs)economie

91202 Econoom, bedrijfseconoom (excl. wetens onderzoek)

91602 Public relations adviseur, voorlichtingsfunctionaris (wetens)

91601 Wetens onderzoeker marketing 
SBC-beroepsklasse

SBC-nr. SBC-beroepsgroep/ ROA-nr. ROA-beroepsgroep Beroep

91205 Economisch adviseur, nijverheidsconsulent

91201 Beleidsambtenaar financiële, economische zaken (excl. fiscale zaken; wetens)

91603 Leidinggevend public relations adviseur, voorlichtingsfunctionaris

88201 Beleidsambtenaar transport, vervoer (wetens)

913 Wetenschappelijke (technisch-) bedrijfskundige, wiskundig-economische beroepen / 88 Organisatiedeskundigen

91302 Bedrijfsorganisatiedeskundige (excl. technisch), personeelsorganisatie-adviseur (wetens)

92103 Bedrijfsorganisatiedeskundige (technisch; wetens)

92104 Actuaris

91303 Bedrijfshoofd middelgroot organisatie-adviesbureau (niet technisch)

92106 Bedrijfshoofd middelgroot organisatie-adviesbureau (technisch); leidinggevend bedrijfsorganisatiedeskundige (technisch; wetens)

914 Wetenschappelijke administratieve beroepen (automatisering ed.) / 107 Informatici

91401 Projectadviseur automatisering en informatievoorziening; programmeur (wetenschappelijke toepassingen; administratief; wetens)

91402 Leidinggevende automatisering (administratieve toepassingen; wetens)

915 Wetenschappelijke administratieve beroepen (excl. automatisering ed.) / 92 Accountants

91503 Accountant

91502 Boekhouder (wetens)

91505 Bedrijfshoofd middelgroot accountantsbureau

91506 Leidinggevend boekhouder (wetens)

93

\section{WETENSCHAPPELIJKE JURIDISCHE, BESTUURLIJKE BEROEPEN}

932

Wetenschappelijke juridische, bestuurlijke beroepen / 100 Juristen

93208

93209

93201

Advocaat, notaris, rechter, officier van justitie, juridisch adviseur

Belastingconsulent (wetens)

Beleidsambtenaar juridische zaken, sociale zekerheid, openbare orde en veiligheid (wetens); raadsadviseur overheidsdienst

93211 Inspecteur belastingen, bewaarder hypotheken, kadaster

93210 Secretaris, griffier rechtbank

93101 Lid eerste en tweede kamer, provinciale, gedeputeerde staten, gemeenteraad, heemraad

93202 Lid raad van state, staatsraad; beleidsmedewerker juridische zaken (excl. rijk, provincie, gemeente; wetens)

93212 Leidinggevend advocaat, notaris, fiscaal-, juridisch adviseur

93207 Octrooigemachtigde

93402 Inspecteur algemene inspectie landbouw en visserij, milieuhygiëne

93602 Inspecteur arbeid, geneeskunde, vee-artsenij, volksgezondheid

93501 Houtvester, hoofd afdeling bodemkartering, kadaster, landbouw (overheid)

93205 Wetens onderzoeker juridisch, veiligheidsonderzoek

93303 Inspecteur onderwijs

93206 Wetens onderzoeker bestuurskunde, criminologie

93705 Inspecteur domeinen

93203 Diplomatiek vertegenwoordiger

93703 Secretaris overheidsdiensten, organisaties (economisch, administratief; wetens)

93401 Secretaris overheidsdiensten, organisaties (landbouw; wetens)

96 WETENSCHAPPELIJKE BEROEPEN MBT. GEDRAG EN MAATSCHAPPIJ ED.

962 Wetenschappelijke theologische beroepen / 25 Geestelijken

96202 Bedienaar eredienst (wetens)

96201 Wetens onderzoeker theologie 


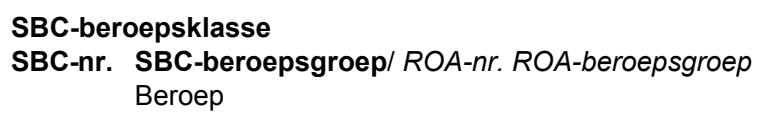

963 Wetenschappelijke sociaal-maatschappelijke beroepen / 111 Sociale raadslieden en hoofden personeelszaken

96307 Maatschappelijk werker (excl. kinderbescherming, voogdij, reclassering; wetens)

96308 Leidinggevende afdeling personeelszaken, sociale zaken, beleidsvoorbereiding sociaal-cultureel werk

96304 Maatschappelijk werker kinderbescherming, voogdij (wetens)

96306 Coördinator maatschappelijk, sociaal-cultureel werk (wetens)

96310 Leidinggevend maatschappelijk werker (wetens)

96302 Adviseur, consulent sociaal-cultureel werk (wetens)

96305 Schooldecaan, studentendecaan (wetens)

96301 Beleidsmedewerker sociaal-cultureel werk (excl. rijk, provincie, gemeente)

96309 Leidinggevend adviseur, consulent sociaal-cultureel werk

96303 Sociaal raadsman (wetens)

964 Wetenschappelijke journalistieke, taalkundige, culturele beroepen / 27 Taalkundigen

95201 Wetens onderzoeker humaniora

96402 Redacteur (uitgeverij bladen, boeken; wetens)

95302 Bibliothecaris (excl. jeugd-, muziekbibliotheek; wetens)

96403 Bedrijfshoofd middelgrote uitgeverij bladen; hoofdredacteur, algemeen redactiechef (uitgeverij bladen; wetens);

95303 Leidinggevend archivaris, bibliothecaris (wetens)

95404 Kunstgalerij-, museumconservator (wetens)

95402 Wetens onderzoeker kunstgeschiedenis

95403 Educatief medewerker museum (wetens)

95301 Beleidsambtenaar documentatie, bibliotheek, informatievoorziening (wetens)

95405 Leidinggevend kunstgalerij-, museumconservator

Wetenschappelijke sociaal-wetenschappelijke beroepen / 113 Sociaal-wetenschappelijk onderzoekers

96503 Sociaal-wetenschappelijk onderzoeker (excl. andragogie, volkenkunde)

96501 Beleidsambtenaar ruimtelijke ordening, welzijnsbeleid (wetens)

96505 Klinisch psycholoog; psychotherapeut (wetens)

96504 Psychologisch adviseur

$98 \quad$ MANAGERS (WETENSCHAPPELIJK WERK- EN DENKNIVEAU)

988 Managers (wetenschappelijk werk- en denkniveau) / 103 Managers

98801 Manager economische, administratieve, commerciële zaken, algemene leiding industrieel bedrijf 98202 Manager school voor voortgezet of hoger onderwijs

98501 Manager industriële productie (excl. farmaceutische industrie), weg- en waterbouw (wetens)

98701 Manager farmaceutische industrie, ziekenhuis, kruisvereniging, medisch laboratorium, instelling gezondheids- en wetens)

99102 Bestuurder overheid, manager overheidsinstellingen, openbaar bestuur

99101 Manager fiscale, juridische, beveiligingszaken; beroepsmilitair (majoor en hoger)

98601 Manager zeevaartbedrijf, visserij-, verkeers- en transportonderzoek, post-en telecommunicatiedienst

99401 Manager thuiszorginstelling, bejaardentehuis, kinderopvang

98502 Manager woningcorporaties

99103 Voorzitter bedrijfschap, ser, raad van arbeid

99301 Manager school- en beroepskeuzeadvies, maatschappelijk-, personeelswerk, sociaal wetens onderzoek, volksuniversiteit

98401 Manager wiskundig en natuurwetenschappelijk onderzoek

99201 Manager archief, bibliotheek, museum, theater, grafisch ontwerpbureau, film-, geluidsstudio, vertaalbureau

98301 Manager landbouwproefstation, veredelingsbedrijf, landbouwkundig, milieukundig onderzoek landbouw, landbouweconomisch onderzoek

98602 Havenmeester luchtvaart 


\section{BEDRIJFSSECTOREN}





\section{Beknopte bedrijfsclassificatie SBI ‘93}

\begin{tabular}{rll}
\hline ROA-nr. & Bedrijfscluster & SBI '93 \\
\hline 1 & Landbouw en visserij & $01000-02999,05000-05999$ \\
2 & Voeding & $15000-16999$ \\
3 & Chemie & $24000-25999$ \\
4 & Metaal en elektrotechniek & $27000-36999,36200-36599,36700-36999$ \\
5 & Overige industrie & $17000-22999,26000-26999$, \\
& & $36100-36199,36600-36699$ \\
6 & Energie & $10000-11999,14000-14999$, \\
7 & Bouw en onroerend goed & $23000-23999,40000-41999$ \\
8 & Handel en reparatie & $45000-45999,70000-70999$ \\
9 & Transport en communicatie & $50000-50402,50500-54999$ \\
10 & Bank- en verzekeringswezen & $60000-64999$ \\
11 & Horeca en zakelijke dienstverlening & $65000-67999$ \\
12 & Kwartaire diensten & $55000-55999,71000-72999,74000-74999$, \\
& & $90000-90999,92400-92799,93000-95999$ \\
13 & Overheid en onderwijs & $73000-73999,85000-85999,91000-91999$, \\
& & $92000-92399,92500-92799$ \\
\end{tabular}





\section{Uitgebreide bedrijfsclassificatie SBI ' 93}

\begin{tabular}{|c|c|c|}
\hline ROA-nr. & Bedrijfssector & SBI ‘93 \\
\hline 1 & Tuinbouw & 01120-01199 \\
\hline 2 & Veehouderij & $01200-01599$ \\
\hline 3 & Akkerbouw, bosbouw en visserij & 00001-01119,02000-02999,05000-05999 \\
\hline 4 & Vlees- en visverwerking & $15000-15299$ \\
\hline 5 & Overige voedingsproducten & $15300-15899$ \\
\hline 6 & Drank en tabaksproducten & $15900-16999$ \\
\hline 7 & Basischemie & $24000-24199$ \\
\hline 8 & Eindproducten chemie & $24200-24999$ \\
\hline 9 & Kunststofverwerking & $25000-25999$ \\
\hline 10 & Basismetaal & $27000-27999$ \\
\hline 11 & Metaalproducten & $28000-28999,36000-36099,36200-36599,36700-36999$ \\
\hline 12 & Machine-industrie & $29000-29999$ \\
\hline 13 & Elektrotechniek & $30000-33999$ \\
\hline 14 & Transportmiddelen & $34000-35999$ \\
\hline 15 & Textiel & $17000-19999$ \\
\hline 16 & Hout- en bouwmaterialen & $20000-20999,26000-26999,36100-36199,36600-36699$ \\
\hline 17 & Papier & $21000-21999$ \\
\hline 18 & Grafische industrie & $22000-22999$ \\
\hline 19 & Energie & $10000-11999,14000-14999,23000-23999,40000-41999$ \\
\hline 20 & Bouw & $45000-45999$ \\
\hline 21 & Exploitatie van onroerend goed & $70000-70999$ \\
\hline 22 & Handel en reparatie & $50000-50402,50500-52999$ \\
\hline 23 & Scheep- en luchtvaart & $61000-62999$ \\
\hline 24 & Weg- en railvervoer & $60000-60999,63000-63999$ \\
\hline 25 & Communicatie & $64000-64999$ \\
\hline 26 & Bankwezen & $65000-65999,67000-67199$ \\
\hline 27 & Verzekeringswezen & $66000-66999,67200-67999$ \\
\hline 28 & Horeca & $55000-55999$ \\
\hline 29 & Zakelijke dienstverlening & $71000-72999,74000-74999$ \\
\hline 30 & Overige commerciële dienstverlening & $90000-90999,92400-92799,93000-95999$ \\
\hline 31 & Gezondheidszorg & $85000-85999$ \\
\hline 32 & Overige kwartaire diensten & $73000-73999,91000-91999,92000-92399$ \\
\hline 33 & Onderwijs & $80000-80999$ \\
\hline 34 & Overheid & $75000-75999,99000-99500$ \\
\hline
\end{tabular}





\section{Bedrijfstakken per bedrijfssector}

\begin{tabular}{|c|c|c|}
\hline Bedrij & $\begin{array}{l}\text { scluster } \\
\text { Bedrijfssector } \\
\text { SBI '93 }\end{array}$ & Bedrijfstak \\
\hline \multicolumn{3}{|c|}{1 Landbouw en visserij } \\
\hline \multirow[t]{3}{*}{1} & Tuinbouw & \\
\hline & 01120 & Tuinb. (excl. fruitteelt) \\
\hline & 01130 & Fruitteelt \\
\hline \multirow[t]{5}{*}{2} & Veehouderij & \\
\hline & 01200 & Fokken/houden dieren \\
\hline & 01300 & Akker- en/of tuinb. comb. met fokken/houden dieren \\
\hline & 01400 & Dienstverl. tbv landb. (excl. veterin.dienst.) \\
\hline & 01500 & Jacht \\
\hline \multirow[t]{4}{*}{3} & Akkerbouw, b & sbouw en visserij \\
\hline & 01110 & Akkerbouw \\
\hline & 02000 & Bosb./dienstverl. tbv bosb. \\
\hline & 05000 & Visserij/kweken vis/schaaldieren \\
\hline
\end{tabular}

2 Voeding

4 Vlees- en visverwerking

$15100 \quad$ Slachterijen/vleesverwerking

$15200 \quad$ Visverwerking

5 Overige voedingsproducten

$15300 \quad$ Groente-/fruitverwerking

$15400 \quad$ Vervaard. plantaard./dierl. olien/vetten

$15500 \quad$ Vervaard. zuivelprodukten

$15600 \quad$ Vervaard. meel

$15700 \quad$ Vervaard. diervoeder

$15800 \quad$ Vervaard. ov. voedingsmid.

6 Drank en tabaksproducten

$15900 \quad$ Vervaard. dranken

$16000 \quad$ Verwerking tabak

3 Chemie

7 Basischemie

24100

Vervaard. basischemicaliën

8 Eindproducten chemie

$24200 \quad$ Vervaard. landbouwchemicaliën

$24300 \quad$ Vervaard. verf/lak/vernis/inkt/mastiek

$24400 \quad$ Vervaard. farmac. prod.

24500 Vervaard. zeep-,was-,reinig.-/onderhoudsmid.,parfum/cosmet.

$24600 \quad$ Vervaard. ov. chem. prod.

$24700 \quad$ Vervaard. synth./kunstmat. vezels

9 Kunststofverwerking

$25100 \quad$ Vervaard. prod. rubber

$25200 \quad$ Vervaard. prod. kunststof

4 Metaal en elektrotechniek

10 Basismetaal

$27100 \quad$ Vervaard. ijzer/staal/van ferro-legeringen (EGKS)

$27200 \quad$ Vervaard. gietijzeren/stalen buizen

$27300 \quad$ Ov. eerste verwerking ijzer/staal

$27400 \quad$ Vervaard. non-ferrometalen

$27500 \quad$ Gieten metalen

11 Metaalproducten

$28100 \quad$ Vervaard. metalen constructiew./ramen/deuren/kozijnen

$28200 \quad$ Vervaard. tanks/reservoirs/ketels/radiat. centr. verwarm.

$28300 \quad$ Vervaard. stoomketels

$28400 \quad$ Smeden/persen/stampen/profielwals. metaal;poedermetallurgie

$28500 \quad$ Oppervlaktebehandeling/ov. metaalbewerking

$28600 \quad$ Vervaard. scharen/bestek/gereedsch./hang-/sluitw.

28700 Vervaard. ov. prod. metaal (excl. mach./transportmid.)

$36100 \quad$ Vervaard. meubels

$36200 \quad$ Vervaard. sieraden ed (excl. imitatie-) 
10. Bedrijfssectoren naar bedrijfstakken (vervolg)

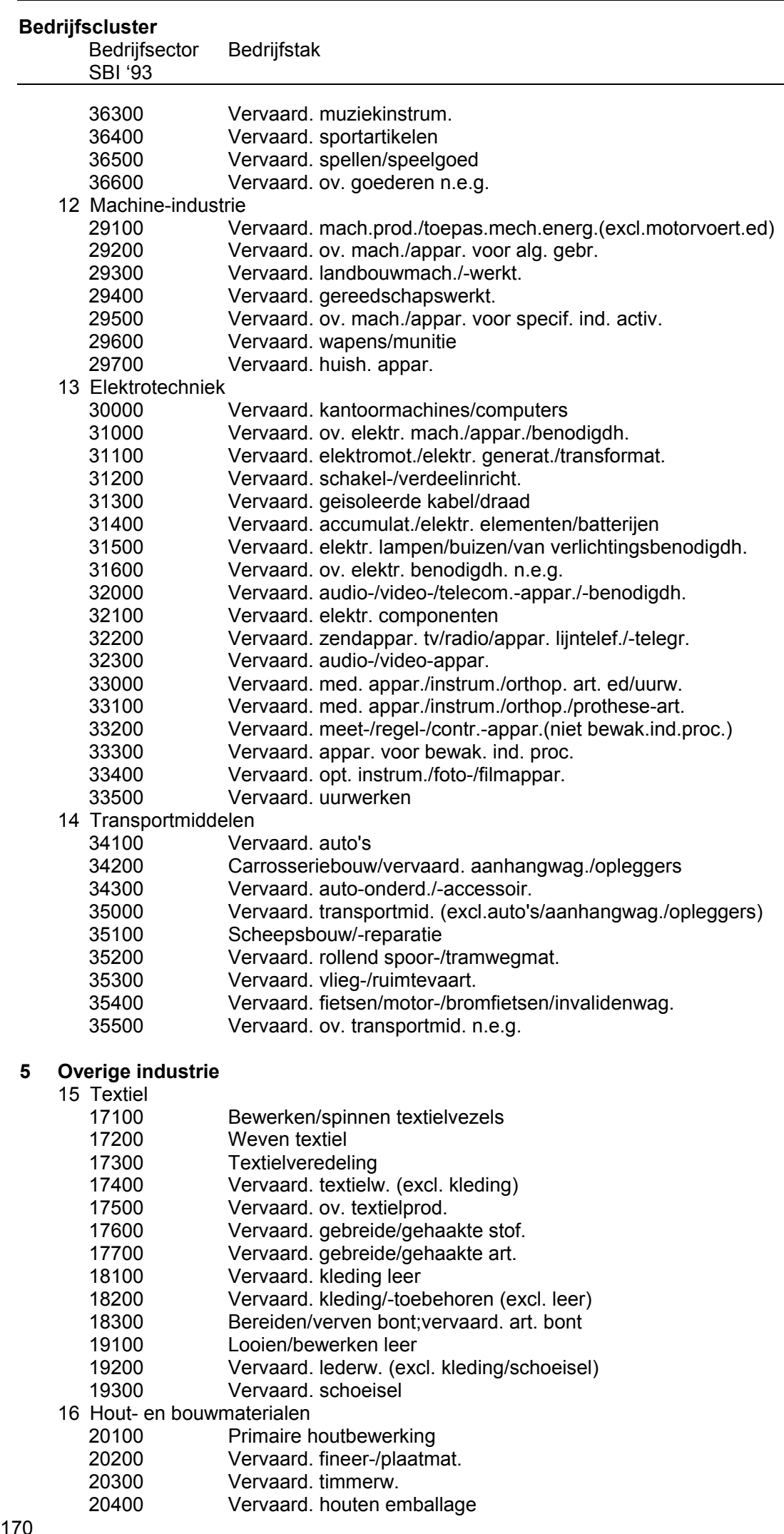


10. Bedrijfssectoren naar bedrijfstakken (vervolg)

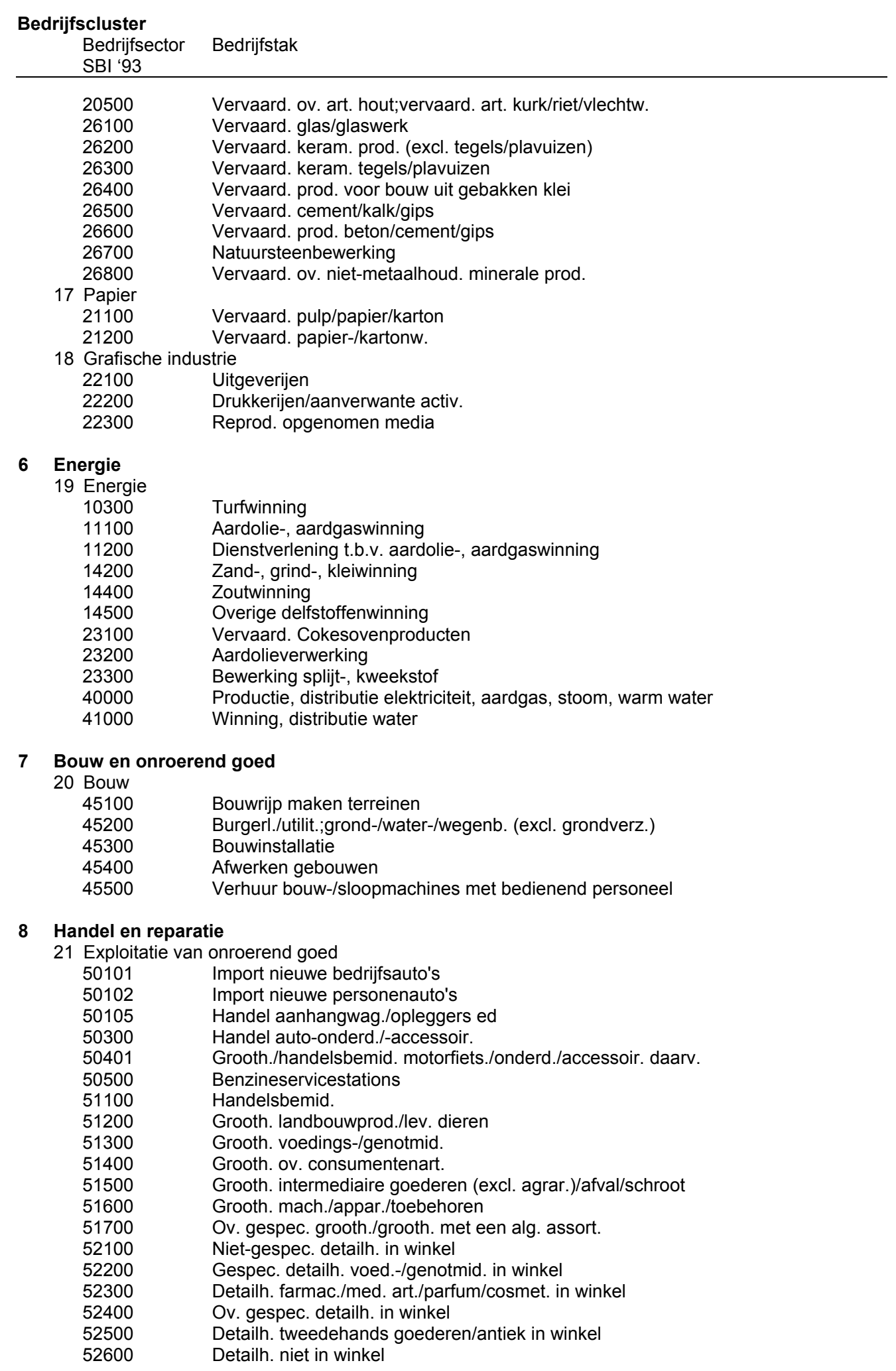


10. Bedrijfssectoren naar bedrijfstakken (vervolg)

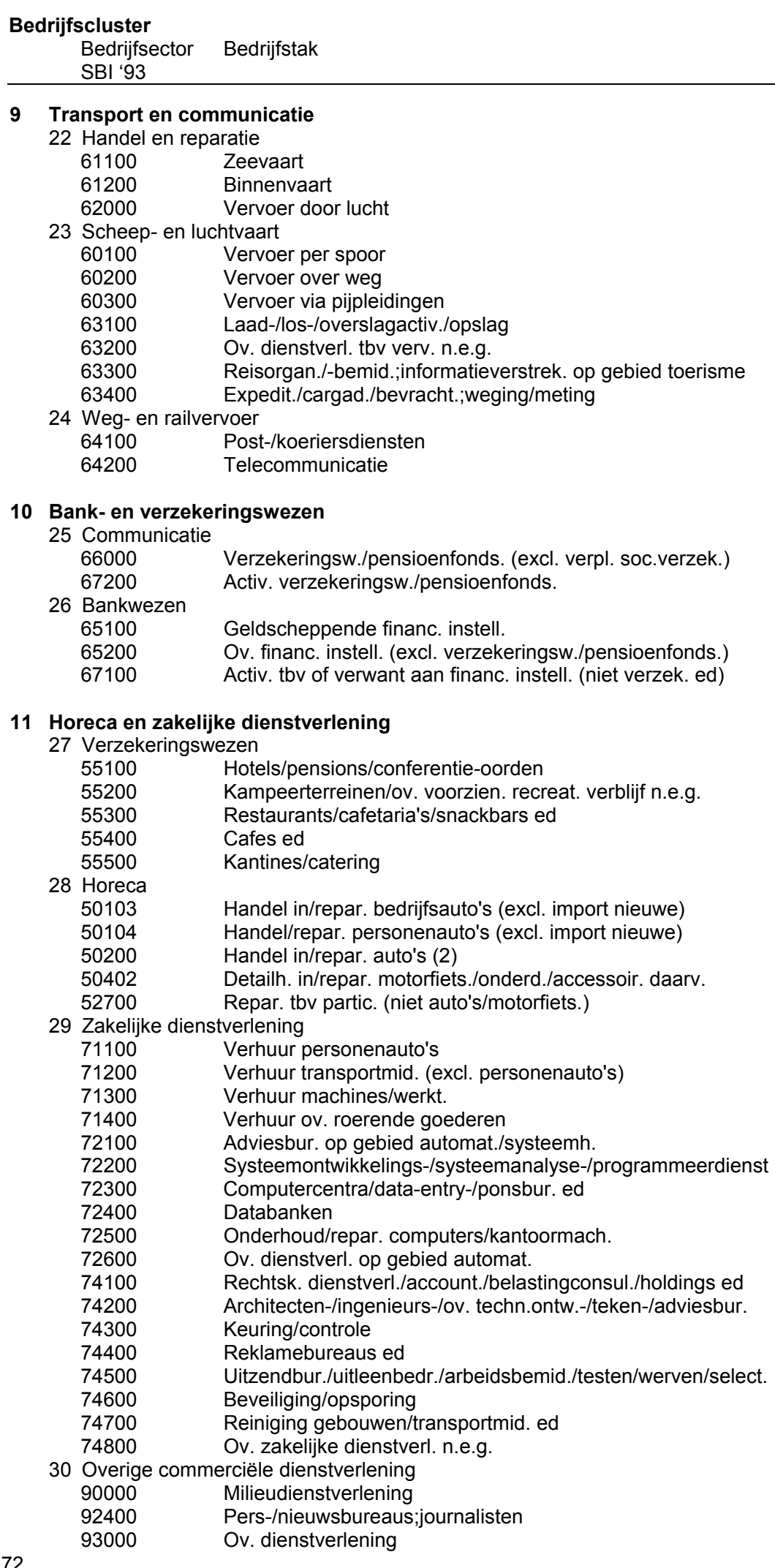


10. Bedrijfssectoren naar bedrijfstakken (vervolg)

\begin{tabular}{cc}
$\begin{array}{c}\text { Bedrijfscluster } \\
\text { Bedrijfsector } \\
\text { SBI '93 }\end{array}$ & Bedrijfstak \\
\hline 95000 & Particuliere huishoudens met personeel in loondienst
\end{tabular}

12 Kwartaire diensten

31 Gezondheidszorg

$85100 \quad$ Gezondheidszorg

$85200 \quad$ Veterinaire diensten

$85300 \quad$ Welzijnszorg

32 Overige kwartaire diensten

$73100 \quad$ Natuurwet. speur-/ontwikkelingsw.

$73200 \quad$ Maatschappij-/geesteswet. speur-/ontwikkelingsw.

$91100 \quad$ Bedrijfs-/werkgev.-/beroepsorganisaties

$91200 \quad$ Werknemersorganisaties

$91300 \quad$ Levensbesch./politieke organ.;ov. ideele organ. ed

$92100 \quad$ Activ. op gebied film/video

$92200 \quad$ Radio/tv

$92300 \quad$ Overig amusement/kunst

$92500 \quad$ Cult. uitl.centra/openb. arch./musea/dieren-/plantentuin ed

$92600 \quad$ Sport

$92700 \quad$ Ov. recreatie

13 Overheid en onderwijs

33 Onderwijs

75100

75200

Openbaar bestuur

75300

Overheidsdienst.

99000

Verpl. soc. verzekeringen

34 Overheid

80100

Extra-territoriale lichamen/organisaties

80200

80300

Basisonderwijs voor leerplichtingen/speciaal onderwijs

Voortgezet onderwijs

Hoger onderwijs

80400

Overig onderwijs 